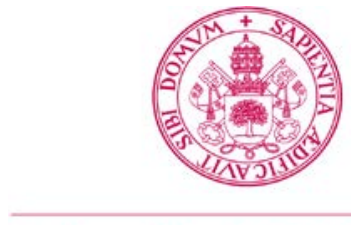

Universidad deValladolid

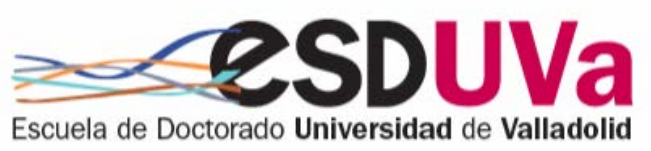

UNIVERSIDAD DE VALLADOLID

FACULTAD DE FILOSOFÍA Y LETRAS

DEPARTAMENTO DE FILOLOGÍA INGLESA

PROGRAMA DE DOCTORADO EN

ESTUDIOS INGLESES AVANZADOS:

LENGUAS Y CULTURAS EN CONTACTO

TESIS DOCTORAL:

\title{
THE ACQUISITION OF ENGLISH AND SPANISH DATIVE ALTERNATION STRUCTURES IN THE LONGITUDINAL SPONTANEOUS PRODUCTION OF MONOLINGUAL AND BILINGUAL CHILDREN
}

Presentada por Silvia Sánchez Calderón para optar al grado de doctora por la Universidad de Valladolid

\section{Dirigida por:}

Raquel Fernández Fuertes 2018 


\begin{abstract}
The chief ongoing debate in the domain of dative alternation (DA) structures revolves around the syntactic derivational relationship (or lack thereof) between prepositional and double object constructions (DOCs) in English (i.e. to/for-datives and DOCs) and in Spanish (i.e. a/para-datives and dative-cliticdoubled (DCLD) structures). In English, the debate has centered on the derivation of DOCs from to/fordatives (e.g. Czepluch 1982; Haspelmath 2006; Larson 2014, 1990, 1988; Oehrle 1976) or to/for-datives from DOCs instead (e.g. Aoun and Li 1989; Dryer 1986; Koizumi 1994). In Spanish, a/para-datives are analyzed as the source structure of DCLDs (e.g. Bruhn de Garavito 2000; Demonte 1995, 1994; Kempchinsky 2004). Non-derivational approaches have proposed that DA constructions stem from two different structures (e.g. Marantz 1993; Mulder 1992 in English; Cuervo 2003a, 2003b in Spanish) or establish a common underlying configuration (e.g. Snyder and Stromswold 1997; Snyder 2001, 1995). Yet, prepositional structures are also argued to be subject to additional syntactic and semantic requirements that double object constructions are not (e.g. Larson 1990, 1988; Marantz 1984; Pesetsky 1985; Snyder and Stromswold 1997). Semantically, there is also a debate in the literature as to whether the two DA structures share a similar theta role distribution (Baker 1988) or whether they denote a semantic difference (e.g. Colleman 2010; Colleman and De Clerk 2011 in English; Demonte 1994; Romero Morales 2008 in Spanish).

Monolingual (L1) and bilingual (2L1) acquisition works on English and Spanish DA are rather scarce and there is no consensus in the findings reported. While some L1 English studies (e.g. Bowerman 1990; Campbell and Tomasello 2001) and 2L1 English studies (e.g. Gu 2010) point to the later emergence of to/for-datives, other L1 English works (e.g. Snyder and Stromswold 1997) report a similar emergence for English DA structures. In Spanish, only the study conducted by Torrens and Wexler (2000) reports the early onset of DCLDs from the initial L1 acquisition stages.

Data analyses in the present dissertation show that prepositional and double object constructions emerge at an approximately similar age in English and in Spanish alike, as analyzed in the L1 children's data and in each of the 2L1 English/Spanish children's two languages. Biological gender differences are not seen in the two language groups either. These data point to the syntactic non-derivational relationship (e.g. Marantz 1993; Mulder 1992; Snyder and Stromswold 1997; Snyder 2001, 1995; in English; Cuervo 2003a, 2003b in Spanish) and to the semantic analogy (Baker 1988) between DA constructions in English and in Spanish. Although the two DA constructions mature at a similar age, prepositional structures show a later onset and a lower incidence through language development when compared to double object constructions, as equally seen in the L1 and in the 2L1 children's data in each language. These findings might be related to the additional properties required in the production of English to/for-datives and Spanish a/para-datives and/or the role played by adult input in child output. Similar results appear when comparing across English and Spanish in the case of the production of both the two L1 groups (intergroup comparison) and the 2L1 children (intra-group comparison). Thus, as per the acquisition pattern, the properties that characterize double object and prepositional constructions indicate a cross-linguistic parallelism in English and Spanish and the amount of exposure to these constructions could also have played a similar role in the children's output across the two languages.
\end{abstract}

Key words: Dative alternation, double object constructions, prepositional constructions, monolingual acquisition, bilingual acquisition, age of onset, language development, adult input, child output, biological gender 


\section{ACKNOWLEDGEMENTS}

I am extremely thankful to the many people who have contributed, in many different ways, to the elaboration of this dissertation. The research reported in this dissertation is the result of all their help.

I owe a special debt to my supervisor, Raquel Fernández Fuertes, because her dedication and her time are reflected in this dissertation. I am thankful for her thoughtprovoking questions that helped me to structure my ideas. I cannot forget her constant guidance in times of need and her thorough feedback provided in several drafts of this dissertation, in papers and in conference abstracts; let alone her kindness and her emotional support. I give her thanks for her contagious enthusiasm and for the knowledge she has shown me through her unimpeachable attributes as a researcher. I will be eternally thankful.

I would also like to thank the financial support provided by the University of Valladolid, Spain, co-funded by Santander bank from 06/02/2014 to 14/10/2014, and by the Castile and León Regional Government, Spain (ORDEN EDU/1083/2013, 27 December), co-funded by the European Social Funding from 17/10/2014 to 31/04/2018.

This dissertation is framed in the project 'la transmisión de estereotipos de género a través de la canción y su relación con la violencia de género' ('the conveyance of gender stereotypes through song and its relation with domestic violence'), granted by the Women Institute (Health, Social Services and Equality Department, Spain), BOE 22 February 2013, 039/12. I am very grateful to the principal investigator, Laura Filardo Llamas, for her worthwhile comments, her advice and her generous help whenever I needed them.

During the realization of this dissertation, I had the opportunity of carrying out a research stay at the Institute of Linguistics (University of Malta) from 01/06/2015 to 01/09/2015 where I benefitted from several experts' knowledge on quantitative and qualitative techniques of selection and classification of data. I would like to express my sincere gratitude to Marie Alexander, Stavros Assimakopoulos, Ray Fabri, Albert Gatt, Sarah Grech, Natalie Schembri and Lonneke van der Plas. I am immensely grateful for their advice, their kind words, their involvement and their encouragement.

My statistical results would not have been possible without the help of Albert Gatt (University of Malta), Andrés Palacios Picos (University of Valladolid) and Qianting 
Yuan (University of Valladolid). I benefitted enormously from their expertise, their comments and their suggestions.

I would like to give thanks to the audience for their valuable comments and their helpful discussions while presenting results at the XXIX Congreso Internacional de la Asociación de Jóvenes Lingüistas (University of Murcia, Spain, 2014), the VII Congreso Internacional de Lingüística de Corpus (University of Valladolid, Spain, 2015), the Linguistics Circle (University of Malta, Malta, 2015), the I International UCM Predoctoral Conference on English Linguistics (Complutense University of Madrid, Spain, 2015), the XXXIII International Conference of the Spanish Society for Applied Linguistics (AESLA, University of Alicante, Spain, 2016), the IV Congreso Internacional de Lingüística y Literatura (University of Cantabria, Spain, 2016), the XXXIV International Conference of the Spanish Society for Applied Linguistics (AESLA, University of Jaén, Spain, 2017), the Multilingual Language Theories and Practices (University of Valladolid, Spain, 2018) and the III Lancaster Conference on Infant and Early Child Development (University of Lancaster, UK, 2018).

I would like to mention those professors who played an important role in the first stages of my knowledge on linguistic theory (Cayetano Estébanez Estébanez, University of Valladolid, Spain; Axiotis Kechagias, University of Salford, UK; Luis Santos Domínguez, University of Valladolid, Spain). Special thanks go to Ismael Iván Teomiro García, who served as my supervisor during my Master's thesis at the National University of Distance Education (Spain), for having introduced me to the study of child language acquisition.

My fellow colleagues at the Department of English studies have also provided me with much-needed moral support and wise advice. I am particularly thinking of Esther Álvarez de la Fuente, Diana Carrascal Tris, Laura Filardo Llamas, Eduardo Gómez Garzarán, Sonja Mujcinovic, Ana Sáez Hidalgo, Radoslava Stankova and Qianting Yuan.

I would also like to give thanks to the two anonymous reviewers for their careful reading and for providing insightful comments and suggestions. Their valuable supportive work has considerably improved this dissertation.

This dissertation owes a special word of thanks to my parents and my sister for their unconditional love and their generosity; I am very grateful for their continuous support and their understanding. A big 'thank you' also goes to my partner, James, for 
having answered innumerable questions about my English whenever my native-like intuitions faltered; I wish to thank him for his constant support and encouragement in hard times. 


\section{TABLE OF CONTENTS}

ABSTRACT

ACKNOWLEDGEMENTS

TABLE OF CONTENTS

LIST OF TABLES

LIST OF FIGURES

LIST OF ABREVIATIONS

INTRODUCTION
II

III

VI

$\mathbf{X}$

XIII

XV

1

CHAPTER 1 FORMAL APPROACHES TO ENGLISH AND SPANISH DATIVE ALTERNATION STRUCTURES

1.1 Argumenthood and general defining properties

1.2 Case marking

1.3 Syntactic (non-)derivational relationship

1.3.1 English DOCs and to/for-datives

1.3.2 Spanish DCLDs and a/para-datives

1.4 Thematic role assignment

1.5 Concluding remarks: English and Spanish dative alternation structures

CHAPTER 2 ON THE ACQUISITION OF DATIVE ALTERNATION STRUCTURES 42

2.1 Monolingual and bilingual first language acquisition

2.1.1 Language developmental stages: Age and mean length of utterance 42

2.1.2 The role of biological gender

2.1.3 Cross-linguistic influence between two first languages 
2.1.4 The role of dual input in child dual output

2.2 Previous studies on the acquisition of dative alternation structures

2.2.1 Age of onset

2.2.1.1 English DOCs and to/for-datives 68

2.2.1.2 Spanish DCLDs and a/para-datives 75

2.2.2 The effect of adult input in child output

82

\section{CHAPTER 3 RESEARCH QUESTIONS}

3.1 English dative alternation structures in the production of monolingual and bilingual children

3.2 Spanish dative alternation structures in the production of monolingual and bilingual children

3.3 Dative alternation structures across English and Spanish

3.3.1 Inter-group comparison: English and Spanish monolingual children 93

3.3.2 Intra-group comparison: English and Spanish bilingual children 96

\section{CHAPTER 4 METHODOLOGY}

4.1. Corpora selection from the CHILDES database: Monolingual and simultaneous bilingual participants

4.2 Measuring linguistic development: MLUw and age

4.3 Data extraction and codification criteria

4.3.1 The search for the target structures: The KWAL program and manual extraction

4.3.2 Codification criteria of dative alternation structures

4.3.2.1 English to/for-datives and DOCs

4.3.2.2 Spanish a/para-datives and DCLDs 
4.4. Frequency distribution of English and Spanish structures

4.5 Statistical methods for data analyses

CHAPTER 5 THE PRODUCTION OF ENGLISH AND SPANISH DATIVE ALTERNATION STRUCTURES IN MONOLINGUAL AND IN BILINGUAL CHILDREN

5.1 Dative alternation in monolingual and bilingual English

5.1.1 The age of onset

5.1.2 Dative alternation through language development

5.1.2.1 Age stages

5.1.2.2 MLUw stages

5.1.3 The influence of adult input in children's output

139

5.1.5 Main findings

5.2 Dative alternation in monolingual and bilingual Spanish

5.2.1 The age of onset

5.2.2 Dative alternation through language development

5.2.2.1 Age stages

5.2.2.2 MLUw stages

5.2.3 The influence of adult input in children's output

5.2.5 Main findings

5.3 Dative alternation across English and Spanish

5.3.1 Inter-group comparison: English and Spanish dative alternation in the production of monolingual children

5.3.2 Intra-group comparison: English and Spanish dative alternation in the production of bilingual children 
CONCLUSIONS 173

BIBLIOGRAPHY 187 


\section{LIST OF TABLES}

\section{Chapter 2. On the acquisition of dative alternation structures}

Table 1. Correspondence between the 5 linguistic stages in child language development and the 13 age stages established for the study of English and Spanish dative alternation structures. . .44

Table 2. MLUm stages (Brown 1973: 79) .45

Table 3. MLUm-age correspondence in monolingual acquisition (Brown (1973: 79) and adapted from Crain and Lillo-Martín (1999)). 47

Table 4. Mean vocabulary production scores in monolingual Swedish children as a function of biological gender, birth order and childcare (Berglund et al. 2005: 489).

Table 5. Developmental Sentence Scoring means and standard deviations in the production of subjectverb utterances by monolingual English children (Koenigsknecht and Friedman 1976: 1111)...50

Table 6. Developmental Sentence Scoring means and standard deviations in the production of words by monolingual English children (adapted from Koenigsknecht and Friedman 1976:

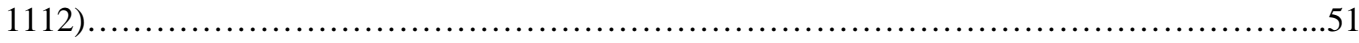

Table 7. Means and standard deviations in the production of words and MLUm values by monolingual English children (adapted from Lovas 2011: 92). .53

Table 8. Non-adult-like use of auxiliary in English wh-questions by bilingual English/Spanish and by monolingual English children (\# of cases (\%)) (Hsin 2012: 112)....

Table 9. Age of onset of English dative alternation constructions in bilingual English/Cantonese children and in monolingual English children (adapted from Gu 2010: 72 and 80).....

Table 10. The production of overt and null subjects in Spanish by bilingual English/Spanish and by monolingual Spanish children (\# of occurrences (\%)) (Paradis and Navarro 2003: 380).....

Table 11. Parents' production of overt and null subjects in Spanish declarative utterances (\# of occurrences (\%)) (adapted from Paradis and Navarro’s (2003: 382-383) tables 4 and 5)..... 65

Table 12. Age of emergence and verb type in the production of DOCs and to/for-datives by monolingual English children (adapted from Gropen et al.’s (1989: 213-216) tables 2 to 6).

Table 13. Ages of acquisition of DOCs and to-datives by monolingual English children (Snyder and Stromswold 1997: 290). . .70

Table 14. Age of first use of DOCs, to-datives and for-datives by monolingual English children (Campbell and Tomasello 2001: 256).

Table 15. Acceptability Judgement Task ratings on the (un)grammaticality of dative alternation constructions by monolingual English children (\%) (Mazurkewich and White 1984: 281)......75

Table 16. Elicited production of simple and clitic doubling mono-transitive constructions in monolingual Romanian children's data (Ungureanu 2017: 23). .77

Table 17. The production (\# of occurrences) of DOCs and to-datives by monolingual English children and by adults (adapted from De Marneffe et al 2001: 5 and 16) .84

Table 18. The production of DOCs and to-datives by monolingual English children and by adults (\# of occurrences (\%)) (adapted from Campbell and Tomasello 2001: 258)...... .85 
Table 19. The production of DOCs and to-datives per verb type by monolingual English children and by adults (\# of occurrences) (adapted from Campbell and Tomasello 2001: 258). 85-86

\section{Chapter 3. Research questions}

Table 1. Summary of the focus and the variables targeted in the research questions formulated in the study..... .87

\section{Chapter 4. Methodology}

Table 1.

Monolingual

English

children

selected.

Table 2. Monolingual Spanish children selected....

100

Table

3.

Simultaneous

English/Spanish

bilingual

children

selected.... 100

Table 4. Adult input in the simultaneous English/Spanish bilingual children selected

Table 5. Sample of the MLUw computation per file based on the production of English dative alternation structures [Ross, the MacWhinney corpus, CHILDES].... 104

Table 6. MLUw stages for the study of dative alternation

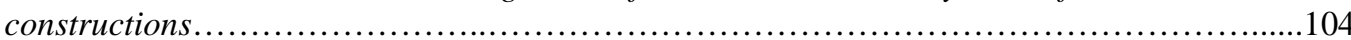

Table 7. Age stages for the study of dative alternation constructions. 105

Table 8. Sample of data classification in terms of age stages and MLUw stages in Simon's longitudinal production of DOCs [the FerFuLice corpus, CHILDES]. 106

Table 9. Corpora selection procedure via the KWAL program. 108

Table 10.

Manual

corpora selection procedure.

Table 11. Frequency distribution of English and Spanish structures in the production of monolingual and bilingual children (\# of cases (\%)). 118

\section{Chapter 5. The production of English and Spanish dative alternation structures in monolingual and} in bilingual children

Table 1. English and Spanish dative alternation structures in child and in adult monolingual and bilingual speech (\# of cases (\%))....

Table 2. English and Spanish dative alternation structures in girls' and in boys' monolingual and bilingual speech and in adult input (\# of cases $(\%))$ 122

Table 3. Age of onset of English dative alternation structures in monolingual and in bilingual child speech. ..124

Table 4. Age of onset of English dative alternation structures in monolingual and in bilingual girls' and boys' speech. .125

Table 5. The production of English dative alternation structures per monolingual and per bilingual child output and adult input (\# of cases (\%)). 
Table 6. Age of onset of Spanish dative alternation structures in monolingual and in bilingual child speech...... .144

Table 7. Age of onset of Spanish dative alternation structures in monolingual and in bilingual girls' and boys' speech.

Table 8. The production of Spanish dative alternation structures per monolingual and per bilingual child output and adult input (\# of cases (\%)).... 


\section{LIST OF FIGURES}

\section{Chapter 4. Methodology}

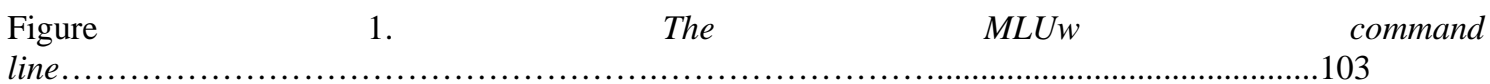

Figure 2. MLUw CLAN output window [Ross, the MacWhinney corpus, CHILDES, file 07a1.cha] ..................................................................103

Figure 3. KWAL command string on the basis of the keyword 'verb'.....' .108

Figure 4. KWAL output of trimmed English dative alternation utterances [Ross, the MacWhinney corpus, CHILDES].....

Figure 5. KWAL output of trimmed Spanish dative alternation utterances [María, the Ornat corpus, CHILDES] 109

\section{Chapter 5. The production of English and Spanish dative alternation structures in monolingual and in bilingual children}

Figure 1. The monolingual English children's production of dative alternation structures per age stages.

Figure 2. The production of dative alternation structures in the monolingual English girls and in the monolingual English boys per age

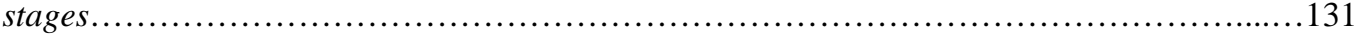

Figure 3. The bilingual English children's production of dative alternation structures per age stages.

Figure 4. The production of dative alternation structures in the bilingual English girls and in the bilingual English boys per age stages 133

Figure 5. The monolingual English children's production of dative alternation structures per MLUw stages

Figure 6. The production of dative alternation structures in the monolingual English girls and in the monolingual English boys per stages. 135

Figure 7. The bilingual English children's production of dative alternation structures per MLUw stages 136

Figure 8. The production of dative alternation structures in the bilingual English girls and in the bilingual English boys per MLUw stages.

Figure 9. The production of English dative alternation structures in the adult input and in the monolingual children's output.

Figure 10. The production of English dative alternation structures in the adult input and in the bilingual children's output. 
Figure 11. The production of English dative alternation structures in the adult input, the monolingual girls' autput the monolingual boys' output 140

Figure 12. The production of English dative alternation structures in the adult input, the bilingual girls' output and the bilingual boys' output

Figure 13. The monolingual Spanish children's production of dative alternation structures per age stages.

Figure 14. The production of dative alternation structures in the monolingual Spanish girls and in the monolingua Spanish boys per age stages.

Figure 15. The bilingual Spanish children's production of dative alternation structures per age stages

Figure 16. The production of dative alternation structures in the bilingual Spanish girls and in the bilingual Spanish boys per age

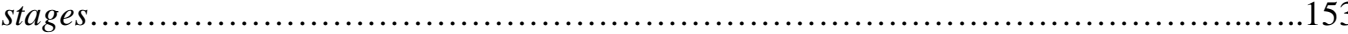

Figure 17. The monolingual Spanish children's production of dative alternation structures per MLUw stages

Figure 18. The production of dative alternation structures in the monolingual Spanish girls and in the monolingual Spanish boys per stages. 156

Figure 19. The bilingual Spanish children's production of dative alternation structures per MLUw stages 157

Figure 20. The production of dative alternation structures in the bilingual Spanish girls and in the bilingual Spanish boys per MLUw stages. 158

Figure 21. The production of Spanish dative alternation structures in the adult input and in the monolingual output.

Figure 22. The production of Spanish dative alternation structures in the adult input and in the bilingual children's output....

Figure 23. The production of Spanish dative alternation structures in the adult input, the monolingual girls' output and the monolingual boys' output.

Figure 24. The production of Spanish dative alternation structures in the adult input, the bilingual girls' output and the bilingual boys' output.... 160 


\section{LIST OF ABREVIATIONS}

A

Acc

$\mathrm{ADH}$

AJT

APPL

Appl

Asp

BP

C

CHAT

CHILDES

$\mathrm{Cl}$

CLAN

CP

DA

Dat

DCLD

DCIP

DO

DOC

DOCD parameter

DP

DSS

D-Structure

ECP

EN

EPP

GB

IAP

IDH

Inf

Inh

IO

IP

KWAL

L1

$\mathrm{L} 2$

2L1

$\mathrm{M}$

MCDI

MLU

MLUm

MLUw

MVPH

Nom

NP
Adjunct

Accusative Case

Autonomous Development Hypothesis

Acceptability Judgment Task

Applicative Affix

Applicative Argument

Aspect

Beta Phrase

Complementizer

Codes for the Human Analysis of Transcripts

CHIld Language Data Exchange System

Clitic

Computerized Language ANalysis

Complementizer Phrase

Dative Alternation

Dative Case

Dative-CLitic-Doubled

Dative Clitic Phrase

Direct Object

Double Object Construction

The Direct Object Clitic Doubling Parameter

Determiner Phrase

Developmental Sentence Scoring

Deep-Structure

Empty Category Principle

English

Extended Projection Principle

Government and Binding

Inner Aspect Phrase

Interdependent Development Hypothesis

Infinitive

Indirect Object

Inherent Case

Inflectional Phrase

Key Word And Line

First Language

Second Language

Two First Languages

Masculine

MacArthur-Bates Communicative Development

Inventory

Mean Length of Utterance

Mean Length of Utterance measured in morphemes

Mean Length of Utterance measured in words

Multiple-headed Verbal Phrase Hypothesis

Nominative

Noun Phrase 


P
Part
Perf
PF
Pl
PO
PP
Pres
Pron
Refl
RG
RQ
SC
SCS18
SD
Sg
SO
SP
SPSS
SU
Subj
SVO
T
T
TEGI
TP
UG
UTAH
V
V
VP
V-Raising
Vs
VS Constructions
$\phi$ HAVE

Person

Participle

Perfect Tense

Phonological Form

Plural

Primary Object

Prepositional Phrase

Present Tense

Pronoun

Reflexive

Relational Grammar

Research Question

Small Clause

Swedish Communicative Screening at 18 Months

Standard Deviation

Singular

Secondary Object

Spanish

Software Package for the Social Sciences

Subject

Subjunctive

Subject-Verb-Object

Trace

Tense

Test of Early Grammatical Impairment

Tense Phrase

Universal Grammar

Uniformity of Theta Assignment Hypothesis

Little Verb

Verb

Verb Phrase

Verb-Raising

Versus

Verb-Subject Constructions

Empty Causative Verb 


\section{INTRODUCTION}

The present dissertation is concerned with the acquisition of the so-called dative alternation (DA) structures in English (e.g. Dryer 1986; Larson 2014, 1990, 1988; Pylkkänen 2002; Snyder 2001; Snyder and Stromswold 1997) and in Spanish (e.g. Bruhn de Garavito 2000; Cuervo 2007, 2003a, 2003b; Demonte 1995, 1994; Kempchinsky 2004). More specifically, it analyzes the spontaneous longitudinal production of monolingual (L1) and bilingual (2L1) children in order to provide further insight into the syntactic and the semantic properties that underlie and connect prepositional and double object constructions, as two instances of DA structures. While, in English, to/for-datives of the type in (1a-b) alternate as double object constructions (DOCs) of the type in (1c), in Spanish, a/para-datives, as in (2a-b), alternate as dativeclitic-doubled (DCLD) constructions, as in (2c), in which a pre-verbal dative clitic ' $l e$ ' ('him' or 'her'; singular) or 'les' ('them'; plural) is doubled by a prepositional complement, headed by ' $a$ ' (i.e. 'to'), sharing gender, number and person features as well as Case and theta role properties.

(1) a. I give that to you

b. I buy cereal for my baby

c. Give me some [to-dative]

[Nina, 2;01, the Suppes corpus, CHILDES]

[for-dative]

[Ross, 2;08, the MacWhinney corpus, CHILDES]

[DOC]

[Ross, 1;04, the MacWhinney corpus, CHILDES]

(2)
a. Estoy
sacando algo
a la mamá
be.1p.sg.pres. take.ing. something to the mummy
[a-dative]
'I am taking something out for the mummy'

[Koki, 2;05, the Montes corpus, CHILDES]
b. Tú sabes cocinar papilla para Simon [para-dative] you know.2p.sg.pres. cook.inf. baby food for Simon 'You know how to cook baby food for Simon'

[Leo, 2;08, the FerFuLice corpus, CHILDES]
c. $\mathrm{Le}_{\mathrm{i}}$ voy a hacer un regalo [ a Mónica $]_{\mathrm{i}}$ [DCLD] her.dat.cl. go.1p.pres. to make.inf. a gift to Mónica 'I am going to give Mónica a gift'


The objective of this dissertation is twofold. First, it investigates the production of English and Spanish DA constructions through language development in L1 and in 2L1 children. In this case, findings can contribute to shed light on the syntactic derivational relationship (or lack thereof) between the two DA constructions in English and in Spanish; that is, whether double object and prepositional constructions are the source or the derived structure or, rather, whether the two DA structures do not undergo a syntactic derivational relationship. Second, it examines the relationship that exists in the acquisition process of these constructions across English and Spanish. In this case, findings can elucidate whether the syntactic (non-)derivational relationship between double object and prepositional constructions is analogous or differs across the two languages.

Formal approaches on the DA of prepositional and double object constructions are divided into those that take the two structures to derive from its DA counterpart (e.g. Dryer 1986; Oehrle 1976; Haspelmath 2006; Larson 2014, 1990, 1988 in English; Demonte 1995, 1994 in Spanish) and into those that argue for the lack of a syntactic derivational relationship between the two DA constructions (e.g. Marantz 1993; Mulder 1992; Snyder and Stromswold 1997 in English; Cuervo 2003a, 2003b in Spanish). Within the derivational approaches, prepositional or double object constructions have usually been claimed to be derived by a lexical rule (Czepluch 1982), by a transformational rule (Oehrle 1976) or by a passive-like mechanism (Aoun and Li 1989; Demonte 1995, 1994; Dryer 1986; Haspelmath 2006; Larson 2014, 1990, 1988). Alternatively, and under the light of non-derivational approaches, prepositional and double object constructions are analyzed as having two different base structures (Cuervo 2003a, 2003b; Marantz 1993; Mulder 1992) or a shared underived complex predicate or small clause (SC) structure. This last view is captured in the Complex Predicate Parameter (Snyder 2001, 1995) whereby English is a [+complex predicate] language and Spanish is a [-complex predicate] language. This is so given the unavailability of English-like DOCs in Spanish and, thus, double object constructions are argued to differ in the syntactic status across the two languages.

Semantically, there is also a formal debate in earlier works as to whether the two English and Spanish DA structures share a similar theta role distribution that complies with the Uniformity of Theta Assignment Hypothesis (UTAH, Baker 1988); or whether they denote a semantic difference. In the case of the latter, this ongoing debate has been 
equally proposed for English (e.g. Colleman 2010; Colleman and De Clerk 2011; Goldberg 1995, 1992) and for Spanish (e.g. Demonte 1994; Romero Morales 2008). More specifically, while prepositional DA structures (i.e. English to/for-datives and Spanish a/para-datives) are argued to involve caused motion (cause-to-GO), double object constructions (i.e. English DOCs and Spanish DCLDs) are said to denote transfer of possession (cause-to-HAVE).

Previous empirical studies on DA have mainly focused on L1 English children's data (Bowerman 1990; Campbell and Tomasello 2001; Gropen et al. 1989; Snyder and Stromswold 1997) and, to the best of our knowledge, only Gu's (2010) study investigates the 2L1 children's acquisition of DOCs and to/for-datives in English in contact with those in their other L1, Cantonese. Within the domain of Spanish DA structures, earlier works on the acquisition of DCLDs and a/para-datives have primarily targeted second language (L2) learners (Bruhn de Garavito 2000; Cuervo 2007; Perpiñán and Montrul 2006; among others). To date, only Torrens and Wexler (2000) have examined the emergence of DCLDs in L1 Spanish children's data, but no information is provided in relation to a/para-datives. In view of the bulk of L1 and 2L1 research on the acquisition of English and Spanish DA structures, further empirical investigation is required to better inform on the syntactic relationship between prepositional and double object constructions in English and in Spanish, be it derivational or non-derivational. What could be inferred from these analyses is that a later onset, and possibly a lower incidence through language development, of one of the two DA structures may imply a grammatical complexity that could be associated with its derivational status. In other words, the grammatical properties of the derived DA structure would be subject to language maturation and, therefore, they would cause a delay in their production. Nevertheless, if prepositional and double object constructions emerge at an approximately similar age, and possibly show an analogous incidence through language development, what could be suggested is that the two structures are not derivationally related from one another and, thus, they mature at around the same age.

Another factor under investigation is the role played by adult input in child output. Input-based approaches in the literature have claimed that productivity in adult language is related to children's relative timing of acquisition (e.g. Legate and Yang 2002; Lust 2006; Pullum and Scholz 2002; Sampson 2002; Yang 2016, 2011, 2002). In the case of 
DA structures, most research has been carried out with L1 English children and the findings reported do not clearly elucidate whether the amount of exposure to DOCs and to/for-datives plays a crucial role in L1 English children's use of these structures (Campbell and Tomasello 2001; De Marneffe et al. 2012; Snyder and Stromswold 1997). To the best of our knowledge, analogous empirical works have not been conducted in Spanish.

Biological gender is also considered as part of the analysis. Although there is not a great bulk of studies that have addressed the differences between girls and boys in terms of maturational patterns, there are a few precedents in this respect. With regards to L1 acquisition works, an agreement appears in the literature regarding girls' earlier maturation when compared to boys in motor movements (e.g. Nagy et al. 2007), in lexical use (e.g. Berglund et al. 2005; Eriksson et al. 2012), and in syntactic development (e.g. Cornett 2014; Lovas 2011). In the case of bilinguals, only one empirical study (Eriksson et al. 2012) has reported on the 2L1 girls' higher rate in the lexical production of different word types in their dominant language when compared to 2L1 boys. Most of these divergences have been argued to stem from brain lateralization (e.g. Burman et al. 2008; Shakouri et al. 2016) or from different parent-child interactions when parents engage in conversations with their sons or with their daughters (e.g. Gleason 1990; Lovas 2011). Based on these empirical works, we seek to examine whether biological gender differences exist in the case of English and Spanish DA structures. In particular, we analyze whether girls differ from boys in (a) the monolingual and in the bilingual acquisition processes of these constructions and in (b) the role played by adult input in child output when addressing boys or girls.

Considering the above-mentioned theoretical and empirical works as a point of departure, four analyses are carried out to explore the acquisition process of the properties that characterize and relate prepositional and double object constructions in English and in Spanish. The first two analyze the two languages individually and compare the L1 children's data to the 2L1 children's data. The last two establish a comparison across languages, that is, English and Spanish DA constructions in the production of L1 children (inter-group comparison) and in that of 2L1 children (intragroup comparison). In each of these four analyses, two further issues are taken into consideration, namely, biological gender and adult input. To be more precise, we investigate whether biological gender differences (or lack thereof) appear in the 
acquisition of these structures. Moreover, we examine whether the relative frequency rate with which the two English and Spanish DA structures are used in the adult input is consistent with the children's output.

The data analyzed in this dissertation come from 25 longitudinal corpora available in the CHIld Language Data Exchange System (CHILDES, MacWhinney 2000). These corpora include the production of 13 L1 English children (age range: 0;06 to 8;00; 8 girls and 5 boys), 9 L1 Spanish children (age range: 0;11 to 4;08; 6 girls and 3 boys), and 9 2L1 English/Spanish children (1;01 to 6;11; 3 girls and 6 boys). We have also considered the production of the adults that the children interact with (mainly parents, as well as other caregivers and researchers).

The extraction of English and Spanish DA structures in the production of the 31 children selected and in that of the child-directed speech combines automatic morphosyntactic searches with manual extraction. In the former, the contexts in which a verb is used are extracted via KWAL (Key Word And Line), one of the CLAN (Child Language ANalysis) programs, in those selected corpora that have a $+\mathrm{t} \%$ mor (morphology dependent tier) available in the CHAT (Codes for the Human Analysis of Transcripts) written format. On the contrary, manual data extraction includes those selected corpora that do not include a $+\mathrm{t} \%$ mor in their transcripts.

The results of this dissertation contribute to shed light on the parallel syntactic non-derivational relationship between the two DA structures across English and Spanish, as reflected in the significantly similar emergence of prepositional and double object constructions in the L1 and in the 2L1 children's data, both in girls and in boys. This suggests that, despite the different properties that the phenomenon of DA presents across the two languages, as per the Complex Predicate Parameter (Snyder 2001, 1995), the two English and Spanish DA structures could be construed under a shared underlying structure (e.g. Aoun and Li 1989; Kayne 1984; Snyder and Stromswold 1997 in English; earlier formal works have not addressed this issue in Spanish) or under two opposing underived representations (e.g. Marantz 1993; Mulder 1992 in English; Cuervo 2003; 2003b in Spanish). An alternative explanation to the similar onset of these constructions could lie in the similar thematic relationship when double object constructions alternate as prepositional DA structures in English and in Spanish alike, as per UTAH requirements. Nevertheless, although English and Spanish DA constructions emerge at a rather similar age, the three language groups (i.e. L1 English, L1 Spanish 
and 2L1 English/Spanish) show a later onset and a lower incidence of English to/fordatives and Spanish a/para-datives when compared to English DOCs and Spanish DCLDs, respectively, and biological gender differences do not appear in this respect. These findings could lend support to the additional properties of the prepositions 'to/for' in English and 'a/para' in Spanish (e.g. Larson 1990; 1988; Marantz 1984; Pesetsky 1985; Snyder and Stromswold 1997) and/or the role played by adult input in child output (e.g. Legate and Yang 2002; Lust 2006; Pullum and Scholz 2002; Sampson 2002; Yang 2016, 2011, 2002).

The results accomplished in the present dissertation also contribute to fill the gap between theorical and empirical research on the syntactic status and on the acquisition of English and Spanish DA structures, respectively. With regards to acquisition, this study provides with novel spontaneous production data analyses that focus on the acquisition of DA constructions by L1 Spanish children and by 2L1 English/Spanish children. Previous empirical works have not investigated the acquisition of Spanish DA structures (with the exception of Torrens and Wexler 2000 who analyze the acquisition of DCLDs only) or their acquisition in contact with other languages such as English. Moreover, the present dissertation also contributes novel English data on DA structures since it investigates L1 English and 2L1 English children's acquisition of these constructions following different data classification criteria from what has been reported in the literature (e.g. Campbell and Tomasello 2001; De Marneffe et al. 2012; Snyder and Stromswold 1997, see chapter 4). This study also examines the possible biological differences (or lack thereof) in L1 and in 2L1 children's acquisition of English and Spanish DA structures, an issue that earlier L1 and 2L1 empirical works have not looked into from this perspective.

This dissertation is structured into 5 chapters preceded by this introduction and followed by a final section on the conclusions reached. Chapter 1 addresses the domain of DA structures in English and in Spanish from a formal approach and focuses, on the one hand, on the general defining properties (section 1.1) and Case marking properties (section 1.2) of prepositional and double object constructions and, on the other hand, on the debate regarding the syntactic derivational vs. non-derivational relationship between the two DA structures in the two languages under analysis (section 1.3.). From a semantic perspective, the thematic role distribution of English and Spanish DA structures is also discussed in section 1.4. Finally, a comparative syntactic and semantic 
account of the differences and the similarities of English and Spanish DA structures is provided in section 1.5 .

The backbone of chapter 2 is organized into two main sections. Section 2.1 deals with four general L1 and 2L1 acquisition properties that are later present in the analysis of DA structures in chapter 5: (a) Age and mean length of utterance (MLU), as two language developmental measures; (b) the role of biological gender; (c) cross-linguistic influence in 2L1 acquisition, that is, whether one language influences the course of development of the other language, as per the Interdependent Development Hypothesis (IDH, henceforth; Meisel 2004, 2001, 1989; Paradis and Genesee 1996; among others), or whether each of the two languages follows analogous developmental paths to their respective L1 peers, as per the Autonomous Development Hypothesis (ADH, henceforth; Álvarez de la Fuente 2007; Bergman 1976; Clark 2009; Genesee et al. 1995; among others); and (d) the role of dual adult input in 2L1 child dual output ${ }^{1}$. Section 2.2 is concerned with previous L1 and 2L1 acquisition works on English and Spanish DA structures. Issues such as the age of onset and the influence of adult input in child use of prepositional and double object constructions are addressed in this section.

Chapter 3 is divided into three main sections and formulates the research questions (RQs) under investigation. Sections 3.1 and 3.2 explore the syntactic derivational and non-derivational relationship between the two DA structures in English and in Spanish, respectively, as well as the role played by adult input in child output. This is analyzed in the production of L1 and 2L1 children. Section 3.3 seeks to answer whether prepositional and double object constructions share an analogous syntactic (non-)derivational relationship across English and Spanish, and whether adult inputchild output patterns are equally observed across the target languages. This is analyzed in the production of L1 children (inter-group comparison, section 3.3.1), on the one

\footnotetext{
${ }^{1}$ We refer to dual adult input when 2L1 children are exposed to two languages from birth via the one parent-one language strategy (Deuchar and Quay 2000; Hoff et al. 2014, 2012; Meisel 2004; Ronjat 1913; Silva Corvalán 2007; Takeuchi 2006; Yip and Matthews 2005; among others). As a result of the dual language exposure, 2L1 children produce dual output, that is, they develop and are able to communicate in two languages simultaneously.
} 
hand, and in the production of 2L1 children (intra-group comparison, section 3.3.2), on the other hand.

Chapter 4 is concerned with the methodological issues of the present study. It provides a detailed description of the participants (i.e. children and adults) (section 4.1), the methods used for data analysis (section 4.2), namely, developmental stages based on age and on MLU values measured in words (i.e. MLUw), the procedure of data extraction and data codification criteria (section 4.3), along with the frequency distribution of English and Spanish structures (section 4.4) as well as the statistical methods for data analyses (section 4.5).

Chapter 5 presents the analysis of English and Spanish DA structures and discusses the findings observed in line with previous formal accounts (chapter 1) and empirical works (chapter 2). This chapter is organized into three core sections. Section 5.1 presents the production of English DA structures (i.e. DOCs and to/for-datives) in both L1 and 2L1 children. Section 5.2 focuses on the production of Spanish DA structures (i.e. DCLDs and a/para-datives) in both L1 and 2L1 children. Section 5.3 offers a comparative analysis of English and Spanish DA structures, as it appears in the production of L1 children (section 5.3.1) and in the production of 2L1 children (section 5.3.2). In the discussion of results, each of these three sections considers the following variables under analysis: Age of onset, incidence through language development (in terms of age and MLUw values), biological gender, and the role played by adult input in child output. Moreover, a partial overview of the main findings is provided at the end of each section. The results reported in the data analyses lead to give an answer to the initial RQs formulated in chapter 3.

Once the data analyses are presented, the conclusions drawn from the present dissertation are outlined and some relevant suggestions for further research are also provided. 


\section{CHAPTER 1}

\section{FORMAL APPROACHES TO ENGLISH AND SPANISH DATIVE ALTERNATION STRUCTURES}

This chapter offers an overview of previous linguistic theoretical works that constitute the basis for the English-Spanish comparative empirical study of DA constructions. The description that is provided in this chapter is not comprehensive; rather, it aims at shedding light on the basic syntactic and semantic properties of English and Spanish DA structures as well as determining their cross-linguistic similarities and differences.

We start in section 1.1 with the general properties that define the two types of DA structures in English and in Spanish, namely, prepositional and double object. Syntactically, two issues have focused the debate on DA in different formal studies: Case marking properties (Aranovich 2012, 2011; Chomsky 1996, 1981; Radford 1990; among others), as discussed in section 1.2, and the syntactic (non-)derivational relationship of DA constructions (Aoun and Li 1989; Dryer 1986; Larson 2014, 1990, 1988; Marantz 1993; among others in English; Cuervo 2003a, 2003b; Demonte 1995, 1994; among others in Spanish), as addressed in section 1.3. Thematic role assignment is also discussed across the two languages in section 1.4. A summary of the main points appears in section 1.5.

\subsection{Argumenthood and general defining properties}

DA refers to the possibility of a verb to alternate the argument structure between prepositional and double object constructions. This phenomenon appears in English (Den Dikken 1991; Larson 2014, 1990, 1988; Malchukov et al. 2007; Oehrle 1976; Pylkkänen 2002; Quirk et al. 1985; Rill 2011; Sadler and Camilleri 2013; Snyder 2001; Snyder and Stromswold 1997; Zhang 1998; among others) and in Spanish (Anagnostopoulou 2003; Anderssen et al. 2012; Bruhn de Garavito 2000; Cuervo 2007, 2003a, 2003b; Demonte 1995, 1994; Kempchinsky 2004; Marantz 1993; Pineda 2012; among others).

In English, prepositional DA structures include to-datives, as in (1a), and fordatives, as in (1c). These constructions alternate as DOCs, as in (1b) and (1d), respectively. 
(1) a. John gave a book to Mary

b. John gave Mary a book

c. John bought a book for Mary

d. John bought Mary a book [to-dative]

[DOC]

[for-dative]

[DOC]

In Spanish, prepositional DA structures divide into a-datives, as in (2a), and paradatives, as in (2c), while double object ones include DCLD constructions, as in (2b) and (2d), in which a prepositional complement introduced by the preposition ' $a$ ' ('to') doubles a pre-verbal dative clitic 'le’ ('him’ or 'her’; singular) or 'les’ ('them'; plural).
a. Juan dio un libro a María
John give.3p.sg.past a book to Mary
'John gave a book to Mary'
[a-dative]
b. Juan $\mathrm{le}_{\mathrm{i}}$ dio John him.cl.dat. give.3p.sg.past a book to Mary 'John gave Mary a book'
c. Juan compró un libro para María John buy.3p.sg.past a book for Mary 'John bought a book for Mary'
[para-dative]
d. Juan le $e_{i}$ compró un libro [ a María $]_{i}$ John him.cl.dat. buy.3p.sg.past a book to Mary 'John bought Mary a book'

\section{[DCLD]}
[DCLD]

English DA structures have been analyzed as an instance of complex predicates. According to Snyder (2001), complex predicates consist of a main verb which is combined with a secondary predicate and both constituents form a new expression that is semantically akin to a simple verb. As will be illustrated in the examples provided in section 1.3.1 for each of the structures under analysis, other alternative approaches to that proposed by Snyder (2001) account for the combination of a main verb and a secondary predicate, forming a syntactic complex predicate (Larson 2014, 1990, 1988; Marantz 1993), or the subcategorization of a DA verb for an SC that contains the internal arguments of prepositional and double object constructions (Aoun and Li 1989; Den Dikken 1995; Kayne 1975; Koizumi 1994; among others). In prepositional DA structures, the SC holds a direct object (DO)-determiner phrase (DP) and an indirect object (IO)-prepositional phrase (PP) in $a$-datives or an adjunct (A)-PP in para-datives, while, in DOCs, a DO-DP followed by an IO-DP (if DOCs alternate as $a$-datives) or by an A-DP (if DOCs alternate as para-datives) reside in an SC domain. 
Snyder (2001: 325) includes the complex predicate constructions in (3) and argues that they all constitute a natural syntactic class which depends on a shared parametric property $^{2}$.

(3) a. John painted the house red

b. Mary picked the book up/picked up the book

c. Fred made Jeff leave

d. Fred saw Jeff leave

e. Bob put the book on the table

f. Alice sent the letter to Sue

g. Alice sent Sue the letter [resultative]

[verb-particle]

[make-causative]

[perceptual report]

[put-locative]

[to-dative]

[double-object dative]

To the list of complex predicate structures in (3), Snyder (2001) adds Noun-Noun compounds. Out of the eight structures in the parameter, two of them will be examined in the present study: to-datives (3f) and DOCs (or double-object datives) (3g). In particular, the verb 'sent' in (3f) subcategorizes for a DO-DP 'a letter' and an IO-PP 'to Sue', headed by the preposition 'to', while the linear order of the internal arguments in the DOC (3g) is reversed form that of to-datives, where no preposition 'to' appears. This means that, comparing to-datives and DOCs in (3f) and in (3g), respectively, the form of the IO changes from a PP 'to Sue' in to-datives to a DP 'Sue' in DOCs.

Although for-datives are not considered in Snyder's (2001) classification as complex predicates, they exhibit a similar syntactic pattern with to-datives in undergoing DA and, therefore, having an alternative DOC (Drosdowski 1984; Goldberg 2006; Hudson 1991; Larson 1990; Williams 1970). As in (4a), the verbal head 'prepared' subcategorizes for a DO-DP, 'a cake', as well as an A-PP, 'for Peter', headed by the preposition 'for'. In turn, the verbal head 'prepared' can take the form of a DOC, as in (4b), where no preposition 'for' appears in the A-DP 'Peter'.
(4)

[for-dative]

[DOC]

\footnotetext{
${ }^{2}$ Snyder (2001) confirms the syntactic analysis with language acquisition data. According to his proposal, L1 English children acquire the structures in (3) as a group given their shared parametric property as complex predicate constructions. In other words, as soon as a child acquires one of the structures, the acquisition of the other ones will quickly follow. Results on the acquisition of the structures in (3b-g) are reported in Snyder and Stromswold (1997); resultative constructions of the type in (3a) are excluded from the analysis due to their low frequency in the spontaneous speech of children and adults. See chapter 2 for further details on Snyder and Stromswold's (1997) study regarding the acquisition of the two types of complex predicates at stake in the present dissertation, i.e. (3f) and (3g).
} 
As an optional A, the PP 'for Peter' does not render the sentence ungrammatical when it is not overtly realized, as in (5). On the contrary, the IO-PP 'to his best friend' in the to-dative (6a) and the IO-DP 'his best friend' in the DOC (6b) are required by the verbal subcategorization framework, regardless of the nature of the IO, that is, whether it is overt, as in (6a) and (6b), or null, as in (6c).

(5) He prepared a cake

(6) a. He sent a letter to his best friend

b. He sent his best friend a letter

c. He sent a letter $e$ [mono-transitive]

[to-dative]

[DOC]

[to-dative or DOC; null PP]

The Complex Predicate Parameter (Snyder 2001, 1995) determines whether a language permits the syntactic formation of complex predicates in (3), in general, and the syntactic formation of to-datives and DOCs, in particular. The availability of complex predicates is not universal, and it varies across languages (Kayne 1975; Larson 2014, 1990, 1988; Snyder 2001, 1995); so, for instance, while English is a [+complex predicate] language, Spanish (and Romance languages, in general) is a [-complex predicate] language. In particular, it is argued that Spanish lacks direct counterparts of the four types of complex predicates in English, namely, resultatives, verb-particles, make-causatives and double-object datives (i.e. DOCs) even if examples of these could be found in the language; in other words, these complex predicates in Spanish do not share the same status as those in [+complex predicate] languages. Therefore, there is a parametric distinction between the availability of complex predicates in English and in Spanish, and more specifically, with regards to the two types of DA structures (Beavers and Nishida 2009; Bleam 2003, 2000; Cuervo 2007, 2003a, 2003b; Delbecque 1992; Demonte 1995, 1994; García Maroto 1985; Gutiérrez Ordoñez 1999; Kayne 1975; Masullo 1992; Ormazabal and Romero 1999; Uriagereka 1988). While the prepositions ' $a$ ' and 'para' in Spanish a/para-datives cannot be removed in the formation of DCLDs (and this could suggest the unavailability of English-like DOCs), they show similar grammatical properties when compared to English to/for-datives. In terms of the parametric variation of double object constructions across the two languages, Spanish DCLDs are characterized by the verbal subcategorization for a DO and a prepositional complement headed by the preposition ' $a$ ' that, in turn, doubles a dative clitic ' $l e(s)$ ' in gender, number, person, Case and theta role properties. A different status is given to double object constructions in English in that the verb subcategorizes for two nominal 
arguments, an IO and a DO (if they alternate as to-datives) or a DO as well as an A (if they alternate as for-datives).

Regarding a-datives, the verb 'mandó' ('he sent'), as in (7a), subcategorizes for a DO-DP 'una carta’ ('a letter’) and an IO-PP ‘a María’ ('to María'), headed by the preposition ' $a$ '. These types of canonical $a$-datives can reverse their internal arguments, as in (7b), since Spanish is a free constituent order language (Cuervo 2007, 2003a, 2003b; Demonte 1995, 1994; Romero Morales 2008; Hernanz and Brucart 1987). However, non-canonical $a$-datives might not be judged entirely grammatical by some speakers and they are, in fact, considered illicit by some others in that, as argued by Demonte (1994: 85), (7b) 'asks for a clitic'.

$$
\begin{aligned}
& \text { a. Juan mandó una carta a María [a-dative; canonical] } \\
& \text { John send.3p.sg.past a letter to Mary } \\
& \text { 'John sent a letter to Mary' } \\
& \begin{array}{c}
\text { b. */?Juan mandó } \quad \text { a María una carta } \\
\text { Juan send.3p.sg.past to María a letter } \\
\text { 'John sent a letter to Mary' }
\end{array}
\end{aligned}
$$

[Demonte 1994: 84]

Contra the Complex Predicate Parameter (Snyder 2001, 1995), double object structures have been argued to be available in Spanish, and so, a-datives, of the type in (7), with a prepositional complement doubling a pre-verbal dative clitic (singular le, plural les), alternate as DCLDs (Aranovich 2012, 2011; Beavers 2003; Bleam 2003; Beavers and Nishida 2009; Bruhn de Garavito 2000; Cuervo 2007, 2003a, 2003b; Demonte 1995, 1994; among others). As pointed out by Romero Morales (2008: 16), 'son dativas todas aquellas construcciones en las que aparece el clítico le(s)' ('all constructions with a clitic ' $l e(s)$ ' are considered to be dative constructions'). Similar to a-datives, the internal arguments of DCLDs can be construed canonically, as in (8a), or non-canonically, as in (8b). 
(8)
a. $\mathrm{Le}_{\mathrm{i}}$
di
el libro [a María $]_{\mathrm{i}}$
[DCLD; canonical]
him.cl.dat. give.3p.sg.past
'John gave Mary the book'
the book to María
b. [ A María $]_{\mathrm{i}}$ le $_{\mathrm{i}}$ di el libro to María him.cl.dat. give.3p.sg.past the book 'John gave Mary the book'

[DCLD; non-canonical]

[Demonte 1994: 86]

The IO-PP, doubling a dative clitic, may be null (e), as in (9), and the sentence still remains grammatical.
(9) Sara le envió un libro $e$ [DCLD; null IO-PP]
Sara him.cl.dat. send.3p.sg.past a book
'Sara sent him a book'

Dative clitics in DCLDs agree in gender, person, number, Case and theta role with the prepositional complement given that they must conform to the Matching Hypothesis (Suñer 1988). As an example, the dative clitic ' $l e$ ' in (8) and the prepositional complement 'María' constitute a well-formed co-indexed chain with shared agreement features (i.e. feminine, third person, singular), so that only one Case (i.e. dative) and only one theta role (i.e. recipient) are assigned to the chain via the preposition ' $a$ ', thus meeting the Case Filter (Chomsky 1996, 1981) and the Theta Criterion (Baker 1988; Carrier-Duncan 1985; Chomsky 1981), respectively.

When the dative clitic ' $l e(s)$ ' is combined with a pronominal accusative clitic ' $l o(s) / l a(s)$ ', as in (10a), it is replaced by an impersonal dative pronoun 'se', as in (10b), via a phonological dissimilation process (Alonso Cortés 1939; Aranovich 2012, 2011; Bruhn de Garavito 2000; García Maroto 1985; Jaeggli 1986; Romero Morales 2008).

$$
\begin{array}{lll}
\text { a. } & \text { Sara le } \quad \text { lo } & \text { envió } \\
\text { Sara him.cl.dat. it.cl.acc. } & \text { send.3p.sg.past } \\
\text { 'Sara sent him a book' } &
\end{array}
$$

\section{[DCLD]}

\footnotetext{
${ }^{3}$ Although Demonte $(1995,1994)$ argues that Spanish DA constructions share the syntactic properties of English DA constructions, the examples she provides of DCLDs and a/para-datives are both translated into English as to/for-datives. That is, she does not respect in the examples the link between, on the one hand, Spanish DCLDs and English DOCs and, on the other, Spanish a/para-datives and English to/fordatives. The present dissertation will include the corresponding English DOCs in the translation of DCLDs since we assume that double object constructions are present in English and in Spanish alike despite the differences in their surface structure.
} 

b. Sara se lo envió
Sara him.cl.dat. it.cl.acc. send.3p.sg.past
'Sara sent him a book'

[Romero Morales 2008: 16]

Similar to English for-datives, Spanish para-datives are analyzed as monotransitive predicates with an optional A-PP headed by the preposition 'para'. As in (11a), the verbal head ‘cocinó' ('she cooked') subcategorizes for a DO-DP ‘un pavo’ ('a turkey') as well as an A-PP 'para los invitados' ('for the guests'). Given the adjunct status of the PP, its non-overt realization does not render ungrammaticality, as in (11b) (Aoun and Li 1981; Bleam 2000; Creissels 2010; Givón 1990; Hurtado 1984; Jaeggli 1986; Romero Morales 2008).
(11) a. Luisa cocinó un pavo para los invitados [para-dative] Louisa cook.3p.sg.past a turkey for the guests
'Louisa cooked a turkey for the guests'
b. Luisa cocinó un pavo [mono-transitive]
Luisa cook.3p.sg.past a turkey
'Luisa cooked a turkey'

Nevertheless, as opposed to the DA between $a$-datives and their DCLD variant, para-datives do not allow to alternate with DCLDs when the IO-PP in the latter is headed by the preposition 'para', as in (12a). Rather, the IO-PP in DCLDs can only be headed by the preposition ' $a$ ', as in (12b).
a. ${ }^{*}$ Luisa $_{\text {les }}$ cocinó un pavo [para los invitados $]_{i}$ [DCLD] Luisa them.cl.dat. cook.3p.sg.past a turkey for the guests
'Louisa cooked the visitors a stuffed turkey'
b. Luisa les $\mathrm{i}_{\mathrm{i}}$ cocinó un pavo [ a los invitados $]_{\mathrm{i}}$ Luisa them.cl.dat. cook.3p.sg.past a turkey to the guests 'Louisa cooked the visitors a stuffed turkey'
[DCLD]

The following sections will address the Case marking properties and the semantic specificities that revolve around both types of DA variants and the debate regarding the syntactic (non-)derivational relationship of these constructions in English and in Spanish. 


\subsection{Case marking}

Both prepositional DA structures, English to/for-datives and Spanish a/paradatives, equally conform to the Case Filter requirements. This means that the arguments and the adjuncts of to/for-datives and a/para-datives are allocated analogous Cases in English and in Spanish. That is, the external (i.e. the subject-DP) and the internal (i.e. the DO-DP and the IO-DP) arguments of English to-datives and Spanish $a$-datives are allocated nominative, accusative and dative Cases by the verbal inflection, by the verb and by the prepositions ' $t o$ ' and ' $a$ ', respectively. In the case of English for-datives and Spanish para-datives, the external argument, the internal argument (i.e. the DO-DP) and the adjunct (i.e. the A-PP) are assigned nominative, accusative and dative Cases by the inflection, by the verb and by the prepositions 'for' and 'para', respectively, in the two languages.

As in (13) and (14), the verbs 'gave/dio' and 'bought/compró' assign accusative (acc.) Case to their adjacent DO-DPs 'a book/un libro' and 'a present/un regalo', respectively. In turn, the prepositions 'to/a' and 'for/para' allocate dative (dat.) Case to their adjacent prepositional complement 'Mary/María'.
a. John gave a book
nom.
acc.
to Mary
dat.
[to-dative]
[Case theory]
b. Juan dio
nom.
un libro
dat.
'John gave a book to Mary'
a María
a. John bought
a present for Mary
dat.
acc.
[for-dative]
nom.
[a-dative]
[Case theory]
b. Juan compró un regalo para María
nom. acc. dat.
'John bought a present for Mary'
[Case theory]
[para-dative]
[Case theory]

(14)

English and Spanish double object structures pose an issue to the Case Filter and, in particular, with regards to the Case assignment of DO-DPs in English DOCs and dative clitics in Spanish DCLDs. This appears to be so given that, on the surface, these two arguments do not have a Case assigner (i.e. either a verb or a preposition) from which they can be allocated Case. However, different accounts have been proposed to deal with how Case Filter conditions are met in each language. 
As far as English DOCs are concerned, there is only one Case assigner (i.e. the verbal head) which is able to assign accusative Case to its adjacent complement (i.e. the IO-DP) or adjunct (i.e. the A-DP); thus, leaving the DO-DP Caseless. This scenario would violate the Case Filter since all DPs need to receive Case. As in (15a) and (15b), the verbs 'sent' and 'bought' can only assign accusative Case to their adjacent IO-DP and A-DP 'Mary', respectively. In order for the DO-DPs 'a letter' and 'a present' to avoid violating Case Filter conditions, Radford (1990) proposes the Proper Antecedent Condition which resorts to null categories (e) as Case assigners via an SC approach.
a. John sent
[sc Mary
(e) a letter]
[DOC]
nom.
acc.
inh. acc.
[Case theory]
b. John
bought [sc Mary
(e) a present]
inh. acc.
[DOC]
[Case theory]

Under the Proper Antecedent Condition (Radford 1990: 192), 'an empty head can only function as a Case assigner if it has a proper antecedent (i.e. if it has a linguistic antecedent which has the same categorial status as an empty category, and which assigns Case in the appropriate way'. Under this condition, the DO-DPs 'a letter' in (15a) and 'a present' in (15b) receive inherent (inh.) Case from the empty head $(e)$ since they have a proper verbal antecedent (i.e. 'sent' and 'bought', respectively) from which they can inherit the accusative Case properties. Recall that inherent Case is assigned if and only if the Case receiver (i.e. DO-DP) is in the SC domain of the Case assigner (i.e. the empty head).

An alternative explanation to the Case assignment of DOCs is offered by Larson (2014, 1990, 1988). The verbal heads 'sent' and 'bought' in (16a) and in (16b), respectively, base-generate in a lower VP-shell domain and they move, via V-Raising, to a higher VP-shell domain to assign (structural) accusative Case to their adjacent IO/A-DP 'Mary'; this movement leaves a trace of the verbal heads in their base VP positions and creates a sequence of co-indexed V positions. Inherent accusative Case assignment to the DO-DPs 'a letter/a present' in (16a) and in (16b), respectively, is licensed by their adjacent and governing complex transitive predicate $\left[v t_{\mathrm{i}} t_{\mathrm{j}}\right]$. This is done via V' Reanalysis which states that 'let $\alpha$ be a phrase $\left[V^{\prime} . ..\right]$ whose theta-grid contains one undischarged internal theta role. Then, $\alpha$ may be reanalyzed as [v...]' (Larson 1990: 348). 
(16)
a. John [vp $\left[\mathrm{v}\right.$, sent $\mathrm{i}_{\mathrm{i}}\left[\mathrm{vP} \operatorname{Mary}_{\mathrm{j}}\left[\mathrm{v},\left[\mathrm{v} t_{\mathrm{i}}\right] t_{\mathrm{j}}\right]\right.$ [a letter]]]
[DOC]
nom.
acc.
inh. acc.
[Case theory]
b. John [vp [v, bought ${ }_{\mathrm{i}}\left[\mathrm{vP} \operatorname{Mary}_{\mathrm{j}}\left[\mathrm{v},\left[\mathrm{v} t_{\mathrm{i}}\right] t_{\mathrm{j}}\right]\right.$ [apresent]]]
[DOC]
nom.
acc.
inh. acc.
[Case theory]

[adapted from Larson 1990: 617]

Under the light of V' Reanalysis, the verbs 'sent/bought' in (16a) and in (16b) assign a recipient/beneficiary theta role to the IO/A-DP 'Mary' which undergoes, in turn, DP-movement to be allocated accusative Case once their corresponding verbal heads have undergone V-to-V movement. This movement leaves a trace $\left(t_{j}\right)$ of the $\mathrm{IO} / \mathrm{A}-\mathrm{DP}$ in its base position and, thus, the IO/A-DP 'Mary' is discharged. Because the lowest V' has one unsaturated theta role (that is, the DO-DP-theme 'a letter/a present'), $\mathrm{V}^{\prime}$ Reanalysis allows the recategorization of the lowest $\mathrm{V}^{\prime}\left[\mathrm{v}^{\prime}\left[t_{\mathrm{i}}\right] t_{\mathrm{j}}\right]$ as a complex transitive predicate $\left[\mathrm{v}\left[t_{\mathrm{i}}\right] t_{\mathrm{j}}\right]$. Hence, it is the relation between the verbal trace $\left(t_{\mathrm{i}}\right)$ and the trace of the IO/A-DP $\left(t_{\mathrm{j}}\right)$ in the reanalyzed complex transitive predicate the one that allows the DO-DP 'a letter/a present' to receive inherent accusative Case. In other words, $\left[\mathbf{v}\left[t_{\mathrm{i}}\right] t_{\mathrm{j}}\right]$ inherits the Case assigning properties of the verbal heads 'sent/bought'.

Therefore, the conundrum of Case assignment to the DO-DP in English DOCs is solved under the Proper Antecedent Condition (Radford 1990) and under V’ Reanalysis (Larson 1990). Hence, the result is that the Case Filter requirements are met for both DPs in DOCs, that is, the IO/A-DP and the DO-DP.

In the case of Spanish DCLDs, what is at stake is Case assignment to the dative clitic ' $l e(s)$ ' since, apparently, there is no Case assigner for the clitic. To begin with, as in (17), the verbal head 'dio' ('he gave') assigns accusative Case to its adjacent DO-DP ‘un libro’ ('a book’).
(17) Juan le $e_{i}$ dio
un
[a $\quad$ María $]_{i}$
[DCLD]
nom. inh. dat./affixal
dat.
[Case theory]
'John gave Mary a book'

Likewise, dative Case assignment to the prepositional complement 'María' in (17) is allocated via the preposition ' $a$ ', satisfying, so far, the Case assignment requirements of the DO-DP and the prepositional complement. However, in order for the dative clitic ' $l e$ ' to avoid violating the Case Filter, two proposals have been put forward: (a) Dative clitics inherit the Case properties of their co-indexed prepositional complements 
(Aranovich 2011; Cuervo 2003a, 2003b; among others) or (b) dative clitics are considered to be verbal affixal morphemes (Anagnostopoulou 2006, 2003; Beavers and Nishida 2009; Borer 1984; among others).

There are some studies which propose that dative clitics in DCLDs are doubled arguments of prepositional complements and, as such, they share Case properties (Aranovich 2011; Cuervo 2003a, 2003b; Demonte 1995, 1994; Torrens and Wexler 2000). This means that in order to avoid violating the Case Filter in which only one Case can be assigned to one and only one argument, dative clitics and prepositional complements are understood as part of a chain and, therefore, they receive the same Case from the preposition ' $a$ '. As in (17) above, the prepositional complement 'María' receives dative Case from the preposition ' $a$ ', while the dative clitic ' $l e$ ' shares this dative Case as per the co-indexation with 'María'.

Other studies consider dative clitics to be morphological verbal affixal agreement markers which, akin to verbal inflectional affixes, are adjoined to the verb in pre-verbal position (Anagnostopoulou 2006, 2003; Aranovich 2012, 2011; Baker 1988; Beavers and Nishida 2009; Bleam 2000; Borer 1984; Durán Arboisiere 2004; García Maroto 1985; Gerlach 2002; Jaeggli 1986, 1982; Kayne 1975; Masullo 1992; Strozer 1976; Suñer 1988). Under this proposal, the dative clitic and the verb behave as one single Case assigner; however, dative clitics are argued to be bound morphemes which are affixed onto verbs, as opposed to verbal inflectional affixes which are verbal features. In other words, dative clitics are not seen as verbal arguments, but they are part of the verbal phrase and, as such, the verb and the dative clitic are able to assign accusative Case to their adjacent DO-DP. This means that the dative clitic is a Case assigner, while under the co-indexation approach, as discussed earlier, it is a Case receiver.

Therefore, although different formal analyses have been proposed to account for the Case assignment of the two types of DA constructions in English and in Spanish, the Case Filter requirements are met to guarantee the grammatical distribution of nominal arguments.

\subsection{Syntactic (non-)derivational relationship}

There is a debate in the literature as to whether there is a syntactic derivational or non-derivational relationship between DOCs and to/for-datives in English DA structures (section 1.3.1) and between DCLDs and a/para-datives in Spanish DA structures (section 1.3.2). 
With regards to the syntactic derivation of English DA structures, two standpoints appear. One of these views lends support to the derivation of DOCs from to/for-datives following either a transformational rule, as put forward by Oehrle (1976), or a passivelike movement which is discussed in terms of (a) an advancement rule under Relational Grammar (RG; Haspelmath 2006; Perlmutter 1980) or (b) a DP-movement under Government and Binding (GB) theory (Larson 2014, 1990, 1988). Conversely, to/fordatives are also argued to derive from DOCs via (a) a lexical rule, as an alternative proposal to Case theory within GB theory (Czepluch 1982) or (b) a passive-like mechanism which is accounted for by either an advancement rule, in contrast to the one proposed by RG (Dryer 1986), or a DP-movement (Aoun and Li 1989; Koizumi 1994), as an alternative analysis to the one argued in Larson (2014, 1990, 1988). Other studies do not assume a syntactic derivational relationship between the two types of DA constructions in English and they argue for the formation of two syntactically and semantically different structures (Marantz 1993; Mulder 1992) or a shared underlying (complex predicate or SC) structure (Snyder and Stromswold 1997).

A similar issue has arisen regarding the syntactic (non-)derivation of DA structures in Spanish. From the syntactic derivational approach, there seems to be an agreement in arguing for the derivation of DCLDs from a/para-datives despite the scarce works on the topic (Bruhn de Garavito 2000; Demonte 1995, 1994; among others) if compared to those on DA structures in English. In contrast, other studies (Cuervo 2003a, 2003b) propose that DA structures in Spanish differ in the status of the head that they project, namely, an applicative head (i.e. a dative clitic) in DCLDs and a verbal head in $a /$ para-datives. 


\subsubsection{English DOCs and to/for-datives}

One of the first linguists to address the issue of a derivational account of DOCs from to/for-datives in English is Oehrle (1976). As in (18), a scale of prominence ${ }^{4}$ based on the linear constituent order of to/for-datives (i.e. the base structure) assumes that a $\mathrm{N}$ (oun) P(hrase) (DO)-3 precedes an NP (prepositional complement)-5, headed by a preposition-4 'to' or 'for'. Taking this hierarchy of prominence into consideration, the NP (prepositional complement)-5 in (18) takes an NP (DO)-5 position, triggering the derived transformational rule in (19). Moreover, the NP (DO)-3 in the base structure (that is, to/for-dative) occupies a lower position than the NP (prepositional complement)-5 in the derived DOC. As a result of the derivational process, the preposition-4 in (18) is deleted in (19).

(18) X-V-NP-to/for-NP $\begin{array}{lllll}1 & 2 & 3 & 4 & 5\end{array}$

[to/for-dative; base structure]

(19) X-V-NP-NP $\begin{array}{llll}1 & 2 & 5 & 3\end{array}$

[DOC; derived structure]

[Oehrle 1976:169]

However, Oehrle (1976) does not offer a detailed explanation as to whether the syntactic derivational process of DOCs from to/for-datives is lexically, syntactically or semantically driven.

Taking Oehrle’s (1976) prominence hierarchy of grammatical relations into consideration, the syntactic derivational relationship of English DA structures is defined in RG (Haspelmath 2006; Perlmutter 1980) as the advancement of IO-3 over DO-2 (also known as 3-to-2 advancement), assuming, therefore, that to/for-datives are the base structure from which DOCs derive. This means that this advancement rule changes the

\footnotetext{
${ }^{4}$ According to Oehrle (1976: 168), 'prominence (or linear order of constituents) is defined with respect to the following hierarchy: A lower number reflects lower prominence'. This means that, on the basis of Oehrle's (1976) assumption, the elements in the to/for-dative construction (i.e. subject, V, DO, prepositions 'to/for', prepositional complement and adjuncts) are assigned a number according to the linear order that they occupy in the structure, namely, subject-1, V-2, DO-3, to/for-4, prepositional complement-5 and other adjuncts-6. Following this hierarchy of structural prominence, DOCs are argued to derive from to/for-datives via a transformational rule, and so, the linear constituent order of the derived DOC is distributed as follows: The prepositional complement-5 occupies a higher position than DO-3 and the prepositions 'to/for' are deleted.
} 
grammatical relation of the IO-3 'to Aisha' at the underlying (i.e. 'initial') to-dative structure in (20) to a DO-2 position at the surface (i.e. 'final') structure in the derived DOC in (21) without being headed by the preposition 'to'. Furthermore, the DO-2 'his e-mail address' in (20) is demoted to an adjunct (or chômeur) position in (21) as a result of this advancement, akin to by-phrases in passives.

(20) Pedro gave his e-mail address to Aisha SU-1 DO-2 IO-3
(21) Pedro gave Aisha his e-mail address SU-1 IO-3 DO-2 SU-1 DO-2 chômeur

[to-dative; base structure] [grammatical relations]

[DOC; derived structure] [grammatical relations-initial] [grammatical relations-final]

[Haspelmath 2006: 3]

Larson $(2014,1990,1988)$ accounts for the derivation of DOCs from to-datives via an analogous process to the derivation of passives from active mono-transitives, that is, via DP-movement. The constructional process of the base to-dative takes place in an underlying clause-like VP domain, as in (22), where the verbal head 'sends' basegenerates in a lower VP-shell and subcategorizes for an internal object-like PP 'to Mary' as well as an external subject-like DP 'a letter', developing the complex VP [a letter sends to Mary].

(22) John [vp sends $s_{\mathrm{i}}\left[\mathrm{vp}\right.$ a letter [v, $t_{\mathrm{i}}$ to Mary] $]$

[to-dative; base structure]

[Larson 1988: 342-343]

In order for the internal arguments of the to-dative in (22) to satisfy the Case Filter requirements (Chomsky 1996, 1981; Haegeman and Guerón 1999), the IO-PP 'to Mary' is assigned dative Case by the preposition 'to'. However, due to the fact that Case is allocated under adjacency and government conditions, the DO-DP 'a letter' would remain Caseless and, consequently, it would violate the Case Filter since there is no adjacent Case assigner in the lower VP-shell structure. Thus, the verb 'sends' undergoes V-Raising (or head-to-head movement; see section 1.2) to the empty position of the higher VP-shell so that the DO-DP 'a letter' is able to receive accusative Case from the verbal head. This movement leaves a trace $\left(t_{\mathrm{i}}\right)$ and 'it creates a sequence of coindexed V positions' (Larson 1988: 343). 
Under these premises, Larson $(2014,1990,1988)$ argues that DOCs are derived from to-datives via a mechanism akin to passives. The Case assigning properties of the preposition 'to' in (22) are absorbed in the derived DOC in (23); this means that the prepositional complement 'Mary' is Caseless as it does not have a Case assigner. Although Larson $(2014,1990,1988)$ does not motivate this prepositional deletion, he assumes that Case absorption of the preposition 'to' is analogous to that of verbs in the derivation of passives from active mono-transitives.

(23) John [vp sends $\mathrm{ivp}_{\mathrm{vp}} \operatorname{Mary}_{\mathrm{j}}\left[\mathrm{v},\left[\mathrm{v} t_{\mathrm{i}}\right] t_{\mathrm{j}}\right]$ a letter $\left.]\right]$

[DOC; derived structure]

[Larson 1988: 359]

Hence, similar to the syntactic derivation of passives, the object-like DP 'Mary' in the base to-dative in (22) undergoes DP-movement to the subject-like position (i.e. to the specifier of the lower VP-shell) in the derived DOC in (23) in order to be assigned accusative Case by the moved verbal head 'sends'. Therefore, verbal movement (i.e. VRaising) from the head of the lower VP-shell to the head of the higher VP-shell (both in to-datives and in DOCs) besides DP-movement of the object-like DP in the base todative to a subject-like position in the derived DOC are motivated by Case-driven conditions.

Moreover, the DO-DP 'a letter' in the base to-dative in (22), which functions, according to Larson $(2014,1990,1988)$, as the subject of the clause-like VP structure in the lower VP-shell domain, takes an adjunct status, similar to by-phrases in passives, as indicated by the recursive V' node in (23). Inherent accusative Case assignment to the DO-DP 'a letter' is licensed by V' Reanalysis of the complex transitive verb [ $t_{\mathrm{i}} t_{\mathrm{j}}$ ] by assuming that this complex predicate inherits the Case assigning properties of its verbal head 'sends' (see section 1.2).

Therefore, the passive-like derivation of DOCs from to-datives resembles that of passives from active mono-transitives because (a) the object-like properties of the IO$\mathrm{PP}$ in the base to-dative and the DO-DP in the active mono-transitive undergo DPmovement to a subject-like position in DOCs and to a subject position in passives so as to satisfy the Case Filter in their corresponding derived structures and (b) the subjectlike properties of the DO-DP in the base to-dative as well as the subject in the active mono-transitive assume an adjunct-like status in DOCs and an adjunct status in passives. 
However, there are some differences between DOCs and passives. First of all, unlike the optional realization of by-phrases in passives, the DO-DP 'a letter' in the DOC in (23) is an obligatory argument as part of the subcategorization framework of the verb 'sends'. Moreover, the passive-like formation of DOCs takes place in different domains since DP-movement occurs in a clause-like VP domain, in contrast with passives where DP-movement targets an I(inflectional) P(hrase) domain. In turn, the inflectional morphology of the verb differs between DOCs (whose form is in active voice) and passives (whose form is in passive voice with either be or get as passive auxiliary verbs).

Despite the shared underlying thematic relationships between to-datives and DOCs (see section 1.4), Jackendoff (1990) observes that the syntactic derivation of DOCs in Larson $(2014,1990,1988)$ does not meet the Uniformity of Theta Assignment Hypothesis (UTAH, Baker 1988: 46) because the identical thematic relations between the internal arguments of to-datives and DOCs are not represented by analogous underlying structural relations. Thus, in order to meet the UTAH requirements and in order to preserve the derivational account of DOCs from to-datives, Larson (1990) states the principle of Relativized UTAH, described in (24).

(24) Relativized UTAH: Identical thematic relationships are represented by identical relative hierarchical relations between items at D(eep)-structure.

[Larson 1990: 601]

In other words, Relativized UTAH assures that, in spite of the shared thematic relations between the DO and the IO in to-datives and in DOCs, their underlying structures are hierarchically different, as opposed to the standard principles put forward by UTAH. Therefore, Relativized UTAH lends support to DOCs as being syntactically derived from to-datives via a passive-like process.

Czepluch (1982) revises Oehrle's (1976) transformational rule and he proposes a lexical (or subcategorization) rule, as in (25), under which DA verbs subcategorize for two nominal (i.e. DP) arguments. This means that DOCs (or prepositionless IO constructions, as termed by Czepluch (1982)) are considered to be the base structure from which to/for-datives (or prepositional IO constructions in Czepluch's (1982) terms) syntactically derive. 
(25) verb (+ $\mathrm{DP}($ to/for $) \mathrm{DP})$

Czepluch's (1982) rule is assumed under what he terms 'the lexical covertcategory PP analysis', an alternative proposal to Case theory within GB theory, which argues that to/for-datives are Case-related to DOCs. As in (26a), the verb 'give' subcategorizes for two internal arguments in DOCs, namely, an IO-DP 'Mary', headed by an empty preposition (e), and a DO-DP 'the book'. Following the Empty Category Principle (ECP, Chomsky 1981; Kayne 1981), the null preposition (e) and the verbal trace $\left(t_{\mathrm{i}}\right)$ function as exceptional governors and they assign accusative Case to the IODP 'Mary' and inherent accusative Case to the DO-DP 'the book' through Case transmittance by the verb 'give'. Therefore, the Case Filter is satisfied via empty categories.

(26) a. John [vp gave [pp $_{\mathrm{p}} e$ ] Mary] $t_{\mathrm{i}}$ [the book]]

[DOC; base structure]

b. John gave the book to Mary

[to-dative; derived structure]

[Czepluch 1982: 14]

The Case assignment requirements of the internal arguments in the derived todative in (26b) are met. This means that the DO-DP 'the book' and the prepositional complement 'Mary' receive accusative and dative Case from their corresponding governors, that is, the verb 'gave' and the preposition 'to'.

Contra the above-mentioned 3-to-2 advancement rule proposed by the RG approach (Haspelmath 2006; Perlmutter 1980), Dryer (1986) postulates an anti-dative analysis where DOCs are the base and to/for-datives are the derived structure. He follows Ellis (1983: 284) in determining that DOCs are base-generated structures: 'The person to whom a thing is given, lent, shown, told, etc. is the immediate object of the verb. The thing given, lent, shown, etc. is the second object and one position further removed'. By means of an advancement rule, the DO-DP 'the book' in (27a), taking a secondary position (SO) in the base DOC, advances to a primary object (PO) position in the derived to-dative in (27b). In turn, the IO (PO) 'Mary' in the base DOC assumes a chômeur (i.e. an adjunct) status in the derived to-dative, akin to the demotion of byphrases in passives. 
(27)
a. John gave Mary
the book
$\mathrm{SU}$
$\mathrm{IO}(\mathrm{PO})$
$\mathrm{DO}(\mathrm{SO})$
b. John gave the book to Mary
SU DO (SO) IO (PO)
SU $\quad \mathrm{DO}(\mathrm{PO})$ chômeur

[DOC; base structure]

[syntactic function]

[to-dative; derived structure]

[syntactic function-initial]

[syntactic function-final]

[Dryer 1986: 821]

There are other proposals that lend support to the derivation of to/for-datives from DOCs via a passive-like movement (Aoun and Li 1989; Koizumi 1994). They consider Kayne’s (1984) SC analysis and Larson's (2014, 1990, 1988) passive-like derivational mechanism to account for the derivation of to/for-datives from DOCs. As in (28a), the verb 'gave' stems as the head of a higher VP-shell and subcategorizes for an SC in which the IO-DP 'Mary' and the DO-DP 'a book' function as the subject and as the complement, respectively. In order to meet the Case Filter requirements, the verb 'gave' assigns accusative Case to its adjacent IO-DP 'Mary' and the DO-DP 'a book' receives inherent accusative Case from the empty verb $(e)$ which denotes transfer of possession. Thus, the empty verb inherits the Case assigning properties of the verbal head 'gave'.

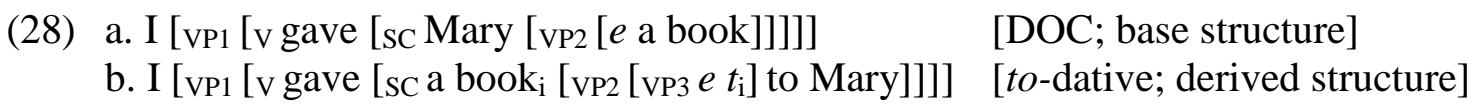

[Aoun and Li 1989: 163-164]

Similar to Larson's $(2014,1990,1988)$ syntactic derivational mechanism (although Larson argues for the derivation of DOCs from to-datives), passivization of the to-dative in (28b) takes place when an empty verb $(e)$ in the base DOC in (28a) lacks the ability of assigning Case to its adjacent DO-DP 'a book' in an SC domain, similar to the past participle in passive structures (recall that, in Larson (2014, 1990, 1988), it is the preposition 'to' the one that loses the Case assigning properties in the derivation of DOCs). Therefore, the DO-DP 'a book' in (28b) undergoes DP-movement to the specifier of the SC in order to be assigned accusative Case by the verb 'gave'. As a result of this movement, the DO-DP leaves a trace $\left(t_{\mathrm{i}}\right)$ in its original position (i.e. in the lower VP-shell domain). Besides, the subject of the SC in the base DOC (that is, the IO-DP 'Mary') adopts an adjunct status in the derived to-dative and receives dative Case from the preposition 'to' within a recursive VP2 domain. Thus, the status given to the A-PP ‘to Mary’ is similar to that allocated to by-phrases in passives. 
Despite the debate with regards to the derivation of DOCs from to/for-datives (Oehrle 1976 via a scale of prominence; Haspelmath 2006; Perlmutter 1980 in RG; Larson 2014, 1990, 1988 in GB theory) or the derivation of to/for-datives from DOCs (Czepluch 1982 via the lexical covert-category PP analysis; Dryer 1986 in RG; Aoun and Li 1989; Koizumi 1994 in GB theory), both analyses resort to a passive-like mechanism to explain the formation of the derived structure.

Alternatively, non-derivational approaches regarding DOCs and to/for-datives account for the formation of either two opposing syntactic constructions (Marantz 1993; Mulder 1992) or a shared underlying structure (Snyder and Stromswold 1997).

Mulder (1992) bases his proposal on the Multiple-headed Verbal Phrase Hypothesis (MVPH) in which a verbal head takes an SC complement, as also argued in Kayne's (1981) SC analysis. In the case of DOCs, as in (29), the verbal head 'gave' selects an SC headed by an empty causative verb (i.e. $\phi_{\mathrm{HAVE}}$ ) with possessive meaning. This means that $\phi_{\mathrm{HAVE}}$ is semantically interpreted as the empty counterpart of the verb 'have', and, therefore, the DOC in (29) is in line with the possessive interpretation in (30). In turn, the empty head subcategorizes for an IO-DP 'John', as the subject of the SC, and a DO-DP 'the book', as the complement of the SC.

(29) I [vp gave [sC John $\phi_{\mathrm{HAVE}}$ the book]]

(30) John has the book

[Mulder 1992: 69]

In terms of Case assignment of the DOC in (29), Mulder (1992) assumes that the empty possessive verbal head $\phi_{\mathrm{HAVE}}$ does not undergo V-Raising to the verbal head 'gave' and, therefore, the IO-DP 'John' and the DO-DP 'the book' are assumed to be assigned structural (accusative) Case by 'gave' and by $\phi_{\mathrm{HAVE}}$, respectively. However, the type of Case assignment that is allocated to the internal arguments (i.e. be it accusative or inherent accusative) is not addressed in Mulder (1992).

With regards to to/for-datives, Mulder (1992) argues that the verbal head 'give' in (31) selects an SC, akin to the formation of DOCs in (29). Nevertheless, the SC is headed by an empty verbal head $(\phi)$ which subcategorizes for a DO-DP 'the book', as the subject of the SC, and an IO-PP 'to John', as the complement of the SC. This empty verbal head does not convey a possessive meaning, as it does in DOCs. In this 
approach, Mulder (1992) does not elucidate whether the empty verbal head has Case assigning properties.

(31) I [vp gave [sc the book $\phi$ to John]]

[Mulder 1992: 69]

Marantz (1993) assumes that DOCs take a Chomskian-Larsonian VP-shell structure, as in (32a). However, there are certain differences between (32a) and Larson's (2014, 1990, 1988) analysis since Marantz (1993) argues that (a) a null applicative affix (APPL) is analyzed as a verb that subcategorizes for the DO-DP 'the porcupine', as the specifier of a lower VP-shell, and the verb 'give', as the head of this VP-shell; (b) the IO-DP 'Hortense' base-generates as the specifier of the higher VP-shell, akin to Larson’s (2014, 1990, 1988) approach; and (c) the verb ‘give’ undergoes V-Raising and merges (or incorporates; Baker 1988) with the APPL.

(32) a. [IP [DP Elmer][I' [I past][vP [DP Hortense][v' [v give $\left._{\mathrm{i}}+\mathrm{APPL}\right][\mathrm{vP}$ [DP the porcupine $\left.\left.\left.\left.\left.]\left[\mathrm{v},\left[\mathrm{v} t_{\mathrm{i}}\right]\right]\right]\right]\right]\right]\right]$

b. Elmer gave Hortense the porcupine

[adapted from Marantz 1993: 119]

However, Marantz (1993) argues that it is not clear that the merged verb and the APPL raise to inflection and yield the structure in (32b); rather, he assumes that the constituent order of (32b) is the result of the interface between superficial structure and phonological form (PF) (Marantz 1988). Thus, (32b) is formed by assuming that 'the structural Case relation between $V$ and the accusative object corresponds to a left-right adjacency' (Marantz 1993: 130) via the superficial structure and the PF mapping between the verb 'gave' and the DO-DP 'the porcupine'. Recall that in Larson (2014, 1990, 1988), V-Raising in DOCs is Case- and theta role-motivated so as to (a) assign accusative Case to the IO-DP which has previously undergone DP (or passive-like) movement from a verbal complement position to the specifier of a lower VP-shell; and (b) preserve the UTAH requirements.

To/for-datives, following Marantz's (1993) analysis, have the structure in (33), which contrasts with that in (32a) in that a VP-shell and an APPL head are not assumed. 
Under one single VP projection, the verb 'gave' selects an IO-PP 'to Hortense', occupying a complement position (as also argued in Larson 2014, 1990, 1988), and a DO-DP 'the porcupine’, occupying a specifier position.

(33) [IP [DP Elmer] [I, [i past] [VP [DP the porcupine] [V, [v give] [pp to Hortense]]]]]

[Marantz 1993: 120]

Snyder and Stromswold (1997) address the syntactic non-derivational relationship of English DA constructions by testing their acquisition in L1 children's spontaneous production. They report that DOCs (mean age: 2;02) and to-datives (mean age: 2;06) begin to be produced at approximately the same age ( $r=.76, t(10)=3.67, p=.0043)$; this suggests that these structures share analogous properties (i.e. Property A) as complex predicates (in line with Larson 2014, 1990, 1988; Marantz 1993; among others) or as SC constructions (in line with Aoun and Li 1989; Kayne 1984; among others) ${ }^{5}$. However, the delay in the emergence of to-datives when compared to DOCs $(t(11)=4.15, p=.002)$ is explained by the additional Case- and theta-assigning properties of the preposition 'to' in to-datives (i.e. Property B) (see further details in section 2.2, chapter 2).

Considering the two formal views on the syntactic relationship between DOCs and to/for-datives (i.e. derivational and non-derivational), the present dissertation will ultimately defend the non-derivational approach, as tested against L1 English and 2L1 English children's spontaneous production data (see chapter 3). As will be discussed in section 5.1 (chapter 5), our findings reveal that, given that the two English DA structures begin to emerge at an approximately similar age, this points to the fact that DOCs and to/for-datives are not syntactically derived from one another, and thus, they could either stem from two syntactically and semantically opposing structures (in line with Marantz 1993; Mulder 1992) or be built under one shared underlying structure (in line with Snyder and Stromswold 1997).

\footnotetext{
${ }^{5}$ Snyder and Stromswold (1997: 307) claim, in a footnote, that they 'will not attempt to distinguish these two approaches (i.e. the complex predicate and the SC approach). As long as both approaches can be extended to the full range of constructions under discussion (i.e. DOCs and to-datives, including other related complex predicates, as in (3)), our acquisitional data are compatible with either'.
} 


\subsubsection{Spanish DCLDs and a/para-datives}

Contra the opposing viewpoints on the syntactic derivational relationship of English DA constructions (see section 1.3.1), derivational approaches on Spanish argue for the derivation of DCLDs, as in (34b), from a/para-datives, as in (34a) (Bruhn de Garavito 2000; Demonte 1995, 1994; Kempchinsky 2004). In contrast to the shift of arguments that occurs in the underlying structure of the two English DA constructions, the derivation of DCLDs from a/para-datives in Spanish takes place in a ChomskianLarsonian VP-shell structure via the presence or the absence of a dative clitic which is doubled by a prepositional complement headed by the preposition ' $a$ ' (see section 1.1). Therefore, the shift of internal arguments in English vs. the presence-absence of a dative clitic in Spanish could be the point of cross-linguistic difference across the two languages.
a. Entregué las llaves al conserje [a-dative; base structure] give.1p.sg.past the keys to+the janitor 'I gave the keys to the janitor'
b. Le entregué las llaves al conserje [DCLD; derived structure] him.cl.dat. give.1p.sg.past the keys to+the janitor 'I gave the janitor the keys'

[Demonte 1995: 6]

Demonte (1995: 6) argues that DA occurs via the presence or the absence of a dative clitic in the third person (i.e. singular ' $l e$ ' or plural 'les'). This is so given that first (i.e. ' $m e$ ') and second person (i.e. 'te') dative clitics are required to be overt when doubled by a pronominal prepositional complement, as in (35a); therefore, the nonspell-out of these clitics renders a/para-datives ungrammatical, as in (35b).

$$
\begin{aligned}
& \text { a. Te entregaron a ti a tus enemigos [DCLD] } \\
& \text { you.cl.dat. hand.3p.pl.past to you to your enemies } \\
& \text { 'They handed you to your enemies' } \\
& \text { b.*Entregaron a ti a tus enemigos } \\
& \text { [ungrammatical } a \text {-dative] } \\
& \text { 'They handed you to your enemies' }
\end{aligned}
$$

[Demonte 1995:6]

As will be discussed in chapter 4, DCLDs are analyzed on the basis of a preverbal dative clitic in the third person, regardless of the spell-out of the co-occurring IO- 
PP. In (36), the dative clitic ' $l e$ ' takes a third person singular form and it co-occurs with a null IO-PP (e) which could refer to a pronominal (i.e. 'a él' ('to him') or a nonpronominal (i.e. 'a Juan' ('to John')) prepositional complement.

(36) Le traigo su coche $(e)$ ? [DCLD; null IO-PP]
him.cl.dat. bring.1p.sg.pres. his car
'Shall I bring him his car?'

[María, 3;06, the Ornat corpus, CHILDES, MacWhinney 2000]

Most studies on the derivation of Spanish DA constructions take as a point of departure Demonte’s (1995, 1994) works (Bruhn de Garavito 2000; Kempchinsky 2004). She assumes that the syntactic properties of DA in Spanish are akin to the ones exhibited in English. More specifically, Demonte (1995, 1994) argues, along the lines of Larson's (2014, 1990, 1988) VP-shell structure, that the two DA structures in Spanish are 'derivationally related in the syntax' (Demonte 1995: 9) since they partially share an underlying VP-shell structure. This derivation is related to the presence or the absence of a dative clitic 'le(s)' and it safeguards the UTAH principles (Baker 1988) in that the same theta roles are assigned to the underlying structure of DCLDs when derived from a/para-datives, as will be discussed in section 1.4.

The syntactic properties of a/para-datives in Spanish are argued to be shared by those of to/for-datives in English. Therefore, the Chomskian-Larsonian VP-shell structure for (34a) is given in (37), where the verb 'entregué' ('I gave') base-generates as the head of the lower VP-shell and subcategorizes for an IO-PP 'al conserje' ('to the janitor'). In terms of the Case Filter requirements, the prepositional complement (i.e. 'el conserje') receives dative Case from the preposition ' $a$ ' and the verb undergoes head-tohead movement (i.e. V-Raising) so that it can assign accusative Case to the DO-DP 'las llaves' ('the keys'). As a result of this movement, the verb leaves a trace $\left(t_{i}\right)$ in the head of the lower VP-shell.

(37) $\left[\mathrm{vP}_{\mathrm{V}}\left[\mathrm{v},\left[\mathrm{v}\right.\right.\right.$ entregué ${ }_{\mathrm{i}}\left[\mathrm{vP}\right.$ [DP las llaves] [v, [v $\left.t_{\mathrm{i}}\right]$ [Pp al conserje]]]]]]

[adapted from Demonte 1995:16]

The underlying structure of DCLDs, as in (38), departs slightly from the one displayed in (37) in that the dative clitic ' $l e$ ' projects a $\mathrm{D}$ (ative) $\mathrm{Cl}(\mathrm{itic}) \mathrm{P}$ (hrase) 
(Demonte 1995), also termed B(eta/beneficiary) P(hrase) (Demonte 1994) or I(nner) A(spect) P(hrase) (Bruhn de Garavito 2000; Kempchisnky 2000), occupying the higher position of a Chomskian-Larsonian VP-shell structure.

(38) a. $\left[\mathrm{vp}\left[\mathrm{v},\left[\mathrm{v}\right.\right.\right.$ entregué ${ }_{\mathrm{i}}\left[\mathrm{DClP}[\mathrm{pP}\right.$ al conserje $]$ [DCl' [Cl le $\left[\mathrm{vp} t_{\mathrm{j}}\left[\mathrm{v},\left[\mathrm{v} t_{\mathrm{i}}\right][\mathrm{DP}\right.\right.$ las llaves]]]]]]]]

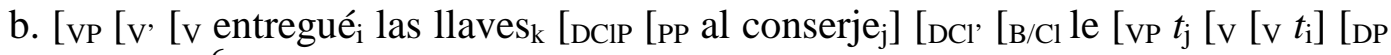
$\left.\left.\left.\left.\left.\left.\left.t_{\mathrm{k}}\right][]\right]\right]\right]\right]\right]\right]^{6}$

[adapted from Demonte 1995: 17-18]

The verb 'entregué' ('I gave') in the DCLD in (38) base-generates in the lower VP-shell and subcategorizes for a DO-DP 'las llaves' ('the keys'). Nevertheless, the verb does not undergo V-Raising so as to satisfy the Case Filter requirements (as argued in Larson 2014, 1990, 1988); rather, Demonte (1995: 19) claims that verb raising 'is necessary for conceptual reasons, since from this position (i.e. the landing $\mathrm{V}$ position in the higher VP-shell), it would be able to rise again in order to satisfy morphological properties'.

The IO-PP 'al conserje' ('to the janitor') in (38) generates as the specifier of the lower VP-shell, a position which is higher than the DO-DP. However, the free constituent order in Spanish allows the IO-PP to occupy two positions 'to check its morphological features against the clitic head (i.e. dative Case from the preposition ' $a$ ' via specifier-head agreement of the IO-PP (as specifier) and the dative clitic (as head) in the DClP)' (Demonte 1995: 23). These two positions refer to (a) the specifier of the DClP, as in the non-canonical DCLD in (38a) or (b) the movement of the verb and the DO-DP to the head of the higher VP-shell over the IO-PP 'al conserje', forming a complex predicate unit (i.e. 'entregué las llaves'), as in the canonical DCLD in (38b). As a consequence of this movement, the IO-PP and the DO-DP leave a trace $\left(t_{\mathrm{i}}\right.$ and $t_{\mathrm{k}}$, respectively) in the reanalyzed head of the lower VP-shell. Therefore, Demonte (1995) resorts to Larson's $(2014,1990,1988)$ V' Reanalysis of the verb and the DO-DP as a complex transitive verb.

\footnotetext{
${ }^{6}$ Demonte (1995) argues that the verb and the DO undergo V' Reanalysis (Larson 2014, 1990, 1988) since they form a complex lexical category, that is, a complex transitive verb.
} 
Although the spell-out of dative clitics determines the syntactic derivation of DCLDs from a/para-datives, their pre-verbal landing position (recall that they basegenerate as heads of a DCIP) is left unexplained in Demonte (1995, 1994). Nevertheless, as discussed in section 1.2 earlier, in order for the dative clitic not to violate the Case Filter, two arguments are proposed, namely, a co-indexation chain of shared dative Case between the dative clitic and the prepositional complement as assigned by the preposition ' $a$ ' (Aranovich 2011; Cuervo 2003a, 2003b; Hurtado 1984; among others) or an approach where the dative clitic incorporates to the verbal head as an affixal agreement morpheme, forming with the verb a single accusative Case assigner to their adjacent DO-DP (Anagnostopoulou 2006, 2003; Beavers and Nishida 2009; Borer 1984; among others).

Regarding non-derivational approaches to Spanish DA constructions, Cuervo (2003a, 2003b) argues that DCLDs and a-datives correspond to two underlying syntactically and semantically opposing structures which differ in the status of the head that is projected as well as in the thematic roles assigned to the IO. Broadly speaking, $a$ datives are said to be headed by a verb which subcategorizes for a DO-DP (theme) and an IO-PP (goal), while DCLDs are headed by a dative clitic which functions as an applicative head (following Pylkkänen’s (2000) low applicatives) and which selects a DO-DP (theme) and an IO-PP (beneficiary). The properties of each structure are detailed below.

A-datives are analyzed as in (39). The verbal head 'envió' ('she sent') subcategorizes for a DO-DP (the theme) 'un diccionario' ('a dictionary') and an IO-PP (the goal) 'a Gabi’ ('to Gabi’).

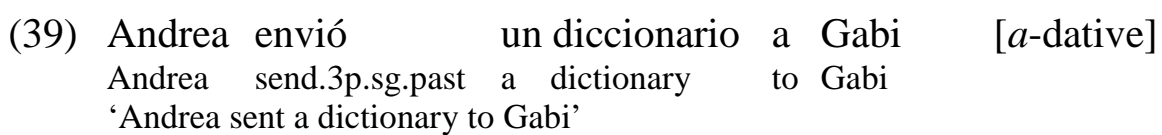




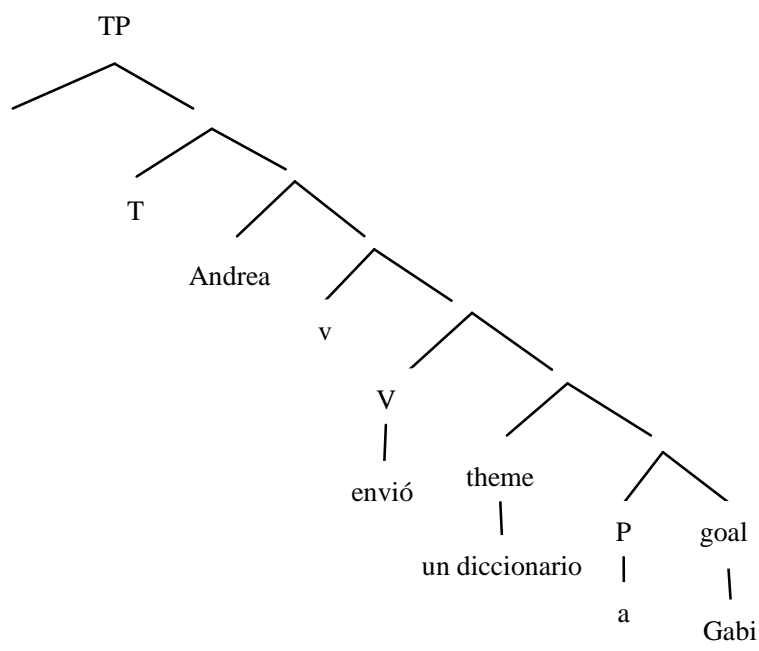

[Cuervo 2003b: 125]

DCLDs are analyzed as instances of Pylkkänen's (2000) low applicatives. The dative clitic ' $l e$ ', as in (40), is the morphological spell-out of an applicative argument (Appl) and it base-generates below the verb 'envió' ('she sent'). In turn, this applicative argument selects (or relates, as in Pylkkänen's (2002) analysis) a DO-DP 'un diccionario' ('a dictionary'), as its complement (theme), and an IO-PP 'a Gabi' ('to Gabi'), as its specifier (beneficiary). Recall that the IO-PP in DCLDs is not allocated a goal theta role as it does in $a$-datives.
(40) Andrea le
envió
un diccionario a Gabi
[DCLD]
Andrea him.cl.dat. send.3p.sg.past a dictionary to Gabi 'Andrea sent Gabi a dictionary'

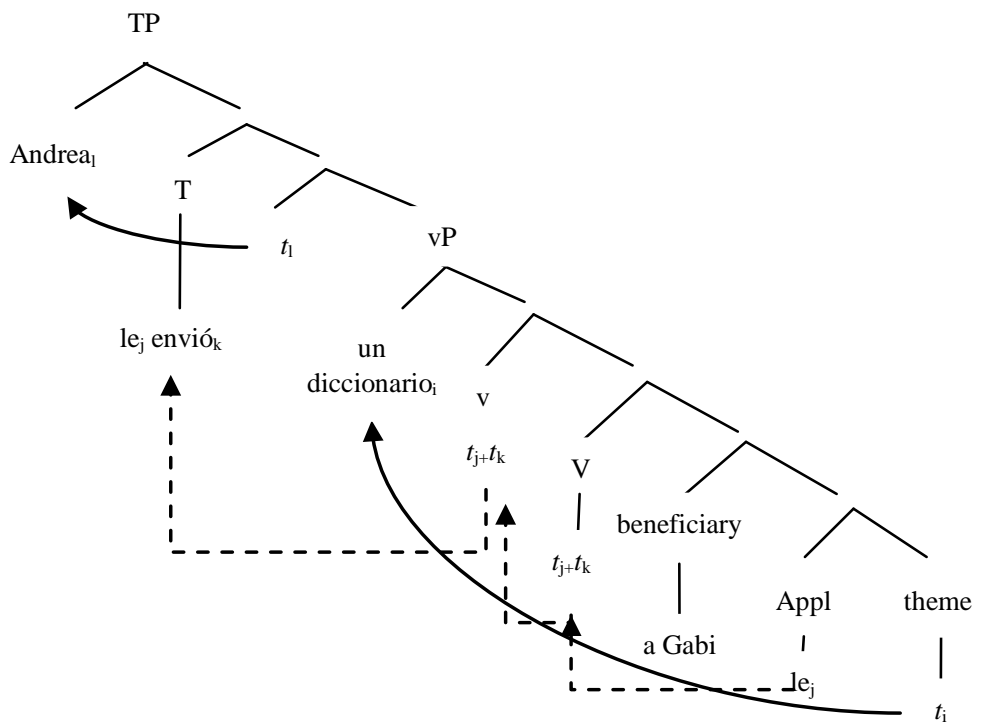

[Cuervo 2003b: 126] 
The DO-DP (theme) 'un diccionario' ('a dictionary') moves across the IO-PP (beneficiary) 'a Gabi' ('to Gabi') to the specifier of a vP. This movement is triggered by the Extended Projection Principle (EPP; Marantz 1991) since the transitive 'v' 'envió' ('she sent') is argued to be analogous to tense (T) in English given that it has obligatory EPP features Thus, movement of the DO-DP (theme) to the specifier of ' $v$ ' (once the $\mathrm{v}$ 'envió' undergoes V-to-v movement) takes place to satisfy accusative Case features. The applicative head ' $l e$ ' is responsible for the inherent dative Case of the prepositional complement 'Gabi', contra the Matching Principle (Suñer 1988) (see section 1.1) where the dative clitic is assigned inherent dative Case by the preposition ' $a$ '. The dative clitic merges with the verb in tense position once it undergoes two head-to-head movements: From the applicative head position to V and from V to v. However, Cuervo (2003b) leaves the pre-verbal position of the dative clitic unaccounted for. Finally, the functional head ' $\mathrm{T}$ ' has a nominative Case feature that is checked by the subject-DP 'Andrea'.

The two sides of the formal debate on the syntactic relationship between the two Spanish DA structures (i.e. derivational and non-derivational) will be examined in L1 and in 2L1 children's spontaneous production data (see chapter 3). As will be discussed in section 5.2 (chapter 5), our results will lend support to the syntactic non-derivational approach since the two language groups show a rather similar onset of DCLDs and a/para-datives. This could suggest that Spanish DA structures might be construed as two underived representations (in line with Cuervo 2003a, 2003b) or as a shared underlying structure (as argued by Snyder and Stromswold 1997 for English).

\subsection{Thematic role assignment}

From a semantic perspective, DA structures are defined as 'constructions with an actor, a theme plus a proto-recipient argument' (Haspelmath 2006: 1). In line with the Theta Criterion, the three arguments of DOCs that alternate as to-datives along with the external, the internal argument as well as the adjunct in DOCs that alternate as fordatives must be assigned three different theta roles. These theta roles include an agent (i.e. the argument that carries out the action), a theme (i.e. the constituent that undergoes the action) and a recipient or a beneficiary (i.e. the person who the action is addressed to or is benefitted from the action, respectively) (Adger 2003; Carrier-Duncan 1985; Chomsky 1996; Hernanz and Brucart 1987; Jackendoff 1990; Kittilä 2005; Quirk et al. 1985; Romero Morales 2008). 
When DA takes place, theta roles are symmetrically preserved in double object and in prepositional constructions in English and in Spanish, conforming to the UTAH conditions. Identical theta roles are allocated between to-datives and $a$-datives, as in (41), as well as between for-datives and para-datives, as in (42), as follows: The DODPs 'a book/un libro' are assigned a theme theta role by the verbs 'gave/dio' and 'bought/compró', respectively, while the prepositional complement 'Mary/María' receives a recipient or a beneficiary theta role depending on whether it is assigned by the preposition 'to/a' or 'for/para', accordingly. The subject-DP 'John/Juan' is assigned an agent theta role by the verb.

(41)
a. John
agent
gave
a book
to Mary
recipient
b. Juan dio
agent
theme
María
recipient
un libro
theme
Mary
a. John
agent
bought a book
theme
beneficiary
b. Juan
agent
[to-dative]
[theta roles]
[a-dative]
[theta roles]
[for-dative]
[theta roles]
[para-dative]
[theta roles]

An underlying theta role distribution is also shared between the internal arguments of English DOCs that alternate as to-datives and Spanish DCLDs that alternate as a-datives. As in (43a) and (43b), the IO-DP 'Mary' (in English) and the prepositional complement 'María' (in Spanish) are allocated a recipient theta role by the verb and by the preposition ' $a$ ', respectively. Following Larson $(2014,1990,1988)$, the DO-DP 'a book' (in English) is assigned a theme theta role by the reanalysis of the verb and the IO-DP as a complex transitive predicate (see section 1.2), while the DO-DP 'un libro' (in Spanish) is allocated a theme theta role by the verb. In turn, the pre-verbal dative clitic of Spanish DCLDs also receives a recipient theta role and two explanations have been provided (see section 1.2) in order for the dative clitic not to violate the Theta Criterion: (a) It may form a chain with the prepositional complement and, thus, it inherits the recipient theta role assigned by the preposition ' $a$ ', complying with the Matching Principle (Suñer 1988), or (b) it may have the status of an affixal morpheme and, therefore, the dative clitic and the verb assign a theme theta role to the DO-DP and 
an agent theta role to the subject-DP via inflection (Anagnostopoulou 2006, 2003; Beavers and Nishida 2009; Borer 1984; among others).
a. John
agent
gave
Mary
a book
theme
[DOC]
[theta roles]
b. Juan $\mathrm{le}_{\mathrm{i}}$ agent recipient/ affixal
dio
un libro [a María $]_{\mathrm{i}}$
theme
recipient
[DCLD]
[theta roles]

Regarding English DOCs that alternate as for-datives and Spanish DCLDs that alternate as para-datives, the DO-DP equally receives a theme theta role although they differ in the theta role assigner. As discussed earlier with regards to DOCs that alternate as to-datives, the reanalysis of the verb 'bought' and the A-DP 'Mary' in (44a) as a complex transitive predicate (Larson 2014, 1990, 1988) allows the theme theta role assignment to the DO-DP 'a book', while the verb 'compró' in (44b) allocates a theme theta role to the DO-DP 'un libro'. Furthermore, a theta role symmetry is observed between the A-DP 'Mary' in English DOCs that alternate as for-datives and the prepositional complement 'María' in Spanish DCLDs that alternate as para-datives given that the former is allocated a beneficiary theta role by the verb 'bought' and the latter is allocated a beneficiary theta role by the preposition ' $a$ ' (recall that when the prepositional complement in DCLDs that alternate as para-datives is headed by the preposition 'para', it renders the structure ungrammatical). With regards to the dative clitic ' $l e$ ' in (44b), the Theta Criterion is satisfied since one beneficiary theta role is assigned to only one argument via the clitic/IO-PP chain (under the co-indexation approach), or else, the dative clitic along with the verb are a theme theta role assigner to the DO-DP and a nominative theta role assigner to the subject via inflection (under the affixal morpheme approach).
a. John
bought
Mary
beneficiary
a book
[DOC]
agent
theme
[theta roles]
b. Juan le compró agent
beneficiary/ affixal
un libro
theme
[a María $]_{i}$ [DCLD] beneficiary [theta roles]

In contrast to the previous analyses presented where the distribution of thematic roles was maintained in the two DA structures, other studies argue that DA involves a 
semantic change both in English (Beck and Johnson 2004; Colleman 2010; Colleman and De Clerk 2011; Goldberg 1995; Gropen et al. 1989; Harley 2003, 2002; Krifka 2003; Larson 2014; Levin and Rappaport Hovav 2001; Rappaport Hovav and Levin 2008; among others) and in Spanish (Demonte 1994; Romero Morales 2008; among others). In particular, the prepositional variants (i.e. to/for-datives in English and a/para-datives in Spanish) are said to denote caused motion (cause-to-GO). This means that, as in (41) and (42) above, the theme-DO 'a book/un libro' undergoes movement from the agent-subject 'John/Juan' to the recipient-IO or to the beneficiary-A 'Mary/María', respectively. By contrast, the double object variants (i.e. DOCs in English and DCLDs in Spanish) are claimed to encode transfer of possession (cause-toHAVE). To present an example, the possessor of the theme-DO 'a book/un libro' is transferred from the agent-subject 'John/Juan' to the recipient-IO 'Mary/María', as in (43), or to the beneficiary-A 'Mary', as in (44a).

Considering the semantic debate on English and Spanish DA structures, the present dissertation aims at shedding light on whether prepositional and double object constructions are semantically related, as per UTAH conditions, or whether they imply a difference in meaning (e.g. Beck and Johnson 2004; Colleman 2010; Colleman and De Clerk 2011), as analyzed in L1 and in 2L1 children's spontaneous production data. As will be discussed in chapter 5, the similar emergence of the two English and Spanish DA constructions provides supportive evidence for the semantic relationship between prepositional and double object constructions in English (see section 5.1), in Spanish (see section 5.2) and across languages (see section 5.3).

\subsection{Concluding remarks: English and Spanish dative alternation structures}

Chapter 1 has been concerned with a formal description of DA structures. Although DA occurs in English and in Spanish, the alternation between prepositional and double object constructions exhibits different grammatical properties in these two languages. English DA analyses have focused on the presence or the absence of the prepositions 'to/for' in to/for-datives and in DOCs, respectively (Larson 2014, 1990, 1988; among others). In Spanish, the prepositions 'a/para' do not seem to play a role in the DA; rather, it is the presence or the absence of a dative clitic in DCLDs and a/paradatives, respectively, which differentiates between the two structures (Demonte 1995, 1994; among others). 
Two main issues have been addressed: How the Case and the theta role requirements are met and the type of derivational relationship (or lack thereof) that exists between the two types of DA constructions (that is, prepositional and double object) in the two languages under analysis.

Regarding the first issue, English and Spanish prepositional DA structures exhibit an analogous distribution with regards to the Case and the theta role properties. Thus, the Case Filter and the Theta Criterion are equally fulfilled in English to/for-datives and in Spanish a/para-datives since, under locality and government conditions, the verbal head assigns accusative Case and a theme theta role to its adjacent DO-DP, while the prepositions 'to/for' (in English) and 'a/para' (in Spanish) allocate dative Case and a recipient or a beneficiary theta role to their corresponding prepositional complements.

Double object constructions are argued to alternate with the prepositional variants both in English and in Spanish (Cuervo 2007, 2003a, 2003b; Demonte 1995, 1994). However, the Case and the theta role assignment of English DOCs and Spanish DCLDs is not parallel since they differ in their superficial structure. In English DOCs, the verb assigns accusative Case and a recipient theta role to the IO-DP (if to-datives are the prepositional DA counterpart) or a beneficiary theta role to the A-DP (if for-datives are the prepositional DA counterpart); however, the verb cannot assign Case and theta role to the DO-DP because it is not adjacent to it. In order for the DO-DP to avoid Case Filter and Theta Criterion violations, it receives inherent accusative Case and a theme theta role from the trace of the moved verbal head given that this trace inherits the verbal Case assigning properties, conforming to the Proper Antecedent Condition (Radford 1990). From the V' reanalysis approach (Larson 2014, 1990, 1988), the verb and the IO/A-DP are argued to form a complex transitive predicate allowing accusative Case and theme theta role assignment to the DO-DP. In Spanish DCLDs, on the other hand, the Case Filter and the Theta Criterion are satisfied for the DO-DP, by receiving accusative Case and a theme theta role from the verb, and for the prepositional complement, by being assigned dative Case and a recipient theta role from the preposition ' $a$ '. The pre-verbal dative clitic 'le(s)' in Spanish DCLDs would initially violate the Case Filter and the Theta Criterion since it does not have an adjacent Case and a theta role assigner; however, two main approaches have shed light on this issue, namely, the co-indexation and the affixal morpheme approach. 
Under the co-indexation approach (Aranovich 2011; Cuervo 2003a, 2003b; among others), the dative clitic forms a chain with the prepositional complement and both constituents comply with the Matching Principle (Suñer 1988). The Case Filter and the Theta Criterion are met for the dative clitic since it inherits the Case and the theta role properties of the prepositional complement, namely, dative Case and a recipient theta role, as assigned by the preposition ' $a$ '. Alternatively, the dative clitic is also argued to be a verbal affixal morpheme in conjunction with the verb and, under this approach, both constituents function as a compound accusative Case assigner and as a single theme theta role assigner to their adjacent DO-DP (Anagnostopoulou 2006, 2003; Beavers and Nishida 2009; Borer 1984; among others).

Regarding the second issue, there has been a debate in the literature on English and Spanish DA structures as to whether double object and prepositional constructions have a syntactic derivational relationship or, rather, no syntactic derivation occurs between the two types of DA constructions.

In the case of English, the debate on the syntactic derivational approach has focused on whether (a) DOCs are derived from to/for-datives (Haspelmath 2006; Larson 2014, 1990, 1988; Perlmutter 1980) or (b) DOCs are the base structure from which to/for-datives derive (Aoun and Li 1989; Dryer 1986; Koizumi 1994). Despite this dichotomy, both approaches resort to a common syntactic derivational mechanism, namely, a passive-like movement, regardless of whether there is a DP-movement (from the viewpoint of GB; Aoun and Li 1989; Koizumi 1994; Larson 2014, 1990, 1988) or a 3-to-2 advancement rule (from the perspective of RG; Dryer 1986; Haspelmath 2006; Perlmutter 1980).

Oehrle (1976) and Czepluch (1982) take a different approach to the derivation of English DA constructions. Oehrle (1976) argues for a transformational rule which, based on a scale of prominence, accounts for the derivation of DOCs from to/for-datives and Czepluch (1982) revises Oehrle's (1976) rule and proposes 'the lexical covertcategory PP analysis', as an alternative proposal to Case theory that lends support to the derivation of to/for-datives from DOCs.

Moreover, English DA structures have also been argued not to be derivationally related (Marantz 1993; Mulder 1992; Snyder and Stromswold 1997). With regards to the formation of DOCs, a null verb is argued to function as an applicative affix (Marantz 1993) or as an empty causative verb (i.e. $\left.\phi_{\mathrm{HAVE}}\right)$ which denotes possession 
(Mulder 1992). These two types of null verbs are projected in a Chomskian-Larsonian VP-shell or in an SC domain, respectively. To/for-datives contrast with the two analyses above-mentioned in that an overt verb heading a single VP structure (Marantz 1993) or an empty verbal head $(\phi)$ in an SC domain (Mulder 1992) give rise to the formation of these structures.

Alternatively, Snyder and Stromswold (1997) propose a shared underlying structure for English DA structures which may be analyzed as an instance of complex predicates (in line with Larson 2014, 1990, 1988; Marantz 1993; among others) or SC constructions (in line with Aoun and Li 1989; Kayne 1984; among others).

There seems to be an agreement in the syntactic derivational approach to Spanish DA constructions, motivated by the presence or by the absence of a dative clitic 'le(s)' in DCLDs and in a/para-datives, respectively. As proposed by Demonte (1995, 1994), and followed by others (Bruhn de Garavito 2000; Kempchinsky 2004), the syntactic properties of DA in Spanish are assumed to be analogous to those exhibited in English (Larson 2014, 1990, 1988) and, thus, DCLDs are argued to derive from a/para-datives on the basis of a Chomskian-Larsonian VP-shell structure. In the case of DCLDs, a dative clitic projects a DCIP (also termed BP or IAP) which occupies a higher position of a Chomskian-Larsonian VP-shell structure. However, the pre-verbal position of the dative clitic remains unclear in this analysis.

From a non-derivational approach, Cuervo (2003a, 2003b) argues that Spanish DA structures differ syntactically in the status of the head that they project (namely, a verb in a/para-datives and a dative clitic in DCLDs) and semantically in the theta role that is allocated to the prepositional complement (namely, a goal in a/para-datives and a beneficiary in DCLDs).

As will be discussed in chapter 2, the syntactic (non-)derivational status of DA constructions in English and in Spanish has also been explored in acquisition studies. 


\section{CHAPTER 2}

\section{ON THE ACQUISITION OF DATIVE ALTERNATION STRUCTURES}

Chapter 2 is organized into two core sections. Section 2.1 presents an overview of the general properties in L1 acquisition and in 2L1 acquisition that are of special relevance for the present investigation. Section 2.2 reviews empirical studies on the acquisition of English and Spanish DA structures. Further details of each section are discussed below.

\subsection{Monolingual and bilingual first language acquisition}

This section is not meant to be a comprehensive account of (2)L1 acquisition properties but, rather, a way of discussing the ones that are relevant for the analysis carried out in this dissertation. Two properties concern both L1 and 2L1 acquisition, namely, how different developmental stages could be established in the children's longitudinal production (section 2.1.1) and whether biological gender plays a role in acquisition (section 2.1.2), that is, whether differences between girls and boys appear along the acquisition process. The other two properties under consideration are related to 2L1 acquisition and they refer to the possible cross-linguistic influence between the two first languages in contact (section 2.1.3) and to the role of adult input in child bilingual output (section 2.1.4).

\subsubsection{Language developmental stages: Age and mean length of utterance}

Studies on early language development have traditionally been making reference to different developmental stages established on the basis of two main criteria: Age and MLU. In the case of the latter, a debate has arisen as to whether MLU should be measured in morphemes (Brown 1973) or in words (Aguado 1988; De Villers and De Villers 1973; Hickey 1991; among others).

As far as age is concerned, 5 linguistic stages have been systematically established in child language development (Bel and Rosado 2009; Bloom 1990; Brown and Fraser 1963; Clark 2009; Crain and Lillo-Martín 1999; Goodluck 1991; Guasti 2004; Hyams 2004, 1987; Loeb and Leonard 1991; O’Grady 1997; Padilla and Liebman 1975; Radford 1990; Rizzy 1994; Roeper and Rohrbacher 1994; Rowland 2014; 
Schutze and Wexler 1996; Valian 1991; Wexler 1997; Yule 1996; among others) ${ }^{7}{ }^{8}$ : (a) The 1 -word or the holophrastic stage $(1 ; 00-1 ; 06)$, at which the child uses single-unit utterances that function as a phrase or as a sentence; (b) the 2-word stage $(1 ; 06-1 ; 08)$, where the child starts putting 2 words together in his/her speech; however, the 2-word utterances often lack functional words; (c) the telegraphic speech stage $(1 ; 09-2 ; 02)$, characterized by the production of non-adult-like phrases and/or sentences which also lack functional words; (d) the multiple-word speech stage (2;00-3;05), where functional categories start to emerge; and (e) the multiple-clause speech stage (3;05-4;00), at which the production of complex sentences appears.

Taking the 5 linguistic stages mentioned above as a point of departure, 13 stages (ranging from 1;00-1;06 to 7;00-7;06) have been established in the present study (see chapter 4) so as to examine the spontaneous production of English and Spanish DA constructions through language development in L1 and in 2L1 children. Table 1 shows a correspondence between the 5 linguistic stages in child language development and the 13 age stages we will consider for the data analysis.

${ }^{7} \mathrm{~L} 1$ acquisition stages are preceded by pre-language stages which start with some pre-linguistic sounds called 'cooing' and 'babbling' between 3 months (0;03) and 11 months (0;11) (Brown 1973; Crain and Lillo-Martín 1999; Goodluck 1991; Guasti 2004; Jackobson 1968; Yule 1996). More specifically, the first recognizable sounds appear between 0;03 and 0;05 at the 'cooing' stage with the production of velar consonants such as [k] and [g], along with that of high vowels such as [i] and [u]. Later, from 0;06 to $0 ; 08$, the child is able to produce a number of distinct vowels and consonants such as fricatives and nasals; this period is referred to as babbling given that the child produces repetitive syllable-type sounds which lack semantic meaning (e.g. 'da'). At the last pre-language stage (between 0;09 and 0;11), children continue to babble but they incorporate distinguishable intonation patterns in the syllable-type sounds produced.

${ }^{8}$ Ages are approximate in each stage since the ages at which linguistic features emerge vary across children (Crain and Lillo-Martín 1999; Yule 1996). Children's years and months are indicated following the CHIld Language Data Exchange System (CHILDES) (see MacWhinney 2000: 34-35). 


\begin{tabular}{c|c}
\hline Stages in child language development & Stages for the study of English and Spanish DA structures \\
\hline 1-word or holophrastic $(1 ; 00-1 ; 06)$ & $1(1 ; 00-1 ; 06)$ \\
\hline 2-word $(1 ; 06-1 ; 08)$ & $2(1 ; 07-1 ; 11)$ \\
\hline Telegraphic speech $(1 ; 09-2 ; 02)$ & $3(2 ; 00-2 ; 06)$ \\
Multiple-word speech $(2 ; 00-3 ; 05)$ & $4(2 ; 07-2 ; 11)$ \\
& $5(3 ; 00-3 ; 06)$ \\
\hline Multiple-clause speech stage (3;05-4;00) & $6(3 ; 07-3 ; 11)$ \\
& $7(4 ; 00-4 ; 06)$ \\
\cline { 2 - 2 } & $8(4 ; 07-4 ; 11)$ \\
\cline { 2 - 2 } & $9(5 ; 00-5 ; 06)$ \\
\cline { 2 - 2 } & $10(5 ; 07-5 ; 11)$ \\
\cline { 2 - 2 } & $11(6 ; 00-6 ; 06)$ \\
\cline { 2 - 2 } & $12(6 ; 07-6 ; 11)$ \\
\hline
\end{tabular}

Table 1. Correspondence between the 5 linguistic stages in child language development and the 13 age stages established for the study of English and Spanish dative alternation structures

These 13 stages have been adjusted in terms of the data available in CHILDES (MacWhinney 2000) and considering the children's age range of the study period. This will allow, in particular, a fine-grained examination of the last age stages where the incidence of English and Spanish DA structures appears to be more frequent given that L1 and 2L1 children have to deal with a complex predicate structure.

The MLU has been considered as an effective measure of linguistic development ensuring that MLU-matching children are at a similar developmental stage (Aguado 1988; Brown 1973; De Villiers and De Villiers 1973; Miller 1981; Silva Corvalán and Sánchez Walker 2007). Indeed, Brown (1973: 55) claims that 'two children matched for $M L U$ are much more likely to have speech that is, on internal grounds, at the same level of constructional complexity than are two children at the same chronological age'.

The MLU value could be calculated by counting the number of morphemes per utterance (MLUm, hereinafter; as in Brown's (1973) study), or the number of words per utterance (MLUw, hereinafter; Aguado 1988; De Villers and De Villers 1973; Malakoff et al. 1999; Hickey 1991; among others), and dividing it by the total number of (ideally, 100) utterances produced by the child (Brown 1973; MacWhinney 2000).

As shown in table 2, Brown (1973) establishes 5 stages, based on MLUm values, which range from 1.75 morphemes (stage I) to 4.00 morphemes (stage V). There is an increase of 0.50 morphemes between stage I (MLUm=1.75) and stage II (MLUm=2.25), between stage II and stage III (MLUm=2.75), and between stage IV (MLUm=3.50) and stage V $(M L U m=4.00)$, while in the transition from stage III $(M L U m=2.75)$ to stage IV (MLUm=3.50), there is an increase of 0.75 morphemes. 


\begin{tabular}{cc}
\hline Stages & Mean MLUm values \\
\hline I & 1.75 \\
\hline II & 2.25 \\
\hline III & 2.75 \\
\hline IV & 3.50 \\
\hline V & 4.00 \\
\hline
\end{tabular}

Table 2. MLUm stages (Brown 1973:79)

Brown (1973) observes in a study on the spontaneous production of 3 L1 English children (Adam, Eve and Sarah), who have also been selected among the participants in the present thesis, that their MLUm values increase through the 5 stages as they produce longer utterances. He believes that MLUm reflects syntactic growth more accurately than MLUw, as observed in the three participants' gradual development of the following grammatical morphemes: Present progressive $>$ prepositions ('in', 'on') > plural $>$ past irregular $>$ possessive $>$ uncontractible copula $>$ articles $>$ past regular $>$ third person regular $>$ third person irregular $>$ uncontractible auxiliary $>$ contractible copula > contractible auxiliary. According to Brown (1973), language development is no longer represented in terms of MLUm values after stage V (MLUm=4.00) given that children have already developed a linguistic complexity in the production of utterances without them becoming necessarily longer. In other words, MLUm loses its value as an indicator of grammatical development after stage $\mathrm{V}$.

Language development measured in terms of MLUm and MLUw values has been compared in cross-linguistic studies, bringing forth opposing results: (a) MLUm and MLUw values have been found to be correlated measures in some cases (Aguado 1988; Fernández Fuertes and Liceras 2010; Hickey 1991; Malakoff et al. 1999; among others) and (b) MLUw values have been argued to be a more effective measure than MLUm ones in some other studies (De Villiers and De Villiers 1973; Kvaal et al. 1988; Silva Corvalán and Sánchez Walker 2007; among others).

As pointed out earlier, few studies on acquisition lend support to MLUm and MLUw being equally effective language development measures. For instance, Hickey (1991) reports a significant correlation between a morpheme and a word count MLU ( $r=0.99)$ in the spontaneous production of 3 L1 Irish children: Cian (age range: 1;113;00), Eoin (age range: 1;06-2;06) and Eibhlís (age range: 1;04-2;01). This points to the fact that a developmental analysis in terms of either MLUw or MLUm would yield 
similar results. Therefore, MLUw and MLUm turn out to be similar developmental measures and this is even in the case of a highly inflected language such as Irish.

Likewise, Malakoff et al. (1999) find that MLUm significantly correlates with MLUw ( $r=.97)$ in a cross-sectional study that compares the spontaneous production of 74 inner-city L1 English children (26 cocaine-exposed and 28 (non-)cocaine-exposed), observed prior to (i.e. in utero) or at birth for a minimum of 2 years during play sessions. Their findings show that cocaine-exposed children produce shorter utterances (that is, there is a delay in language development) than did non-cocaine exposed children, as measured in MLUm values $(F(1,61)=8.08, p<.01)$ and in MLUw values $(F(1,61)=6.25, p<.05)$.

Conversely, other cross-linguistic works involving morphologically imbalanced languages such as English (i.e. a morphologically poor language) and Spanish (i.e. a morphologically richer language) consider MLUw to be a more adequate comparative measure of grammatical complexity than MLUm (Brown 1973; De Villers and De Villers 1973; Hickey 1991; Kvaal et al. 1988; Silva Corvalán and Sánchez Walker 2007; among others). In fact, Brown (1973) points out that MLUm poses some difficulties when applying the MLUm calculation rules that he sets for English to highly inflected languages such as Finnish, Spanish and Swedish.

Since the languages at stake in the present study (i.e. English and Spanish) are morphologically imbalanced, an MLUw-based data classification has been established (see chapter 4).

In spite of the difference between measuring language development in terms of age or MLU values, some correlation could be established between the two (Crain and Lillo-Martín 1999; Miller and Chapman 1981; among others). As depicted in table 3, Crain and Lillo-Martín (1999) find a correspondence between Brown’s (1973) MLUm stages (see table 2) and three of the age stages in L1 acquisition, namely, the telegraphic speech, the multiple-word speech and the multiple-clause speech. More specifically, Crain and Lillo-Martín (1999) argue that as L1 children's age increases, so does their MLUm. 


\begin{tabular}{cc}
\hline $\begin{array}{c}\text { MLUm stages } \\
\text { (Brown 1973) }\end{array}$ & $\begin{array}{c}\text { Age stages } \\
\text { (Crain and Lillo-Martín 1999) }\end{array}$ \\
\hline I (MLUm=1.75) & Telegraphic speech (2;00-2;05) \\
\hline II (MLUm=2.25) & Multiple-word speech (2;05-3;05) \\
\hline III (MLUm=2.75) & Multiple-clause speech (3;05-5;00) \\
\hline IV (MLUm=3.50) & \\
\hline V (MLUm=4.00) &
\end{tabular}

Table 3. MLUm-age correspondence in monolingual acquisition (Brown (1973: 79) and adapted from Crain and Lillo-Martín (1999))

The language developmental stages in table 3 show that, when L1 children reach an MLUm of 1.75 (stage I), their production is classified under the telegraphic speech stage which corresponds to the period between 2;00 and 2;05. Also, it is not until their MLUm ranges between 2.25 (stage II) and 2.75 (stage III) when L1 children's production evidences the properties of the multi-word speech stage and this occurs between 2;05 and 3;05. Finally, between an MLUm of 3.50 (stage IV) and an MLUm of 4.00 (stage V), L1 children's language development seems to qualify as being in the multiple-clause speech stage and this takes place between 3;05 and 5;00. Children are said to have acquired the main grammatical properties of their L1 by 5;00 when their MLUm reaches 4.00. After stage V $(M L U m=4.00)$, language acquisition continues to develop, and more complex structures are produced between 5;00 and 10;00 although they do not necessarily increase in length.

The MLUm-age correspondence is in line with Miller and Chapman's (1981) study on the spontaneous production of 123 middle to upper-middle class L1 English children (age range: 1;05-5;00) in interplay with their mothers at home or in an experimental room. The results of this study reveal a significant correlation between MLUm and age ( $r=0.88$ ), that is, MLUm values increase at an average of 1.2 morphemes per year as age, grouped by 3-month intervals, increases.

All in all, L1 children gradually develop their language competence which is reflected in higher MLU values (measured in morphemes or in words) as they grow older. Age and MLUw values will be used in the present dissertation as two language development measures that set the basis for the analysis of the spontaneous production of English and Spanish DA constructions in L1 and in 2L1 children (see chapter 4).

\subsubsection{The role of biological gender}

Numerous L1 acquisition studies have considered biological gender and have found an advantage of girls over boys with regards to motor movements (Nagy et al. 
2007), lexical production (Berglund et al. 2005; Coates 1993; Eriksson et al. 2012; Galsworthy et al. 2000; Halpern 2000; Mills et al. 1993; among others) and syntactic development (Cornett 2014; Dini 2011; Harris 1978; Horgan 1976; Koenigsknecht and Friedman 1976; Lovas 2011; Tse et al. 2002; among others). To the best of our knowledge, only one study (Eriksson et al. 2012) has accounted for 2L1 girls' higher rate in the lexical production of different word types in their dominant language when compared to 2L1 boys. The divergences between girls and boys have been explained in terms of brain lateralization (Burman et al. 2008; Hyde and Linn 1988; Kimura 1992; Shakouri et al. 2016) or parent-child interaction, that is, when parents engage in conversations with their sons or with their daughters (Cherry and Lewis 1975; Gleason 1990; Lovas 2011).

From early on, female and male newborns show differences in motor movements. Nagy et al. (2007) analyze the social interactions of 41 newborn infants (22 boys and 19 girls) in their first 3 to 96 hours. The children's language profile in Nagy et al.'s (2007) study is not made explicit. Imitation by means of index finger extension gestures is observed in the participants as it is considered to be the earliest way of communication. The findings of this study show that girls perform better than boys in their imitative gestures $(t(2,39)=-2.53, p<.05)$ as well as in their index finger extension movements $(t(2,39)=-2.85, p<.01)$.

Biological gender differences have also been attested in the lexicon, as reported in cross-sectional studies (Berglund et al. 2005; Galsworthy et al. 2000) and in longitudinal studies (Eriksson et al. 2012). Berglund et al. (2005) conduct a crosssectional study with 1,019 L1 Swedish children (age: 1;06) in order to test their lexical comprehension and production by means of a parental report, called the Swedish Communicative Screening at 18 Months (SCS18). As illustrated in table 4, girls score higher than boys, regardless of the adult input source that they receive (i.e. family childcare, home care or day-care center). 


\begin{tabular}{ccccc}
\hline & & Family childcare & Home care & Day-care center \\
\hline \multirow{2}{*}{ Boys } & First-born & 26.1 & 29.1 & 30.3 \\
\cline { 2 - 5 } & Later-born & 22.1 & 24.5 & 24.5 \\
\hline \multirow{2}{*}{ Girls } & First-born & 41.1 & 38.2 & 37.8 \\
\cline { 2 - 5 } & Later-born & 26.7 & 28.5 & 37.5 \\
\hline
\end{tabular}

Table 4. Mean vocabulary production scores in monolingual Swedish children as a function of biological gender, birth order and childcare (Berglund et al. 2005: 489) ${ }^{9}$

Moreover, first-born children show higher scores than later-born children in each biological gender group because 'later-borns had to compete with their older siblings for their mum's attention' (Berglund et al. 2005: 485). Therefore, adult input plays a role with regards to birth order since later-born children are argued to receive a lower input frequency when compared to first-born children, irrespective of the biological gender.

Galsworthy et al. (2000) assess the lexical production of over 3,000 L1 English twin pairs (476 male and 563 female identical twin pairs, 496 male and 497 female same-sex non-identical twin pairs and 974 opposite-sex non-identical twin pairs) at 2;00. Through an adaptation of the MacArthur-Bates Communicative Development Inventory (MCDI, Fenson et al. 1994), girls display higher scores than boys on lexical skills ( $t=13.38, p<.0001)$ as per parents' report.

As mentioned above, longitudinal works have also found a higher lexical productivity in girls than in boys. Eriksson et al. (2012) analyze 13,783 European children (6,892 girls and 6,891 boys) from 10 language communities (Croatia, Denmark, Estonia, France, Germany, Slovenia, Spain (the Basque Country and Galicia) and Sweden) whose ages range from 0;08 to 2;06. Croatian, Danish, Estonian, French, German, Slovenian and Swedish are the children's L1s and, in the case of the Spanish children, despite them being simultaneous bilinguals (i.e. Basque/Spanish and Galician/Spanish), they are examined in their dominant language (that is, Spanish).

\footnotetext{
${ }^{9}$ There are three types of childcare in Sweden, namely, regular day-care centers, family childcare centers and home care (Andersson 1989; Berglund et al. 2005). In regular day-care centers, 1-to-5-year-old children are cared for by trained people (i.e. preschool teachers and daycare attendants). In family childcare centers, 1-to-5-year-old children stay in the home of a municipal childminder who has less formal training than the staff at day-care centers. Indeed, family childcare centers complement regular day-care centers in that they provide service to children who need to be in small groups or who do not live close to day-care centers; for this reason, family child care centers are more common in rural areas and in small towns. With regards to home care, children are cared for in the home by their parents.
} 
Similar to Galsworthy et al.'s (2000) study, girls understand and produce more word types when compared to boys $(F(3,4546)=9.895, p<.01)$ and these differences increase with age $(F(42,13486)=3.267, p<.01)$ in each language community, as found in parents' report using an adapted version of the MCDI (Fenson et al. 1994).

As for the acquisition of syntax, differences between girls and boys have also been identified. Koenigsknecht and Friedman (1976) use the Developmental Sentence Scoring (DSS; Koenigsknecht 1974; Lee 1974; Lee and Canter 1971), a weighted score scale of syntax acquisition that measures the language development of 40 L1 English children's spontaneous production with aid of stimulus materials (e.g. toys, pictures and stories). Children are equally distributed into 20 girls and 20 boys at 5 age stages (2;00, 3;00, 4;00, 5;00 and 6;00). Syntax maturity and utterance length are computed in terms of the overall mean DSS scores obtained from the production of subject-verb sentences and the total number of words produced. As shown in table 5, the means and the standard deviations (SD) for the overall DSS scores in the production of subject-verb sentences increase with age; however, girls reflect higher DSS scores if compared to boys $(F(4,190)=12.95, p<.01)$ from $4 ; 00$, and it becomes more evident at higher age stages, that is, at $5 ; 00$ and at $6 ; 00(F(4,190)=2.52, p<.05)$.

\begin{tabular}{ccccc}
\hline \multirow{2}{*}{ Age stage } & \multicolumn{2}{c}{ Boys } & \multicolumn{2}{c}{ Girls } \\
\cline { 2 - 5 } & Mean & SD & Mean & SD \\
\hline $2 ; 00-2 ; 11$ & 3.67 & 1.11 & 3.78 & 1.41 \\
\hline $3 ; 00-3 ; 11$ & 6.59 & 0.97 & 6.68 & 1.00 \\
\hline $4 ; 00-4 ; 11$ & 7.74 & 1.61 & 8.32 & 1.59 \\
\hline $5 ; 00-5 ; 11$ & 8.49 & 1.93 & 9.89 & 1.53 \\
\hline $6 ; 00-6 ; 11$ & 9.99 & 2.04 & 11.89 & 2.00 \\
\hline
\end{tabular}

Table 5. Developmental Sentence Scoring means and standard deviations in the production of subjectverb utterances by monolingual English children (Koenigsknecht and Friedman 1976: 1111)

In turn, girls show higher mean and SD scores when compared to boys in the use of each of the 8 grammatical categories $(F(8,183)=2.08, p<.05)$ across the 5 stages: Conjunctions, indefinite pronouns or noun modifiers, interrogative questions, main verbs, negatives, personal pronouns, secondary verbs and wh-questions. Likewise, when analyzing the number of words produced, girls also obtain higher scores than boys $(F(1,190)=10.32, p<.01)$ and they gradually increase as the children grow older, as shown in table 6. 


\begin{tabular}{cccc}
\hline Age stage & Biological gender & Mean & SD \\
\hline \multirow{2}{*}{$2 ; 00-2 ; 11$} & Male & 174.70 & 79.48 \\
\cline { 2 - 4 } & Female & 206.85 & 94.09 \\
\hline \multirow{2}{*}{$3 ; 00-3 ; 11$} & Male & 284.00 & 48.33 \\
\cline { 2 - 4 } & Female & 298.35 & 74.48 \\
\hline \multirow{2}{*}{$4 ; 00-4 ; 11$} & Male & 332.00 & 74.22 \\
\cline { 2 - 4 } & Female & 357.35 & 81.70 \\
\hline \multirow{2}{*}{$5 ; 00-5 ; 11$} & Male & 340.90 & 72.22 \\
\cline { 2 - 4 } & Female & 403.70 & 92.03 \\
\hline \multirow{2}{*}{$6 ; 00-6 ; 11$} & Male & 437.90 & 106.65 \\
& Female & 492.55 & 95.62 \\
\cline { 2 - 4 }
\end{tabular}

Table 6. Developmental Sentence Scoring means and standard deviations in the production of words by monolingual English children (adapted from Koenigsknecht and Friedman 1976: 1112)

Therefore, Koenigsknecht and Friedman's (1976) study evidences that girls develop language at a faster rate if compared to boys given the significant differences $(p<.05)$ observed in the spontaneous production of subject-verb sentences and word frequency along the 5 stages under analysis.

Another study conducted by Tse et al. (2002) also shows differences between girls and boys with regards to early syntactic development. 180 L1 Cantonese children (age range: 3;00-6;00), divided into 3 groups aged 3;05, 4;05 and 5;05 (30 girls and 30 boys per group), are examined in their spontaneous production during 30-minute free play sessions per child. Girls (90 girls: $M L U w=6.25, S D=1.23$ ) develop language faster than boys (90 boys: $\mathrm{MLUw}=5.74, \mathrm{SD}=1.11$ ) for the 3 age groups (Tukey’s $\mathrm{Q}=2.69, p<.05$ ). These MLUw values are associated with a gradual syntactic complexity which develops with children's age; in particular, declarative utterances become longer as they are more syntactically elaborated upon with simple modifiers $(F(1,2)=4.19, p<.05)$ or when they function as the subject or as the object of subordinate declarative clauses $(F(1,2)=4.07$, $p<.05)$.

Differences between girls and boys regarding syntactic development have also been reported to persist in adolescence. Cornett (2014) examines 6 adolescents (3 boys and 3 girls; age range: 14;00-15;00) with a similar socioeconomic and educational background. These participants, whose language profile is not addressed, are asked to complete the Peer Conflict Resolution task (Nippold et al. 2007) where solutions to story issues are provided and stories are told with the adolescents' own words. The syntactic complexity targeted in Cornett's (2014) study is measured by means of MLUw values and clausal density (i.e. the number of subordinate clauses such as adverbial, relative and nominal clauses). The results show that female adolescents 
produce longer utterances (MLUw=9.25) and a higher rate in the use of subordinate clauses (mean clausal density score $=1.35$ ) when compared to male adolescents (MLUw =8.45; mean clausal density score=1.27). Therefore, female participants seem to have a more complex syntactic development if compared to male participants, as reflected in the higher MLUw values and in the subordinate clausal density.

Neurological factors have been argued to shape language proficiency in girls and in boys (Burman et al. 2008; Hyde and Linn 1988; Joseph 2000; Kimura 1992; Shakouri et al. 2016; Shaywitz et al. 1995). The bilateral organization of the female brain in 2 hemispheres (i.e. the right and the left) facilitates language processing during speaking (and listening), in contrast with the male brain which is more unilaterally structured. These divergences are said to come to an end when boys' language development 'catches up' with that of girls by adulthood (Burman et al. 2008).

Another aspect that could explain biological gender differences in early language development is parent-child interactions. Girls are reported to receive a higher adult input frequency than boys; thus, these differences in exposure may cause language delay in the latter when compared to the former (Clearfield and Nelson 2006; Gleason 1990; Lovas 2011). A longitudinal study conducted by Lovas (2011) examines the influence of parental input in the spontaneous production of 50 girls and 63 boys at 2 stages (i.e. 1;07 and 2;00), recruited through birth records at hospitals in California. The parents, whose ethnicity is diverse (89\% Caucasian, 14\% multi-ethnic, 6\% Hispanic, 4\% Asian American and 1\% African American) report their children's number of words produced, using the MCDI (Fenson et al. 1994), and the 3 longest sentences (measured in MLUm values) as 2 markers of grammatical complexity. According to the results of this study, girls outperform boys despite the small biological gender effect size both in words $(d=.007$ at $1 ; 07 ; d=.30$ at $2 ; 00)$ and in MLUm values $(d=.26$ at $1 ; 07 ; d=.45$ at 2;00). As shown in table 7, girls (mean=89.82, $\mathrm{SD}=82.53$ at $1 ; 07$; mean=314.22, $\mathrm{SD}=142.40$ at 2;00) produce more words than boys (mean=83.63, $\mathrm{SD}=88.91$ at 1;07; mean=265.46, $\mathrm{SD}=174.60$ at 2;00). Likewise, girls (mean=2.15, $\mathrm{SD}=1.07$ at 1;07; mean $=4.47, \mathrm{SD}=2.32$ at $2 ; 00$ ) use longer utterances than boys (mean=1.90, $\mathrm{SD}=0.90$ at $1 ; 07 ;$ mean $=3.51, \mathrm{SD}=1.87$ at $2 ; 00)$. 


\begin{tabular}{|c|c|c|c|c|c|}
\hline \multirow[t]{2}{*}{ Age stage } & \multirow[t]{2}{*}{ Children and parent-child interaction } & \multicolumn{2}{|c|}{ Words } & \multicolumn{2}{|c|}{ MLUm } \\
\hline & & Mean & SD & Mean & SD \\
\hline \multirow{6}{*}{$1 ; 07$} & Girls & 89.82 & 82.53 & 2.15 & 1.07 \\
\hline & Boys & 83.63 & 88.91 & 1.90 & 0.90 \\
\hline & Mother-daughter & 97.58 & 84.06 & 2.35 & 1.05 \\
\hline & Mother-son & 93.00 & 92.27 & 2.03 & 0.90 \\
\hline & Father-daughter & 82.06 & 81.08 & 1.96 & 1.07 \\
\hline & Father-son & 74.25 & 85.12 & 1.78 & 0.89 \\
\hline \multirow{6}{*}{$2 ; 00$} & Girls & 314.22 & 143.40 & 4.47 & 2.32 \\
\hline & Boys & 265.46 & 174.60 & 3.51 & 1.87 \\
\hline & Mother-daughter & 340.62 & 131.34 & 4.29 & 2.13 \\
\hline & Mother-son & 260.14 & 149.44 & 3.81 & 1.80 \\
\hline & Father-daughter & 287.83 & 150.29 & 4.65 & 2.51 \\
\hline & Father-son & 270.79 & 199.28 & 3.20 & 1.91 \\
\hline
\end{tabular}

Table 7. Means and standard deviations in the production of words and MLUm values by monolingual English children (adapted from Lovas 2011: 92)

When parents communicate with their children, mother-daughter and father-son interactions reveal the highest and the lowest scores at 1;07, respectively, as observed in the number of words used (although with a small effect size, $d=.27$ ) and in MLUm values $(t(111)=3.15, p<.01, d=.57)$. At 2;00, parent-child interactions are of borderline significance in terms of the number of words used $(F(1,55)=3.51, p=.07)$, and clearly significant in terms of MLUm values $(F(1,55)=4.18, p=.01)$. In particular, words are mostly reported in mother-daughter interactions if compared to mother-son interactions $(t(55)=2.16, p<.05, d=.55)$, while the longest and the shortest MLUm values are found in father-daughter and in father-son interactions, respectively $(t(55)=2.44, p<.05$, $d=.62$ ). Therefore, parents are said to be behind biological gender differences in the children's language development given that they engage in more complex conversations and they produce more words with their daughters than with their sons.

From the studies referred to above, it seems that differences between girls and boys could appear at different linguistic levels (e.g. lexicon or syntax) and they could be attributed to different factors (e.g. brain lateralization or input conditions). As will be discussed in the participants' selection criteria (chapter 4) and in the data analysis (chapter 5) of the present study, the emergence and the use of English and Spanish DA constructions are examined in L1 and in 2L1 girls' and boys' data, as well the role of adult input in girls' and in boys’ output. Issues such as lexical production will remain open for further research. 


\subsubsection{Cross-linguistic influence between two first languages}

The simultaneous acquisition of two first languages (2L1), also referred to as simultaneous bilingual acquisition or bilingual first language acquisition, involves the exposure to two languages from birth in a natural setting, that is to say, without formal instruction (Albrecht 2006; Álvarez de la Fuente 2007; Baker and PrysJones 1998; Clark 2009; De Groot 2011; De Houwer 1996; Deuchar and Quay 2000; Du 2010; Grosjean 2008, 2001, 1982; Mackey 2000; Meisel 1989; Pearson 2012; Pena Díaz 2006; Romaine 2004, 1989; Rowland 2014; Silva Corvalán 2014; Wei 2000; among others).

Recent studies on 2L1 acquisition have focused on a wide array of linguistic phenomena that are characteristic of both 2L1 children and adults. These include, among many others, the role played by language dominance (e.g. Bedore et al. 2012; Döpke 1992; Fernández Fuertes and Liceras 2018; Gathercole and Thomas 2009; Genesee and Paradis 1995; Grosjean 1982; Liceras et al. 2016), input frequency (e.g. Argyri and Sorace 2007; De Houwer 2009, 2003, 1996, 1990; Kupisch 2006; Romaine 1989), cross-linguistic influence (e.g. Fernández Fuertes and Liceras 2010; Hulk and Müller 2000; Nicoladis 2012; Paradis and Genesee 1996) or code-switching (e.g. Fernández Fuertes et al. 2016; Jake et al. 2002; Liceras et al. 2008) and natural translation (e.g. Álvarez de la Fuente 2007; Fernández Fuertes and Álvarez de la Fuente 2017; Harris 1992, 1977). Out of these phenomena, two will guide the data analysis of the present thesis: Cross-linguistic influence and the role played by adult input in children's output; the latter will be discussed in section 2.1.4.

There is no consensus in 2L1 research as to whether the bilinguals' two L1s develop (a) autonomously and, thus, no interaction is observed between language A and language $\mathrm{B}$ so that the developmental paths of the bilingual grammars are analogous to those of their respective L1 peers, as per the ADH (Paradis 2001; Paradis and Genesee 1996; Yip and Matthews 2007; among many others); or (b) interdependently, and so, influence from one language into the other one appears, which makes bilinguals differ from monolinguals in the course of development, as captured in the IDH (Meisel 2004, 2001, 1989; Paradis and Genesee 1996; among others).

Under the $\mathrm{ADH}$, the 2L1 children's two languages are expected to show a similar maturational pace and analogous developmental patterns when compared to their L1 counterparts. Even more, the presence of the two autonomous systems is argued not to 
involve cross-linguistic influence from language A into language B (e.g. Álvarez de la Fuente 2007; Bergman 1976; Clark 2009; Genesee et al. 1995; Gleitman and Newport 1995; Lindholm and Padilla 1978a, 1978b; Meisel 2001, 1989; Mishina-Mori 2005; Padilla and Liebman 1975; Paradis 2001; Paradis and Genesee 1996; Yip and Matthews 2007; among many others).

Several studies comparing bilinguals and monolinguals have observed no differences in their developmental paths (e.g. De Houwer 1990; Mishina-Mori 2001; Paradis and Genesee 1996; among others). To present an example, Mishina-Mori (2005) reports that English and Japanese develop independently, despite the underlying structural differences between the two languages. She conducts a longitudinal analysis on the spontaneous production of yes/no questions by 2 2L1 English/Japanese children born and raised in the USA, Ken (age range: 1;11-3;02; MLUm=1.21-2.52 in English and 1.06-1.75 in Japanese) and Rie (age range: 2;04-3;03; MLUm=1.10-2.27 in English and 1.28-2.55 in Japanese). The one-parent one-language strategy is used in exposing the children to Japanese by their mothers and to English by their fathers. The results indicate that the developmental course of the language pair being acquired seems to be independent, that is, it follows a similar pattern to that found in their corresponding L1 counterparts. In the case of the English data, the 3 L1 acquisition stages of yes/no question formation (Bellugi 1971, 1965; Klima and Bellugi 1966) are also found in the 2 2L1 English/Japanese children: (a) A first stage (before an MLUm of 2.00), characterized by the production of yes/no questions being marked by rising intonation; however, subjects and auxiliaries are null and, therefore, there is no subject-auxiliary inversion, as in (1a); (b) a second stage (at around an MLUm of 2.00) where, in spite of the fact that auxiliaries and subject-auxiliary inversion are still not developed, inflections, modifiers, negative auxiliaries (e.g. 'can't' and 'don't'), PPs and determiners, as in (1b), begin to be produced; and (c) a third stage (when MLUm goes beyond 3.00), in which auxiliaries and subject-auxiliary inversion emerge, as in (1c). 
(1) a. Read book?

[Ken, MLUm<2, Mishina-Mori 2005: 305]

b. This a horse?

c. Is this broken?

[Ken and Rie, MLUm 2, Mishina-Mori 2005: 306]

[Ken and Rie, MLUm >3, Mishina-Mori 2005: 302]

Likewise, the 2 2L1 English/Japanese children's formation of Japanese yes/noquestions is parallel to that of their L1 peers (as reported by Clancy 1985). This means that adult-like questions are produced based on declarative sentences with rising intonation. Although the earliest questions consist of 1 word, as in (2a), they are considered to be adult-like in Japanese conversational contexts. As the children grow older, other constituents emerge in multi-word questions such as the combination of demonstratives and nouns, as in (2b), or grammatical particles, as in (2c).

(2) a. Ouchi?

home

'(Is this) home?'

b. Kore Totoro?

[Ken, MLUm 1.07, 2;03, Mishina-Mori 2005: 304]

this Totoro

'(Is) this Totoro?'

c. Iru koko ni?

is there particle

'Is (he) there?'

[Ken, MLUm 1.21, 2;07, Mishina-Mori 2005: 304]

[Rie, MLUm 2.14, 2;11, Mishina-Mori 2005: 305]

Thus, given that the 2L1 children's developmental patterns in the production of English and Japanese yes/no questions are comparable to those of their L1 peers, these findings lend support to the $\mathrm{ADH}$.

In contrast to the $\mathrm{ADH}$, when the properties of one of the L1s (language A) influence those of the other L1 (language B), cross-linguistic influence has been said to occur in the development of the two grammatical systems, as captured by the IDH (Döpke 1998; Hulk 1997; Meisel 2004, 2001, 1989; Paradis and Genesee 1996; Yuan 2016; among others). The IDH entails that bilinguals can acquire certain grammatical properties sooner (also referred to as acceleration, positive cross-linguistic influence or bilingual bootstrapping) or later (also known as delay or negative cross-linguistic influence) when compared to their L1 peers (Argyri and Sorace 2007; Fernández Fuertes and Liceras 2010; Hulk and Müller 2000; Kupisch 2005; Liceras and Fernández 
Fuertes 2018; Müller 2001; Silva Corvalán 1994; Yip and Matthews 2007, 2005, 2000; among many others).

Acceleration takes place when a certain property emerges earlier in the 2L1 children's grammar than what the norm would be in monolingual language development (Gawlitzek-Maiwald and Tracy 1996, Fernández Fuertes and Liceras 2010; Hsin 2012; Liceras and Fernández Fuertes 2018; Liceras et al. 2012; Paradis and Genesee 1996; among others). This would be so if the acquisition of such a grammatical property is attained in language A before it is in language B, as reflected in L1 performance, and thus, the property that is already acquired in language A boosts the earlier acquisition in language B if compared to their corresponding L1 peers. In other words, language A plays a facilitating role in the earlier acquisition of a grammatical property in language $\mathrm{B}$, in line with the Bilingual Bootstrapping Hypothesis (Gawlitzek-Maiwald and Tracy 1996). For instance, Hsin (2012) has provided evidence for an acceleration effect in the acquisition of English wh-questions (with a special focus on auxiliaries) by analyzing the spontaneous production of 3 2L1 English/Spanish children, namely, María (the Deuchar corpus), Simon and Leo (the FerFuLice corpus), and 1 L1 English child, Becky (the Manchester corpus), as available in CHILDES. The children are matched for age (i.e. from 1;03 to 3;03) and for MLUw (i.e. below 2 words). As shown in table 8, the 3 2L1 English/Spanish children produce adult-like wh-questions with overt auxiliaries: Manuela always uses an auxiliary when producing wh-questions, in contrast with Simon and Leo who, out of a total of 79 wh-questions, 8 are produced with a null auxiliary. Despite these differences, the 3 2L1 English/Spanish children never fail to (a) inflect auxiliaries, (b) avoid the use of auxiliaries in subject-oriented questions or (c) invert auxiliaries when required. 


\begin{tabular}{cccccc}
\hline \multirow{2}{*}{ Language group } & \multirow{2}{*}{\begin{tabular}{c} 
Children \\
\cline { 2 - 5 }
\end{tabular}} & \multicolumn{4}{c}{ Auxiliary $^{\mathbf{1 0}}$} \\
\cline { 2 - 5 } (\# of questions produced) & Omitted & *Infl. & Su.-Q. w/aux. & 2x Infl. \\
\cline { 2 - 5 } 2L1 & Manuela (42) & - & - & - & - \\
\cline { 2 - 5 } English/Spanish & Leo (39) & $4(10.3)$ & - & - & - \\
\hline L1 English & Simon (40) & $4(10.0)$ & - & - & - \\
\hline
\end{tabular}

Table 8. Non-adult-like use of auxiliary in English wh-questions by bilingual English/Spanish and by monolingual English children (\# of cases (\%)) (Hsin 2012: 112)

Conversely, the L1 English child (Becky) produces non-adult-like wh-questions with (a) null functional words (29.5\%) such as the auxiliary 'has' or the determiner 'the' in (3a); (b) incorrect inflections (3.9\%) such as the auxiliary 's' in (3b); (c) incorrect auxiliaries in subject-oriented questions (3.6\%); or (d) double inflections both on the auxiliary and on the lexical verb (1.7\%) such as the auxiliary 's' and the main verb 'goes' in (3b).

(3) a.*Where other one gone?

b. ${ }^{*}$ Where's the bed goes?

[Becky, the Manchester corpus, CHILDES, Hsin 2012: 109-110]

Therefore, given the data analyzed by Hsin (2012), it seems that the 3 2L1 English/Spanish children show an earlier development in the formation of adult-like English wh-questions if compared to the L1 English child. Indeed, although Manuela does not produce non-adult like utterances, Simon and Leo use fewer null auxiliaries when compared to the L1 English child $\left(X^{2}=5.907, p<.02\right.$ when Simon and Becky are compared; $\mathrm{X}^{2}=5.583, p<.02$ when Leo and Becky are compared). This acceleration effect is explained by the earlier development of the required functional and inflectional elements in Spanish, as reported by previous L1 Spanish acquisition works (e.g. Aparici et al. 2001; Pérez-Leroux and Dalious 1998). In particular, as argued by the author, the 3 2L1 English/Spanish children's earlier development of the C(omplementizer) domain in Spanish, as in (4), has been a facilitator in the earlier emergence of adult-like English

${ }^{10}$ Auxiliary labels: (a) 'Omitted'= an omitted auxiliary when required; (b) '*Infl.'= an inflection used incorrectly (i.e. singular-plural disagreement); (c) 'Su.-Q. w/aux.'= a subject-oriented question where the auxiliary is incorrectly used; (d) '2xInfl.'= finite inflection both on auxiliary and on lexical verb (Hsin 2012: 112). 
wh-questions when compared to the L1 English child who has not developed this domain during the study period yet.

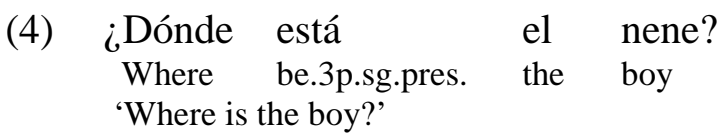

[María, the Ornat corpus, CHILDES, MLUw 2.26, Hsin 2012: 109]

Delay could also take place as an effect of cross-linguistic influence in which the influence from language A into language B causes 2L1 children to acquire certain grammatical properties in language B later than their L1 counterparts (Bubenik 1978; Gu 2010; Hulk and Müller 2000; Paradis and Genesee 1996; Swain 1972; Vihman 1982; among others). This has been linked to the so-called bilingual effect, that is, the burden of acquiring two languages which can slow down the attainment of the adult grammar if compared to their L1 peers. Such a delay effect has been reported by Gu (2010) on the acquisition of English DA constructions by 5 2L1 English/Cantonese children (age range: 1;03-3;06): 4 children are Cantonese-dominant (Alicia, Llywelyn, Sophie and Timmy) and 1 child is English-dominant (Charlotte). Their spontaneous production is taken from the YipMatthews corpus in CHILDES. These participants are compared to 9 of the 12 L1 English children (age range: 1;02-5;02) selected by Snyder and Stromswold (1997), as also available in CHILDES: Adam, Eve and Sarah (the Brown corpus), Mark (the MacWhinney corpus), Naomi (the Sachs corpus), Nathaniel (the Snow corpus), Nina (the Suppes corpus), Peter (the Bloom corpus) and Shem (the Clark corpus). As illustrated in table 9, 2L1 English/Cantonese children produce DOCs (mean age: 2;00) before to/for-datives (mean age: 2;09), akin to L1 English children producing DOCs earlier (i.e. 2;02) than to-datives (i.e. 2;04). 


\begin{tabular}{ccc}
\hline 2L1 English/Cantonese & DOCs & To/for-datives \\
\hline Alicia & $1 ; 05$ & $2 ; 11$ \\
\hline Charlotte & $2 ; 00$ & $2 ; 06$ \\
\hline Llywelyn & $2 ; 02$ & $3 ; 04$ \\
\hline Sophie & $2 ; 01$ & $2 ; 09$ \\
\hline Timmy & $2 ; 02$ & $2 ; 04$ \\
\hline Mean & $\mathbf{2 ; 0 0}$ & $\mathbf{2 ; 0 9}$ \\
\hline L1 English & $\mathbf{D O C s}$ & $\mathbf{T o - d a t i v e s ~}$ \\
\hline Adam & $2 ; 03$ & $2 ; 11$ \\
\hline Eve & $1 ; 07$ & $2 ; 00$ \\
\hline Mark & $2 ; 07$ & $3 ; 04$ \\
\hline Naomi & $2 ; 00$ & $2 ; 05$ \\
\hline Nathaniel & $2 ; 05$ & $2 ; 07$ \\
\hline Nina & $2 ; 00$ & $2 ; 01$ \\
\hline Peter & $2 ; 00$ & $2 ; 00$ \\
\hline Sarah & $2 ; 10$ & $3 ; 02$ \\
\hline Shem & $2 ; 02$ & $2 ; 04$ \\
\hline Mean & $\mathbf{2 ; 0 2}$ & $\mathbf{2 ; 0 6}$ \\
\hline
\end{tabular}

Table 9. Age of onset of English dative alternation constructions in bilingual English/Cantonese children and in monolingual English children (adapted from Gu 2010: 72 and 80)

Despite the similar pattern of emergence (i.e. DOCs $>$ to/for-datives), 2L1 English/Cantonese children show delay when considering the onset of to/for-datives if compared to their L1 peers. In particular, an average temporal gap of 9 months is observed between the onset of DOCs and to/for-datives in 2L1 English/Cantonese children's data, in contrast to the 4-month temporal gap between the emergence of DOCs and to-datives in L1 English children's data ${ }^{11}$. Language dominance is argued to play a role in this delay in that there seems to be a difference between the Englishdominant child (Charlotte) and the Cantonese-dominant children (Alicia, Llywelyn, Sophie and Timmy). As depicted in table 9, Charlotte shows a smaller gap of 6 months between the onset of DOCs and to/for-datives, if compared to the 3 Cantonese-dominant children's wider temporal gap between the emergence of DOCs and to/for-datives (i.e. Shopie-8 months, Alicia-17 months and Llywelyn-14 months). An exception to this is Timmy who, despite being a Cantonese-dominant child, progresses faster than Charlotte between his first DOC and his first to/for-dative, as seen in the 2-month gap. Therefore, the English-dominant child's better performance if compared to the Cantonese-

\footnotetext{
${ }^{11}$ Unlike Gu's (2010) study, Snyder and Stromswold (1997) do not include for-datives among their target structures given that they argue for a lack of clear-cut distinction between for-datives and other constructions involving for-phrases. Despite this exclusion, for-datives are also observed to emerge 3 months later if compared to DOCs when the former are included in the data analysis $(t(10)=3.17, p=.009)$, as also seen in Gu's (2010) findings.
} 
dominant children indicates that the grammatical knowledge of English DA structures has facilitated the acquisition of to/for-datives. In the case of Timmy's data, the earlier emergence of English DA structures when compared to the other 3 Cantonese-dominant children seems to be rooted in the relatively less dominance in Cantonese. Input ambiguity factors are also argued to have played a role in 2L1 English/Cantonese children's delay in the acquisition of to/for-datives if compared to their corresponding L1 peers. This could be so given that 2L1 English/Cantonese children need to disambiguate the shared recipient and beneficiary theta role marker 'bei2' in Cantonese prepositional DA structures, as in (5a) and (5b), respectively, and the two distinct theta role markers in English, namely, 'to' (a recipient theta role assigner) and 'for' (a beneficiary theta role assigner). In other words, the lack of a lexical-semantic transparency of the shared recipient and beneficiary marker 'bei2' in Cantonese prepositional DA structures has had an interfering effect in the acquisition of these structures in English, a language that is not lexically and semantically ambiguous in this respect given the presence of two distinct recipient and beneficiary theta role markers, namely, 'to' and 'for', respectively.

$\begin{array}{lllllll}\text { a. Siu2ming4 } & \text { gei3 } & \text { zo2 } & \text { jatl fungi seon3 bei2 } & \text { ngo5 } \\ \text { Siuming } & \text { send } & \text { perf. } & \text { one cl. letter give I }\end{array}$ 'Siuming sent a letter to me'

[Gu 2010: 24]

b. Ngo5 guk6 zo2 go3 daan6goul bei2 maa4mi4 I bake asp. cl. cake give mother 'I baked a cake for my mother'

[Gu 2010: 37]

In order to shed further light on the ADH/IDH debate as well as on the nature of cross-linguistic influence in 2L1 acquisition, we examine the developmental patterns 2L1 English/Spanish children follow and the interaction of the two grammars in the domain of DA structures (i.e. DOCs and to/for-datives in English; DCLDs and a/paradatives in Spanish). At this point, a clarification on cross-linguistic influence is at hand. In the present dissertation, cross-linguistic influence refers to the possible transfer of the syntactic status of DA structures from one language into the other language, rather than to specific grammatical properties defining each of the four DA structures analyzed. By transfer of the syntactic status of DA structures, we mean whether the syntactic 
derivational or non-derivational relationship that underlies and connects the two DA structures in language A is transferred (or not) into language B.

\subsubsection{The role of dual input in child dual output}

The relative frequency rate with which a construction is used in the adult input is argued to go hand in hand with the child output (e.g. Legate and Yang 2002; Lust 2006; Pullum and Scholz 2002; Sampson 2002; Yang 2016, 2011, 2002). This assumption affects bilinguals and monolinguals alike. However, the relatively balanced or skewed dual language exposure in bilinguals might or might not influence the developmental patterns in language A and in language B when compared to monolinguals (Bybee and Hopper 2001; De Houwer 2009, 1990; Gathercole 2007; Hoff et al. 2014; Paradis and Genesee 1996; Paradis and Navarro 2001; Paradis et al. 2011; among others).

The one-parent one-language strategy (a term first coined by Ronjat 1913, and later adopted by other linguists such as Deuchar and Quay 2000; Meisel 2004; Romaine 2004; Takeuchi 2006; among many others) is argued to provide 2L1 children with a balanced frequency of exposure whereby parents address their children in each of their L1s (Álvarez de la Fuente et al., in progress; Fernández Fuertes and Álvarez de la Fuente 2017; Gleitman and Newport 1995; Paradis et al. 2006; Paradis and Genesee 1996; among others). Taking this strategy into account, balanced input bilinguals are prone to exhibit analogous acquisition patterns to their L1 peers, as reported in lexical production (Genesee 2003; Patterson and Pearson 2004; Pearson et al. 1997; among others), in the knowledge of phonological forms (Bosch and Sebastián-Gallés 1997; Polka and Sundara 2003; Vihman 1996; among others) or in morpho-syntactic development (De Houwer 2005, 1990; Deuchar and Quay 2000; Meisel 2001; Paradis and Genesee 1996; among others).

Nevertheless, not every 2L1 child receives a balanced input in the two L1s. This differential exposure is also argued to be a factor that might cause delay or acceleration in the acquisition rates of one (or both) language(s); these input conditions tease 2L1 and L1 acquisition apart (Bybee and Hopper 2001; De Houwer 1996; Ellis 2002; Gathercole 2007; Goldberg 2006; Grüter and Paradis 2014; Hoff et al. 2012; Paradis and Genesee 1996; Paradis et al. 2011; Paradis and Navarro 2001; Rowland 2014; Theakston et al. 2004; among others). 
Paradis et al. (2011) argue that the acquisition of past tense by 25 2L1 English/French children (age range: 4;01-5;07) from Edmonton (Canada) is sensitive to dual input conditions. In particular, home differential exposure to English and French, as measured by parental reports, is found to influence the children's accuracy in the production of regular past tenses. Parents are asked to report the language(s) of greater home exposure when they address their children: (a) 8 children are exclusively exposed to French in the home context (i.e. French-dominant) and their exposure to English comes from the community; (b) 15 children are only exposed to English both at home and in the community (i.e. English-dominant); and (c) 2 children are equally exposed to French at home and English both at home and in the community (however, this group is not considered in the analysis given the low number of participants). These participants' performance is compared to L1 English children, via the norming sample provided by the standardized Test of Early Grammatical Impairment (TEGI; Rice and Wexler 2001), as well as to $21 \mathrm{~L} 1$ French children (age range: 3;07-5;04). The results indicate that accuracy in the production of regular past tense turns out to be influenced by the language of greater exposure at home. Regarding the English data, the Englishdominant group shows higher accuracy rates than the French-dominant group $(F(1,21)=2.51, p=0.001)$. However, no significant differences are found between the English-dominant group and the L1 English children, in contrast with the lower accuracy rates in the French-dominant group when compared to L1 English children's data $(t(7)=-2.964, p=0.021)$. In the case of the French data, the French-dominant group is observed to show better accuracy when compared to the English-dominant group $(F(1,21)=9.841, p=0.001)$. Nevertheless, no significant differences appear between the French-dominant group and their L1 French peers, in contrast with the lower performance in the English-dominant group when compared to the L1 French group $(t(34)=-2.407, p=0.02)$. Therefore, 2L1 English/French children receiving a relatively higher input in English pattern closer to their L1 English counterparts in the production of English regular past tenses, while no significant differences between the Frenchdominant group and the L1 French children appear in the production of regular past tense forms in French. This suggests that home input factors influence 2L1 English/French children's acquisition rates in the production of regular past tense if compared to their respective L1 peers. 
Paradis and Navarro (2003) also observe that input factors may have an effect on 2L1 children's acquisition of (overt and null) subject realization in Spanish declarative utterances. The participants include 3 children whose spontaneous data are taken from CHILDES: 1 2L1 English/Spanish child, Manuela (the Deuchar corpus; age range: 1;09-2;06; MLUw=1.26-2.08) and 2 L1 Spanish children, used as a control group, Emilio (the Vila corpus; age range: 1;08-2;07; MLUw=1.20-2.12) and María (the Ornat corpus; age range: 1;08-1;11; $M L U w=1.99-2.07)$. With regards to the input the 2L1 English/Spanish child is exposed to, both parents address Manuela in Spanish at home (her father is an L1 Cuban Spanish speaker and her mother is an L1 British English speaker); caretakers (at nursery) and her maternal grandmother speak to the child in English. As illustrated in table 10, Manuela shows a higher rate in the use of overt subjects (35.32\%) if compared to L1 Spanish children's data, that is, Emilio (16.95\%) and María (20.13\%). Yet, Manuela produces most of the utterances with a null subject (64.68\%), akin to her L1 Spanish peers (Emilio (83.05\%) and María (79.87\%)).

\begin{tabular}{cccc}
\hline Child & Overt & Null & Total \\
\hline Manuela (2L1EN/SP) & $83(35.32)$ & $152(64.68)$ & $\mathbf{2 3 5 ( 1 0 0 )}$ \\
\hline Emilio (L1 SP) & $59(16.95)$ & $289(83.05)$ & $\mathbf{3 4 8 ( 1 0 0 )}$ \\
\hline María (L1 SP) & $31(20.13)$ & $123(79.87)$ & $\mathbf{1 5 4 ( 1 0 0 )}$ \\
\hline
\end{tabular}

Table 10. The production of overt and null subjects in Spanish by bilingual English/Spanish and by monolingual Spanish children (\# of occurrences (\%)) (Paradis and Navarro 2003: 380)

The production of overt and null subjects in the 2L1 English/Spanish child and in the L1 Spanish children's data is in line with the frequency of distribution analyzed in the adult input. As shown in table 11, Manuela's parents show a higher rate in the use of overt subjects (i.e. $61.76 \%$ in the mother's and $60.00 \%$ in the father's speech) when compared to Emilio's and María's parents (i.e. between $35.32 \%$ and $42.90 \%$ ). Furthermore, Manuela's parents produce fewer declarative utterances with a null subject (i.e. $38.24 \%$ in the father's data and $40.00 \%$ in the mother's data) if compared to those ones with an overt subject; however, this is not observed in the L1 Spanish children's parents whose frequency of use of null subjects (i.e. between $57.10 \%$ and $64.68 \%$ ) outperforms that of overt ones (i.e. between $35.32 \%$ and $42.41 \%$ ). 


\begin{tabular}{cccc}
\hline Parent (child) & Overt & Null & Total \\
\hline Mother (Manuela-2L1 EN/SP) & $168(61.76)$ & $104(38.24)$ & $\mathbf{2 7 2 ( 1 0 0 )}$ \\
\hline Father (Manuela-2L1 EN/SP) & $174(60.00)$ & $116(40.00)$ & $\mathbf{2 9 0}(\mathbf{1 0 0})$ \\
\hline Mother (Emilio-L1 SP) & $201(42.41)$ & $273(57.59)$ & $\mathbf{4 7 4 ( \mathbf { 1 0 0 } )}$ \\
\hline Mother (María-L1 SP) & $184(35.32)$ & $337(64.68)$ & $\mathbf{5 2 1}(\mathbf{1 0 0})$ \\
\hline Father (María-L1 SP) & $57(42.90)$ & $76(57.10)$ & $\mathbf{1 3 3 ( 1 0 0 )}$ \\
\hline
\end{tabular}

Table 11. Parents' production of overt and null subjects in Spanish declarative utterances (\# of occurrences (\%)) (adapted from Paradis and Navarro's (2003: 382-383) tables 4 and 5) ${ }^{12}$

Paradis and Navarro (2003) suggest two possible interpretations for the overproduction of subjects in the 2L1 English/Spanish child if compared to the higher rate in the use of null subjects in her L1 Spanish peers: (a) The effect of adult input in the exposure to Spanish declarative utterances, that is to say, the 2L1 English/Spanish child output might be influenced by her parents’ high use of overt subjects and/or (b) the cross-linguistic influence from English into Spanish since the overt subject realization in English could influence the optional use of overt subjects in Spanish. However, Paradis and Navarro (2003) argue that even though the 2L1 English/Spanish child's overproduction of subjects differs from the L1 Spanish children's use, null subjects are still more frequently produced than overt ones in both child groups.

Several studies have examined the source of imbalanced frequency of exposure in bilinguals, that is, whether it is rooted in the language of the community and/or in the language(s) spoken at home (Álvarez de la Fuente et al., in progress; De Houwer 1996; Hoff et al. 2014; Romaine 2004; among others). These works point to home input, rather than the language of the community, as a determining factor that might cause differences in the bilinguals' language development, when compared to their L1 peers. For instance, Hoff et al. (2014) demonstrate that the amount of English adult input that 47 2L1 English/Spanish children (age range: 1;05-2;06) from South Florida (USA) are exposed to affects their vocabulary growth, their mean length of the 3 longest utterances

\footnotetext{
12 The number of cases and percentages in Emilio's mother's production of overt and null subjects are misplaced in Paradis and Navarro's (2003: 382-383) table 4 given that she produces more null subjects than overt subjects and this is not reflected in table 4 (i.e. 273 overt subjects, $42.41 \%$ and 201 null subjects, 57.59\%). In fact, the total number of overt subjects in Emilio's mother's data can be checked in Paradis and Navarro's (2003: 383) table 5 where a distinction is made between the production of lexical overt subjects (i.e. 135 cases, 67.16\%) and pronominal overt subjects (i.e. 66 cases, 32.84\%) so that the overall number of overt subjects produced is 201 (100\%).

Another error observed in Paradis and Navarro's (2003: 382) table 4 is María’s father's production of overt subjects (i.e. 76 cases, 42.90\%). This is evidenced in Paradis and Navarro's (2003: 383) table 5 where the sum of the number of cases attested, regardless of whether overt subjects are lexical (i.e. 37 cases, $64.91 \%$ ) or pronominal (i.e. 20 cases, 35.09\%), is 57 (42.90\%).
} 
and their word combinations. These participants are divided into 3 groups according to the adult input they receive: (a) English-dominant bilinguals, if the mother is an L1 English speaker or if the child has school-aged older siblings (>16;00); (b) Spanishdominant bilinguals, if the mother or both parents are L1 Spanish speakers or if there is no presence of school-aged older siblings; and (c) balanced bilinguals if they are equally exposed to English and Spanish. These groups are compared to a control group of 56 L1 English children, born and bred in South Florida, and whose age is comparable to that of the 2L1 English/Spanish children. The participants' exposure to each language is measured via a wide range of tools: (a) Interviews to their caregivers or the language diary method (developed by De Houwer and Bornstein 2003) which consists of videorecording the participants every 30 minutes for 7 weeks; (b) the MacArthur-Bates inventories, namely, the Communicative Development Inventory (Fenson et al. 2007) as well as the Inventario del Desarrollo de Habilidades Comunicativas (Jackson Maldonado et al. 2003); and (c) the Expressive One Word Picture Vocabulary Test (Brownwell 2001) whereby the children are asked to label drawings. According to Hoff et al.’s (2014) study, home language exposure to English predicts 2L1 English/Spanish children's lexical production and grammatical complexity in the early stages of language development and this is so regardless of the language of the community (i.e. English in all cases). That is, the 2L1 Spanish-dominant children receiving less input in English at home (at least 70\% of the input is in Spanish) lag behind their L1 English peers (i.e. they have $100 \%$ of the input in English) both in vocabulary size and in grammatical complexity (as measured by the mean length of the 3 longest utterances and by word combinations) at the 3-month intervals (i.e. 22, 25 and 30). On the contrary, the English-dominant children, who receive at least $70 \%$ of the input in English, pattern closely with their L1 English counterparts in the above-mentioned measures at the 3 stages under investigation; these participants cannot be followed by the balanced bilinguals' developmental pattern which is influenced by the amount of exposure to both languages, and in particular, to English (i.e. between $40 \%$ and $60 \%$ ).

Different studies also suggest that the low exposure to one of the two languages in a bilingual setting may cause attrition or temporary loss (De Houwer 2009; Köpke and Schmid 2003; Montrul 2008, 2004, 2002; Slavkov 2012; Yang and Montrul 2016; among others). To present an example, Slavkov (2012) conducts a case study of a 2L1 English/Bulgarian girl (Sophie) in Canada whose mother and father are L1 English and 
L1 Bulgarian speakers, respectively. The parents adopt the one parent-one language strategy and each one addresses their child in their L1s, a practice that they have followed since the child was born. Once the child starts socializing out of the home setting (i.e. at 1;09), her exposure to English turns out to be higher if compared to that in Bulgarian. Consequently, her Bulgarian output begins to gradually decrease until it virtually disappears. However, a 10-day trip to Bulgaria at 2;03 triggers the reactivation of her bilingual development since the input during that period is exclusively in Bulgarian. The data analysis shows that Sophie's MLUw, after the trip, increases in Bulgarian while that in English decreases. Therefore, the amount of input a child is exposed to through language development plays a crucial role in 2L1 acquisition.

The present study will take into consideration the adult input variable so as to examine whether 2L1 children's use of English and Spanish DA structures is influenced by the amount of exposure they receive in these structures. These results are compared to their corresponding L1 peers whose exposure to the target structures is restricted to only one language, that is, English or Spanish. Finally, we investigate whether the adult input-child output patterns of English and Spanish DA structures appear in 2L1 and in L1 children’s data alike.

\subsection{Previous studies on the acquisition of dative alternation structures}

This section discusses earlier works on the production of DA constructions in English and in Spanish. This is so in the case of L1 children since, to the best of our knowledge, research on the acquisition of these structures in 2L1 children has not been developed yet.

Section 2.2.1 presents studies on the age of onset of double object and prepositional DA constructions dealing with spontaneous and experimental data. In the case of English (section 2.2.1.1), works on the age of acquisition of these structures are focused on L1 children, in contrast with those in Spanish (section 2.2.1.2) which are chiefly focused on second language (L2) acquisition. Indeed, not much research has been done so far with L1 Spanish children, except for Torrens and Wexler's (2000). L1 and L2 studies on the role that adult input plays in child production of DA structures are addressed in section 2.2.2 and they mainly examine the two types of constructions in English, i.e. DOCs and to/for-datives. 


\subsubsection{Age of onset}

\subsubsection{English DOCs and to/for-datives}

The debate regarding the derivational relationship (or lack thereof) between the two DA structures in English, as discussed in section 1.3.1 (chapter 1), has sought confirmation in spontaneous data analyses. These studies find evidence for a sequential order in the earlier and in the later emergence of double object and prepositional constructions, respectively (Bowerman 1990; Campbell and Tomasello 2001; Gropen et al. 1989; Snyder and Stromswold 1997).

Gropen et al. (1989) analyze the DA structures that appear in the spontaneous production of 5 L1 English children (age range: 1;05-5;01), taken from CHILDES: Adam (age range: 2;03-5;02), Eve (age range: 1;06-2;03) and Sarah (age range: 2;035;01) available in the Brown corpus; as well as Mark (age range: 1;05-4;07) and Ross (age range: 2;07-6;06) available in the MacWhinney corpus. Utterances are classified in terms of 11 semantic classes of DA verbs: (a) Giving (e.g. 'give'); (b) communication (e.g. 'tell'); (c) creation (e.g. 'make'); (d) obtaining (e.g. 'buy'); (e) accompanied motion in a direction (e.g. 'bring'); (f) sending (e.g. 'send'); (g) ballistic motion (e.g. 'throw'); (h) manner of accompanied motion (e.g. 'push'); (i) other manner of speaking verbs (e.g. 'shout'); (j) future having (e.g. 'promise'); and (k) other benefactive verbs (i.e. for-datives whose verbs do not fall into the classes (c) and (d)). As shown in table 12, Gropen et al. (1989) find out that the emergence of DOCs precedes that of to/fordatives in 4 out of the 5 children; the exception is Mark who shows a reverse pattern. Furthermore, out of the 11 semantic categories mentioned above, all the L1 English children have mostly used the giving category (i.e. 'give'), regardless of the type of DA structure. 


\begin{tabular}{ccc}
\hline Children & DOC & To/for-dative \\
\hline Adam & $2 ; 03$ ('give') & 2;08 ('give') \\
\hline Eve & $1 ; 08$ ('read') & 1;11 ('do', 'fix', 'hold', 'read') \\
\hline Mark & $3 ; 07$ ('take') & 3;05 ('give') \\
\hline Ross & $2 ; 07$ ('give') & $2 ; 08$ ('buy') \\
\hline Sarah & $2 ; 11$ ('give') & $3 ; 00$ ('make') \\
\hline Mean & $\mathbf{2 ; 0 6}$ & $\mathbf{2 ; 0 7}$ \\
\hline
\end{tabular}

Table 12. Age of emergence and verb type in the production of DOCs and to/for-datives by monolingual English children (adapted from Gropen et al.’s (1989: 213-216) tables 2 to 6)

As claimed by Snyder and Stromswold (1997), Gropen et al.'s (1989) classification procedure may have had an effect on the results since they include, among the target structures, constructions with a locative/directional meaning, as in (6). Also, Snyder and Stromswold (1997: 290) report that (a) the ages provided for 2 of the participants are erroneous: Mark's onset of DOCs is at 2;07 and Mark’s and Ross' first occurrences of to-datives are at 3;04 and at 2;09, respectively; (b) the participants' sample is scarce given that only 5 children are analyzed; and (c) no statistical analyses lend support to the subsequent order of acquisition of DA structures (i.e. DOCs $>$ to/fordatives).

(6) Mommy, take me to Delma's

[Snyder and Stromswold 1997: 286]

Based on Gropen et al.’s (1989) study, Snyder and Stromswold (1997) conduct an analysis on the spontaneous speech of 12 L1 North American English children (age range: 1;04-2;06), taken from CHILDES. 5 of them are already analyzed in Gropen et al. (1989): Adam (age range: 2;03-5;02), Eve (age range: 1;06-2;03) and Sarah (age range: 2;03-5;01) available in the Brown corpus; Allison (age range: 1;04-2;10) and Peter (age range: 1;10-3;02) available in the Bloom corpus; April (age range: 1;10-2;11) available in the Higginson corpus; Mark (age range: 1;05-6;00) and Ross (age range: 2;06-7;10) available in the MacWhinney corpus; Naomi (age range: 1;02-4;09) available in the Sachs corpus; Nathaniel (age range: 2;06-3;09) available in the Snow corpus; Nina (age range: 2;00-3;03) available in the Suppes corpus; and Shem (age range: 2;03-3;02) available in the Clark corpus. The aim of their study is twofold: (a) To test the derivational relationship of DA constructions by examining the ages of first occurrence of DOCs and to-datives and (b) to analyze whether the acquisition of the 
derived DA structure is subject to maturation as it occurs with other DP-movement constructions such as passives and unaccusatives (Borer and Wexler 1987). It is observed that 11 out of the 12 L1 English children acquire DOCs (mean age: 2;02) earlier than to-datives (mean age: 2;06), as depicted in table 13, and that this difference is statistically significant $(t(11)=4.15, p=.002)$; however, the ages of acquisition of DOCs and to-datives are highly correlated with one another ( $r=.76, p=.0043)$.

\begin{tabular}{ccc}
\hline Children & DOCs & To-datives \\
\hline Adam & $2 ; 03$ & $2 ; 11$ \\
\hline Allison & $1 ; 10$ & $2 ; 10$ \\
\hline April & $1 ; 10$ & $2 ; 01$ \\
\hline Eve & $1 ; 07$ & $2 ; 00$ \\
\hline Mark & $2 ; 07$ & $3 ; 04$ \\
\hline Naomi & $2 ; 00$ & $2 ; 05$ \\
\hline Nathaniel & $2 ; 05$ & $2 ; 07$ \\
\hline Nina & $2 ; 00$ & $2 ; 01$ \\
\hline Peter & $2 ; 00$ & $2 ; 00$ \\
\hline Ross & $2 ; 07$ & $2 ; 09$ \\
\hline Sarah & $2 ; 10$ & $3 ; 02$ \\
\hline Shem & $2 ; 02$ & $2 ; 04$ \\
\hline Mean age & $\mathbf{2 ; 0 2}$ & $\mathbf{2 ; 0 6}$
\end{tabular}

Table 13. Ages of acquisition of DOCs and to-datives by monolingual English children (Snyder and Stromswold 1997: 290)

The significant correlation between the onset of DOCs and to-datives is argued to show evidence of a parametric model of child language acquisition in which DA constructions are all acquired as part of the single syntactic package of complex predicates captured in the Complex Predicate Parameter (Snyder 2001, 1995). Therefore, the language-specific knowledge required to produce these structures is not construction-specific. Rather, English DA constructions are related by means of a language-specific syntactic parametric property (namely, Property A) that is shared by both DOCs and to-datives; indeed, this syntactic relation is explained by the significant correlation between L1 English children's ages of onset of DOCs and to-datives.

Although DOCs and to-datives share an underlying structure, as in Snyder and Stromswold's (1997) study, L1 English children show significant differences in the order of onset (i.e. DOCs $>$ to-datives). These differences do not mean that to-datives are syntactically derived from DOCs; instead, they suggest that the later acquisition of to-datives depends on an additional or a second property (namely, Property B) to that required in the production of English DA structures (i.e. Property A). In other words, although DOCs and to-datives share an underlying structure, the emergence of DOCs 
takes place earlier if compared to to-datives since the required language-specific grammatical knowledge to produce the former belongs to Property $\mathrm{A}$, while for the latter Property A and an additional Property B are required. The additional Property B that is required to produce to-datives is related to the status of the preposition 'to'. More specifically, Property B is associated with the special Case and theta mediatedassignment between the preposition 'to' and the verbal head in to-datives, that is, the verb assigns dative Case and goal theta role to the prepositional complement through the preposition 'to' since the preposition has the property of 'mediating' the process of Case and theta role assignment by the verb onto the DP (Larson 1990, 1988; Marantz 1984; Pesetsky 1985). This special status of the preposition 'to' is found in the significant correlation ( $r=.83, p=.0009)$ between L1 English children's ages of onset of to-datives and other related dative structures (chiefly, dyadic to-datives) given that the mean age of onset of both constructions is concurrent at 2;06. Nevertheless, the verbal head in dyadic to-datives selects one internal argument (namely, an IO-PP), as in (7), while that in DA to-datives subcategorizes for a DO-DP and an IO-PP. On the contrary, DOCs (mean age: 2;02) start being produced before dyadic to-datives (mean age: 2;06), and this order of emergence is statistically significant $(t(11)=3.38, p=.006)$.

(7) Something happened to Fred

[Snyder and Stromswold 1997: 284]

A 4-month difference appears between the onset of the two types of DA constructions (i.e. DOCs and to-datives) and between that of DOCs and other related todative structures (i.e. dyadic to-datives). Thus, the age of acquisition of to-datives predicts that of other uses of the preposition 'to' in dyadic constructions; this suggests that both DA to-datives and dyadic to-datives depend on Property A (because of their shared underlying structure as complex predicates) as well as on Property B (because of the mediated Case and theta-assignment role of the preposition 'to'). All in all, the properties required to produce DA to-datives (and dyadic to-datives) are argued to cause a delay in their acquisition when compared to those required to produce DOCs.

Moreover, Snyder and Stromswold (1997) examine the issue of whether one type of DA construction is syntactically derived from its structure counterpart via DPmovement. They hypothesize that, if this is so, these findings would be consistent with 
Borer and Wexler's (1987) prediction that DP-movement structures are not available to the child in the early stages of language acquisition since they are subject to maturation. Correlation and $t$-test analyses are run for the ages of onset of two prototypical DPmovement constructions (namely, passives and unaccusatives) and for the ages of onset of each of the two types of DA structures. If DOCs or to-datives undergo DPmovement, a significant correlation and non-significant differences are expected between the derived DA construction and the DP-movement constructions. According to Snyder and Stromswold's (1997) results, the 12 L1 English children start producing unaccusatives (mean age: 2;01) earlier than passives (mean age: 2;05) and this order effect is statistically significant $(t(11)=3.15, p=.009)$. Furthermore, no significant differences are observed between the ages of onset of (a) DOCs and unaccusatives; (b) DOCs and passives; and (c) to-datives and passives since all $p$ 's are >.1. On the contrary, a marginal significant difference is found between the ages of first occurrence of to-datives and unaccusatives $(t(1)=3.13, p=.009)$. With regards to correlational analyses, a marginally significant correlation is reported between the ages of onset of todatives and passives ( $r=.55, p=.064$ ), while no significant correlation (all $p$ 's $>.10$ ) is observed between the ages of acquisition of (a) to-datives and unaccusatives; (b) DOCs and unaccusatives; and (c) DOCs and passives. Therefore, the non-significant correlation between the ages of onset of DOCs and the two DP-movement structures infers that DOCs are not syntactically derived from to-datives via DP-movement (contra Larson 2014, 1990, 1988; among others; see section 1.3.1 in chapter 1). Alternatively, the marginal significant correlation between the ages of first occurrence of to-datives and passives could be argued to lend support to the derivation of to-datives from DOCs via DP-movement (in line with Aoun and Lin 1989; among others; see section 1.3.1 in chapter 1). Yet, the two opposing statistical results when analyzing the ages of onset of to-datives and unaccusatives (that is, there are significant differences, but they are nonsignificantly correlated) 'is inappropriate to draw any firm conclusions from our analysis of NP (or DP)-movement constructions' (Snyder and Stromswold 1997: 296).

Campbell and Tomasello (2001) carry out a similar study to that of Snyder and Stromswold's (1997). They analyze the spontaneous production of 7 L1 English children (age range: 1;02-5;00), extracted from CHILDES: Abe (age range: 2;04-5;00), available in the Kuczaj corpus; Adam (age range: 2;03-4;10), Eve (age range: 1;062;03) and Sarah (age range: 2;03-5;01), available in the Brown corpus; Naomi (age 
range: $1 ; 02-4 ; 09$ ), available in the Sachs corpus; Nina (age range: 1;11-3;03), available in the Suppes corpus; and Peter (age range: 1;09-3;01), available in the Bloom corpus. Despite the children's age range contrast between Snyder and Stromswold's (1997) study (i.e. 1;04-2;06) and Campbell and Tomasello's (2001) (i.e. 1;02-5;00), the results in the latter confirm those in the former in that an order effect is found in the earlier emergence of DOCs (mean age: 2;02) when compared to to/for-datives (mean age: $2 ; 04)$, as shown in table 14. There is an exception with 2 children's ages of first occurrence: Peter begins to use to-datives at 2;00 before DOCs and for-datives at 2;01, in contrast with Abe who starts producing for-datives at 2;05, 1 month earlier than the onset of to-datives and DOCs at 2;06.

\begin{tabular}{cccc}
\hline Children & DOC & To-dative & For-dative \\
\hline Abe & $2 ; 06$ & $2 ; 06$ & $2 ; 05$ \\
\hline Adam & $2 ; 03$ & $2 ; 11$ & $2 ; 10$ \\
\hline Eve & $1 ; 06$ & $1 ; 10$ & $1 ; 11$ \\
\hline Nina & $1 ; 11$ & $2 ; 00$ & $2 ; 01$ \\
\hline Naomi & $2 ; 01$ & $2 ; 05$ & $2 ; 03$ \\
\hline Peter & $2 ; 01$ & $2 ; 00$ & $2 ; 01$ \\
\hline Sarah & $2 ; 09$ & $3 ; 02$ & $3 ; 00$ \\
\hline Mean age & $\mathbf{2 ; 0 2}$ & $\mathbf{2 ; 0 4}$ & $\mathbf{2 ; 0 4}$ \\
\hline
\end{tabular}

Table 14. Age of first use of DOCs, to-datives and for-datives by monolingual English children (Campbell and Tomasello 2001: 256)

Given that Campbell and Tomasello (2001) do not carry out statistical analyses that lend support to the 2-month gap between the onset of DOCs and to/for-datives, these findings cannot be statistically compared to those reported by Snyder and Stromswold (1997) on the emergence of DOCs and to-datives. Rather, statistical correlational analyses are run by Campbell and Tomasello (2001) to examine whether adult input plays a role in L1 English children's age of onset (see section 2.2.2).

Some ages of onset of DOCs and to-datives differ between Campbell and Tomasello’s (2001) and Snyder and Stromswold's (1997) studies, as displayed in table 14 and in table 13, respectively. This is caused by the different criteria followed in each of the studies, namely, Campbell and Tomasello (2001) also consider non-adult-like cases such as to-datives with a null preposition $(\phi)$, as in (8), while Snyder and Stromswold (1997) focus on adult-like utterances.

(8) Miriam gave it $\phi$ me

[Nina, 2;00, the Suppes corpus, CHILDES, Snyder and Stromswold 1997: 257] 
Semantics may also play a role in the emergence of DA constructions. Bowerman (1990) proposes that children are endowed with an innate knowledge of the canonical mapping between thematic roles and grammatical functions. Taking this argument into consideration, the emergence of to/for-datives is expected to occur earlier when compared to DOCs because of the canonical theta role mapping of to/for-datives (i.e. agent $>$ theme $>$ goal/beneficiary) with their corresponding grammatical relations (i.e. $\mathrm{SU}>\mathrm{DO}>\mathrm{IO} / \mathrm{A})$. As in (9a), the agent 'I', the theme 'that' and the beneficiary 'you' are canonically mapped with their corresponding grammatical relations (i.e. SU, DO and A, accordingly), while the thematic roles and the grammatical functions of the DOC in (9b) are non-canonically mapped since the goal-IO 'me' precedes the theme-DO 'train'.

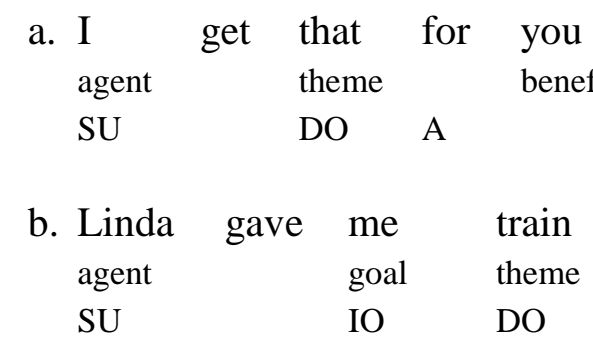
[thematic roles]
[grammatical relations]

[thematic roles] [grammatical relations]

[Eva, 1;10, Bowerman 1990: 1271]

Under these premises, Bowerman (1990) examines the above-mentioned hypothesis using the spontaneous data of her 2 L1 English daughters (age range: 1;0810;08). Contrasting results are found between the children: Eva starts producing DOCs and to/for-datives at around the same age (i.e. at 1;10), in contrast with Christy who begins to produce DOCs at 1;11, 1 month before to/for-datives (i.e. at 2;00). Therefore, the emergence of to/for-datives is not produced earlier if compared to DOCs; rather, the onset of to/for-datives occurs either later than DOCs (in line with Snyder and Stromswold's (1997) findings), as observed in Christy's data, or concurrently with DOCs, as found in Eva's. Hence, these findings do not shed light on the thematic rolesyntactic canonical mapping hypothesis.

Experimental works have also been conducted to investigate whether older children than the ones in the previous studies discussed above display a grammatical competence in the production of English DA constructions. Mazurkewich and White 
(1984) use 3 groups of L1 English participants (mean ages: 9;00, 12;03 and 15;06) who have to judge the (un)grammaticality of DOCs and to/for-datives via an Acceptability Judgment Task (AJT). As presented in table 15, all the groups are highly accurate in evaluating the grammaticality of DA constructions, regardless of the type of structure (range of accuracy rate: $96.7 \%-100 \%$ in to/for-datives and $86.7 \%-100 \%$ in DOCs). Very few children judge ungrammatical DA structures as grammatical, as evidenced by their low rates of acceptance.

\begin{tabular}{ccccccc}
\hline & \multicolumn{2}{c}{ 9-year-olds } & \multicolumn{2}{c}{ 12-year-olds } & \multicolumn{2}{c}{ 15-year-olds } \\
\cline { 2 - 7 } & Gramm. & Ungramm. & Gramm. & Ungramm. & Gramm. & Ungramm. \\
\hline To-datives & 96.7 & 3.3 & 100 & - & 100 & - \\
\hline DOCs (from to-datives) & 100 & - & 90 & 10 & 100 & - \\
\hline For-datives & 100 & - & 96.7 & 3.3 & 100 & - \\
\hline DOCs (from for-datives) & 96.7 & 3.3 & 93.3 & 6.7 & 86.7 \\
\hline
\end{tabular}

Table 15. Acceptability Judgement Task ratings on the (un)grammaticality of dative alternation constructions by monolingual English children (\%) (Mazurkewich and White 1984: 281)

These findings reveal that L1 English speakers between 9;00 and 15;00 have an adult-like competence of prepositional and double object constructions and the two DA structures are argued to be learnt on an item-by-item basis.

These previous studies, and especially those using spontaneous data (namely, Snyder and Stromswold 1997 and Campbell and Tomasello 2001), serve as the basis for the present investigation to examine the production of English DA structures (i.e. DOCs and to/for-datives) and Spanish DA constructions (i.e. DCLCDs and a/para-datives) by L1 and by 2L1 children. The participants' ages of onset and incidence through language development will shed light on the syntactic derivational or non-derivational status of the target structures.

\subsubsection{Spanish DCLDs and a/para-datives}

To the best of our knowledge, very few studies have discussed the acquisition of DA constructions in L1 Spanish. In fact, only Torrens and Wexler (2000) have reported on the emergence of DCLDs by L1 Spanish children, while no L1 acquisition works have been concerned with a/para-datives or with the relation between DCLDs and a/para-datives. Parallel L1 studies on the emergence of structures that allow the presence or the absence of clitic doubling have been found in languages such as Romanian where a DO-DP doubles an accusative clitic in mono-transitive constructions (Ungureanu 2017). Most research studies on DA structures have accounted for their 
learning by L2 Spanish speakers (Bruhn de Garavito 2000; Cuervo 2007; Perpiñán and Montrul 2006; among others).

Torrens and Wexler (2000) focus on the emergence of DCLDs in the production of an L1 Spanish child, María (the Ornat corpus, CHILDES), whose age ranges from 1;07 to 3;11 with a gap between 3;01 and 3;06 in the transcripts. DCLDs start emerging between 1;07 and 2;03, regardless of whether the dative clitic is optional with nonpronominal prepositional complements, as in (10), or obligatory with pronominal prepositional complements, as in (11).

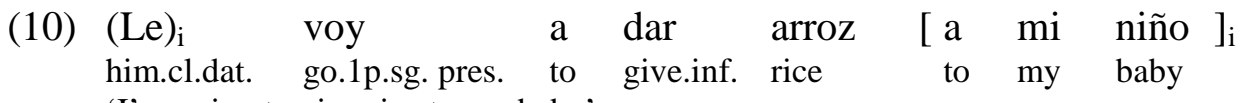
'I'm going to give rice to my baby'

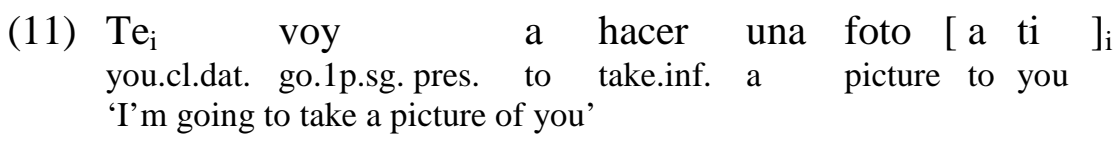

[María, 2;04, the Ornat corpus, CHILDES, Torrens and Wexler 2000: 288]

Therefore, Torrens and Wexler (2000) observe that the child starts producing DCLDs at an early stage and shows a native-like knowledge of the grammatical mechanisms (i.e. the use of the clitic).

L1 acquisition studies on clitic doubling have also been attested in languages such as Romanian. Ungureanu (2017) conducts a pilot experiment on the acquisition of, what he terms, the Direct Object Clitic Doubling (DOCD, henceforth) parameter in Romanian (a [+DOCD] language) by 3 L1 Romanian boys at two different age stages (i.e. one boy at 2;08 and two boys at 3;01). In Romanian mono-transitive constructions, an accusative clitic shares analogous features (i.e. Case, gender, number and person) with the DO-DP, as in (12a); these structures reflect the [+DOCD] option of the parameter. In turn, Romanian also allows the [-DOCD] option, as seen in the formation of the so-called simple clitic constructions where the accusative clitic 'l-' (i.e. 'him'), as in (12b), is co-indexed with a null DO-DP (i.e. 'pro'). 
(12)
a. $\mathrm{L}_{\mathrm{i}^{-}}$am vazut pe Milu
cl.acc.3sg.m. have seen to Milu
'I saw Milu'
$\begin{array}{llll}\text { b. L- } & \text { am } & \text { vazut } & \text { pro }_{\mathrm{i}} \\ \text { cl.acc.3sg.m. } & \text { have } & \text { seen }\end{array}$
'I saw him'
[+DOCD $]$
[-DOCD]

[Ungureanu 2017: 18]

The fact that Romanian allows both options of the DOCD parameter is argued as follows: 'Within the cross-linguistic distribution of clitic use, the [-DOCD] parameter is a proper subset of the [+DOCD] parameter since all languages that permit [+DOCD] constructions (such as Romanian) also permit [-DOCD] constructions, and the opposite does not hold true' (Ungureanu 2017: 19). As shown in table 16, the results evidence that L1 Romanian children begin to acquire the default option of the DOCD parameter (i.e. [-DOCD]) since all the participants start producing simple monotransitives with an overt accusative clitic. The [+DOCD] option of the parameter is acquired later, as seen in Silviu's and in Steven's lack of production of mono-transitive structures with an overt DO-DP doubling an accusative clitic, except for Paul who is at a more advanced stage in the acquisition of these structures. Ungureanu (2017) argues that the amount of exposure to clitic doubling mono-transitive constructions will facilitate their emergence.

\begin{tabular}{ccccc}
\hline Structures & $\begin{array}{c}\text { Silviu } \\
(\mathbf{2 ; 0 8 )}\end{array}$ & $\begin{array}{c}\text { Steven } \\
\mathbf{( 3 ; 0 1 )}\end{array}$ & $\begin{array}{c}\text { Paul } \\
\mathbf{( 3 ; 0 1 )}\end{array}$ & Adults \\
\hline$[-$ DOCD] simple clitic & $2 / 3$ & $3 / 3$ & $3 / 3$ & $3 / 3$ \\
\hline$[+$ DOCD] clitic doubling & $-/ 6$ & $-/ 5$ & $5 / 6$ & $6 / 6$ \\
\hline
\end{tabular}

Table 16. Elicited production of simple and clitic doubling mono-transitive constructions in monolingual Romanian children's data (Ungureanu 2017: 23)

All in all, the findings in Ungureanu's (2017) study are in accordance with the Full Competence Hypothesis (Poeppel and Wexler 1993) given that functional categories (i.e. clitics) are present in the child's grammar from early on.

An extensive research has been conducted on the learning of DA structures by L2 Spanish speakers, focusing, specifically, on adults' data. Experimental tests have been used to analyze whether the syntactic properties of the participants' L1 delay or accelerate the learning process of DCLDs and a/para-datives (Bruhn de Garavito 2000; Perpiñán and Montrul 2006; Sikorska 2009; among others). For instance, Perpiñán and 
Montrul (2006) examine whether L1 English learners of Spanish, intermediate ( $n=23)$ and advanced ( $\mathrm{n}=13)$, whose L1 is argued not to exhibit the direct counterpart of English DOCs, consider DCLDs as illicit structures in their initial learning stages. A group of 8 L1 Spanish speakers (6 from Spain and 2 from Latin America) perform as control. The 3 groups of participants have to judge whether DCLDs are grammatical, as in (13a), or ungrammatical, as in (13b), by means of an AJT.

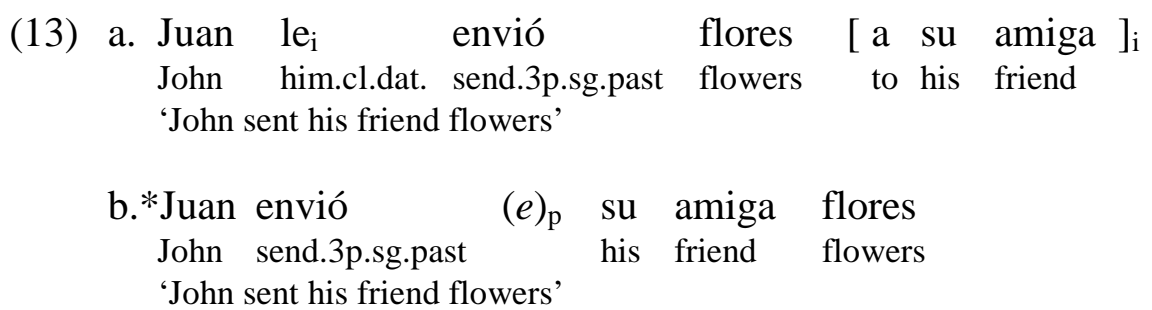

Perpiñán and Montrul (2006) observe that intermediate L2 Spanish speakers’ data lend support to the Full Transfer/Full Access Hypothesis (Schwartz and Sprouse 1996, 1994). This means that they rely on the grammatical properties available in their L1 (i.e. English) when judging grammatical DCLDs, namely, the null preposition 'to' and the constituent order. This is seen in the lower acceptance rates of grammatical DCLDs (i.e. close to 50\%) if compared to those of the advanced L2 and L1 Spanish groups who do not differ in their higher frequency acceptance rates (i.e. about $90 \% ; F(2,44)=20.223$, $p<.0001$, [native=advanced]\#intermediate). ${ }^{13}$ With regards to the acceptability of ungrammatical DCLDs, the intermediate L2 Spanish group displays a 30\% acceptance rate, while the advanced L2 and L1 Spanish groups judge them as grammatical between $5 \%$ and $0 \%$ of the time, respectively $(F(2,44)=8.848, \quad p<.001$, [native=advanced]\#intermediate). Furthermore, Perpiñán and Montrul (2006) analyze the acceptability of a/para-datives with two possible grammatical constituent orders, canonical, as in (14a), and non-canonical, as in (14b).

\footnotetext{
${ }^{13}$ Perpiñán and Montrul (2006: 142) 'use the symbol '=' to mean not significantly different from each other and the symbol '\#' to mean significantly different. Square brackets '[]' indicate the groups that patterned together statistically'.
} 

(14)
a. Juan devolvió el libro a María John give back.3p.sg.past the book to María
'John gave back the book to Mary'
b. Juan devolvió a María el libro John give back.3p.sg.past to María the book 'John gave back the book to Mary'

[Perpiñán and Montrul 2006: 142]

The response patterns of a/para-datives show that the intermediate L2 Spanish group prefers the canonical (i.e. about $60 \%$ of acceptance) rather than the non-canonical constituent order (i.e. about $30 \%$ of acceptance). These findings significantly differ from the advanced L2 Spanish and L1 Spanish groups $(F(2,44)=3.745, p<.031)$ who show similar rates in accepting canonical and non-canonical a/para-datives (i.e. about $60 \%$ ). Thus, the learning process of (un)grammatical DCLDs as well as grammatical (non-)canonical a/para-datives by L1 English learners of Spanish is subject to proficiency level and amount of exposure to the L2 (i.e. Spanish).

Nevertheless, Bruhn de Garavito (2000) argues that, irrespective of whether the L1 grammar has overt dative clitics (e.g. French) or not (e.g. English), L2 learners do not always rely on their L1. In her study, there are 3 groups of participants: 2 nearnative L2 Spanish groups (10 L1 English and 10 L1 French speakers; age range: 26;0062;00), 1 advanced L2 Spanish group (10 L1 English speakers; age range: 21;00-27;00) and 1 control group (11 L1 Spanish speakers; age range: 18;00-45;00). They have to perform an AJT and have to judge the acceptance of (a) grammatical a/para-datives, as in (15); (b) grammatical DCLDs with a prepositional complement bearing [+human] features, as in (16a), or [-human] features, as in (16b); and (c) DCLDs with ungrammatical co-indexation (i.e. Case, number, person and theta role) between the dative clitic and the prepositional complement, as in (17). In the latter, the prepositional complement might also bear [+human] features, as in (17a), or [- human] features, as in (17b).
(15) Planché la falda para María iron.1p.sg.past the skirt for Mary 'I ironed the shirt for Mary'


(16)

$\begin{array}{lll}\text { a. } \mathrm{Le}_{\mathrm{i}} & \text { dejé } & \text { los libros }\end{array}$ [ a Juan $]_{\mathrm{i}}$

'I left John the books'

[Bruhn de Garavito 2000: 197]

b. $\mathrm{Le}_{\mathrm{i}}$ puse una tapa [a la jarra $]_{\mathrm{i}}$

him.cl.dat. put.1p.sg.past a cover to the jar

'I put a cover in the jug'

[Bruhn de Garavito 2000: 204]

(17)

a. ${ }^{*} \mathrm{Te}_{\mathrm{i}}$ dejé los libros $[\text { a Juan }]_{\mathrm{i}}$
you.dat.cl. leave.1p.sg.past the books to John
'I left the books with John for you'

[Bruhn de Garavito 2000: 198]

b. ${ }^{*} \mathrm{Te}_{\mathrm{i}} \quad$ coloqué
$\begin{aligned} & \text { you.dat.cl. put.1p.sg.past a tapa } \\ & \text { 'I placed a cover in the jug' }\end{aligned}$

[Bruhn de Garavito 2000: 206]

Bruhn de Garavito (2000) observes that the near-native and the advanced L2 Spanish groups do not significantly differ from the control group $(F(3,37)=2.432$, $p=.0804$ ) in accepting grammatical a/para-datives. These findings suggest that the L2 Spanish learners' L1 aids the learning of these structures because of their shared properties with those in French and in English. Moreover, all the groups differentiate between grammatical and ungrammatical DCLDs when the prepositional complement is [+human] $(F(3,37)=1976, p=.1345)$. However, the L1 English speakers (i.e. the nearnative and the advanced groups) significantly differ from the L1 French and the L1 Spanish speakers in that they do not distinguish between grammatical and ungrammatical DCLDs when the prepositional complement is [-human] $(F(3,37)=5.28$, $p=.0039$ ). All in all, the L1 French speakers' acceptability rate of (un)grammatical DCLDs, regardless of whether the prepositional complement bears [+human] or [human] features, is identical to that of the control group despite the fact that these constituents are restricted to [+human] features in French. This means that the L1 French speakers' attainment of native-like Spanish proficiency is related to Universal Grammar (UG) availability given that the properties of double object constructions in their L1 (i.e. French) have not constrained the judgement of DCLDs. Furthermore, the L1 English speakers pattern closely with the control group in that they distinguish grammatical and ungrammatical DCLDs with prepositional complements bearing [+human] features; however, those ones with [-human] features are argued to evidence 
transfer from the properties of English DOCs into Spanish DCLDs since prepositional complements in the former are restricted to [+human] features and, what is more, dative clitics do not appear on the surface structure.

In line with Bruhn de Garavito’s study, Cuervo (2007) investigates the grammatical knowledge of Spanish DA constructions in the data of 43 intermediate level L1 English speakers (age range: 19;00-29;00) and 17 L1 Spanish adults who are tested as control. By means of an AJT, the participants have to judge the acceptability of (a) grammatical a/para-datives, as in (15), and ungrammatical a/para-datives with the wrong preposition, as in (18); (b) grammatical DCLDs with prepositional complements bearing [+/-human] features, as in (16); and (c) DCLDs with an ungrammatical coreference between the dative clitic and the prepositional complement, as in (17).

*Dejé los libros en Juan
leave.1p.sg.past the books in John
'I left the books in John'

[Cuervo 2007: 600]

The L2 Spanish learners and the L1 controls perform uniformly in differentiating grammatical from ungrammatical $a /$ para-datives $(F(3,58)=9.92, p<.0001)$. These results suggest that prepositional DA structures share analogous properties in Spanish and in English. Although grammatical DCLDs with prepositional complements bearing [+human] features are accepted by both groups, the L2 Spanish learners judge DCLDs as ungrammatical when prepositional complements display [-human] features, while the L1 controls consider these structures as acceptable $(F(1,58)=85.92, p<.0001$ between groups; $F(2,58)=30.73, p<.0001$ between the animacy features of prepositional complements). Despite the fact that the L2 Spanish group rejects DCLDs with agreement mismatches between the dative clitic and the prepositional complement at significantly lower accuracy rates than the L1 Spanish group $(F(3,58)=58.37, p<.0001)$, both groups show sensitivity to the properties of DCLDs. These results speak against the Fundamental Difference Hypothesis (Bley-Vroman 1997, 1996) since the L2 Spanish learners have been able to go beyond the properties of DA structures in their L1 (i.e. English) given that DOCs do not exhibit dative clitic doubling and constituent order differs from that of DCLDs. In other words, these findings are in line with the Full Transfer/Full Access approach (Montrul 2000; Schwartz and Sprouse 1996) which 
claims that UG guides L2 acquisition. Nevertheless, the L2 Spanish learners have not learned that prepositional complements in DCLDs are also available for [-human] features.

Given the scarce L1 and 2L1 acquisition works on Spanish DA constructions, the present study contributes to fill this gap in empirical research and aims at shedding light on their syntactic status. In particular, we analyze the production of DCLDs and a/paradatives in L1 Spanish and in 2L1 English/Spanish children's data so as to determine whether these two constructions hold a syntactic derivational relationship, or, rather, they stem from a shared or from two distinct underlying structure(s). In the case of DCLDs, it is especially relevant to highlight that the present study will consider dative clitics in the third person (i.e. ' $l e(s)$ '), in contrast with Torrens and Wexler's (2000) data classification criteria. We follow Demonte (1995: 6; see footnote 5 in chapter 1 ) in the characterization of DA in Spanish, namely, the presence or the absence of third person dative clitics helps distinguish DCLDs from a/para-datives, while first and second person dative clitics are always present in DCLDs when the prepositional complement is pronominal and, therefore, these structures are not considered for analysis given that they do not allow DA as a/para-datives.

\subsubsection{The effect of adult input in child output}

Adult input has been found to play a crucial role in children's production of DA constructions. This has been reported in L1 English works on the length and the nominal type of the internal arguments (De Marneffe et al. 2012) as well as on the emergence of DOCs and to/for-datives (Campbell and Tomasello 2001; Snyder and Stromswold 1997). However, similar studies have not been done on Spanish.

De Marneffe et al. (2012) analyze the spontaneous speech of 7 L1 English children (age range: 2;00-5;00), from CHILDES: Abe (the Kuczaj corpus), Adam and Sarah (the Brown corpus), Naomi (the Sachs corpus), Nina (the Suppes corpus), Shem (the Clark corpus) and Trevor (the Demetras-Trevor corpus). Their study aims at investigating whether adults' choices (in particular, those occurring in the data from Adam, Nina and Shem) of DOCs and to-datives with the verbs 'give' and 'show' are also reflected in the children's output. Two grammatical factors are considered for analysis, namely, the length (i.e. number of words) and the nominal type (i.e. pronoun/lexical) of the DO and the IO. Further details are discussed as follows: 
(a) The length of the internal arguments (i.e. longer arguments tend to occur at the end of each of the target structures). Adults favor DOCs over to-datives when a long DO-DP is produced ( $p=.0000)$, while to-datives are prone to be used over DOCs with a short DO-DP ( $p=.0019)$. These preferences in adults are reflected in L1 English children's production of DOCs ( $p=.0175)$, as in (19a), and to-datives $(p=.0211)$, as in (19b).

(19) a. She gives them some broth without any bread

[Naomi, 2;03, the Sachs corpus, CHILDES, De Marneffe et al. 2012: 8]

b. Give that to Poy

[Nina, 2;09, the Suppes corpus, CHILDES, De Marneffe et al. 2012: 8]

(b) The nominal type of the internal arguments (i.e. the choice of a pronoun over a full DP, regardless of the target structure). In adult data, DOCs tend to be used when the IO-DP has a pronominal form $(p=.0000)$, while to-datives are preferred when the DO-DP has a pronominal form $(p=.0000)$. These factors in adults' choices pattern similarly to those observed in L1 English children's production of DOCs $(p=.0000)$, as in (20a), and to-datives ( $p=.0000)$, as in (20b).

(20) a. Give him a hug

[Nina, 2;11, the Suppes corpus, CHILDES, De Marneffe et al. 2012: 8]

b. Give it to the man

[Adam, 4;00, the Brown corpus, CHILDES, De Marneffe et al. 2012: 8]

Therefore, De Marneffe et al.'s (2012) study shows that L1 English children's choices when producing DOCs and to-datives are sensitive to the nature of the input they receive in terms of the length and the nominal type of the internal arguments. Furthermore, the use of English DA structures in the adult input has also played a role in L1 English children's higher rate of use of DOCs when compared to to-datives, as shown in table 17. This is so regardless of the length and the nominal type of the DO and the IO in the choice of the two types of constructions. 


\begin{tabular}{cccccc}
\hline & & Child & & \multicolumn{2}{c}{ Adult input } \\
\cline { 2 - 5 } & DOC & To-dative & DOC & To-dative \\
\hline Abe & 53 & 22 & - & - \\
\hline Adam & 180 & 41 & - & - \\
\hline Naomi & 18 & 3 & 337 & 106 \\
\hline Nina & 108 & 38 & - & - \\
\hline Sarah & 12 & 7 & 107 & 31 \\
\hline Shem & 7 & 3 & - & - \\
\hline Trevor & 30 & $\mathbf{1 2 2}$ & $\mathbf{5 8 4}$ & $\mathbf{2 0 4}$ \\
\hline Total & $\mathbf{4 0 8}$ & &
\end{tabular}

Table 17. The production (\# of occurrences) of DOCs and to-datives by monolingual English children and by adults (adapted from De Marneffe et al. 2001: 5 and 16)

Snyder and Stromswold (1997) examine whether adults' use of DOCs and todatives influences the emergence of these structures in 12 L1 North American English children (age range: 1;04-2;06). Adult input frequency is calculated based on the verb 'give' as an indicator of the overall frequency of production of the target structures: DOCs and to-datives account for an average of $73.2 \%$ and $26.8 \%$, respectively. Based on the results, the use of these constructions in the adult input does not significantly correlate with their order of emergence $(p>.10)$ in the L1 North American English children's data, namely, DOCs (mean age: 2;02) > to-datives (mean age: 2;06), as reported in section 2.2.1.1. In other words, adult input appears not to influence the L1 English children's emergence of DOCs and to-datives.

Contrasting viewpoints to those reported by Snyder and Stromswold (1997) are observed in Campbell and Tomasello's (2001) study when analyzing the production of DOCs and to-datives in 7 L1 English children (age range: 1;02-5;00) and in their parents. As shown in table 18, the children's use of English DA structures matches that of their parents since both groups show that DOCs are more frequently produced than to-datives $(\mathrm{p}<.01)$. Exceptionally, Naomi reveals a higher rate in the use of to-datives if compared to DOCs, contrary to the relative frequency rate in the production of these structures in her parent input. 


\begin{tabular}{ccccc}
\hline & \multicolumn{2}{c}{ Child } & \multicolumn{2}{c}{ Adult input } \\
\cline { 2 - 5 } & DOC & To-dative & DOC & To-dative \\
\hline Abe & $92(68)$ & $44(32)$ & $181(71)$ & $74(29)$ \\
\hline Adam & $118(75)$ & $40(25)$ & $125(61)$ & $81(39)$ \\
\hline Eve & $23(62)$ & $14(38)$ & $66(73)$ & $25(27)$ \\
\hline Naomi & $3(33)$ & $6(67)$ & $5(60)$ & $2(40)$ \\
\hline Nina & $78(64)$ & $43(35)$ & $434(68)$ & $207(32)$ \\
\hline Peter & $112(76)$ & $35(24)$ & $30(65)$ & $16(35)$ \\
\hline Sarah & $123(80)$ & $31(20)$ & $327(79)$ & $85(21)$ \\
\hline
\end{tabular}

Table 18. The production of DOCs and to-datives by monolingual English children and by adults (\# of occurrences (\%)) (adapted from Campbell and Tomasello 2001: 258)

Campbell and Tomasello (2001) conclude that the amount of input the children are exposed to goes hand in hand with the earlier emergence of DOCs (mean age: 2;02) and the later emergence of to-datives (mean age: 2;04), as discussed in section 2.2.1.1.

Overall, the contrasting results observed between Snyder and Stromswold's (1997) and Campbell and Tomasello's (2001) studies may be attributed to the structures under analysis. In particular, Snyder and Stromswold (1997) focus on the acquisition of DOCs and to-datives, while Campbell and Tomasello (2001) also include for-datives among their target constructions. Furthermore, Snyder and Stromswold (1997) carry out a single-verb type analysis (i.e. that of the verb 'give'), while Campbell and Tomasello (2001) have a closer look at a wider variety of verb types when analyzing the use of DOCs and to-datives, as illustrated in table 19.

\begin{tabular}{|c|c|c|c|c|c|}
\hline \multirow[b]{2}{*}{ Children } & \multirow[b]{2}{*}{ Verb type } & \multicolumn{2}{|c|}{ Child } & \multicolumn{2}{|c|}{ Adult input } \\
\hline & & DOC & To-dative & DOC & To-dative \\
\hline \multirow{6}{*}{ Adam } & Give & 80 & 8 & 93 & 46 \\
\hline & Get & 14 & 10 & 2 & 5 \\
\hline & Show & 12 & 5 & 23 & 12 \\
\hline & Make & 5 & 10 & 3 & 5 \\
\hline & Buy & 4 & 4 & 2 & 1 \\
\hline & Read & 3 & 3 & 2 & 12 \\
\hline \multirow{6}{*}{ Abe } & Get & 61 & 26 & 78 & 21 \\
\hline & Give & 10 & 7 & 50 & 27 \\
\hline & Show & 10 & 1 & 24 & 5 \\
\hline & Make & 8 & 7 & 14 & 13 \\
\hline & Bring & 2 & 2 & 13 & 0 \\
\hline & Read & 1 & 1 & 2 & 8 \\
\hline \multirow{3}{*}{ Eve } & Give & 14 & 8 & 54 & 20 \\
\hline & Read & 6 & 5 & 4 & 4 \\
\hline & Show & 3 & 1 & 8 & 1 \\
\hline Naomi & Read & 3 & 6 & 5 & 2 \\
\hline \multirow{5}{*}{ Nina } & Give & 65 & 22 & 273 & 91 \\
\hline & Bring & 4 & 3 & 30 & 34 \\
\hline & Read & 4 & 15 & 43 & 35 \\
\hline & Send & 2 & 2 & 30 & 28 \\
\hline & Show & 3 & 1 & 58 & 15 \\
\hline \multirow[b]{2}{*}{ Peter } & Give & 85 & 19 & 16 & 12 \\
\hline & Get & 4 & 11 & 1 & 2 \\
\hline
\end{tabular}




\begin{tabular}{llllll}
\hline Make & 4 & 2 & 2 & 1 \\
\cline { 2 - 5 } & Bring & 4 & 1 & 4 & - \\
\cline { 2 - 5 } & Show & 3 & 2 & 7 & 1 \\
\hline
\end{tabular}

Table 19. The production of DOCs and to-datives per verb type by monolingual English children and by adults (\# of occurrences) (adapted from Campbell and Tomasello 2001: 258)

Based on Campbell and Tomasello's (2001) findings, the conclusions reached for one specific verb in Snyder and Stromswold (1997) may fall short of the whole picture with regards to the influence of adult input in the use of English DA structures on child output, even if the verb 'give' is the most productive verb in the child and in the parent speech.

The results reported by Snyder and Stromswold (1997) and by Campbell and Tomasello (2001) will serve as the basis for the analysis conducted in the present thesis. We aim at investigating whether the patterns that characterize the use of English and Spanish DA structures in the adult input correlate with those in L1 and in 2L1 children's output.

Taking as a point of departure the syntactic and the semantic properties of English and Spanish DA structures (chapter 1) as well as previous works on the acquisition of these constructions (chapter 2), a series of RQs have been formulated as they appear in the following chapter. 


\section{CHAPTER 3}

\section{RESEARCH QUESTIONS}

Taking previous formal accounts (see chapter 1) and empirical works (see chapter 2) as a point of departure, the present chapter formulates 8 RQs that seek to address two issues; namely, the syntactic derivational relationship (or lack thereof) of DA structures in English and in Spanish and the role played by adult input in children's production of English and Spanish DA constructions. A summary of how these 8 RQs are structured is provided in table 1.

\begin{tabular}{|c|c|c|c|c|c|}
\hline \multirow[b]{2}{*}{$\mathbf{R Q}$} & \multicolumn{3}{|c|}{ Focus } & \multirow[b]{2}{*}{ Variable 1} & \multirow[b]{2}{*}{ Variable 2} \\
\hline & Language & Language group & Biological gender & & \\
\hline RQ 1 & \multirow[t]{2}{*}{ English } & \multirow[t]{2}{*}{ L1 vs. 2L1 } & \multirow[t]{2}{*}{ Girls vs. boys } & Age of onset & $\begin{array}{c}\text { Incidence through } \\
\text { language development }\end{array}$ \\
\hline RQ 2 & & & & Adult input & Child output \\
\hline$\overline{\text { RQ } 3}$ & \multirow[t]{2}{*}{ Spanish } & \multirow[t]{2}{*}{ L1 vs. 2L1 } & \multirow[t]{2}{*}{ Girls vs. boys } & Age of onset & $\begin{array}{c}\text { Incidence through } \\
\text { language development }\end{array}$ \\
\hline RQ 4 & & & & Adult input & Child output \\
\hline RQ5 & \multirow{2}{*}{$\begin{array}{l}\text { English vs. } \\
\text { Spanish }\end{array}$} & \multirow{2}{*}{ L1 vs. L1 } & \multirow{2}{*}{ Girls vs. boys } & Age of onset & $\begin{array}{c}\text { Incidence through } \\
\text { language development }\end{array}$ \\
\hline RQ 6 & & & & Adult input & Child output \\
\hline RQ 7 & \multirow{2}{*}{$\begin{array}{l}\text { English vs. } \\
\text { Spanish }\end{array}$} & \multirow{2}{*}{$\begin{array}{c}\text { 2L1 } \\
\text { (compared to L1) }\end{array}$} & \multirow[t]{2}{*}{ Girls vs. boys } & Age of onset & $\begin{array}{c}\text { Incidence through } \\
\text { language development }\end{array}$ \\
\hline RQ 8 & & & & Adult input & Child output \\
\hline
\end{tabular}

Table 1. Summary of the focus and the variables targeted in the research questions formulated in the study

Sections 3.1 and 3.2 deal with questions related to English DA structures and Spanish DA structures, respectively, as reflected in the production of L1 and 2L1 children. In this respect, two issues are at hand in these sections: On the one hand, we examine the syntactic (non-)derivational relationship of DOCs and to/for-datives in English (RQ 1) and that of DCLDs and a/para-datives in Spanish (RQ 3), as observed in L1 and in 2L1 children's ages of onset as well as incidence through language development. These two variables are also viewed considering the children's biological gender. On the other hand, we investigate the role played by adult input in child output of English DA structures (RQ 2) and Spanish DA structures (RQ 4), as seen in the production of adults, L1 and 2L1 children (including, as well, a distinction in terms of the children's biological gender).

Section 3.3 focuses on whether the two DA structures share an analogous syntactic (non-)derivational relationship in English and in Spanish alike and on whether the frequency with which these constructions are used in the adult input is reflected in 
the child output. In order to provide an answer to these issues, we will conduct two types of analyses; namely, we will analyze the production of prepositional and double object constructions in L1 English and in L1 Spanish children's data (section 3.3.1, inter-group comparison), on the one hand, and we will examine these structures in 2L1 English/Spanish children's data (section 3.3.2, intra-group comparison), on the other hand, using their respective L1 peers as a group of comparison. While the age of onset, incidence through language development and biological gender will elucidate the syntactic (non-)derivational relationship that exists between the two DA structures in English and in Spanish (RQ 5 for L1 children and RQ 7 for 2L1 children), the use of the two English and Spanish DA structures, both overall and per biological gender, will account for the role played by adult input in child output in the production of the two languages at stake (RQ 6 for L1 children and RQ 8 for 2L1 children).

\subsection{English dative alternation structures in the production of monolingual and bilingual children}

The first issue we investigate in this group of RQs is the type of syntactic derivational relationship (or lack thereof) that underlies the two English DA structures (i.e. DOCs and to/for-datives), as analyzed in the production of L1 and 2L1 children, including girls and boys. In view of this, RQ 1 is formulated as follows:

- RQ 1. Is there a syntactic derivational relationship (or lack thereof) between the two types of English DA structures; namely, DOCs and to/fordatives in the production of L1 and 2L1 children?

Thus, RQ 1 will shed light on two main issues. Firstly, it will provide information about whether DOCs and to/for-datives are (non-)derivationally related, as analyzed in the patterns of onset and incidence through language development. Two possible derivational and one possible non-derivational patterns could reveal the syntactic relationship of the two English DA structures: (a) To/for-datives might be the source structure from which DOCs derive (e.g. Haspelmath 2006; Larson 2014, 1990, 1988; Perlmutter 1980; Oehrle 1976), as seen in the later emergence, and possibly the lower incidence through language development, of the latter when compared to the former; (b) to/for-datives might be the derived DA structure instead (e.g. Aoun and Li 1989; Czepluch 1992; Dryer 1986; Koizumi 1994), as seen in the later onset, and possibly the 
lower incidence through language development, of these constructions when compared to DOCs; or (c) the two English DA structures might not be syntactically derived from one another, and so, they might be construed under two different underlying representations (e.g. Marantz 1993; Mulder 1992) or under a shared underlying structure (e.g. Snyder and Stromswold 1997), as observed in the relatively similar age of onset, and possibly the fairly similar incidence through language development, of the two English DA structures. Secondly, RQ 1 will also elucidate whether the syntactic derivational or non-derivational pattern of the two English DA structures is equally reflected in the two target groups (i.e. L1 English and 2L1 English) and in the two biological genders (i.e. girls and boys). In the case of 2L1 English children, two scenarios may appear in their data; namely, the patterns of onset and incidence through language development in the production of English DA structures could pattern closer to their respective L1 peers or, as will be explored in RQ 7, the production patterns of English DA structures could be influenced by their other L1 (i.e. Spanish). As for the children's biological gender, RQ 1 will give an answer as to whether girls and boys reflect similar patterns in the production of DOCs and to/for-datives, as analyzed in L1 English and in 2L1 English children's data; or whether biological gender differences appear when examining the production of these structures in the two target language groups. In accordance with earlier L1 English acquisition works (e.g. Bowerman 1990; Campbell and Tomasello 2001; Gropen et al. 1989; Snyder and Stromswold 1991) and with previous 2L1 English empirical studies (e.g. Gu 2010), we predict that both L1 English and 2L1 English children will show a relatively concurrent emergence of the two English DA structures. These data will lend support to the non-derivational approach to DOCs and to/for-datives and, thus, the two DA constructions could be argued to either share an underlying structure (Snyder and Stromswold 1997), as per the Complex Predicate Parameter (Snyder 2001, 1995), or stem from two different underlying representations (Marantz 1993; Mulder 1992). Although the two constructions will begin to be produced at approximately the same time, we also expect the onset of to/for-datives to appear later than DOCs in the two language groups (i.e. L1 English and 2L1 English). This could be so given the additional mediating Case and theta role assigning properties of the prepositions (in line with Snyder and Stromswold 1997) or related to the influence of adult input in the children's production of English DA structures (in line with Campbell and Tomasello 2001). 
When the syntactic non-derivational relationship of English DA structures is analyzed in terms of the children's biological gender, we predict that, based on previous works on L1 English acquisition (e.g. Berglund et al. 2005; Cornett 2014; Dini 2011; Lovas 2011) and on 2L1 English acquisition (e.g. Eriksson et al. 2012), girls will show an earlier onset of the two DA structures if compared to the boys' data. Therefore, biological gender differences in the two language groups are expected to appear in the acquisition of English DA structures.

We also explore in RQ 2 whether the frequency of exposure to DOCs and to/fordatives in the adult input influences their use in the child output.

- RQ 2. Does adult input play a role in L1 and in 2L1 children's production of DOCs and to/for-datives?

Considering RQ 2, we will elucidate whether the relative frequency rate with which the two English DA structures are used by adults is also reflected in children's production. Linked to this, RQ 2 will also untangle two further issues. On the one hand, it will show whether the use of DOCs and to/for-datives in the adult input is reflected in the L1 English and in the 2L1 English children's output alike (e.g. Campbell and Tomasello 2001; De Marneffe et al. 2012); or whether the use of English DA structures in 2L1 English children's output is influenced by the patterns of use of DA constructions in their other L1 (i.e. Spanish), as will be explored in RQ 8. On the other hand, RQ 2 will also reveal whether the patterns of use of DOCs and to/for-datives in the adult input are (or are not) equally seen in girls' and in boys' output, in both L1 English and in 2L1 English children's data.

Given the results attested in earlier L1 English empirical studies (e.g. Campbell and Tomasello 2001), the relative frequency rate of exposure to English DA structures in the adult input will be expected to influence the L1 English and the 2L1 English children's production of these structures. In particular, we expect adults to show a higher frequency rate in the use of DOCs when compared to to/for-datives and this production pattern will also be expected to go hand in hand with the children's output in the two language groups. 


\subsection{Spanish dative alternation structures in the production of monolingual and bilingual children}

With respect to Spanish DA structures, we seek to answer whether DCLDs and a/para-datives are (non-)derivationally related, as reflected in the production of L1 and 2L1 children, both in girls' and in boys’ data. This is formulated in RQ 3 as follows:

- RQ 3. Is there a syntactic derivational relationship (or lack thereof) between DCLDs and a/para-datives in the production of L1 and 2L1 children?

More specifically, RQ 3 will provide evidence as to whether DCLDs and a/paradatives exhibit a syntactic derivational relationship or whether the two Spanish DA structures do not derive from one another, as analyzed in L1 Spanish and in 2L1 Spanish children's ages of onset and incidence through language development. From a derivational approach, RQ 3 will clarify whether DCLDs derive from a/para-datives (e.g. Bruhn de Garavito 2000; Demonte 1995, 1994; Kempchinsky 2004), if the former begin to emerge later, and possibly show a lower incidence through language development, when compared to the latter; or whether a/para-datives derive from DCLDs (previous theoretical works have not argued for this type of syntactic derivational relationship yet), if a/para-datives start being produced later, and possibly reveal a lower incidence through language development, when compared to DCLDs. As for the possible lack of syntactic derivational relationship, RQ 3 will shed light as to whether the two Spanish DA structures stem from different underlying representations (e.g. Cuervo 2003a, 2003b) or from a common underived structure, as argued by Snyder and Stromswold (1997) for English; this could be suggested if the ages of onset and the incidence through language development of DCLDs and a/para-datives do not display significant differences.

RQ 3 will also inform on whether the syntactic relational pattern of DCLDs and a/para-datives is analogous per language group (i.e. L1 Spanish vs. 2L1 Spanish) and per biological gender (i.e. girls vs. boys). This suggests that, in the case of 2L1 Spanish children, two possible outcomes may appear in the data; namely, the patterns of onset and incidence through language development of Spanish DA structures could proceed like in their respective L1 counterparts; or, rather, the production patterns of DCLDs 
and a/para-datives could be influenced by the syntactic derivational relationship (or lack thereof) of DA constructions in their other L1 (i.e. English), as will be investigated in RQ 7. From the standpoint of biological gender, RQ 3 will reveal whether girls and boys in the two language groups (i.e. L1 Spanish and 2L1 Spanish) follow analogous syntactic relational patterns in the production of Spanish DA constructions; or whether these patterns are subject to biological gender maturation, as argued in earlier L1 and 2L1 acquisition works discussed in section 3.3.1.

Having considered all the possible scenarios that could occur in the L1 and in the 2L1 children's acquisition of Spanish DA structures and based on what has been previously attested in L1 Spanish acquisition works on the emergence of DCLDs in the early stages of language acquisition (Torrens and Wexler 2000), we expect a/paradatives to emerge at a later stage when compared to DCLDs in the two language groups (i.e. L1 Spanish and 2L1 Spanish). This would suggest a derivational relationship between the two Spanish DA constructions and, in particular, it would involve that a/para-datives are syntactically derived from DCLDs. This type of syntactic relational pattern has been unattested in earlier formal works.

Given the findings reported in earlier works with regards to biological gender differences in maturational patterns (e.g. Berglund et al. 2005; Cornett 2014; Dini 2011), the acquisition of the expected syntactic derivational relationship between the two Spanish DA structures discussed above is predicted to occur earlier in girls than in boys. And this is assumed to be so in the two language groups (i.e. L1 Spanish and 2L1 Spanish).

Another issue that we explore in this group of RQs is the role that adult input plays in children's production of DCLDs and a/para-datives, both in girls' and in boys' data. In this respect, RQ 4 is formulated as follows:

- RQ 4. Does adult input play a role in L1 and in 2L1 children’s production of DCLDs and a/para-datives?

In view of this RQ, we will elucidate whether the relative frequency rate with which Spanish DA structures are used in the adult input patterns closely with L1 Spanish and with 2L1 Spanish children's output.

In addition, RQ 4 will contribute to explain whether the same or different patterns in the production of Spanish DA structures are observed per language group (i.e. L1 
Spanish vs. 2L1 Spanish) and per biological gender (i.e. girls vs. boys). With regards to 2L1 Spanish children's data, RQ 4 addresses whether adults' and children's use of DCLDs and a/para-datives mirrors their corresponding L1 peers; or whether 2L1 Spanish children are influenced by the patterns of use of DA structures in their other L1 (i.e. English), as will be explored in RQ 8. This last scenario would make the patterns of adults' and 2L1 Spanish children's production of DCLDs and a/para-datives differ from those in their respective L1 peers. In turn, RQ 4 will also reveal whether the amount of exposure to the two Spanish DA structures in the adult input goes hand in hand with girls' and with boys' output alike or whether biological gender differences are seen in L1 Spanish and in 2L1 Spanish children's data.

Given the bulk of previous empirical studies that argue for the role played by adult input in child output (e.g. Hoff et al. 2014; Legate and Yang 2002; Lust 2006; Pullum and Scholz 2002; Yang 2016, 2011, 2002), the relative frequency rate with which L1 Spanish and 2L1 Spanish children hear DCLDs and a/para-datives in the adult input is expected to play a role in their output. If these results are on the right track, differences per language group will not be foreseen in the data. Likewise, and contra the divergent emergence patterns of Spanish DA constructions expected between girls and boys (see RQ 3), biological gender differences will not be predicted in this respect as it will not be biological gender but rather the input these children are exposed to what will determine their corresponding output.

\subsection{Dative alternation structures across English and Spanish}

\subsubsection{Inter-group comparison: English and Spanish monolingual children}

The group of RQs formulated in this section focuses on two types of analyses. Firstly, the syntactic (non-)derivational relationship of the two DA structures when comparing English and Spanish as seen in the L1 children's data (RQ 5). Secondly, the role played by adult input frequency of English and Spanish DA structures in L1 children's output (RQ 6). These questions bring together the analyses previously done for English, on the one hand, (RQs 1 and 2) and Spanish, on the other hand (RQs 3 and 4). Therefore, the focus is now placed on the comparison between the two languages.

Our point of departure in the comparison of English and Spanish DA structures is the different properties underlying prepositional and double object constructions across the target languages. Two main differences have been addressed in chapter 1 . While, in 
English, these DA properties are accounted for via the presence or the absence of the prepositions 'to/for' in the formation of to/for-datives and DOCs, respectively (e.g. Larson 2014, 1990, 1988; Malchukov et al. 2007: Quirk et al. 1985; Sadler and Camilleri 2013), in Spanish, it is so via the presence or the absence of the dative clitic 'le/les' in the alternation of DCLDs and a/para-datives, respectively (e.g. Anagnostopoulou 2003; Cuervo 2007, 2003a, 2003b; Demonte 1995, 1994). Although prepositional and double object constructions are available in the two languages at stake, English is a [+complex predicate] language and Spanish is a [-complex predicate] language, as captured in the Complex Predicate Parameter (Snyder 2001, 1995). This means that there is a parametric distinction in the availability of English and Spanish DA structures which is evidenced in the lack of English-like DOCs in Spanish DCLDs. Thus, as per the Complex Predicate Parameter (Snyder 2001, 1995), complex predicate constructions, in general, and DA structures, in particular, do not to share a similar status in [+complex predicate] languages (i.e. English) and in [-complex predicate] languages (i.e. Spanish).

Considering the properties of the two DA structures in English and in Spanish discussed above, RQ 5 aims at shedding light on the type of syntactic (non-)derivational relationship that exists between prepositional and double object constructions when comparing English and Spanish, as seen in acquisition data.

- RQ 5. Is there an analogous syntactic derivational relationship (or lack thereof) between the two DA structures across English and Spanish in the two L1 children's groups?

To be more precise, RQ 5 will show whether the syntactic derivational relationship (or lack thereof) that characterizes prepositional and double object constructions in English is analogous to or differs from the syntactic derivational relationship (or lack thereof) that characterizes these two structures in Spanish, as analyzed in the ages of onset and in the incidence through language development of L1 English children (see RQ 1) and of L1 Spanish children (see RQ 3).

Thus, if prepositional and double object constructions share a similar syntactic (non-)derivational relationship in English and in Spanish, three patterns could be reflected in the production of L1 English and L1 Spanish children. Firstly, double object 
constructions may derive from prepositional DA structures (e.g. Haspelmath 2006; Larson 2014, 1990, 1988; Oehrle 1976; Perlmutter 1980 in English; Bruhn de Garavito 2000; Demonte 1995, 1994; Kempchinsky 2004 in Spanish), if the former start being produced later, and possibly show a lower incidence through language development, when compared to the latter. Secondly, prepositional DA structures may be derived from double object constructions (e.g. Aoun and Li 1989; Czepluch 1992; Dryer 1986; Koizumi 1994 in English; no works have investigated this derivation in Spanish), if the former emerge later, and possibly reveal a lower incidence through language development, when compared to the latter. Thirdly, prepositional and double object constructions could not be syntactically derived from one another (e.g. Marantz 1993; Mulder 1992; Snyder and Stromswold 1997 in English; Cuervo 2003a, 2003b in Spanish), if they begin to be produced at a fairly similar age, and possibly reflect a rather similar incidence through language development.

Alternatively, if prepositional and double object constructions do not show an analogous syntactic (non-)derivational relationship in English and in Spanish, we would expect L1 English and L1 Spanish children to differ in the patterns of onset and incidence through language development.

Given the differences in the syntactic properties that characterize DA in English (e.g. Larson 2014, 1990, 1988; Malchukov et al. 2007; among others) and in Spanish (e.g. Cuervo 2007, 2003a, 2003b; Demonte 1995, 1994; among others), namely, the presence or the absence of the prepositions 'to/for' in English and the dative clitic 'le(s)' in Spanish, as per the Complex Predicate Parameter (Snyder 2001, 1995), and given the different L1 acquisition patterns of these structures, as reported in previous studies, that is, the similar emergence of prepositional and double object constructions in English (e.g. Snyder and Stromswold 1997) and the earlier onset of the latter in Spanish (e.g. Torrens and Wexler 2000), we predict that L1 English children will exhibit opposing emergence and production patterns when compared to L1 Spanish children's data. As we have foreseen in RQ 1 for L1 English and in RQ 3 for L1 Spanish, these opposing patterns would point to the syntactic non-derivational relationship between the two DA structures in English (in line with Snyder and Stromswold 1997), in contrast to the syntactic derivation of prepositional DA structures from double object constructions in Spanish (recall that this view has not been addressed by earlier formal works). 
Another issue to be explored is, as formulated in RQ 6, whether the use of English and Spanish DA structures in the adult input influences that in the L1 children's output, as previously explored in RQ 2 for English and in RQ 4 for Spanish.

- RQ 6. Does adult input play a role in L1 children’s production of English

DA structures (see RQ 2) and Spanish DA structures (see RQ 4)?

Based on RQ 6, we will elucidate whether the relative frequency rate of exposure to prepositional and double object constructions in English and in Spanish, as seen in the adults’ production, influences the L1 children's output.

Considering the findings from previous works on the role played by the adults' use of a construction in the children's output (e.g. Campbell and Tomasello 2001; Hoff et al. 2014; Legate and Yang 2002; Lust 2006; Pullum and Scholz 2002: Yang 2016, 2011, 2002), we expect L1 English and L1 Spanish children's use of prepositional and double object constructions to be associated with the relative frequency with which they are exposed to these structures in the adult input. This is predicted to be so regardless of the similar or the different patterns of use that DA structures may exhibit in each language (i.e. double object > prepositional; prepositional > double object constructions or prepositional $=$ double object constructions).

\subsubsection{Intra-group comparison: English and Spanish bilingual children}

In this group of RQs, we analyze the syntactic derivational relationship (or lack thereof) of DA structures in the 2L1 English/Spanish children's two grammars (RQ 7) as well as the role played by adult dual input in child dual output (RQ 8). We will do so by using their corresponding L1 peers as a group of comparison. Therefore, this analysis involves the consideration of 6 previous RQs from a different approach; namely, RQs 1 and 2 for 2L1 English, RQs 3 and 4 for 2L1 Spanish as well as RQs 5 and 6 for L1 English compared to L1 Spanish.

As formulated in RQ 7 below, we aim at examining whether prepositional and double object constructions reveal a similar syntactic (non-)derivational relationship in the 2L1 English/Spanish children's two languages, as analyzed in the ages of onset and in the incidence through language development. 
- RQ 7. Is there an analogous syntactic derivational relationship (or lack thereof) between the two DA structures in the 2L1 English/Spanish children's two languages (see RQ 1 for English and RQ 3 for Spanish)?

Therefore, RQ 7 will throw light upon (a) whether 2L1 English/Spanish children's developmental patterns with regards to the syntactic (non-)derivational relationship of English and Spanish DA structures proceed like their corresponding L1 counterparts, as per the ADH (e.g. Álvarez de la Fuente 2007; Bergman 1976; Clark 2009; Genesee et al. 1995; Paradis and Genesee 1996); or (b) whether the syntactic (non-)derivational relational pattern that exists between prepositional and double object constructions in one of the 2L1 English/Spanish children's two languages influences the other language, making 2L1 English/Spanish children's developmental paths in the production of English and Spanish DA structures differ from their respective L1 peers', as in the IDH (e.g. Meisel 2004, 2001, 1989; Paradis and Genesee 1996).

As discussed in the predictions formulated for RQ 5 when comparing English to Spanish in L1 children's data, DA differs across the two languages in both the underlying syntactic properties, as per the Complex Predicate Parameter (Snyder 2001, 1995), and the acquisition patterns (e.g. Snyder and Stromswold 1997 for English; Torrens and Wexler 2000 for Spanish). If this is so for L1 acquisition data and given the monolingual-like findings that we have predicted earlier when 2L1 children were compared to their L1 peers in the acquisition of English DA (see RQ 1) and Spanish DA (see RQ 3), we expect 2L1 English/Spanish children to proceed like their L1 peers in the acquisition of the syntactic non-derivational relationship of English DA structures and in the acquisition of the derivational relationship of prepositional DA structures from double object constructions in Spanish. If these predictions are on the right track, these data would confirm the ADH (e.g. Álvarez de la Fuente 2007; Bergman 1976; Clark 2009; Genesee et al. 1995; Paradis and Genesee 1996), and so, the syntactic status that characterizes English DA will not influence that of Spanish DA in the 2L1 English/Spanish children's two languages.

We also examine, as formulated in RQ 8 below, whether adult dual input equally influences 2L1 English/Spanish children's dual output in the production of English and Spanish DA structures, as previously explored in RQ 2 for English and in RQ 4 for Spanish. 
- RQ 8. Does adult dual input play a role in 2L1 English/Spanish children's dual output in the production of English and Spanish DA structures (see RQ 2 for English and RQ 4 for Spanish)?

RQ 8 will provide information on the simultaneous exposure to English and Spanish regarding the use of prepositional and double object constructions both in the adult input and in the 2L1 English/Spanish children's output. Thus, two possible outcomes may be observed in the data: (a) The relative frequency rate with which the two English and Spanish DA structures are used in the adult input could also be seen in the 2L1 English/Spanish children's output, akin to their respective L1 peers (e.g. Legate and Yang 2002; Lust 2006; Pullum and Scholz 2002; Sampson 2002; Yang 2016, 2011, 2002); or (b) the patterns of use of DA structures in one of the 2L1 English/Spanish children's two languages may influence the ones in their other language. If the scenario stated in (b) is on the right track, the production of English or Spanish DA structures in the 2L1 English/Spanish children's data is expected to differ from their L1 peers. Taking into consideration that the selected 2L1 English/Spanish children in the present dissertation follow the one parent-one language strategy (e.g. Deuchar and Quay 2000; Meisel 2004; Ronjat 1913; among others) and given that such strategy provides 2L1 English/Spanish children with a balanced frequency of exposure to English and Spanish DA structures (in line with Fernández Fuertes and Álvarez de la Fuente 2017; Paradis et al. 2006; Paradis and Genesee 1996; among others), we expect the adults' use of prepositional and double object constructions in English and in Spanish to go hand in hand with the 2L1 English/Spanish children's dual output. These production patterns are predicted to be so regardless of the relative frequency rate in the use of English and Spanish DA structures.

In order to provide an answer to the RQs formulated above, an empirical study has been implemented, as will be discussed in the following chapter. 


\section{CHAPTER 4 METHODOLOGY}

This chapter presents the methodological issues that underlie the data analysis in chapter 5. It is divided into 5 main sections, namely, data selection (section 4.1), language developmental measures (section 4.2), data extraction and codification criteria (section 4.3) as well as frequency distribution (section 4.4) of the structures under analysis, and statistical methods for data analyses (section 4.5).

\subsection{Corpora selection from the CHILDES database: Monolingual and simultaneous bilingual participants}

The participants of the present study are selected from the corpora available in CHILDES (MacWhinney 2000), an open access database (http://childes.psy.cmu.edu) founded by Brian MacWhinney (Department of Psychology, Carnegie Melton University) and Catherine Snow (Graduate School of Education, Harvard University) in 1984. The CHILDES database provides tools for examining children's oral spontaneous longitudinal and cross-sectional interactions with adults (child-directed speech) in order to study the language acquisition process as well as universals or differences across languages. These oral conversations are transcribed in the Codes for the Human Analysis of Transcripts (CHAT) written format and in some cases the transcriptions are linked to the original audio or video data.

The corpora selection criteria include the following prerequisites: (a) The children's production is recorded in spontaneous naturalistic settings; (b) the data are longitudinal; (c) to the extent possible and given the data available, the selected number of participants is equally balanced in each of the three targeted language groups (i.e. English monolingual, Spanish monolingual and English/Spanish bilingual); likewise, a balanced number of girls and boys is aimed at; and (d) the participants cannot involve children who exhibit speech or hearing disabilities and/or language delay.

A total of 19 corpora have been selected and, within these, a total of 31 children have been selected. A detailed description of the participants per target language group is presented below.

As shown in table 1, the data from the 13 L1 English children (8 girls and 5 boys) come from 7 corpora: Brown, Cruttenden, Lara, MacWhinney, Sachs, Suppes and Wells. Their ages range from 0;06 to 8;00. 


\begin{tabular}{cccc}
\hline Corpora & Child & Gender & Age range \\
\hline Brown & Adam & $\mathrm{M}$ & $2 ; 03-4 ; 10$ \\
& Eve & $\mathrm{F}$ & $1 ; 06-2 ; 03$ \\
& Sarah & $\mathrm{F}$ & $2 ; 03-5 ; 01$ \\
\hline Cruttenden & Jane & $\mathrm{F}$ & $1 ; 05-3 ; 07$ \\
& Lucy & $\mathrm{F}$ & $1 ; 05-3 ; 07$ \\
\hline Lara & Lara & $\mathrm{F}$ & $1 ; 09-3 ; 03$ \\
\hline MacWhinney & Mark & $\mathrm{M}$ & $0 ; 07-5 ; 06$ \\
& Ross & $\mathrm{F}$ & $0 ; 06-8 ; 00$ \\
\hline Sachs & Naomi & $\mathrm{F}$ & $1 ; 01-5 ; 01$ \\
\hline Suppes & Nina & $\mathrm{F}$ & $1 ; 11-3 ; 11$ \\
\hline Wells & Benjamin & $\mathrm{M}$ & $2 ; 03-5 ; 00$ \\
& Gerald & $\mathrm{M}$ & $1 ; 06-4 ; 09$ \\
& Jack & $\mathrm{M}$ & $1 ; 05-4 ; 09$ \\
\hline
\end{tabular}

Table 1. Monolingual English children selected $\mathrm{M}=$ male; F=female

As far as the L1 Spanish participants are concerned, the data from the 9 children (6 girls and 3 boys) have been selected from 8 corpora: Linaza, LlinasOjea, Marrero, Montes, Nieva, OreaPine, Ornat and Vila, as displayed in table 2. The ages range from $0 ; 11$ to $4 ; 08$.

\begin{tabular}{cccc}
\hline Corpora & Child & Gender & Age range \\
\hline Linaza & Juan & $\mathrm{M}$ & $2 ; 00-4 ; 00$ \\
\hline LlinasOjea & Irene & $\mathrm{F}$ & $0 ; 11-3 ; 02$ \\
\hline Marrero & Idaira & $\mathrm{F}$ & $2 ; 07-4 ; 07$ \\
\hline Montes & Koki & $\mathrm{F}$ & $1 ; 07-2 ; 11$ \\
\hline Nieva & Mendía & $\mathrm{F}$ & $1 ; 08-2 ; 03$ \\
\hline OreaPine & Juan & $\mathrm{M}$ & $1 ; 10-2 ; 07$ \\
& Lucía & $\mathrm{F}$ & $2 ; 02-2 ; 07$ \\
\hline Ornat & María & $\mathrm{F}$ & $1 ; 07-4 ; 00$ \\
\hline Vila & Emilio & $\mathrm{M}$ & $0 ; 11-4 ; 08$ \\
\hline
\end{tabular}

Table 2. Monolingual Spanish children selected

With regards to the bilingual corpora, table 3 shows the selection of 9 2L1 English/Spanish children (3 girls and 6 boys) whose data appear in 4 corpora: Deuchar, FerFuLice, Pérez-Bazán and Ticio. Their ages range from 1;01 to 6;11.

\begin{tabular}{cccc}
\hline Corpora & Child & Gender & Age range \\
\hline Deuchar & Manuela & $\mathrm{F}$ & $1 ; 03-3 ; 03$ \\
\hline FerFuLice & Leo & $\mathrm{M}$ & $1 ; 01-6 ; 11$ \\
& Simon & $\mathrm{M}$ & $1 ; 01-6 ; 11$ \\
\hline Perez & Carla & $\mathrm{F}$ & $2 ; 00-3 ; 03$ \\
& Sheila & $\mathrm{F}$ & $2 ; 02-2 ; 11$ \\
& Alberto & $\mathrm{M}$ & $1 ; 08-3 ; 00$ \\
& Antonio & $\mathrm{M}$ & $2 ; 11-3 ; 02$ \\
& John & $\mathrm{M}$ & $2 ; 00-3 ; 03$ \\
\hline Ticio & Diego & $\mathrm{M}$ & $1 ; 06-2 ; 04$ \\
\hline
\end{tabular}

Table 3. Simultaneous English/Spanish bilingual children selected 
Child-directed speech or adult input has also been taken into account in each of the three target language groups. Adult input comes from a wide range of sources, namely, parents (the main source of input), other caregivers (grandparents, uncles or aunts) and researchers, as it appears in the data transcriptions available in CHILDES. In the case of the 2L1 English/Spanish children, the exposure to both languages is mainly based on the one parent-one language strategy, where parents address their children in their respective native languages, as shown in table 4. However, some parents address their children in their mother tongues as well as in their L2, that is, English or Spanish, depending on the parents' L1. Such is the case of Alberto's mother (an L1 English speaker), John's father (an L1 Spanish speaker) and Carla's mother (an L1 Spanish speaker) from the Perez corpus, along with Manuela's parents (i.e. her mother is an L1 English speaker and her father is an L1 Spanish speaker) from the Deuchar corpus.

\begin{tabular}{|c|c|c|c|c|c|c|c|c|c|}
\hline & Adult input & Alberto & Antonio & Carla & Diego & John & Manuela & Sheila & $\begin{array}{l}\text { Simon and } \\
\text { Leo }\end{array}$ \\
\hline \multirow[b]{2}{*}{ Mother } & L1 & EN & SP & SP & SP & EN & EN & EN and SP & EN \\
\hline & Child-interaction & EN or SP & SP & $\begin{array}{l}\text { SP or } \\
\text { EN }\end{array}$ & SP & EN & EN or SP & SP & EN \\
\hline \multirow[b]{2}{*}{ Father } & L1 & EN & Arabic & EN & EN & SP & SP & Indonesian & SP \\
\hline & Child-interaction & EN & SP or EN & EN & EN & $\begin{array}{c}\text { SP or } \\
\text { EN }\end{array}$ & SP or EN & EN & SP \\
\hline
\end{tabular}

Table 4. Adult input in the simultaneous English/Spanish bilingual children selected $\mathrm{EN}=$ English; $\mathrm{SP}=$ Spanish

In the Perez corpus, Sheila’s parents' characteristic language background should also be discussed. Her mother is a 2L1 English/Spanish speaker and addresses the child in Spanish, while her father is an L1 Indonesian speaker and addresses the child in his L2 (i.e. English), where he has a native-like level. In the same corpus, it is also remarkable to mention Antonio's father's interaction with the child because, even though he is an L1 Arabic speaker, he communicates with Antonio in his L2 (i.e. English).

Most of the 2L1 English/Spanish children selected receive native input from their parents (with some exceptions of children who receive non-native input). The source of input (i.e. parents, caregivers or researchers), however, will not be differentiated in the present study as it will be collapsed for the data analysis in each of the target language groups (see chapter 6). 


\subsection{Measuring linguistic development: MLUw and age}

The children's language development has been analyzed in terms of two language developmental measures: MLU values measured in words and age. These two measures serve to organize the production of the target structures into MLUw stages and into age stages.

One of the Computerized Language ANalysis (CLAN) software package programs, MLU, is utilized to compute the mean length of utterance for each child and in each file of the target language groups (L1 English, L1 Spanish and 2L1 English/Spanish) in order to determine different developmental stages, and so, be able to measure the production of DA constructions through language development during the study period.

MLU calculations are measured in terms of word counts (MLUw) so as to analyze the children's average of words that are produced through language development. As discussed in cross-linguistic works involving languages that are not morphologically balanced such as English (poor morphology) and Spanish (richer morphology), MLUw is argued to be a more effective measure of language development when compared to MLUm (Aguado 1988; Brown 1973; De Villers and De Villers 1973; Hickey 1991; Kvaal et al. 1988; Silva Corvalán and Sánchez Walker 2007; among others; see section 2.1.1, chapter 2).

The MLUw of all the files available in the selected corpora has been calculated. Figure 1 illustrates the command line that computes MLUw. The syntax line is divided into the following parts: (a) The name of the target program (i.e. MLU); (b) the participant's tier whose production is targeted, in this case the child's tier ( $\left.+\mathrm{t}^{*} \mathrm{CHI}\right)$; (c) the command that allows to do the calculation not in the morphology line but in the main line (-t\%mor) and, therefore, outputs words instead of morphemes; and (d) the '@’ code that appears once the target corpora files have been selected. 


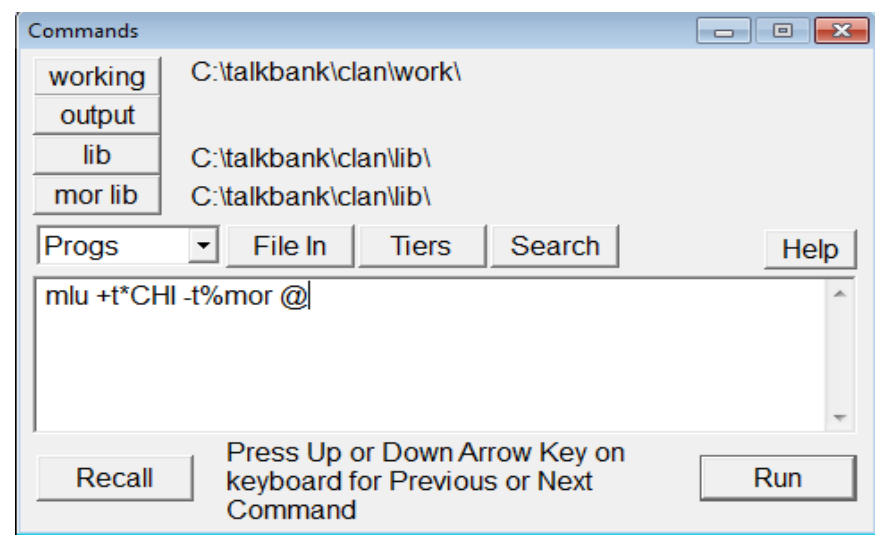

Figure 1. The MLUw command line

An example of the CLAN output window run for the command line in figure 1 is displayed in figure 2, where Ross' MLUw is 1.639 calculated out of a total of 166 utterances and 272 words for the file 07a1.cha.

\begin{tabular}{|l|}
\hline MLU for *CHI: \\
Number of utterances=166, words $=272$ \\
Ratio of words over utterances $=1.639$ \\
Standard deviation=1.071 \\
\hline
\end{tabular}

Figure 2. MLUw CLAN output window

[Ross, the MacWhinney corpus, CHILDES, file 07a1.cha]

MLUw calculations are stored in an Excel spreadsheet for each of the selected participants and for each of the files comprising the children's production. Table 5 offers a fragment of Ross' data codification (files 7a_01.cha to 24a1.cha), where the different examples produced by this child are indicated as well as when no English DA instance is produced in a specific file (as indicated by the hyphens). Further utterances are also available in each of these selected files in table 5 and, in the case of those files where examples are not provided, it is inferred that Ross has not produced English DA structures. 


\begin{tabular}{|c|c|c|}
\hline Utterance & File MLUw & File name \\
\hline *CHI: give me some & 1.639 & 7a_01.cha \\
\hline *CHI: give me that & 1.448 & 7a_01.cha \\
\hline- & 1.389 & 7b1.cha \\
\hline- & 1.459 & 7b2.cha \\
\hline- & 1.679 & 8a.cha \\
\hline *CHI: give me that & 1.545 & 8b.cha \\
\hline- & 3.079 & 19a1.cha \\
\hline- & 2.622 & 19a2.cha \\
\hline- & 2.685 & 19b1.cha \\
\hline- & 2.242 & 19b2.cha \\
\hline *CHI: give big tiger a bracelet & 2.401 & 20a1.cha \\
\hline- & 3.134 & 20a2.cha \\
\hline *CHI: get some candy for me & 3.086 & 20b1.cha \\
\hline- & 2.872 & 21a1.cha \\
\hline- & 3.517 & 22a2.cha \\
\hline- & 4.310 & 22b1.cha \\
\hline- & 3.077 & 22b2.cha \\
\hline- & 4.547 & 23a.cha \\
\hline- & 5.303 & 23b1.cha \\
\hline- & 4.208 & 23b2.cha \\
\hline *CHI: I buy cereal for my baby & 3.911 & 24a1.cha \\
\hline
\end{tabular}

Table 5. Sample of the MLUw computation per file based on the production of English dative alternation structures [Ross, the MacWhinney corpus, CHILDES]

Taking into consideration the MLUw computation through language development, 6 developmental stages have been established to measure the production of English and Spanish DA constructions through the children’s language development. As shown in table 6, these MLUw stages range from an MLU of 1 word to an MLU of over 5 words.

\begin{tabular}{cc}
\hline Stage & MLUw value \\
\hline 1 & 1 \\
\hline 2 & 2 \\
\hline 3 & 3 \\
\hline 4 & 4 \\
\hline 5 & 5 \\
\hline 6 & $>5$ \\
\hline
\end{tabular}

Table 6. MLUw stages for the study of dative alternation constructions

Due to the many fluctuations regarding the MLUw values observed in the files corresponding to each child's output, the beginning of a specific MLUw stage has been 
set the first time the child reaches each of the MLUw values established through the 6 stages.

As for age, intervals of 6 and 5 months have been used to establish 13 stages ranging from $1 ; 00-1 ; 06$ to $7 ; 00-7 ; 06$, as shown in table 7 . Given that the age range covered for the L1 English, the L1 Spanish and the 2L1 English/Spanish children selected goes from 0;06 to 8;00, the ages preceding stage 1 (i.e. 0;06-0;11) and following stage 13 (i.e. 7;07-8;00) are not considered for analysis since DA structures are not produced by any of the three language groups.

\begin{tabular}{cc}
\hline Stage & Age range \\
\hline 1 & $1 ; 00-1 ; 06$ \\
\hline 2 & $1 ; 07-1 ; 11$ \\
\hline 3 & $2 ; 00-2 ; 06$ \\
\hline 4 & $2 ; 07-2 ; 11$ \\
\hline 5 & $3 ; 00-3 ; 06$ \\
\hline 6 & $3 ; 07-3 ; 11$ \\
\hline 7 & $4 ; 00-4 ; 06$ \\
\hline 8 & $4 ; 07-4 ; 11$ \\
\hline 9 & $5 ; 00-5 ; 06$ \\
\hline 10 & $5 ; 07-5 ; 11$ \\
\hline 11 & $6 ; 00-6 ; 06$ \\
\hline 12 & $6 ; 07-6 ; 11$ \\
\hline 13 & $7 ; 00-7 ; 06$ \\
\hline
\end{tabular}

Table 7. Age stages for the study of dative alternation constructions

Table 8 presents a sample of Simon's production of DOCs, classified in terms of 13 age stages and 6 MLUw stages. As an example, the DOC 'give me $t v$ ' is produced when he reaches stage 4 by age (i.e. 2;07-;11) and stage 2 by MLUw (i.e. MLUw 2). When a DA structure is not produced in a specific file, a hyphen is used. 


\begin{tabular}{|c|c|c|}
\hline $\begin{array}{c}\text { Age stage } \\
\text { (age ranges) }\end{array}$ & DOCs & $\begin{array}{l}\text { MLUw stage } \\
\text { (MLUw value) }\end{array}$ \\
\hline $\begin{array}{c}1 \\
(1 ; 00-1 ; 06)\end{array}$ & - & $\begin{array}{c}1 \\
(1)\end{array}$ \\
\hline & - & \multirow{4}{*}{$\begin{array}{c}2 \\
(2)\end{array}$} \\
\hline $\begin{array}{c}2 \\
(1 ; 07-1 ; 11)\end{array}$ & - & \\
\hline $\begin{array}{c}3 \\
(2 ; 00-2 ; 06) \\
\end{array}$ & - & \\
\hline 4 & Give me tv & \\
\hline$(2 ; 07-2 ; 11)$ & - & \multirow{2}{*}{$\begin{array}{c}3 \\
(3)\end{array}$} \\
\hline 5 & - & \\
\hline$(3 ; 00-3 ; 06)$ & Give me that one & $\begin{array}{c}4 \\
(4) \\
\end{array}$ \\
\hline $\begin{array}{c}6 \\
(3 ; 07-3 ; 11)\end{array}$ & $\begin{array}{c}- \\
\text { Read me a book }\end{array}$ & $\begin{array}{c}5 \\
(5)\end{array}$ \\
\hline $\begin{array}{c}7 \\
(4 ; 00-4 ; 06) \\
\end{array}$ & $\begin{array}{c}- \\
\text { Someone gave him a key }\end{array}$ & \multirow[t]{6}{*}{$\begin{array}{c}6 \\
(>5)\end{array}$} \\
\hline $\begin{array}{c}8 \\
(4 ; 07-4 ; 11)\end{array}$ & He gave him three guesses & \\
\hline $\begin{array}{c}9 \\
(5 ; 00-5 ; 06)\end{array}$ & Give us a clue & \\
\hline $\begin{array}{c}10 \\
(5 ; 07-5 ; 11)\end{array}$ & I'm going to get you a surprise & \\
\hline $\begin{array}{c}11 \\
(6 ; 00-6 ; 06)\end{array}$ & Give me this & \\
\hline $\begin{array}{c}12 \\
(6 ; 07-6 ; 11)\end{array}$ & I only give you fifty & \\
\hline $\begin{array}{c}13 \\
(7 ; 00-7 ; 06)\end{array}$ & - & - \\
\hline
\end{tabular}

Table 8. Sample of data classification in terms of age stages and MLUw stages in Simon's longitudinal production of DOCs [the FerFuLice corpus, CHILDES]

As observed in table 8, an age-based stage classification differs from an MLUwbased one in the way data are distributed. For instance, Simon's production of DOCs at age stage $4(2 ; 07-2 ; 11)$ fluctuates between the MLUw stage 2 (MLUw 2) and the MLUw stage 3 (MLUw 3). On the basis of these ages and these MLUw differences in the distribution of the production of English and Spanish DA constructions, the child data analysis (see chapter 5) will shed light as to whether age and MLUw values are two correlated language development measures (Crain and Lillo Martín 1999; Miller and Chapman 1981), or, rather, whether age and MLUw values are not comparable measures (Brown 1973; De Villiers and De Villiers 1973; Miller 1981; Silva Corvalán and Sánchez Walker 2007).

\subsection{Data extraction and codification criteria}

The search for DA constructions combines manual extraction with the use of one of the CLAN programs, KWAL, which searches data for specified words and displays the outputs in which those keywords are used in their context. Both types of searches 
(manual and automatic) are carried out for child and for child directed-speech data transcribed in CHAT written format.

Codification criteria include the manual classification of utterances into prepositional and double object constructions in English and in Spanish. Instances that do not meet the codification criteria are also discussed.

More specific information on data extraction and on data codification appears in subsequent sections.

\subsubsection{The search for the target structures: The KWAL program and manual extraction}

The search for the target structures is performed automatically (via the KWAL program) and manually. However, manual data selection is more time-consuming, if compared to data extraction via the KWAL program, given that the search process is done via a thorough reading of the selected corpora. A description of both procedures is detailed below.

The KWAL program is used to conduct an automatic morpho-syntactic search for the contexts in which the keyword ' $^{*}$ ' (i.e. verb) is produced so that the information regarding the verbal parts of speech in the child's or in the adults' morphology dependent tier (i.e. $+\mathrm{t} \%$ mor) aids the selection of the target structures in the main line. As in (1), the verb 'give' in Adam's main line is syntactically categorized under the tag ' $\mathrm{v}$ ' in the $+\mathrm{t} \%$ mor (among other segments such as pronominal object 'pro: obj'), following the CHAT transcription format.
(1) Give it
v|give pro|it prep|to pro:obj|me
[main line]
[morphology dependent tier]
[Adam, 3;03, the Brown corpus, CHILDES]

The syntax line (or the command string) through which the program is run is provided in figure 3 as follows: (a) The name of the target program (i.e. KWAL); (b) $+\mathrm{t}^{*} \mathrm{CHI}$ analyzes the child's utterance; (c) the string $+\mathrm{s}^{\text {“ }} \mathrm{v}^{*}$ ” includes the uttermost possibilities of the morphological verbal forms produced via the asterisk wildcard character (e.g. continuous tense, past tense or the $-\mathrm{s}$ in the third person of present tense in the case of English verbal forms); (d) the $-\mathrm{w} 2$ and +w2 codes show the two utterances preceding and the two utterances following the keyword " $\mathrm{v}$ "” in the child's 
output, respectively; and (e) the '@’ code analyzes the specific file/s available in the participants' corpora selected in CHILDES.

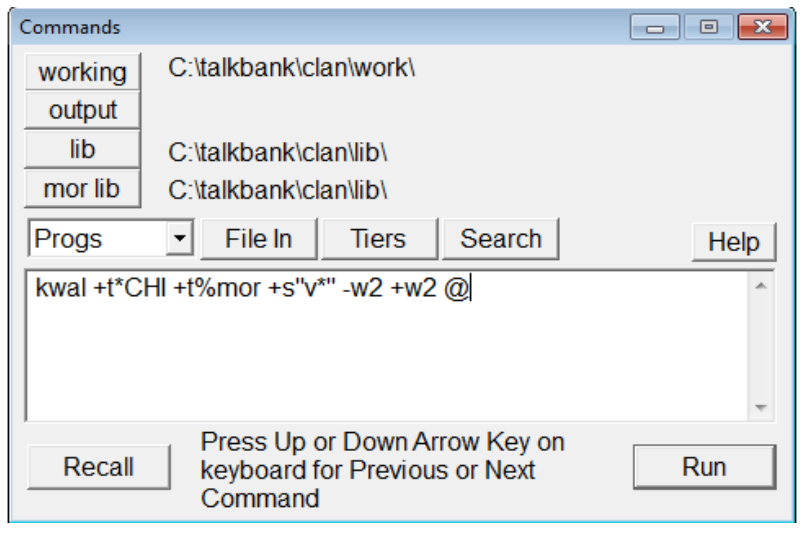

Figure 3. KWAL command string on the basis of the keyword 'verb'

Since automatic data selection via the KWAL program is narrowed on the basis of the keyword " $\mathrm{v}$ *", the selected corpora are required to display a $+\mathrm{t} \%$ mor in their CHAT transcripts. As shown in table 9, $+\mathrm{t} \%$ mor is included in 6 out of the 7 L1 English selected corpora (i.e. Brown, Cruttenden, MacWhinney, Sachs, Suppes and Wells) and 3 out of the 9 L1 Spanish selected corpora (i.e. Linaza, Marrero and Ornat). There is no available +t\%mor among the 2L1 English/Spanish selected corpora.

\begin{tabular}{cccc}
\hline Data selection procedure & L1 English corpora & L1 Spanish corpora & 2L1 English/Spanish corpora \\
\hline KWAL & Brown & Linaza & - \\
$(+\mathrm{t} \%$ mor $)$ & Cruttenden & Marrero & \\
& MacWhinney & Ornat & \\
& Sachs & & \\
& Suppes & & \\
& Wells & & \\
&
\end{tabular}

Table 9. Corpora selection procedure via the KWAL program

However, when we run the KWAL program, the output displays all the utterances that contain a verbal form without establishing a distinction in terms of their verbal subcategorization framework (e.g. DA structures, intransitives, mono-transitives, among others) or the order of their arguments (e.g. subject-verb-object (SVO), wh-movement or VS constructions). Thus, the KWAL output needs to be manually trimmed so as to only contain the structures which are the focus of our analysis.

Figure 4 and figure 5 illustrate Ross' and María's production of English and Spanish DA structures, respectively, after the non-target structures are culled out from the output window. 


\begin{tabular}{|c|c|c|c|}
\hline $\begin{array}{lll}\text { *CHI: you } & \text { will } & \text { get } \\
\text { \%mor:pro|you } & \text { mod|wil } & \text { v|get } \\
\text { [File 27b1.cha: line } & \text { 838] } & \end{array}$ & $\begin{array}{l}\text { my } \\
\text { det:poss|my }\end{array}$ & $\begin{array}{ll}\text { lion } & \text { for } \\
\text { n|lion } & \text { prep|for }\end{array}$ & $\begin{array}{l}\text { me. } \\
\text { pro:obj|me. }\end{array}$ \\
\hline $\begin{array}{l}\text { *CHI: grandpa gave } \\
\text { \%mor: grand\#n|pa v|give\&PAST } \\
\text { [File 27b1.cha: line 889] } \\
\text { @End }\end{array}$ & $\begin{array}{l}\text { me } \\
\text { pro:obj|me }\end{array}$ & $\begin{array}{l}\text { these } \\
\text { pro:dem|these }\end{array}$ & $\begin{array}{l}\text { toys. } \\
\text { n|toy-PL. }\end{array}$ \\
\hline
\end{tabular}

Figure 4. KWAL output of trimmed English dative alternation utterances [Ross, the MacWhinney corpus, CHILDES]

\begin{tabular}{|c|c|}
\hline $\begin{array}{lll}\text { *CHI: el niño } & \text { le } & \text { daba } \\
\text { \%mor: the n|niño-MASC=child } & \text { pro:ind|le=him } & \text { v|da-13S\&PAS=give } \\
\text { [File 13d.cha: line 394] } & & \end{array}$ & $\begin{array}{l}\text { caramelos. } \\
\mathrm{n} \mid \text { caramelo\&PL=caramel. }\end{array}$ \\
\hline 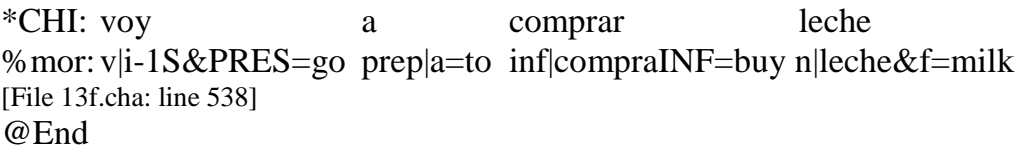 & $\begin{array}{l}\text { para } \\
\text { prep|para=for pro:prep|ti=you. }\end{array}$ \\
\hline
\end{tabular}

Figure 5. KWAL output of trimmed Spanish dative alternation utterances [María, the Ornat corpus, CHILDES]

The data selection in the corpora that do not exhibit a $+\mathrm{t} \%$ mor in their transcript data is executed manually. As depicted in table 10, they involve the Lara corpus (among the L1 English selected corpora), the LlinasOjea corpus, the Montes corpus, the Nieva corpus, the OreaPine corpus and the Vila corpus (among the L1 Spanish selected corpora), as well as all the 2L1 English/Spanish selected corpora (i.e. Deuchar, FerFuLice, Perez and Ticio).

\begin{tabular}{cccc}
\hline Data selection procedure & L1 English corpora & L1 Spanish corpora & 2L1 English/Spanish corpora \\
\hline Manual selection & Lara & LlinasOjea & Deuchar \\
& Montes & FerFuLice \\
& Nieva & Perez \\
& OreaPine & Ticio \\
& Vila & \\
\hline
\end{tabular}

Table 10. Manual corpora selection procedure

Four types of selection criteria have been followed both in the automatic and in the manual searches for the target structures, namely, utterances whose verbal head subcategorizes for (a) a DO and an IO headed by the prepositions 'to' in English and ' $a$ ' in Spanish, as in (2a) and (2b), respectively; (b) a DO, as well as an A headed by the prepositions 'for' in English and 'para' in Spanish, as in (3a) and (3b), respectively; (c) a DO and a preposition-less IO, or a DO and a preposition-less A in English, as in (4a) and (4b), respectively; and (d) a DO and an IO headed by the preposition ' $a$ ', that doubles a pre-verbal dative clitic ' $l e(s)$ ' in Spanish, as in (5); that is, both the prepositional complement and the dative clitic share the same Case, gender, number, 
person and theta role, conforming to the Matching Hypothesis (Suñer 1988), as discussed in section 1.1 (chapter 1 ).

(2) a. Ruth gave one to me

[Gerald, 2;11, the Wells corpus, CHILDES]
b. (Blancanieves) daba '(Snow White) give.3p.sg.past kisses
besos a su mamá
to her mum

[Irene, 2;07, the LinasOjea corpus, CHILDES]

(3) a. The man gave it for me

[Nina, 2;05, the Suppes corpus, CHILDES]
b. Quiero una escoba para el otro muñeco de nieve want.1p.sg.pres. a broom for the other toy of snow 'I want to use a broom for the other snowman'

[Juan, 2;05, the OreaPine corpus, CHILDES]

(4) a. Give her a bottle of ginger ale

[Nina, 2;05, the Suppes corpus, CHILDES]

b. I'll bring you one

[Benjamin, 2;09, the Wells corpus, CHILDES]
(5) Le voy a hacer un regalo a Mónica
him.dat.cl. go.1p.sg.pres. to make.inf. a gift to Mónica
'I am going to give Mónica a gift'

[Juan, 2;04, the OreaPine corpus, CHILDES]

The target utterances extracted by means of either process (i.e. manually and automatically) have been stored in an Excel database to be codified as English or as Spanish DA structures, as will be discussed in the following section.

\subsubsection{Codification criteria of dative alternation structures}

Once DA utterances are extracted (see section 4.3.1), they are classified in terms of language (i.e. English and Spanish) and type of structure (i.e. to/for-datives and DOCs in English; a/para-datives and DCLDs in Spanish). With regards to the latter, declarative (affirmative and negative) and imperative DA constructions are considered 
for codification. However, interrogative DA structures have been excluded from the data analysis (see section 4.3.2.3) given that wh-movement interferes with the word order issues at stake in DA (see section 1.3, chapter 1 ).

The codification of the two English and Spanish DA structures in the production of L1 and 2L1 children as well as in the adult input has been annotated in an Excel spreadsheet.

\subsubsection{English to/for-datives and DOCs}

Verbal heads that subcategorize for a DO and either an IO headed by the preposition 'to' or an A headed by the preposition 'for' are classified as to/for-datives. As in (6a), the verb 'give' selects a DO-DP 'that one' and an IO-PP 'to me'. An analogous pattern is observed in (6b), where the verb 'make' subcategorizes for a DODP 'some presents' as well as an A-PP 'for mom and dad'.

(6) a. You give that one to me

[to-dative]

[Jane, 2;09, the Cruttenden corpus, CHILDES]

b. We made some presents for mom and dad [for-dative]

[Ross, 5;11, the MacWhinney corpus, CHILDES]

When a DA verb also subcategorizes for a DO followed by a preposition-less IO or by a preposition-less A, these structures are codified as DOCs. To present an example, the verb 'show' in (7a) selects an IO-DP 'me' and a DO-C(complementizer) $\mathrm{P}$ (hrase) 'what the directions are', while the verb 'buy' in (7b) selects a DO-DP 'a motor bike' followed by an A-DP 'me'.

(7) a. Show me what the directions are

[Adam, 4;10, the MacWhinney corpus, CHILDES]

b. You buy me a motorbike
[DOC]

[DOC]

[Jane, 3;06, the Cruttenden corpus, CHILDES]

English DA constructions are codified regardless of the form of the internal arguments or of the adjuncts. These forms include (a) pronouns such as the 
prepositional complements 'me' and 'you' of the verbs 'give' and 'hold' in (6a) and in (6b), respectively; (b) CPs such as the DO 'what the directions are' in (7a); or (c) DPs such as the DO 'a motorbike' in (7b).

\subsubsection{Spanish a/para-datives and DCLDs}

Spanish DA constructions whose verbal head subcategorizes for a DO and either an IO headed by the preposition ' $a$ ' or an A headed by the preposition 'para' are classified as $a$-datives and as para-datives, respectively. Moreover, when a Spanish DA verb selects a DO and an IO headed by the preposition ' $a$ ', that, in turn, doubles a preverbal dative clitic 'le(s)', these structures are tagged as DCLDs. As pointed out by Demonte (1995: 6; see footnote 3 in chapter 1), dative clitics in the third person (singular or plural) are the forms that allow the DA of DCLDs (when the dative clitic is overtly realized) and a/para-datives (when the dative clitic is not present). The codification of a/para-datives and DCLDs is accomplished regardless of the order and the form (i.e. DP and CP) of the internal arguments and adjuncts. Instances of each type of construction are provided below.

As far as $a$-datives are concerned, the verb 'dice' ('she says') in (8a) subcategorizes for the DO-DP 'hola' ('hello') and the IO-PP 'a los árboles' ('to the trees'), while the periphrastic verb 'tenemos que decir' ('we have to tell') in (8b) shows a non-canonical order of the internal arguments, and therefore, the IO-PP 'a la Aito' ('to the Aito') is followed by the DO-CP 'que haga cosas' ('that she should do things').

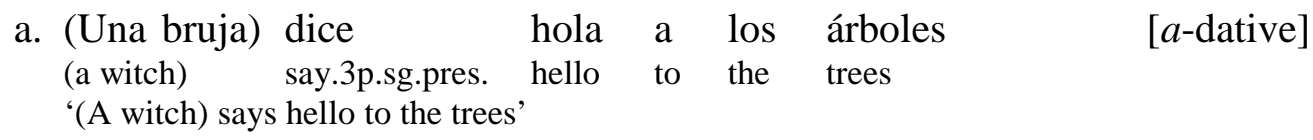

[Juan, 2;03, the OreaPine corpus, CHILDES]

$$
\begin{aligned}
& \text { b. Tenemos que decir a la Aito que haga } \\
& \text { have.1p.pl.pres. that say.inf. to the Aito that do.3p.sg.subj. } \\
& \text { 'We have to tell Aito that she should do things' }
\end{aligned}
$$

[Father, the Ornat corpus, CHILDES]

In the case of para-datives, as in (9), the verb 'cocinar' ('to cook') subcategorizes for the DO-DP 'papilla' ('baby food') as well as the A-PP ‘para Simon' ('for Simon’). Although the order of these two constituents is not a matter of concern for the classification of para-datives, structures with a reversed constituent order do not appear in the data. 
Chapter 4 Methodology 
(9) Tú sabes $\quad \begin{gathered}\text { cocinar } \\ \text { you know.2p.sg.pres. cook.inf. baby food }\end{gathered}$ for
'You know how to cook baby food for Simon'

[Leo, 2;08, the FerFuLice corpus, CHILDES]

As will be discussed in chapter 5, a-datives and para-datives are collapsed in the data analysis under the tag a/para-datives.

Examples of DCLDs are shown in (10). In (10a), the verb 'da' ('he gives') selects the DO-DP 'miedo' ('fear') and the IO-PP 'a la persona' ('to the person'); in turn, the dative clitic ' $l e$ ' shares gender features (feminine), number features (singular), Case (dative) and theta role (recipient) with the prepositional complement 'la persona'. By contrast, the DCLD in (10b) reverses the structural order of the internal arguments, and so, the periphrastic verb 'voy a enseñar' ('I am going to teach') subcategorizes for the IO-PP 'a papá' ('to daddy’) and the DO-CP ‘cómo se va’ ('how we can go’).

a. Le miedo a la persona
[DCLD]
him.dat.cl. give.3p.sg.past fear
'He is afraid of the person'

[Idaira, 4;07, the Marrero corpus, CHILDES]

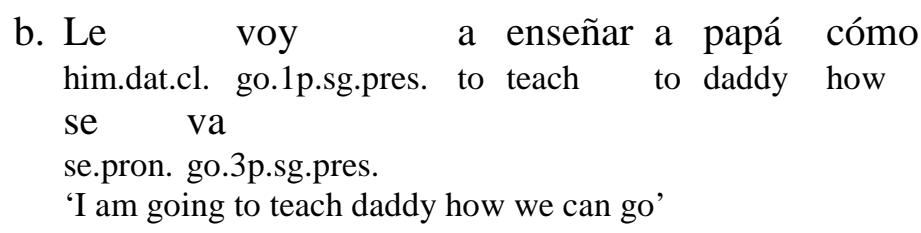

[DCLD]

[María, 2;08, the Ornat corpus, CHILDES]

Other structures have also been classified as DCLDs. The first of these involves cases when the DO and the dative clitic are both pronominalized in accusative and in dative Case, respectively, and the latter takes a 'se' form, as in (11). The second affects cases in which the IO-PP is null (e), as in (12), due to its optional realization.
(11) Se lo voy a decir
[DCLD] se.dat.cl. it.acc.cl. go.1p.sg.pres. to tell 'I am going to tell him it' 

(12) No le
'I do not leave him the pieces (to him)'

\section{(e) [DCLD]}

[Juan, 2;05, the OreaPine corpus, CHILDES]

Taking into account the codification criteria of DA constructions in English (section 4.3.2.1) and in Spanish (section 4.3.2.2), the following section discusses those structures that are excluded from the data classification as well as from the data analysis.

\subsubsection{Discarded structures}

In our data classification procedure, we have discarded a series of constructions that do not meet the extraction criteria (section 4.3.1) and the codification criteria (4.3.2.1 for English and 4.3.2.2 for Spanish). This is done in English and in Spanish data alike.

Idiomatic DA structures of the type in (13), 'le hizo caso' ('(the brush) paid attention (to him)'), are not considered in the present study since they do not evidence a creative and a productive use of the language. Most of these structures have been found in the L1 Spanish and in the 2L1 Spanish children's data.

(13) La escoba le $\quad$ hizo caso (e) [idiomatic DA structure]
the brush him.dat.cl. make.3p.sg.past case
'The brush paid attention (to him)'

[Toya (investigator), the Marrero corpus, CHILDES]

Wh-interrogative DA constructions are also excluded given that wh-movement of one of their internal arguments or adjuncts may interfere with the main issue under investigation, that is, whether the derived structure undergoes DA. This is seen in the English DOC in (14) and in the Spanish DCLD in (15) where the DO-DPs 'what' and 'qué' ('what'), respectively, undergo wh-movement, leaving a trace $\left(t_{i}\right)$ in their corresponding original DO positions.

(14) What $\mathrm{i}_{\mathrm{i}}$ are you giving me $t_{\mathrm{i}}$ ?

[wh-interrogative DOC]

[Jack, 3;03, the Wells corpus, CHILDES] 
(15) ¿Qué ${ }_{i}$ le $\quad$ está
what him.dat.cl. be.3p.sg.pres. doing
'What is s/he doing (to him/her)?'

[Simon, 4;09, the FerFuLice corpus, CHILDES]

DO-DPs embedded in that-relative DA clauses or fronted in declarative DA constructions are also discarded. A few instances are observed in English DOCs and in Spanish DCLDs. In the English DOC (16a), the DO-DP of the verb 'gave' is embedded in the null complementizer 'that' and, in the case of the Spanish DCLD (16b), the DODP 'el cumpleaños' ('the birthday') occupies a fronted position so as to meet discourse emphatic conditions.

(16) a. That's the name $(e)_{\text {that }}$ we gave Max

[DOC, relative DA clause]

[Melanie, mother, the FerFuLice corpus, CHILDES]
b. Cumpleaños feliz le vas a decir a Mónica
birthday happy him.dat.cl. go.2p.sg.pres. to say.inf. to Mónica
'Happy birthday, you are going to tell Mónica' [DCLD, fronted Od-DP]

[Father, the OreaPine corpus, CHILDES]

Null verbs, null internal arguments and null adjuncts in structures that, most likely, would otherwise undergo DA have been removed from the analysis as it is not possible to determine whether DA has applied or not. This is illustrated in (17) for an English for-dative with a null verb, in (18) for an English to-dative with a null DO-DP and in (19) for an ambiguous DA structure that could be interpreted as an English DOC with a null DO-DP (19a) or as an English to-dative with a null DO-DP as well as with a null preposition 'to' (19b). Discarded instances of the type (17) to (19) have not been observed in the L1 Spanish or in the 2L1 Spanish children's data.

(17) (e) A pink one for Jenny

(18) He gives $(e)_{\mathrm{DO}}$ to me [for-dative; null DA verb]

[Jane, 2;01, the Cruttenden corpus, CHILDES]

[to-dative; null DO]

[Simon, 3;10, the FerFuLice corpus, CHILDES] 
(19) a. Show granny $(e)_{\mathrm{DO}}$

b. Show $(e)_{\mathrm{DO}}(e)_{\mathrm{P}}$ granny
[DOC; null DO]

[to-dative; null DO and null 'to']

[Manuela, 2;05, the Deuchar corpus, CHILDES]

Locative mono-transitive structures of the type in (20a) and (20b) have been discarded since the verbal heads 'drive' and 'llevar' ('to carry') subcategorize for a DODP, ‘you' and 'leña' ('wood'), respectively, as well as an A-PP with a locative meaning, 'to the doctors' in English and 'a mi casa' ('to my house') in Spanish.

(20) a. Shall I drive you to the doctors?

b. A llevar leña a mi casa to carry.inf. wood to my house 'Let's carry wood to my house' [locative mono-transitive]

[Lara, 3;00, the Lara corpus, CHILDES]

[locative mono-transitive]

[Raquel, the FerFuLice corpus, CHILDES]

Thus, while the PP in locative mono-transitive structures functions as an A, the PP in prepositional to-datives in English and in prepositional $a$-datives in Spanish functions as an IO.

English for-datives and Spanish para-datives are not considered for analysis when denoting the following: (a) Exchange (i.e. when the preposition is replaceable as 'in exchange for'), as in (21); (b) reason, as in (22); or (c) time, as in (23). This is so since a beneficiary theta role is required to be assigned to the prepositional complement of for/para-datives in prepositional DA constructions.

(21) a. Change it for a dime

\section{[exchange for-dative]}

[Adam, 4;09, the Brown corpus, CHILDES]

b. Cambio ésta por ésta change.1p.sg.pres. this for this 'I exchange this one for this one'

(22) Don’t spank me for this

(23) I got the one for Christmas
[Leo, 5;07, the FerFuLice corpus, CHILDES]

[exchange para-dative]

[reason adverb phrase]

[Ross, 5;03, the MacWhinney corpus, CHILDES]

[time adverb phrase] 
Moreover, English structures which cannot undergo DA, also known as nondativizables, are excluded. Indeed, these constructions are argued to be lexicosyntactically restricted to Latin verbs (Green 1974; Larson 1990; Mazurkewich and White 1984; Oehrle 1976). Examples in (24) illustrate a non-dativizable DOC (24a), a non-dativizable to-dative (24b) and a non-dativizable for-dative (24c).

(24) a. You called them hot plates

b. I can say buster to you

c. We won't need it for his legs [non-dativizable DOC]

[Ross, 6;07, the MacWhinney corpus, CHILDES]

[non-dativizable to-dative]

[Ross, 5;11 the MacWhinney corpus, CHILDES]

[non-dativizable for-dative]

[Ross, 7;00 the MacWhinney corpus, CHILDES]

Non-dativizables of the type in (24) do not occur in Spanish; and in fact, these structures have not been produced by the L1 Spanish and the 2L1 Spanish children. This is so given that, following Demonte's (1995) proposal, Spanish DA always takes place when a dative clitic in the third person is doubled by a prepositional complement headed by ' $a$ ' ('to') in DCLDs and when a dative clitic is not present in a/para-datives.

All in all, the target structures of the present study include English and Spanish prepositional and double object (declarative and imperative) constructions that undergo DA and that conform to the UTAH conditions by preserving the thematic roles in both types of DA structures. In the case of prepositional DA structures, the internal arguments of English to-datives and Spanish a-datives consist of a DO-theme and an IO (i.e. a prepositional complement-recipient headed by the prepositions 'to' in English and ' $a$ ' in Spanish). The verbal head in English for-datives and in Spanish para-datives selects a DO-theme as well as an A (i.e. a prepositional complement-beneficiary headed by the prepositions 'for' in English and 'para' in Spanish). With regards to double object constructions, the verbal head in English DOCs may subcategorize for a DOtheme followed by a preposition-less IO-recipient if they alternate as to-datives or by a preposition-less A-beneficiary if they alternate as for-datives. The internal arguments of Spanish DCLDs involve a DO-theme and an IO (i.e. a prepositional complement- 
recipient, headed by the preposition ' $a$ ', which shares number, gender, person, Case and theta role with a pre-verbal dative clitic ' $l e(s)$ ').

\subsection{Frequency distribution of English and Spanish structures}

Taking as a point of departure the classification criteria of the DA constructions in English (see section 4.3.2.1) and in Spanish (see section 4.3.2.2) as well as the exclusion criteria of the non-target structures (see section 4.3.2.3), an overview of the data extracted is provided in table 11.

\begin{tabular}{ccccc}
\hline Language group & \# Utterances & \# DA structures & $\begin{array}{c}\text { \# Discarded } \\
\text { structures }\end{array}$ & $\begin{array}{c}\text { Total } \\
\text { structures }\end{array}$ \\
\hline L1 English & $239,545(100 \%)$ & $1,014(0.42 \%)$ & $454(0.19 \%)$ & $\mathbf{1 , 4 6 8 ( 0 . 6 1 \% )}$ \\
\hline L1 Spanish & $88,157(100 \%)$ & $827(0.94 \%)$ & $30(0.03 \%)$ & $\mathbf{8 5 7 ( 0 . 9 7 \% )}$ \\
\hline $\begin{array}{c}\text { 2L1 English/Spanish } \\
\text { (English data) }\end{array}$ & $29,897(100 \%)$ & $169(0.56 \%)$ & $35(0.12 \%)$ & $\mathbf{2 0 4 ( 0 . 6 8 \% )}$ \\
\hline $\begin{array}{c}\text { 2L1 English/Spanish } \\
\text { (Spanish data) }\end{array}$ & $26,213(100 \%)$ & $258(0.98 \%)$ & $12(0.04 \%)$ & $\mathbf{2 7 0 ( 1 . 0 2 \% )}$ \\
\hline
\end{tabular}

Table 11. Frequency distribution of English and Spanish structures in the production of monolingual and bilingual children (\# of cases (\%))

As displayed in table 11, both DA and discarded structures represent a low rate of production if compared to the overall utterances produced by the children, and this is so in the three language groups (i.e. L1 English, L1 Spanish and 2L1 English/Spanish) ${ }^{14}$ Having a closer look at each language group, the production of the L1 English children reveals a higher frequency rate in the use of the two types of DA structures (i.e. prepositional and double object), followed by that of the L1 Spanish and the 2L1 English/Spanish children’s, accordingly.

As will be discussed in chapter 5, the present dissertation focuses on the analysis of English and Spanish DA constructions, as observed in the L1 and in the 2L1 children's output and input. Thus, the production of the two DA constructions will be

\footnotetext{
14 The total number of verbal and non-verbal utterances, as in (a) and in (b), respectively, is computed via the MLU program. Although only verbal utterances would have been a better index here, this could not be done given the lack of a $+\mathrm{t} \%$ mor line in some of the selected corpora (see table 6 ). That is, the calculation of verbal utterances needs to be conducted by using the FREQ program to extract the number of verbs used as codified in the $+\mathrm{t} \%$ mor line.
}
(a) Is it hot?
[verbal utterance]
(b) Yeah
[non-verbal utterance]
[Simon, 5;02, the FerFuLice corpus, CHILDES] 
computed out of the overall DA utterances (i.e. 100\%), rather than out of the overall utterances, as shown in table 11.

\subsection{Statistical methods for data analyses}

A series of parametric and non-parametric statistical tests have been run for the data analyses via the Software Package for the Social Sciences (SPSS). When data are normally distributed, and homogeneity of variance is assumed, parametric tests have been implemented. By contrast, when the data are asymmetrically distributed or skewed, alternative non-parametric tests have been run, allowing the data (including outliers and extreme values) to be ranked instead of being compared. A closer look at the implementation of each statistical test is provided below.

In order to examine whether the ages of onset and the use of the two English and Spanish DA structures (as measured in age and in MLUw values) show significant differences through language development in the L1 children's data and in the 2L1 children's data, two statistical tests have been used: The parametric two-tailed pairedsample $t$-test and its non-parametric counterpart the two-tailed Wilcoxon signed rank test. The implementation of a two-tailed statistical test for the analysis of the ages of onset and the developmental use of DA structures involves a cause-and-effect relationship that is examined either way, that is, from to/for-datives to DOCs, and vice versa, in English and from a/para-datives to DCLDs, and vice versa, in Spanish. While each language group (i.e. L1 English, L1 Spanish and 2L1 English/Spanish) has been considered as the independent variable, the ages of onset and the use of the two target English and Spanish DA constructions (i.e. double object and prepositional) are the dependent variables when running both parametric and non-parametric statistical tests per language group.

In line with the previous data analyses, we also investigate whether biological gender differences appear in the emergence and in the incidence of English and Spanish DA constructions through language development, as seen in the L1 children's data and in the 2L1 children's data. The two-tailed (non-)parametric tests discussed earlier (i.e. the paired-sample $t$-test and the Wilcoxon signed rank test) have been run for each biological gender group and for each of the variables under analysis, and the results obtained have been compared between the girls and the boys. 
If significant differences are found in the L1 and in the 2L1 children's ages of onset and incidence of English and Spanish DA structures such that one of the two DA structures begins to be produced significantly earlier or later, and possibly shows a significantly higher or lower incidence, respectively, when compared to their DA counterpart, double object and prepositional DA structures could be argued to derive from one another. On the contrary, if significant differences are not observed in the two variables discussed above (i.e. ages of onset and incidence through the language development), a syntactic non-derivational relationship is suggested between the two DA constructions in English and in Spanish.

In contrast to the analyses run for each language group discussed earlier, further (non-)parametric statistical tests have been used to carry out comparative analyses among the three language groups. To be more precise, when comparisons are established between (a) the L1 English children's data and the 2L1 English children's data; (b) the L1 Spanish children's data and the 2L1 Spanish children's data; and (c) the L1 English children's data and the L1 Spanish children's data, the parametric independent samples $t$-test and its non-parametric counterpart the Mann-Whitney U test have been used depending on whether data are or are not assumed to be normally distributed, respectively. These two statistical tests have determined whether two independent categorical language groups, as indicated in the pairwise comparisons in (a)-(c), differ in the ages of onset (dependent variable 1) and in the incidence through language development (dependent variable 2) in the case of double object constructions, on the one hand, and of prepositional DA structures, on the other hand. In addition, when comparisons are established between the 2L1 English/Spanish children's two languages, the parametric two-tailed paired sample $t$-test and its non-parametric counterpart the Wilcoxon signed ranked test have been run to determine whether there are any statistically significant differences in the emergence and in the use of each DA structure through language development across English and Spanish.

Considering the criteria established for data selection, data extraction and data codification as well as the developmental and the statistical methods for data analyses that have been implemented, the following chapter will discuss the results obtained in the present study. 


\section{CHAPTER 5}

\section{THE PRODUCTION OF ENGLISH AND SPANISH DATIVE}

\section{ALTERNATION STRUCTURES IN MONOLINGUAL AND IN BILINGUAL CHILDREN}

Chapter 5 presents a comprehensive analysis of the data examined in the present study. An overview of the production of English and Spanish DA structures is provided in table 1 for the L1 English, the L1 Spanish and the 2L1 English/Spanish children as well as for the adults they interact with. The production of prepositional DA structures (i.e. English to/for-datives and Spanish a/para-datives) and double object constructions (i.e. English DOCs and Spanish DCLDs) is analyzed by taking into consideration the overall DA utterances (100\%).

\begin{tabular}{|c|c|c|c|c|}
\hline & & Double object & Prepositional & Total \\
\hline \multirow[t]{2}{*}{ L1 English } & children & $752(74.2)$ & $262(25.8)$ & $1,014(100)$ \\
\hline & adults & $1,853(73.9)$ & $655(26.1)$ & $2,508(100)$ \\
\hline \multirow[t]{2}{*}{ L1 Spanish } & children & 775 (93.7) & $52(6.3)$ & $827(100)$ \\
\hline & adults & $4,279(92.4)$ & $352(7.6)$ & $4,631(100)$ \\
\hline 2L1 & children & $136(80.5)$ & 33 (19.5) & $169(100)$ \\
\hline $\begin{array}{l}\text { English/Spanish } \\
\text { (English data) }\end{array}$ & adults & $1,528(71.6)$ & $605(28.4)$ & $2,133(100)$ \\
\hline 2L1 & children & $235(91.1)$ & $23(8.9)$ & $258(100)$ \\
\hline $\begin{array}{c}\text { English/Spanish } \\
\text { (Spanish data) }\end{array}$ & adults & $2,716(91.5)$ & 251 (8.5) & 2,967 (100) \\
\hline \multicolumn{2}{|c|}{ Total (children) } & $1,898(83.7)$ & 370 (16.3) & $2,268(100)$ \\
\hline \multicolumn{2}{|c|}{ Total (adults) } & 10,376 (84.8) & $1,863(15.2)$ & $12,239(100)$ \\
\hline
\end{tabular}

Table 1. English and Spanish dative alternation structures in child and in adult monolingual and bilingual speech (\# of cases (\%))

As shown in the last two rows of table 1, the children and the adults show higher frequency rates in the production of double object constructions when compared to prepositional DA structures. This is seen in the L1 English and in the L1 Spanish children's output and adult input as well as in the input and in the output that the 2L1 English/Spanish children receive in the two languages.

English and Spanish DA structures are also examined from a biological gender approach in the production of the L1 English, the L1 Spanish and the 2L1 English/Spanish children. Table 2 displays the overall incidence of prepositional and double object constructions in the girls' and in the boys' data as well as in the adult input. 


\begin{tabular}{|c|c|c|c|c|c|}
\hline & & & Double object & Prepositional & Total \\
\hline \multirow[t]{4}{*}{ L1 English } & \multirow[t]{2}{*}{ girls } & output & $498(71.4)$ & $200(28.6)$ & $698(100)$ \\
\hline & & adult input & $1,253(72.5)$ & $474(27.5)$ & $1,727(100)$ \\
\hline & \multirow[t]{2}{*}{ boys } & output & 250 (79.1) & $66(20.9)$ & $316(100)$ \\
\hline & & adult input & $600(76.8)$ & $181(23.2)$ & $781(100)$ \\
\hline \multirow[t]{4}{*}{ L1 Spanish } & \multirow[t]{2}{*}{ girls } & output & $483(94.5)$ & $28(5.5)$ & $511(100)$ \\
\hline & & adult input & $2,670(92.5)$ & $217(7.5)$ & $2,887(100)$ \\
\hline & \multirow[t]{2}{*}{ boys } & output & $292(92.4)$ & $24(7.6)$ & $316(100)$ \\
\hline & & adult input & 1,609 (92.3) & $135(7.7)$ & $1,744(100)$ \\
\hline \multirow{4}{*}{$\begin{array}{c}\text { 2L1 } \\
\text { English/Spanish } \\
\text { (English data) }\end{array}$} & \multirow[t]{2}{*}{ girls } & output & - & $1(100)$ & $1(100)$ \\
\hline & & adult input & $26(66.7)$ & $13(33.3)$ & $39(100)$ \\
\hline & \multirow[t]{2}{*}{ boys } & output & $136(80.9)$ & 32 (19.1) & $168(100)$ \\
\hline & & adult input & $1,502(71.7)$ & 592 (28.3) & $2,094(100)$ \\
\hline \multirow{4}{*}{$\begin{array}{c}\text { 2L1 } \\
\text { English/Spanish } \\
\text { (Spanish data) }\end{array}$} & \multirow[t]{2}{*}{ girls } & output & $13(68.4)$ & $6(31.6)$ & $19(100)$ \\
\hline & & adult input & $54(90.0)$ & $6(10.0)$ & $60(100)$ \\
\hline & \multirow[t]{2}{*}{ boys } & output & 222 (92.9) & $17(7.1)$ & $239(100)$ \\
\hline & & adult input & 2,662 (91.6) & $245(8.4)$ & $2,907(100)$ \\
\hline \multicolumn{3}{|c|}{ Total (girls) } & $994(80.9)$ & 235 (19.1) & $1,229(100)$ \\
\hline \multicolumn{3}{|c|}{ Total (boys) } & $900(86.6)$ & 139 (13.4) & $1,039(100)$ \\
\hline \multicolumn{3}{|c|}{ Total (adult input-girls) } & $4,003(84.9)$ & $710(15.1)$ & $4,713(100)$ \\
\hline \multicolumn{3}{|c|}{ Total (adult input-boys) } & $6,373(84.7)$ & $1,153(15.3)$ & $7,526(100)$ \\
\hline
\end{tabular}

Table 2. English and Spanish dative alternation structures in girls' and in boys' monolingual and bilingual speech and in adult input (\# of cases (\%))

As seen in table 2, biological gender differences do not appear in the higher rate of use of double object constructions if compared to prepositional DA structures in the data from the L1 English children, the L1 Spanish children, the 2L1 English/Spanish boys and in their corresponding adult input. Although the 2L1 English/Spanish girls’ production patterns of the two Spanish DA structures are akin to the three groups discussed earlier, we cannot carry out a comparison between prepositional and double object constructions in the English data as only one 2L1 English/Spanish girl produces one to/for-dative and the other two 2L1 English/Spanish girls do not produce DOCs or to/for-datives.

Although girls and boys prefer the use of double object over prepositional constructions, as reflected in the L1 English and in the L1 Spanish children's data alike, girls show a higher overall rate in the use of the two types of DA constructions. Similar findings are reflected in the adult input each biological gender group receives. That is, the same pattern is found across the two groups, but a difference is found in the amount of structures produced, girls being more productive than boys. A reversed pattern is observed in the 2L1 English/Spanish children's data since the production of the two English and Spanish DA structures shows higher rates in the 2L1 English/Spanish boys’ 
data when compared to the 2L1 English/Spanish girls' data, as also reflected in their corresponding adult input frequency rates.

The present chapter is divided into three main sections. Section 5.1 is concerned with the production of English DA structures (i.e. DOCs and to/for-datives) in L1 and in 2L1 children's data. Section 5.2 deals with the production of Spanish DA structures (i.e. DCLDs and a/para-datives) in the data from L1 and from 2L1 children. Section 5.3 offers a cross-linguistic comparison between the two languages, and thus, deals with the production of English and Spanish DA constructions in L1 children's data (inter-group comparison, see section 5.3.1) and in 2L1 children's data (intra-group comparison) when compared to their respective L1 peers (see section 5.3.2). The main findings of the data analysis are summarized at the end of each section.

Three variables are considered for the analysis of English and Spanish DA structures in the production of L1 and 2L1 children (girls and boys): Age of onset, incidence through language development (as seen in different age stages and in different MLUw stages) and the role played by adult input in child output.

\subsection{Dative alternation in monolingual and bilingual English}

\subsubsection{The age of onset}

The L1 English children show an order in the onset of DA structures, namely, DOCs begin to be produced earlier (mean age: 2;02) than to/for-datives (mean age: $2 ; 06)$, as shown in the last row of table 3. However, these differences are not statistically significant $(t(11)=-2.079, p=.067)$. Such an order of emergence is also seen in the 2L1 English children's data given that the onset of DOCs also precedes (mean age: 2;04) that of to/for-datives (mean age: 2;08) and non-significant differences are observed in the emergence of the two English DA structures $(t(4)=-1.858, p=.160)$. 


\begin{tabular}{|c|c|c|c|c|c|}
\hline \multicolumn{3}{|c|}{ L1 English children } & \multicolumn{3}{|c|}{ 2L1 English children } \\
\hline Children & DOCs & to/for-datives & Children & DOCs & to/for-datives \\
\hline Ross & $1 ; 04$ & $2 ; 06$ & Simon & $2 ; 03$ & $3 ; 01$ \\
\hline Eve & $1 ; 08$ & $1 ; 11$ & John & $2 ; 04$ & $2 ; 11$ \\
\hline Jane & $1 ; 11$ & $2 ; 06$ & Leo & $2 ; 05$ & $3 ; 02$ \\
\hline Naomi & $2 ; 01$ & $2 ; 11$ & Manuela & - & $2 ; 01$ \\
\hline Adam & $2 ; 04$ & $2 ; 11$ & Alberto & - & $2 ; 02$ \\
\hline Mark & $2 ; 06$ & $2 ; 09$ & Antonio & - & $2 ; 11$ \\
\hline Sarah & $2 ; 09$ & $3 ; 02$ & Sheila & - & - \\
\hline Nina & $2 ; 01$ & $2 ; 01$ & Carla & - & - \\
\hline Lara & $2 ; 06$ & $2 ; 04$ & Diego & - & - \\
\hline Lucy & $2 ; 07$ & $2 ; 00$ & & & \\
\hline Gerald & - & $2 ; 11$ & & & \\
\hline Jack & $2 ; 02$ & - & & & \\
\hline Benjamin & $2 ; 03$ & - & & & \\
\hline Mean & $2 ; 02$ & $2 ; 06$ & Mean & $2 ; 04$ & $2 ; 08$ \\
\hline
\end{tabular}

Table 3. Age of onset of English dative alternation structures in monolingual and in bilingual child speech $^{15}$

Furthermore, DOCs $(U=14.000, p=.562)$ and to/for-datives $(U=23.000, p=.308)$ start being produced at a similar age of onset when comparing the 2L1 English children' data to the L1 English children's data.

As for the age range of first occurrence, the L1 English children's onset of DA structures ranges from $1 ; 04$ to $2 ; 09$ in DOCs and from $1 ; 11$ to $3 ; 02$ in to/for-datives, while the 2L1 English children's production of DA constructions emerges between 2;03 and 2;05 in DOCs and between 2;01 and 3;02 in to/for-datives.

As shown in table 3 and as reflected in the order in which the participants appear in the table, 7 out of the 13 L1 English children begin to produce DOCs earlier than to/for-datives, in contrast with 2 L1 English children who start producing to/for-datives before DOCs. Furthermore, 1 L1 English child produces DOCs and to/for-datives concurrently and 3 L1 English children produce only one of the two types of DA structures, namely, while Benjamin and Jack produce DOCs, Gerald produces to/fordatives. With regards to the 2L1 English children's data, 3 out of the 9 children show an

\footnotetext{
${ }^{15}$ The overall mean age of onset of each DA structure has been calculated by converting the years and the months observed in the emergence of each child's target structure into a unified measure, that is, months (e.g. Jane starts producing DOCs at 1;11, which equals to 23 months). In this respect, all the children's onset of DOCs, on the one hand, and to/for-datives, on the other hand, has been added up to calculate the overall mean age of emergence (in months) and the sum has been divided into the total number of children. The added result has been later converted into years and months. When the L1 English and the 2L1 English children have not produced DA structures, these participants have not been considered in the calculation of the overall mean age of onset. This is applied to all the participants of the present study, that is, the L1 English children, the L1 Spanish children and the 2L1 English/Spanish children.
} 
earlier emergence of DOCs if compared to to/for-datives, and 3 of them only produce to/for-datives. Moreover, other 3 2L1 English/Spanish children do not produce the target structures.

The pattern observed in the data collapsed for the L1 English children's emergence of DA structures is also seen when analyzed per biological gender. As shown in the means of onset in table 4, the L1 English girls (i.e. DOCs (mean age: 2;01) $>$ to/for-datives (mean age: 2;05)) pattern closer to the L1 English boys (i.e. DOCs (mean age: 2;03) > to/for-datives (mean age: 2;10)) in that both groups start producing DOCs earlier than to/for-datives. Nevertheless, due to the lack of substantial data available in the 2L1 English girl's production of the two English DA structures (i.e. Manuela only produces to/for-datives at 2;01), results cannot be firmly compared to the ones observed in the 2L1 English boys' data. That is, the 2L1 English boys show an order in the emergence of DA structures (i.e. DOCs (mean age: 2;04) > to/for-datives (mean age: 2;10)), akin to that of their L1 peers.

\begin{tabular}{|c|c|c|c|c|c|c|}
\hline \multirow{2}{*}{$\begin{array}{c}\text { Biological } \\
\text { gender }\end{array}$} & \multicolumn{3}{|c|}{ L1 English children } & \multicolumn{3}{|c|}{ 2L1 English children } \\
\hline & Children & DOCs & to/for-datives & Children & DOCs & to/for-datives \\
\hline \multirow{8}{*}{ Girls } & Ross & $1 ; 04$ & $2 ; 06$ & Manuela & - & $2 ; 01$ \\
\hline & Eve & $1 ; 08$ & $1 ; 11$ & Carla & - & - \\
\hline & Jane & $1 ; 11$ & $2 ; 06$ & Sheila & - & - \\
\hline & Naomi & $2 ; 01$ & $2 ; 11$ & & & \\
\hline & Sarah & $2 ; 09$ & $3 ; 02$ & & & \\
\hline & Nina & $2 ; 01$ & $2 ; 01$ & & & \\
\hline & Lara & $2 ; 06$ & $2 ; 04$ & & & \\
\hline & Lucy & $2 ; 07$ & $2 ; 00$ & & & \\
\hline \multicolumn{2}{|c|}{ Mean } & $2 ; 01$ & $2 ; 05$ & Mean & - & $2 ; 01$ \\
\hline \multirow{6}{*}{ Boys } & Adam & $2 ; 04$ & $2 ; 11$ & Simon & $2 ; 03$ & $3 ; 02$ \\
\hline & Mark & $2 ; 06$ & $2 ; 09$ & John & $2 ; 04$ & $2 ; 11$ \\
\hline & Benjamin & $2 ; 03$ & - & Leo & $2 ; 05$ & $3 ; 01$ \\
\hline & Jack & $2 ; 02$ & - & Alberto & - & $2 ; 02$ \\
\hline & Gerald & - & $2 ; 11$ & Antonio & - & $2 ; 11$ \\
\hline & & & & Diego & - & - \\
\hline \multicolumn{2}{|c|}{ Mean } & $2 ; 03$ & $2 ; 10$ & Mean & $2 ; 04$ & $2 ; 10$ \\
\hline
\end{tabular}

Table 4. Age of onset of English dative alternation structures in monolingual and in bilingual girls' and boys' speech

As far as the age range of onset is concerned, the L1 English girls' production of DOCs appears between 1;04 and 2;09 and that of to/for-datives from 1;11 to 3;02. In the L1 English boys' data, DOCs start being produced between 2;02 and 2;06 and the emergence of to/for-datives ranges from 2;09 to 2;11. Although such an analysis cannot 
be done for the 2L1 English girl, the 2L1 English boys start producing DOCs between 2;03 and 2;05 and the onset of to/for-datives ranges from 2;02 to 3;01.

Having a closer look at each participant's data and as reflected in the order in which the data are presented in table 4, 5 out of the 8 L1 English girls begin to produce DOCs earlier if compared to to/for-datives, 1 L1 English girl shows a concurrent onset of the two DA structures, and 2 out of them reveal an opposite order of emergence (i.e. to/for-datives > DOCs). Furthermore, 2 out of the 5 L1 English boys' onset of DOCs occurs before that of to/for-datives and 3 out of them produce only one of the two types of DA structures, that is, DOCs in the Benjamin's data and to/for-datives in the Jack's as well as in the Gerald's data.

As for the 2L1 English children's data, 1 out of the 3 2L1 English girls begins to produce to/for-datives at 2;01 and the 2L1 English boys show a wider variation in the ages of onset of the two English DA structures. To be more precise, 3 out of the 6 2L1 English boys start producing DOCs before to/for-datives, 2 2L1 English boys only produce to/for-datives and 1 2L1 English boy does not produce DOCs or to/for-datives.

Despite the earlier emergence of DOCs if compared to to/for-datives, the L1 English girls $(t(6)=-2.071, p=.077)$ do not differ from the L1 English boys $(t(3)=-2.500$, $p=.242$ ) with regards to the lack of significant differences observed in the onset of the two English DA structures. While these findings are also seen in the 2L1 English boys' data $(t(3)=2.231, p=.155)$, a two-tailed paired-sample $t$-test cannot be run for the 2L1 English girl's ages of first occurrence of English DA structures due to the low sample size of data available in CHILDES.

In view of these findings, the earlier emergence of DOCs when compared to to/for-datives, as observed in the L1 English children's data (girls and boys) and in the 2L1 English children's data (only boys), is in line with previous L1 English works (Campbell and Tomasello 2001; Gu 2010; Snyder and Stromswold 1997) and 2L1 English studies (Gu 2010). In the case of Snyder and Stromswold's (1997) study, 11 out of the 12 L1 North American English children start producing DOCs (mean age: 2;02) before to-datives (mean age: 2;06), showing analogous mean ages of onset to those ones observed in the L1 English children's data in the present study. Although Snyder and Stromswold (1997) do not include for-datives among their target structures, they argue that 'when for-datives were included, DOCs were still acquired an average of 3 months before prepositional datives' (Snyder and Stromswold 1997: 289). Campbell and 
Tomasello (2001) also find the same order in the L1 English children's onset of DOCs (mean age: 2;02) and to/for-datives (mean age: 2;04). However, the contrast between Campbell and Tomasello's (2001) work and the present study regarding the overall mean age of onset of to/for-datives could lie in the selection as well as in the codification criteria of these structures: While Campbell and Tomasello (2001) analyze adult-like and non-adult-like to/for-datives, as in (1), the present study focuses on to/for-datives in their adult-like form, as discussed in chapter 4 (section 4.3).

(1) Miriam gave it me

[non-adult-like to-dative]

[Nina, 2;00, the Suppes corpus, CHILDES]

Also, the monolingual-like behavior of the 2L1 English children's order of emergence of DA structures is consistent with Gu's (2010) study on the 5 2L1 English/Cantonese children's onset of DOCs (mean age: 2;00) and to/for-datives (mean age: 2;09), when compared to 9 out of the 12 L1 English children analyzed by Snyder and Stromswold (1997), where DOCs (mean age: 2;02) also begin to be produced before to/for-datives (mean age: 2;04).

The non-significant differences in onset of DOCs and to/for-datives, as reflected both in the L1 English children's data (girls and boys) and in the 2L1 English boys' data, reveal that these constructions emerge at an approximately similar age. This points to the fact that, as argued by Snyder and Stromswold (1997), the two English DA structures do not derive from one another and, thus, share the same parametric property (or Property A) as complex predicates (Larson 2014, 1990, 1988; Marantz 1993; among others) or as SC constructions (Aoun and Li 1989; Kayne 1984; among others), as per the Complex Predicate Parameter (Snyder 2001, 1995). Indeed, Snyder and Stromswold (1997) find evidence of the shared parametric property of English DA structures in acquisition data where the L1 English children's ages of onset of DOCs and to-datives are significantly correlated $(r=.76, p=.0043)^{16}$. Alternatively, the syntactic non-

\footnotetext{
${ }^{16}$ Snyder and Stromswold (1997) have computed a Pearson's correlation test to explain that DOCs and to-datives are syntactically related given their similar emergence in the L1 English children's data. However, the present study has not implemented this type of statistical analysis because a correlation is not going to reveal whether construction A significantly differs from construction B or whether the two constructions do not differ significantly from one another. Rather, when a correlation between two variables (i.e. the age of onset of DOCs and the age of onset of to/for-datives) is computed, what is being
} 
derivational relationship between the two English DA structures in the two target language groups could also be explained by the formation of two different syntactic structures (Marantz 1993; Mulder 1992, see section 1.3.1, chapter 1).

Therefore, these results speak against the derivation of (a) DOCs from to/fordatives via a transformational rule based on a scale of prominence (Oehrle 1976) or via a passive-like movement under RG (Haspelmath 2006; Perlmutter 1980) and under GB theory (Larson 2014, 1990, 1988); or (b) to/for-datives from DOCs in terms of a lexical rule, as an alternative proposal to Case theory (Czepluch 1982), or a passive-like movement contra RG (Dryer 1986) and contra Larson’s proposal (Aoun and Li 1989; Koizumi 1994).

Even though the two English DA structures do not differ significantly in their emergence, to/for-datives begin to be produced later than DOCs, as seen in the L1 English and in the 2L1 English children's data alike, and this is so regardless of the biological gender (except for the 2L1 English girl's data). This may be caused by the additional property (or Property B) required to produce to/for-datives (Snyder and Stromswold 1997). That is, Property B is argued to be associated with the dative Case and the recipient theta role mediated assigning properties of the preposition 'to' via the verb onto the prepositional complement (Larson 1990, 1988; Marantz 1984; Pesetsky 1985), as reflected in the L1 English children's concurrent emergence of to-datives and other related structures such as dyadic to-datives at 2;06 ( $r=.76, p=.0009)$ in the study conducted by Snyder and Stromswold (1997). Although Property B is argued for todatives, it could also apply to for-datives whereby the preposition 'for' functions as a mediated dative Case assigner and beneficiary theta role marker.

asked is (a) whether we find a systematic relationship between the emergence of construction A and construction B; (b) what type of relationship it is, that is, whether the emergence of the two English DA structures moves in the same direction (positive correlation) or in opposite directions (negative correlation); and (c), if there is such a relationship, how strong it is. Correlations do not tell us, however, whether the two English DA structures are in causal relationship since the correlation between DOCs and to/for-datives is always, by definition, the same as the correlation between to/for-datives and DOCs, and so, the direction of the relationship is irrelevant. Furthermore, correlations establish the degree of association and they do not establish the difference between two samples. On the other hand, when parametric two-tailed paired-sample $t$-tests are run for the ages of onset of the two English DA structures, we are establishing if the emergence of DOCs differs significantly from the emergence of to/for-datives in a way that is not just due to random effects. Therefore, a significant result via a parametric two-tailed paired-sample $t$-test will display different interpretations from those ones run via a correlation: While the former establishes a difference, the latter establishes a degree of association. 
In addition to the syntactic non-derivational relationship between the two English DA structures, the non-significant differences in the ages of onset of to/for-datives and DOCs, as equally observed in the L1 English (girls and boys) and in the 2L1 English boys' data, could also point to a semantic analogy. This is seen in the shared theme and recipient theta roles of to-datives and their DOC variant as well as in the shared theme and beneficiary theta roles of for-datives and their DOC variant, conforming to the UTAH requirements.

The lack of biological gender differences in the L1 English children's acquisition of the syntactic and the semantic analogous relationship between DOCs and to/fordatives is not in line with earlier L1 English empirical studies on the delay of boys when compared to girls in motor movements (Nagy et al. 2007), in lexical production (Berglund et al. 2005; Coates 1993; Galsworthy et al. 2000; among others) and in syntactic development (Cornet 2014; Dini 2011; Koenigsknecht and Friedman 1976; Tse et al. 2002; among others). Further research is required in the 2L1 English girls' data given that the low sample size in the production of the two English DA structures does not allow to carry out a comparative analysis with the 2L1 English boys' data and, as a result, we cannot determine whether the 2L1 English girls perform closer to their 2L1 male peers.

Thus, the 2L1 English children's non-significant differences in the onset of DOCs and to/for-datives when compared to their L1 peers reveals that the acquisition of the syntactic and the semantic properties that underlie the two English DA structures does not seem to have been influenced by their other L1 (i.e. Spanish). Further discussion to this issue appears in section 5.3.2.

\subsubsection{Dative alternation through language development}

This section analyzes the incidence of English DA structures through language development by considering the L1 English and the 2L1 English children's age (section 5.1.2.1) and MLUw values (section 5.1.2.2). The aim of these analyses is to examine whether the L1 English children's use of DA structures sheds further light on the syntactic non-derivational relationship between DOCs and to/for-datives, as argued in section 5.1.1, and whether this is so in the 2L1 English children's data. 


\subsubsection{Age stages}

As illustrated in figure 1, the L1 English children produce DOCs along wider age stages when compared to to/for-datives. That is, while the incidence of DOCs ranges from $1 ; 00-1 ; 06$ to $7 ; 00-7 ; 06$, that of to/for-datives is observed between $1 ; 07-1 ; 11$ and 7;00-7;06.

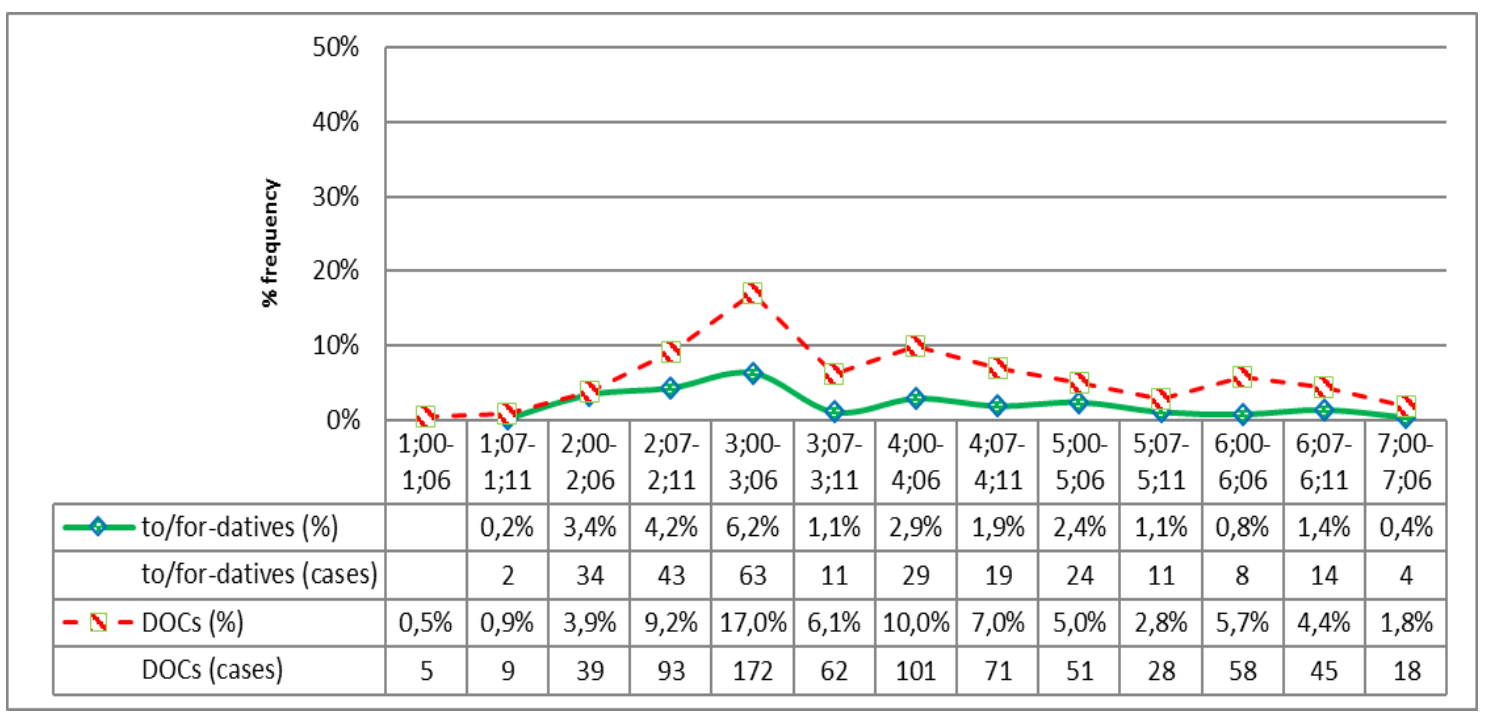

Figure 1. The monolingual English children's production of dative alternation structures per age stages

[100\% = overall DA structures produced by L1 English children $]$

In line with the longitudinal age range in the production of the two English DA structures, the L1 English children show a higher incidence of DOCs if compared to to/for-datives through all the stage stages $(t(11)=-4.453, p=.001)^{17}$. A gradual increase is observed in the use of DOCs from 1;00-1;06 (5 occurrences, 0.5\%) to 3;00-3;06 (172 occurrences, 17\%), stage from which the production of these constructions starts decreasing until 7;00-7;06 (18 occurrences, 1.8\%). Although to/for-datives reveal a lower rate of use when compared to DOCs in each stage, they show a similar pattern to that of DOCs since the incidence rises as age increases from 1;07-1;11 (2 occurrences,

17 Given the low frequency rates in the L1 English children's use of DOCs and to/for-datives, Y frequency axis in figure 1 is scaled from $0 \%$ to $50 \%$. In this way, the reader will be provided with a clearer visual representation of the incidence of these structures through language development. When the frequency of DA structures is rated above $50 \%$, a scale ranging from $0 \%$ to $100 \%$ will be used in the Y frequency axis instead. These scales will be applied to all the figures that illustrate the production of DA structures through the two language development measures under analysis (i.e. age and MLUw values) and for the three target language groups (i.e. L1 English, L1 Spanish and 2L1 English/Spanish). 
$0.2 \%$ ) to $3 ; 00-3 ; 06$ (63 occurrences, $6.2 \%$ ). Then, the use of to/for-datives lowers gradually until 7;00-7;06 (4 occurrences, $0.4 \%$ ).

When analyzing the production of the two English DA structures from a biological gender approach, the L1 English girls produce DOCs and to/for-datives through longer age stages (i.e. from 1;00-1;06 to 7;00-7;06) if compared to the L1 English boys’ data (i.e. from 2;00-2;06 to 7;00-7;06), as illustrated in figure 2.

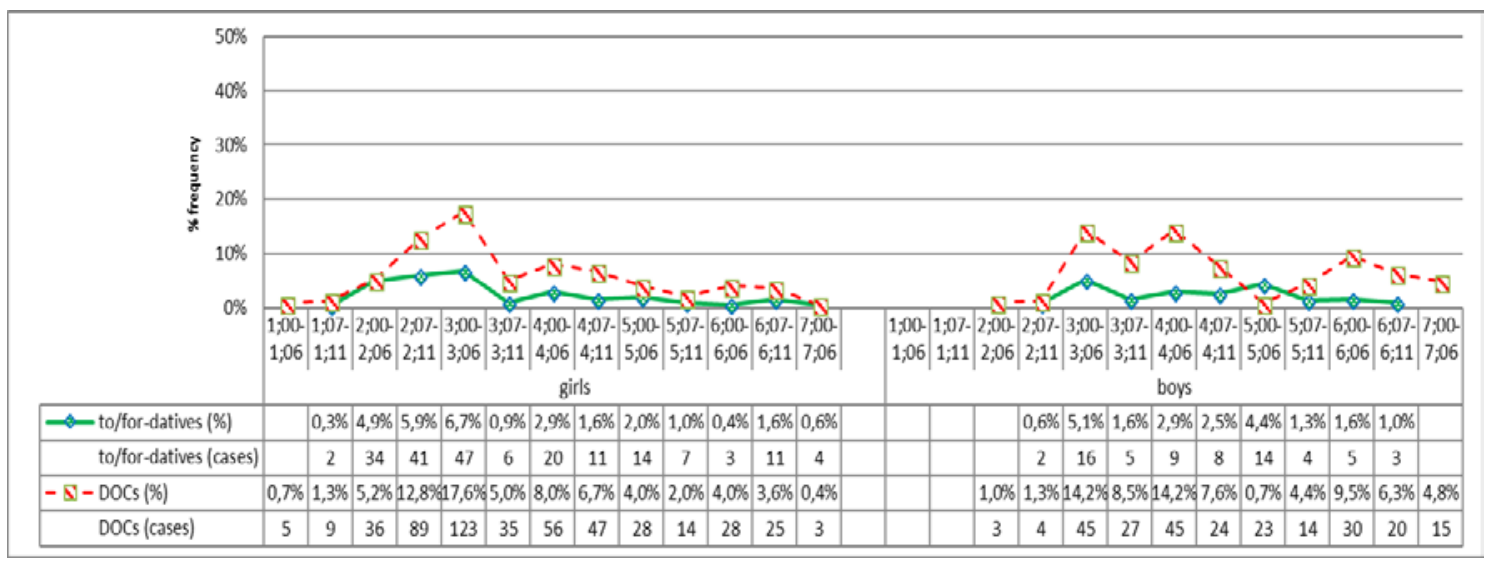

Figure 2. The production of dative alternation structures in the monolingual English girls and in the monolingual English boys per age stages

[100\% = overall DA structures produced by either L1 English girls or by L1 English boys]

Developmentally, both the L1 English girls (t(11)=-3.892, $p=.004)$ and the L1 English boys $(t(9)=-4.460, p=.001)$ produce DOCs more frequently than $t o / f o r$-datives. In the case of the L1 English girls' data, a rising use of DOCs is reflected from 1;001;06 (5 occurrences, $0.7 \%$ ) to 3;00-3;06 (123 occurrences, $17.6 \%$ ), stage from which a gradual decrease of these structures appears until 7;00-7;06 (3 occurrences, 0.4\%). Regarding the incidence of to/for-datives, the L1 English girls increase the use of these structures gradually from 1,07-1;11 (2 occurrences, $0.3 \%$ ) and, once the highest stage of incidence is reached at 3;00-3;06 (47 occurrences, 6.7\%), they sharply lower the production of to/for-datives at 7;00-7;06 (4 occurrences, 0.5\%).

As for the L1 English boys' data, the use of DOCs rises progressively from 2;002;06 (3 occurrences, 1\%) to 3;00-3;06 (45 occurrences, 14.2\%) and remains stable at $4 ; 00-4 ; 06$. Then, a gradual decrease in the production of DOCs is reflected from 4;074;11 (24 occurrences, 7.6\%) to 7;00-7;06 (15 occurrences, 4.8\%). Moreover, the L1 English boys show a lower rate in the use of to/for-datives if compared to DOCs from the stage of onset at 2;07-2;11 (2 occurrences, $0.6 \%$ ) to 6;07-6;11 (3 occurrences, 1\%), 
except for two stages in which these structures are highly used, namely, at 3;00-3;06 (16 occurrences, 5.1\%) and at 5;00-5;06 (14 occurrences, 4.4\%).

As displayed in figure 3, the 2L1 English children's use of DOCs (i.e. from 2;002;06 to 6;07-6;11) and to/for-datives (i.e. from 2;00-2;06 to 6;00-6;06) appears through smaller age ranges when compared to their L1 peers (see figure 1).

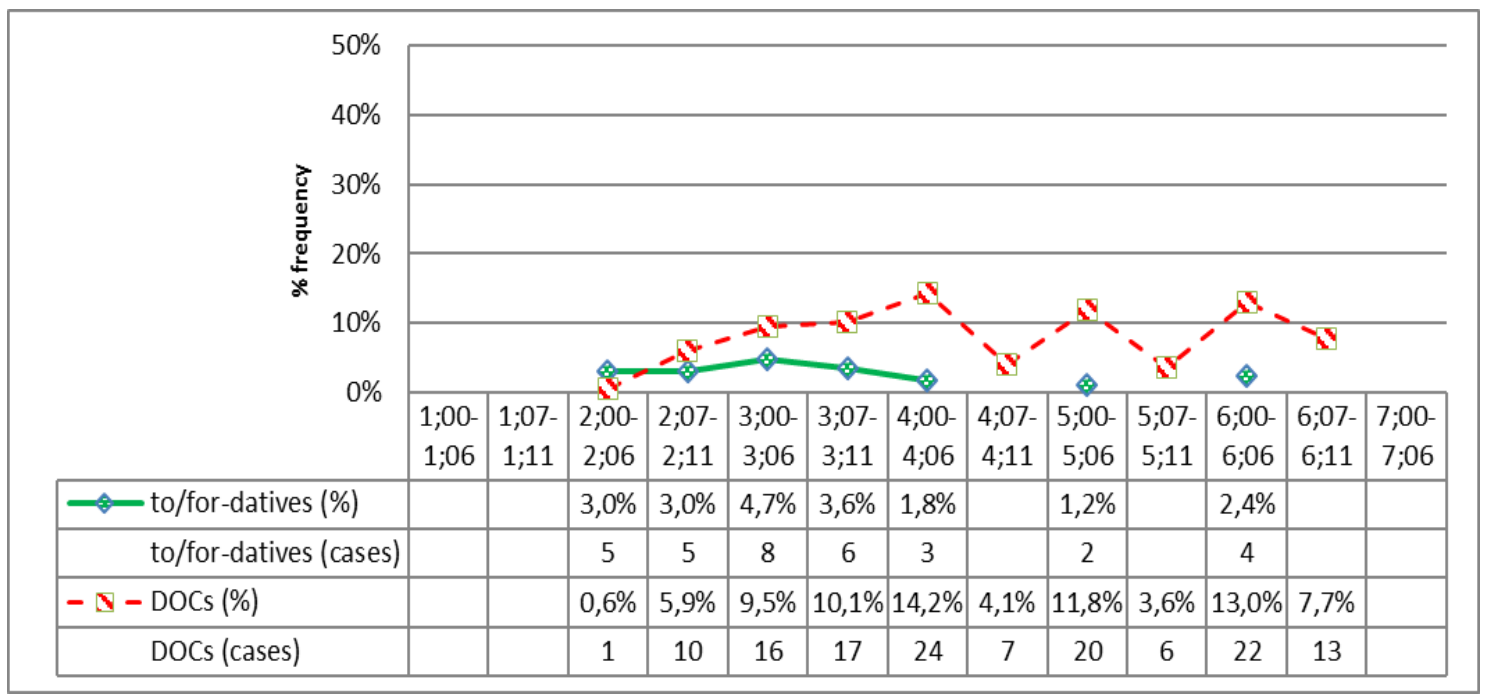

Figure 3. The bilingual English children's production of dative alternation structures per age stages

[100\% = overall DA structures produced by 2L1 English children]

Despite the above-mentioned longitudinal divergences between bilinguals (who produce the two DA structures from 2;00-2;06 to 6;07-6;11) and monolinguals (who produce the two DA structures from 1;00-1;06 to 7;00-7;06), the 2L1 English children show a monolingual-like pattern with regards to the high incidence of DCLDs and the low incidence of $a$ /para-datives $(t(8)=-4.335, p=.002)$. DOCs increase in use gradually from 2;00-2;06 (1 occurrence, $0.6 \%$ ) to 4;00-4;06 (24 occurrences, 14.2\%), stage from which the production of DOCs begins to decrease until 6;07-6;11 (13 occurrences, 7.7\%). The incidence of to/for-datives remains low from 2;00-2;06 (5 occurrences, 3\%) to 6;00-6;06 (4 occurrences, 2.4\%).

A contrast is observed when the 2L1 English children's data are analyzed per biological gender. While the 2L1 English boys' use of DOCs and to/for-datives is reflected through wider age stages (i.e. from 2;00-2;06 to 6;07-6;11), the 2L1 English girl shows a non-longitudinal incidence of the two English DA structures at 2;00-2;06. 


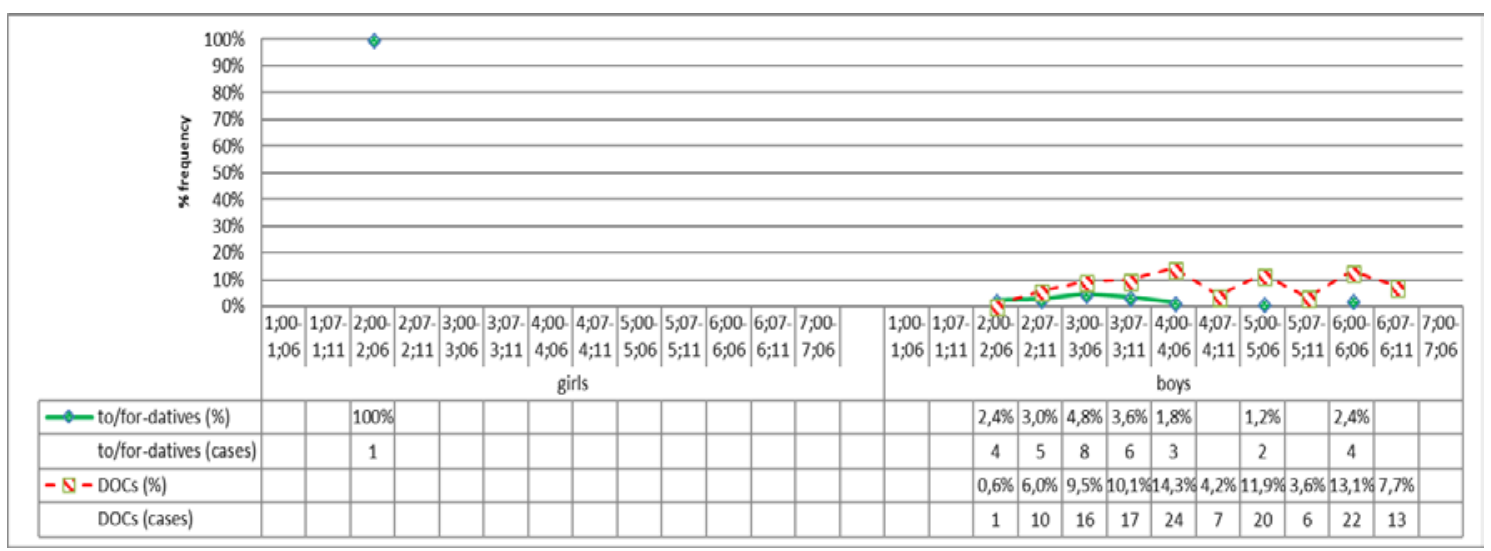

Figure 4. The production of dative alternation structures in the bilingual English girls and in the bilingual English boys per age stages

[100\% = overall DA structures produced by 2L1 English children]

As illustrated in figure 4, the 2L1 English boys follow an analogous pattern to that found in their L1 peers (see figures 1 and 2), that is, DOCs reveal a higher incidence if compared to to/for-datives through the age stages $(t(8)=-4.501, p=.001)$. A low use of the two types of English DA structures is shown in the 2L1 English boys' data at 2;002;06 (1 DOC, 4 to/for-datives; 0.6\%, 2.4\%). Then, the incidence of DOCs increases gradually from 4;00-4;06 (24 occurrences, 14.3\%) and remains stable until 6;00-6;06 (22 occurrences, 13.1\%), stage from which the use of DOCs decreases slightly at 6;076;11 (13 occurrences, 7.7\%). As for the 2L1 English boys' incidence of to/for-datives, a rise in the production of these constructions is observed from 2;00-2;06 to 3;00-3,06 (8 occurrences, 4.8\%). It is not until 6;00-6;06 (4 occurrences, 2.4\%) when the 2L1 English boys show a gradual decrease of to/for-datives, except for two age stages (i.e. 4;07-4;11 and 5;07-5;11) where these constructions are not produced. However, these findings cannot be compared to the 2L1 English girl's data since, as pointed out earlier, she produces only 1 to/for-dative (100\%), and thus, does not reflect a longitudinal incidence of the two English DA structures.

Although a similar order in the longitudinal use of English DA structures is seen in the two target language groups (i.e. L1 English and 2L1 English), the L1 English children show significantly higher frequency rates, when compared to the 2L1 English children, in the production of DOCs $(t(24)=3.708, p=.001)$ and to/for-datives ( $U=21.500, p=.001)$. This is reflected in each developmental age stage.

Considering the data analyzed above and despite the differences regarding the frequency rates in the use of English DA structures when comparing the 2L1 English 
children's data to the L1 English children's data, the lower incidence of to/for-datives through the age stages, as reflected in both language groups, seems to go hand in hand with their later emergence (see section 5.1.1), and a similar pattern is reflected in the production of girls and boys. Therefore, these findings may also be related to the additional properties (or Property B; Snyder and Stromswold 1997) required in the production of to/for-datives, namely, the Case and the theta role mediated assigning properties of the prepositions 'to/for', which are argued to allocate dative Case and recipient or beneficiary theta roles to the DP via the verb. Moreover, the relative frequency rate in the use of DOCs and to/for-datives could also be influenced by the amount of exposure to these structures in the adult input, as will be investigated in section 5.1.3.

\subsubsection{MLUw stages}

As observed in the L1 English children's production of DA structures in figure 5, DOCs show a higher incidence through the 6 MLUw stages when compared to to/fordatives $(t(4)=-2.743, p=.041)$.

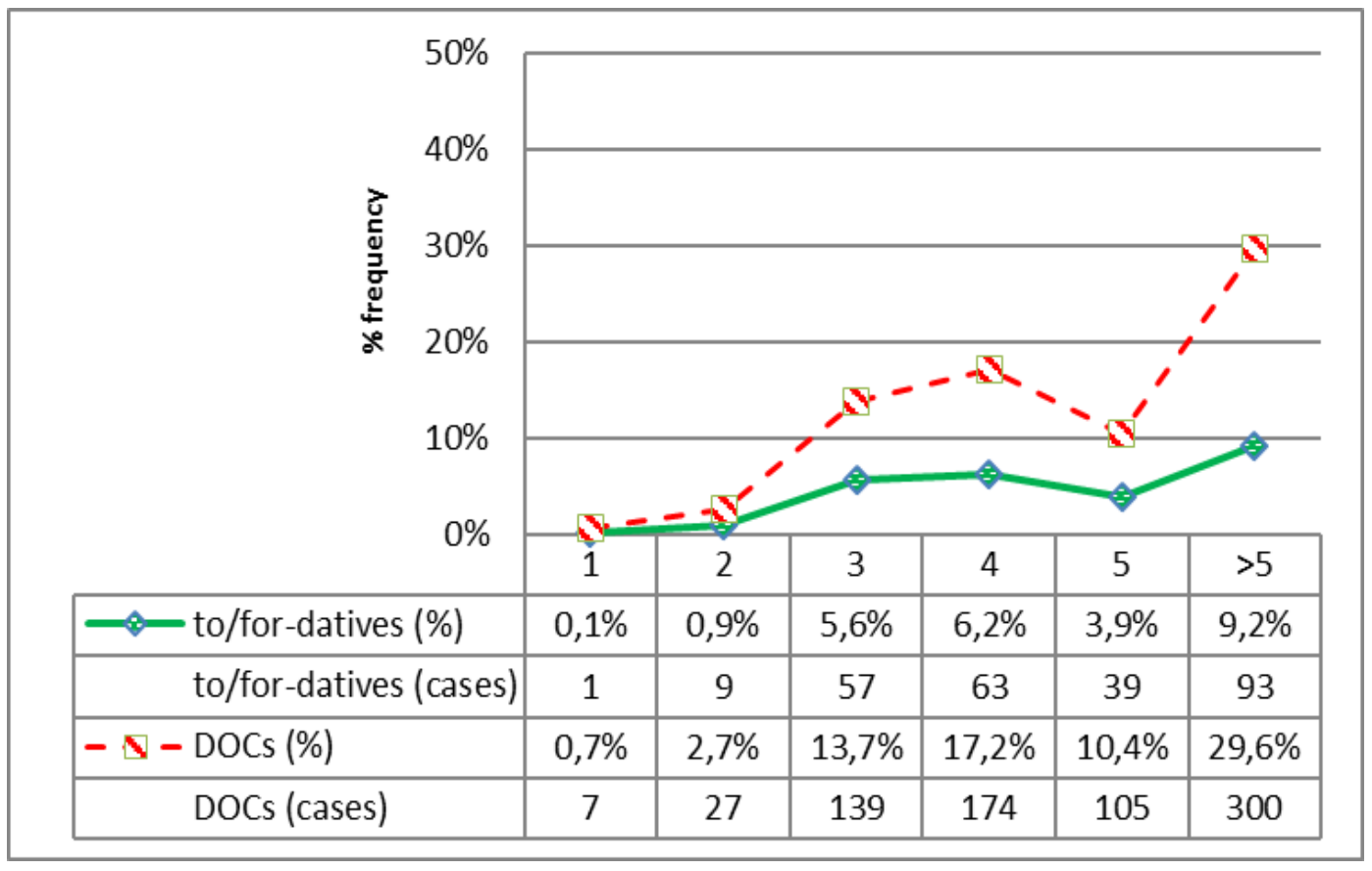

Figure 5. The monolingual English children's production of dative alternation structures per MLUw stages 
More specifically, the L1 English children reveal a low use of the two DA structures at MLUw 1, namely, 7 DOCs and 1 to/for-dative (0.7\% and $0.1 \%)$. Then, the incidence rises gradually until the L1 English children reach an MLU of 4 words (174 DOCs and 63 to/for-datives, 17.2\% and 6.2\%), followed by a decrease at MLUw 5 (105 DOCs and 39 to/for-datives, $10.3 \%$ and 3.9\%). It is not until MLUw >5 when the L1 English children show the highest stage in the use of DOCs (300 occurrences, 29.6\%) and to/for-datives (93 occurrences, 9.2\%).

As illustrated in figure 6, differences are not seen between the L1 English girls' data $(z=-2.201, p=.028)$ and the L1 English boys' data $(t(5)=2.661, p=.045)$ with respect to the higher incidence of DOCs when compared to to/for-datives.

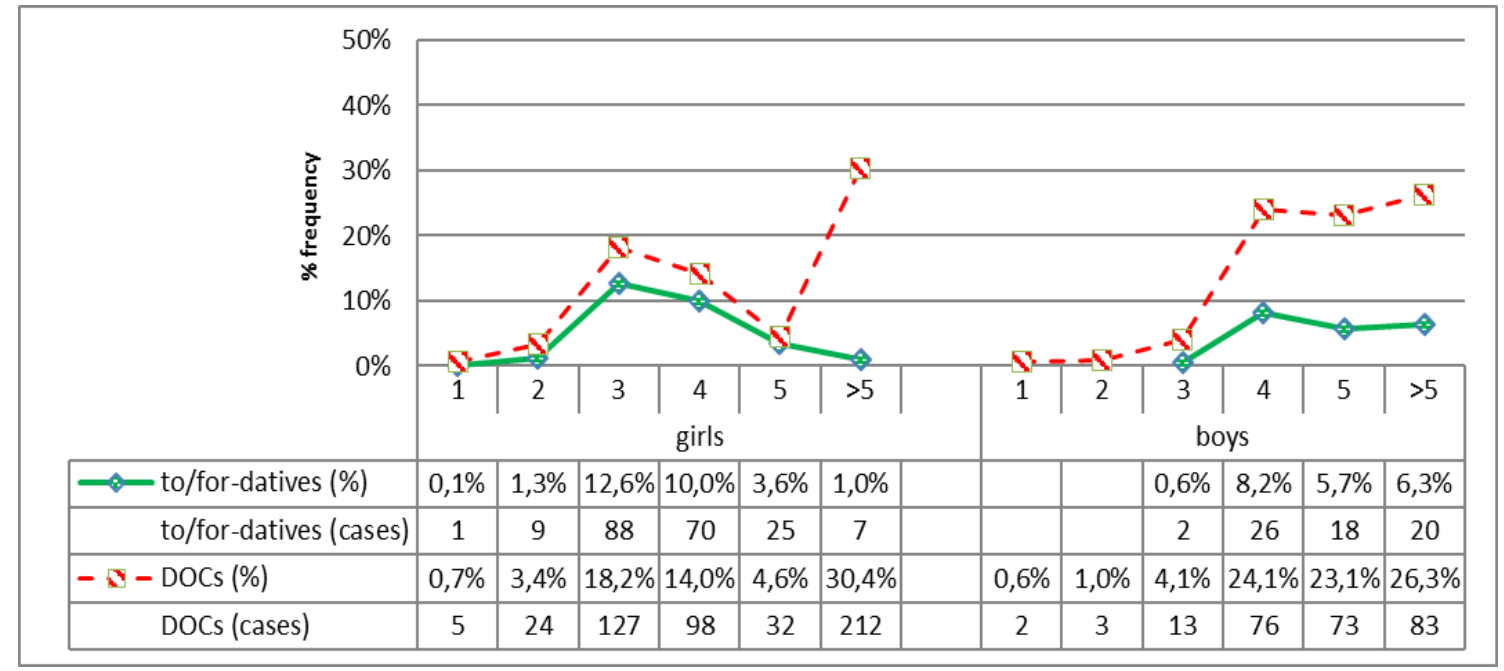

Figure 6. The production of dative alternation structures in the monolingual English girls and in the monolingual English boys per MLUw stages

[100\% = overall DA structures produced by either L1 English girls or by L1 English boys]

The L1 English girls reflect a low incidence of the two DA structures at MLUw 1 (5 DOCs and 1 to/for-dative, $0.7 \%$ and $0.1 \%$ ), and the production of these structures increases gradually until they reach an MLUw 3 (127 DOCs and 88 to/for-datives, $18.2 \%$ and $12.6 \%$ ). From that stage, the use of DOCs and to/for-datives shows a decreasing pattern until the L1 English girls reach an MLU of 5 words (32 DOCs and 25 to/for-datives, 4.6\% and 3.6\%). At MLU >5, the L1 English girls show the highest rates in the use of DOCs (212 occurrences, 30.4\%), whereas the incidence of to/fordatives decreases strongly (7 occurrences, 1\%).

In the case of the L1 English boys' data, a gradual increase in the use of DA structures is reflected between MLUw 1 (2 occurrences, 0.6\%) and MLUw 4 (76 
occurrences, 24.1\%) in DOCs and between MLUw 3 (2 occurrences, 0.6\%) and MLUw 4 (2 occurrences, $0.6 \%$ ) in to/for-datives (26 occurrences, 8.2\%). When the L1 English boys reach an MLUw 4, the incidence of the two DA structures remains stable until they reach an MLUw >5 (83 DOCs and 20 to/for-datives, 26.3\% and 6.3\%).

As far as the 2L1 English children's data are concerned, DOCs and to/for-datives reflect a high and a low incidence, respectively, from MLUw 2 to MLUw >5, as displayed in figure 7. These findings are also observed in their L1 English counterparts (see figure 5).

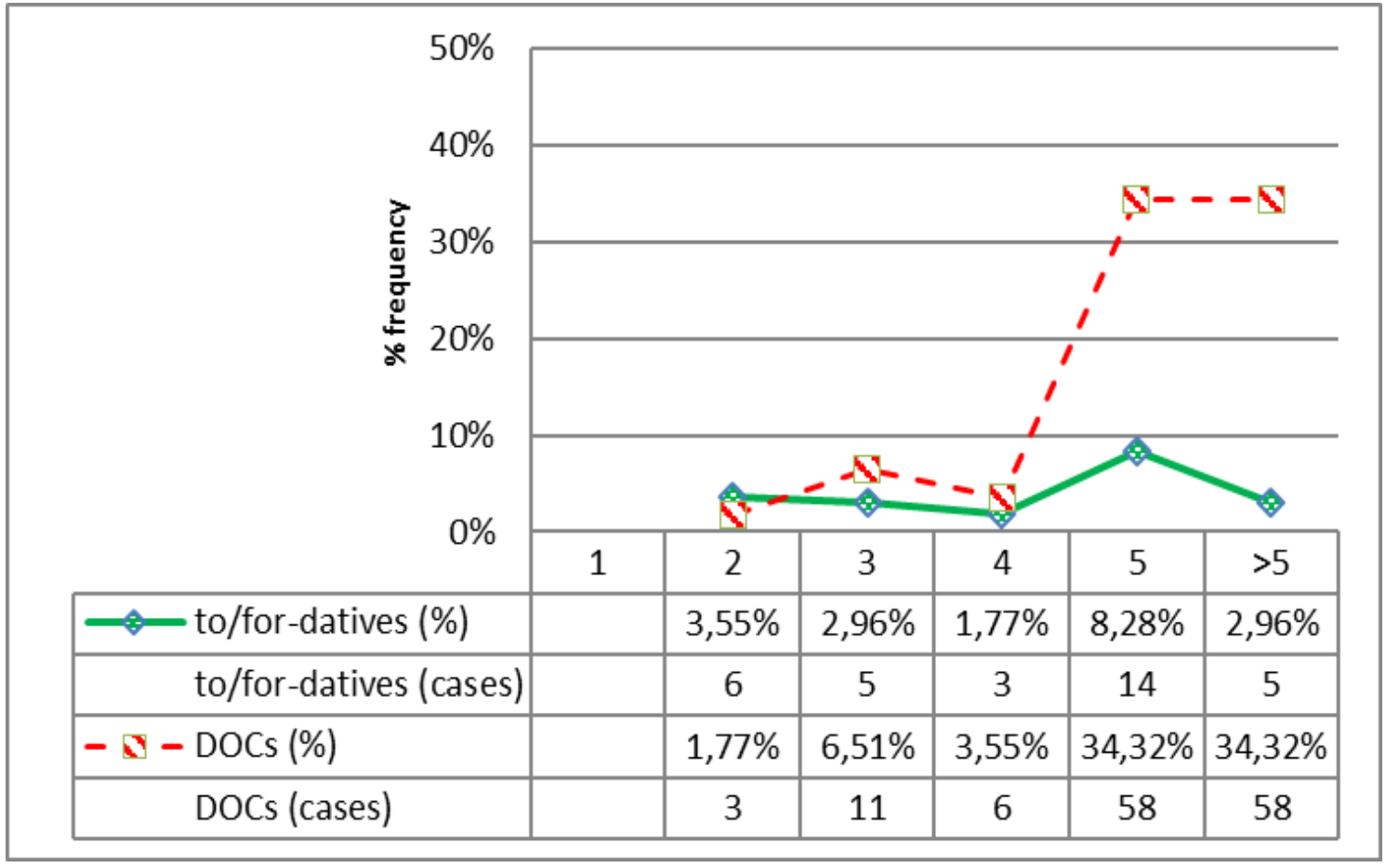

Figure 7. The bilingual English children's production of dative alternation structures per MLUw stages

A gradual increase is observed in the 2L1 English children's use of DOCs and to/for-datives from MLUw 2 (3 DOCs and 6 to/for-datives, 1.8\% and 3.6\%) to MLUw 5 (58 DOCs and 14 to/for-datives, 34.4\% and 8.3\%). However, the incidence of the two DA structures contrasts at MLUw $>5$ : While the production of DOCs remains stable (58 occurrences, $34.4 \%$ ), that of to/for-datives decreases (5 occurrences, 3\%).

Despite the longitudinal relative frequency rate in the use of the two English DA structures, the 2L1 English children do not show significant differences in the production of DOCs and to/for-datives $(z=-1.625, p=.104)$, which contrasts with the 
significant differences in the L1 English children's use of these structures. Thus, the statistical results found in the 2L1 English children's data might be in line with the symmetric increasing production pattern of DOCs and to/for-datives from MLUw 2 to MLUw >5, rather than with the relative frequency rate in the use of the two DA constructions.

As depicted in figure 8, when the 2L1 English children are examined per biological gender, the 2L1 English boys show a higher incidence of DOCs when compared to to/for-datives. The use of the two target structures gradually increases from MLUw 2 (3 DOCs and 5 to/for-datives, 1.8\% and 3\%) to MLUw 5 (58 DOCs and 14 to/for-datives, 3.8\% and 8.3\%). At MLUw >5, while the 2L1 English boys reflect a similar incidence of DOCs to that observed in the previous MLUw stage (i.e. at MLUw 5), to/for-datives decrease in use (5 occurrences, $3 \%$ ).

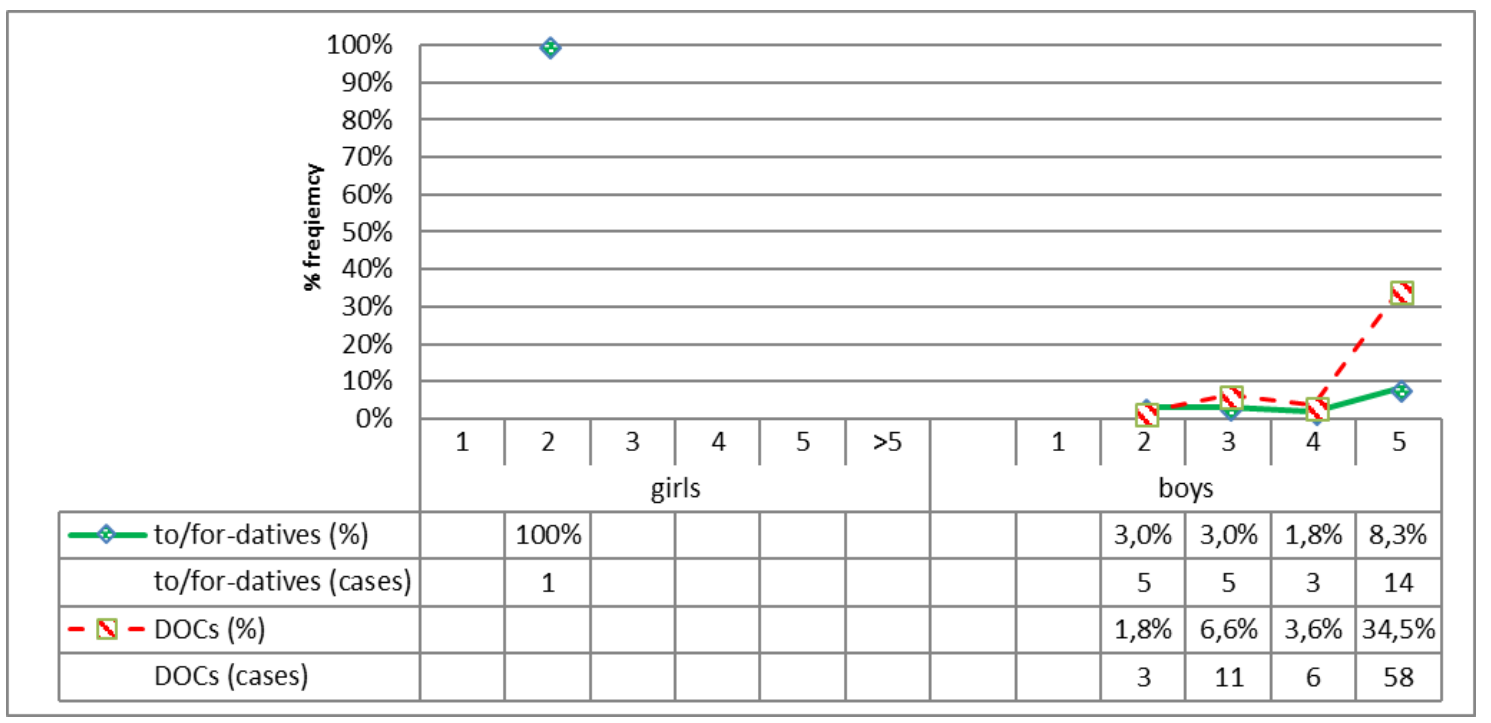

Figure 8. The production of dative alternation structures in the bilingual English girls and in the bilingual English boys per MLUw stages

[100\% = overall DA structures produced by either 2L1 English girls or by 2L1 English boys]

Although the 2L1 English boys show a higher rate in the incidence of DOCs and to/for-datives, significant differences are not seen in the production of these structures from MLUw 2 to MLUw $>5(z=-1.753, p=.080)$. These statistical findings go hand in hand with what has been previously argued in the data collapsed from the 2L1 English children, that is, the rising production pattern of the two English DA structures through the language development. 
In contrast to the 2L1 English boys' data, the 2L1 English girl produces only 1 to/for-dative (100\%) at MLUw 2.

Differences appear when comparing the 2L1 English children's production of DA structures through the 6 MLUw stages to the L1 English children's data. To be more precise, the use of DOCs $(U=5.000, p=.037)$ and to/for-datives $(t(10)=2.668, p=.024)$ in the production of the L1 English children is higher than that of the 2L1 English children, and this is so in each MLUw stage.

Therefore, regardless of the contrast observed in the frequency of use of the two English DA structures when comparing the L1 English children's data to the 2L1 English children's data, the two language groups show a lower incidence of to/fordatives when compared to DOCs through the MLUw stages, and similar patterns are seen in the L1 English girls', in the L1 English boys' and in the 2L1 English boys' data. These results could lend support to the additional properties required to produce to/fordatives (Property B; Snyder and Stromswold 1997) and/or to the role played by adult input in child output (see section 5.1.3), as also discussed in the incidence of these constructions through the age stages (see section 5.1.2.1).

If we analyze the longitudinal production of the two English DA structures in terms of MLUw and age, a similar relative frequency rate in the incidence of these constructions is observed in the two target language groups (i.e. L1 and 2L1). However, the data distribution based on MLUw stages seems to be more homogeneously distributed than the one based on age stages. This is so given the linear progression that is reflected in the production of DOCs and to/for-datives through the 6 MLUw stages, which is not seen when the data are organized in terms of age. Taking these differences into consideration, MLUw appears to be a better predictor than age when analyzing the production of English DA structures, as argued in earlier works (Aguado 1988; Brown 1973; De Villiers and De Villiers 1973; Miller 1981; Silva Corvalán and Sánchez Walker 2007).

\subsubsection{The influence of adult input in children's output}

A similar pattern in the use of English DA structures is observed in the adult input and in the children's output, regardless of the language group. As illustrated in figure 9, DOCs are preferred over to/for-datives and this is equally seen in the adults' speech (1,853 DOCs $>655$ to/for-datives, $73.9 \%>26.1 \%$, out of 2,508 DA structures, $100 \%)$ 
and in the L1 English children's speech (752 DOCs > 262 to/for-datives, 74.2\% > $25.8 \%$, out of 1,014 DA structures, 100\%). Analogous results are found in the 2L1 English children's adult input (1,528 DOCs $>605$ to/for-datives, $71.6 \%>28.4 \%$, out of 2,133 DA structures, 100\%) and output (136 DOCs > 33 to/for-datives, 80.5\% > 19.5\%, out of 169 DA structures, 100\%), as displayed in figure 10.

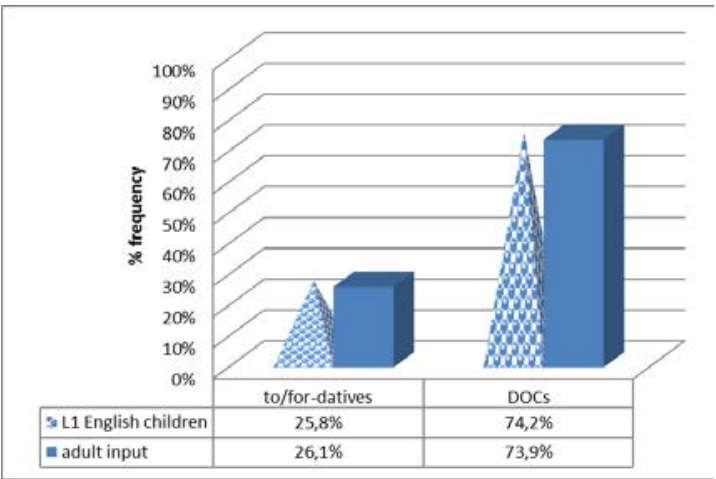

Figure 9. The production of English dative alternation structures in the adult input and in the monolingual children's output

$[100 \%$ = overall DA structures produced by adults or by L1 English children

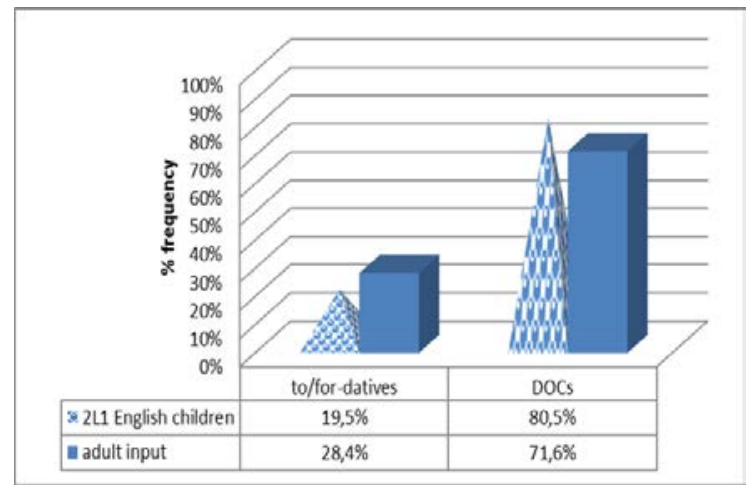

Figure 10. The production of English dative alternation structures in the adult input and in the bilingual children's output

$[100 \%=$ overall DA structures produced by adults or by 2L1 English children]

The relative frequency rate in which DOCs and to/for-datives are used in the adult input does not show differences between the L1 English girls’ and the L1 English boys’ output. As illustrated in figure 11, the amount of input that the L1 English girls receive from the adults' production of DA structures (1,253 DOCs > 474 to/for-datives, $72.5 \%$ $>27.5 \%$, out of 1,727 DA structures, $100 \%$ ) seems to have played a role in their output (498 DOCs > 200 to/for-datives, $71.3 \%>28.7 \%$, out of 698 DA structures, 100\%). Analogous results are seen in the L1 English boys' adult input (600 DOCs > 181 to/fordatives, $76.8 \%>23.2 \%$, out of 781 DA structures, 100\%) and output (254 DOCs > 62 to/for-datives, $80.4 \%>19.6 \%$, out of 316 DA structures, 100\%). 


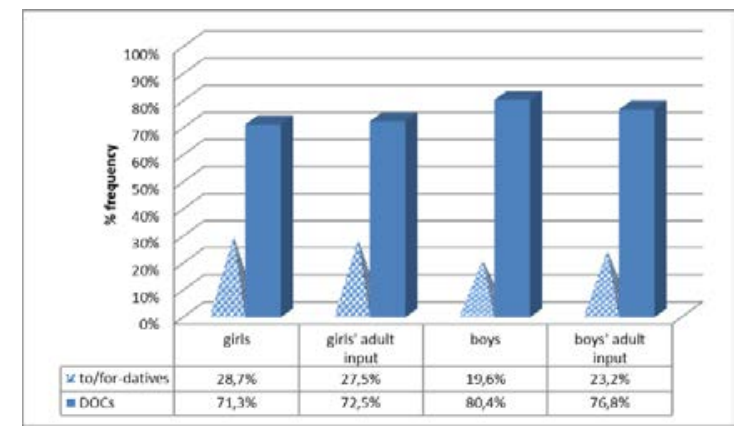

Figure 11. The production of English dative alternation structures in the adult input, the monolingual girls' output and the monolingual boys' output

$[100 \%$ = overall DA structures produced by adults or by $2 \mathrm{~L} 1$ English children]

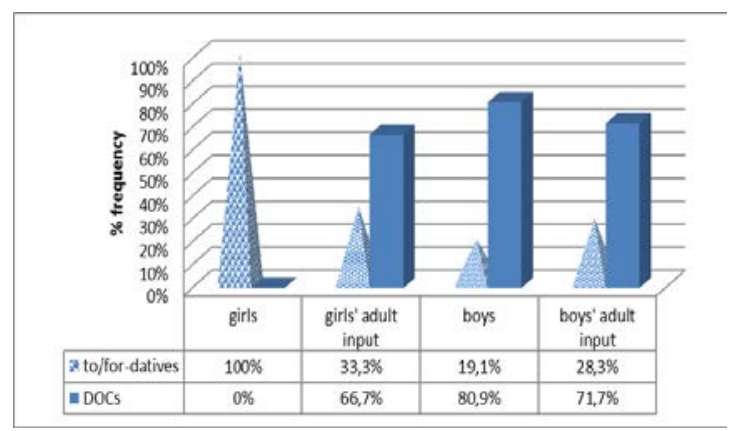

Figure 12. The production of English dative alternation structures in the adult input, the bilingual girls' output and the bilingual boys' output

[100\% = overall DA structures produced by adults, by 2L1 English girls or by 2L1 English boys]

With regards to the 2L1 English boys' data, the production pattern of DA structures is similar to that observed in their L1 peers, as represented in figure 12: DOCs are more frequently used than to/for-datives both in the adult input (1,502 DOCs $>592$ to/for-datives, $71.7 \%>28.3 \%$, out of 2,094 DA structures, $100 \%$ ) and in the output (136 DOCs > 32 to/for-datives, $80.9 \%>19.1 \%$, out of 168 DA structures, 100\%). Although the adult input that the 3 2L1 English girls receive has been collapsed for the two DA structures in figure 12 (26 DOCs $>13$ to/for-datives, $66.7 \%>33.3 \%$, out of 39 DA structures, 100\%), only 1 2L1 English girl produces 1 to/for-dative, 100\%.

A closer look at the use of DOCs and to/for-datives in the children's output and in the adult input is provided in table 5 for the two target language groups (i.e. L1 English and 2L1 English). 


\begin{tabular}{|c|c|c|c|c|c|}
\hline $\begin{array}{l}\text { Language } \\
\text { group }\end{array}$ & Children & $\begin{array}{c}\text { Children's output } \\
\text { of DOCs }\end{array}$ & $\begin{array}{l}\text { Adult input } \\
\text { of DOCs }\end{array}$ & $\begin{array}{l}\text { Children's output } \\
\text { of to/for-datives }\end{array}$ & $\begin{array}{c}\text { Adult input } \\
\text { of } \text { to/for-datives }\end{array}$ \\
\hline \multirow{15}{*}{ L1 English } & Eve & $19(66.3)$ & $96(70)$ & $11(36.7)$ & $42(30)$ \\
\hline & Jane & $11(68.8)$ & - & $5(31.2)$ & - \\
\hline & Lara & $12(35.3)$ & $135(73.4)$ & $22(64.7)$ & $49(26.6)$ \\
\hline & Lucy & $4(30.8)$ & - & $9(69.2)$ & - \\
\hline & Naomi & $17(68)$ & $76(73.8)$ & $8(32)$ & $27(26.2)$ \\
\hline & Nina & $101(72.1)$ & $412(66.8)$ & $39(27.9)$ & $205(33.2)$ \\
\hline & Ross & $239(73.1)$ & 417 (78.7) & $88(26.9)$ & $113(21.3)$ \\
\hline & Sarah & $95(84.1)$ & $117(75.5)$ & $18(15.9)$ & $38(24.5)$ \\
\hline & Total (girls) & $498(71.3)$ & $1,253(72.5)$ & $200(28.7)$ & $474(27.5)$ \\
\hline & Adam & $157(79.3)$ & $155(73.1)$ & $41(20.7)$ & $57(26.9)$ \\
\hline & Benjamin & $4(100)$ & $11(64.7)$ & - & $6(35.3)$ \\
\hline & Gerald & - & $4(57.1)$ & $1(100)$ & $3(42.9)$ \\
\hline & Jack & $4(100)$ & $13(86.7)$ & - & $2(13.3)$ \\
\hline & Mark & $89(81.7)$ & $417(78.7)$ & $20(18.3)$ & $113(21.3)$ \\
\hline & Total (boys) & $254(80.4)$ & $600(76.8)$ & $62(19.6)$ & $181(23.2)$ \\
\hline \multicolumn{2}{|c|}{ Total (overall) } & $752(74.2)$ & $1,853(73.9)$ & $262(25.8)$ & $655(26.1)$ \\
\hline \multirow{11}{*}{$\begin{array}{c}\text { 2L1 } \\
\text { English }\end{array}$} & Carla & - & $1(100)$ & - & - \\
\hline & Manuela & - & $25(65.8)$ & $1(100)$ & $13(34.2)$ \\
\hline & Sheila & - & - & - & - \\
\hline & Total (girls) & - & 26 & 1 & 13 \\
\hline & Alberto & - & $3(100)$ & $4(100)$ & - \\
\hline & Antonio & - & - & $2(100)$ & $1(100)$ \\
\hline & Diego & - & $29(74.4)$ & - & $10(25.6)$ \\
\hline & John & 7 (63.6) & $4(57.1)$ & 4 (36.4) & $3(42.9)$ \\
\hline & Leo & 76 (83.5) & 733 (71.7) & $15(16.5)$ & 289 (28.3) \\
\hline & Simon & $53(88.3)$ & 733 (71.7) & 7 (11.7) & 289 (28.3) \\
\hline & Total (boys) & $136(80.9)$ & $1,502(71.7)$ & 32 (19.1) & $592(28.3)$ \\
\hline \multicolumn{2}{|c|}{ Total (overall) } & $136(80.5)$ & $1,528(71.6)$ & 33 (19.5) & $605(28.4)$ \\
\hline
\end{tabular}

Table 5. The production of English dative alternation structures per monolingual and per bilingual child output and adult input (\# of cases (\%)) $)^{18}$

These findings show that the relative frequency rate of exposure to DOCs and to/for-datives in the adult input appears to be in line with the use of these structures in the L1 English and in the 2L1 English children's output alike (e.g. Campbell and Tomasello 2001; De Marneffe et al. 2012; Legate and Yang 2002; Lust 2006; Pullum and Scholz 2002; Sampson 2002; Yang 2016, 2011, 2002). This is so both in the girls' and in the boys' data in the two language groups, with the exception of the 2L1 English girls' output where further data are required. Campbell and Tomasello (2001) also report that 5 of their 7 L1 English children selected (age range: 1;02-5;00), taken from CHILDES, pattern closely with their adult input in the production of DOCs over to/fordatives ( $p<.01$ ), as observed in 21 of the 26 most salient DA verbs (e.g. bring, get, give, make, read, send, show, among others). The remaining 2 L1 English children reveal an opposite preference pattern as a result of their mothers' higher rate in the use of to-

\footnotetext{
${ }^{18}$ In table 5, the participants of each target language group have been organized in terms of biological gender (first girls and then boys).
} 
datives (Adam; the Brown corpus) and for-datives (Peter; the Bloom corpus) with the verbs 'make' and 'get', respectively. Similar results are found in De Marneffe et al.'s (2012) study on the influence of adults' use of DOCs (584 occurrences) and to/fordatives (204 occurrences) in the 7 L1 English children's output (i.e. 408 DOCs and 122 to/for-datives), as also selected from CHILDES (age range: 2;00-5;00).

Given the lack of biological gender differences regarding the similar patterns observed in the adult input and in the children's output, as reflected in the production of the L1 English children as well as in that of the 2L1 English boys, these results are not in line with previous L1 English empirical works on the imbalanced frequency of exposure when parents engage in conversations with girls or with boys (Clearfield and Nelson 2006; Gleason 1990; Lovas 2011).

\subsubsection{Main findings}

Section 5.1 has been devoted to the analysis of English DA structures, as observed in the production of L1 English and 2L1 English children (girls and boys). These data allow us to provide an answer to the first two RQs formulated in chapter 3.

As for RQ 1, in order to account for the syntactic derivational relationship (or lack thereof) between the two English DA structures (i.e. DOCs and to/for-datives), we have analyzed the L1 English and the 2L1 English children's ages of onset and incidence through language development.

- RQ 1. Is there a syntactic derivational relationship (or lack thereof) between the two types of English DA structures, namely, DOCs and to/fordatives in the production of L1 and 2L1 children? YES, THERE IS A LACK OF DERIVATIONAL RELATIONSHIP BETWEEN DOCs AND TO/FOR-DATIVES

The results of the present study reveal that DOCs and to/for-datives start being produced at approximately the same age, as per the statistical analyses and as equally reflected in the L1 English children's data and in the 2L1 English children's data. What is more, the onset of the two English DA structures does not show significant differences when comparing the two language groups. These results provide support for the syntactic non-derivational relationship and the semantic relatedness between DOCs and to/for-datives. Even though the two English DA constructions emerge concurrently, 
to/for-datives reflect a later emergence and a lower incidence through language development when compared to DOCs, as observed in the L1 English children's data and in the 2L1 English children's data alike. This could be caused by the presence of prepositions and their Case and theta role assignment properties, and/or by the frequency of exposure to these structures in the adult input.

Regarding RQ 2, we seek to answer whether the frequency with which DOCs and to/for-datives are used in the adult input reflects a relationship with the L1 English and with the 2L1 English children's output.

- RQ 2. Does adult input play a role in L1 and in 2L1 children's production of DOCs and to/for-datives? YES

The frequency with which English DA structures are used in the adult input could have played a role in both the L1 English and the 2L1 English children's output. This is reflected in the similar preference to produce DOCs if compared to to/for-datives both in the adults' and in the children's data.

In a nutshell, similar tendencies appear in the L1 English children's and in the 2L1 English children's production of DOCs and to/for-datives, and differences are not seen among the L1 English girls', the L1 English boys' and the 2L1 English boys' data (further data are required in the 2L1 English girls given that only 1 to/for-datives is found in 1 2L1 English girl's speech). Therefore, these production patterns provide supportive evidence that the two language groups seem to have acquired the syntactic and the semantic properties that characterize the two English DA structures, that no biological gender differences appear, and that the amount of exposure to DOCs and to/for-datives in the adult input has played a role in the children's output.

\subsection{Dative alternation in monolingual and bilingual Spanish}

\subsubsection{The age of onset}

As shown in the last row of table 6, the L1 Spanish children's production reflects an earlier emergence of DCLDs (mean age: 2;00) if compared to a/para-datives (mean age: 2;04). Similar results are observed in the 2L1 Spanish children's onset of DCLDs (mean age: 2;04) and a/para-datives (mean age: 2;07). 


\begin{tabular}{cccccc}
\hline & L1 Spanish children & \multicolumn{3}{c}{ 2L1 Spanish children } \\
\hline Children & DCLDs & a/para-datives & Children & DCLDs & a/para-datives \\
\hline Koki & $1 ; 07$ & $2 ; 05$ & Manuela & $2 ; 00$ & $2 ; 02$ \\
\hline Irene & $1 ; 09$ & $2 ; 02$ & Simon & $2 ; 01$ & $2 ; 11$ \\
\hline Emilio & $1 ; 09$ & $2 ; 08$ & Leo & $2 ; 05$ & $2 ; 11$ \\
\hline Juan 1 & $1 ; 10$ & $2 ; 01$ & Carla & $2 ; 04$ & $2 ; 04$ \\
\hline María & $1 ; 11$ & $2 ; 08$ & Alberto & $2 ; 04$ & - \\
\hline Juan 2 & $2 ; 04$ & $4 ; 08^{19}$ & John & $2 ; 04$ & - \\
\hline Lucía & $2 ; 02$ & $2 ; 02$ & Antonio & $2 ; 11$ & - \\
\hline Mendía & $2 ; 01$ & - & Sheila & - & - \\
\hline Idaira & $2 ; 11$ & - & Diego & - & - \\
\hline Mean & $\mathbf{2 ; 0 0}$ & $\mathbf{2 ; 0 4}$ & Mean & $\mathbf{2 ; 0 4}$ & $\mathbf{2 ; 0 7}$ \\
\hline
\end{tabular}

Table 6. Age of onset of Spanish dative alternation structures in monolingual and in bilingual child speech

In spite of the order of emergence, DCLDs and a/para-datives begin to be produced at approximately the same age, as equally seen in the L1 Spanish children's data $(t(7)=.171, p=.869)$ and in the 2L1 Spanish children's data $(t(5)=-2.029, p=.135)$. Likewise, these non-significant differences in the onset of the two Spanish DA structures in each language group are also found in the emergence of DCLDs $(U=13.500, p=.054)$ and in that of $a /$ para-datives $(t(8)=-.852, p=.419)$ when comparing the L1 Spanish children's data to the 2L1 Spanish children's data.

As far as the age range of first occurrence is concerned, the L1 Spanish children's emergence of DCLDs appears between 1;07 and 2;11 and that of a/para-datives is observed between 2;01 and 4;08. In the case of the 2L1 Spanish children's data, the onset of DA structures ranges from 2;00 to 2;11 in DCLDs and from 2;02 to 2;11 in a/para-datives.

As shown in table 6 and as it appears in the order in which the L1 Spanish children begin to produce the two DA structures, the onset of a/para-datives follows that of DCLDs in 6 out of the 9 L1 Spanish children's data and the two DA structures emerge concurrently in the data from 1 L1 Spanish child at 2;02. Although only DCLDs are produced by 2 L1 Spanish children, these structures are assumed to emerge earlier if compared to a/para-datives. With regards to the 2L1 Spanish children's data, DCLDs

\footnotetext{
${ }^{19}$ Juan 2's age of onset of a/para-datives deviates from the mean age of first occurrence of prepositional DA structures in the overall L1 Spanish children's data ( $\mathrm{SD}=.77032$, mean age=2;08, $\mathrm{N}=7$ ). The normal distribution of the L1 Spanish children's emergence of a/para-datives is assumed by excluding Juan 2's data ( $\mathrm{SD}=.03141$, mean age=2;04, $\mathrm{N}=6$ ) both in the computation of the mean age of onset of these structures as well as when running comparative statistical analyses with the emergence of DCLDs.
} 
begin to be produced before a/para-datives, as reflected in 3 out of the 9 2L1 Spanish children's data, and a concurrent emergence of the two DA structures is observed in the data from 1 2L1 Spanish child at 2;04. While an earlier emergence of DCLDs is assumed in 3 2L1 Spanish children's data given that a/para-datives are not produced, the two DA structures are not found in 2 2L1 Spanish children's data.

From a biological gender approach, the L1 Spanish girls and the L1 Spanish boys do not differ in the order of onset of DA structures, and analogous findings are seen when comparing the 2L1 Spanish girls' data to the 2L1 Spanish boys' data. As reflected in the means of onset in table 7, DCLDs start being produced earlier if compared to a/para-datives and this order equally appears in the L1 Spanish girls' data (i.e. DCLDs (mean age: 2;00) > a/para-datives (mean age: 2;04)) and in the L1 Spanish boys' data (i.e. DCLDs (mean age: 1;11) > a/para-datives (mean age: 2;04)). Furthermore, the 2L1 Spanish girls and the 2L1 Spanish boys pattern closer to their L1 peers regarding the order of first occurrence of the two Spanish DA structures, namely, DCLDs (mean age: 2;02) > a/para-datives (mean age: 2;03) in the 2L1 Spanish girls' data and DCLDs (mean age: 2;05) >a/para-datives (mean age: 2;11) in the 2L1 Spanish boys' data. 


\begin{tabular}{|c|c|c|c|c|c|c|}
\hline \multirow{2}{*}{$\begin{array}{c}\text { Biological } \\
\text { gender }\end{array}$} & \multicolumn{3}{|c|}{ L1 Spanish children } & \multicolumn{3}{|c|}{ 2L1 Spanish children } \\
\hline & children & DCLDs & a/para-datives & Children & DCLDs & a/para-datives \\
\hline \multirow{7}{*}{ Girls } & Irene & $1 ; 06$ & $2 ; 02$ & Manuela & $2 ; 00$ & $2 ; 02$ \\
\hline & Koki & $1 ; 07$ & $2 ; 05$ & Carla & $2 ; 04$ & $2 ; 04$ \\
\hline & María & $1 ; 11$ & $2 ; 08$ & Sheila & - & - \\
\hline & Lucía & $2 ; 02$ & $2 ; 02$ & & & \\
\hline & Mendía & $2 ; 01$ & - & & & \\
\hline & Idaira & $2 ; 11$ & - & & & \\
\hline & Mean & $2 ; 00$ & $2 ; 04$ & Mean & $2 ; 02$ & $2 ; 03$ \\
\hline \multirow{7}{*}{ Boys } & Emilio & $1 ; 09$ & $2 ; 08$ & Simon & $2 ; 01$ & $2 ; 11$ \\
\hline & Juan 1 & $1 ; 10$ & $2 ; 01$ & Leo & $2 ; 05$ & $2 ; 11$ \\
\hline & Juan 2 & $2 ; 04$ & $4 ; 08^{20}$ & Alberto & $2 ; 04$ & - \\
\hline & & & & John & $2 ; 04$ & - \\
\hline & & & & Antonio & $2 ; 11$ & - \\
\hline & & & & Diego & - & - \\
\hline & Mean & $1 ; 11$ & $2 ; 04$ & Mean & $2 ; 05$ & $2 ; 11$ \\
\hline
\end{tabular}

Table 7. Age of onset of Spanish dative alternation structures in monolingual and in bilingual girls' and boys' speech

Despite the order of emergence of DCLDs and a/para-datives, the L1 Spanish girls $(t(4)=-3.000, p=.058)$ do not differ from the L1 Spanish boys $(t(1)=-3.607, p=.069)$ in the rather similar age of emergence of the two Spanish DA structures. Similar findings appear in the 2L1 Spanish girls' data $(t(1)=-1.000, p=.500)$ when compared to the 2L1 Spanish boys' data $(t(3)=4.000, p=.156)$.

In terms of the age range of onset of Spanish DA structures, while the L1 Spanish girls begin to produce DCLDs between 1;06 and 2;11 and the emergence of a/paradatives appears between 2;02 and 2;08, the L1 Spanish boys' onset of DCLDs ranges from $1 ; 09$ to 2,04 and that of a/para-datives from $2 ; 01$ to $4 ; 08$. In the case of the 2L1 Spanish children's data, the girls' first occurrence of DCLDs is found between 2;00 and 2;04 and that of a/para-datives emerges between 2;02 and 2;04, whereas the boys' onset of DLCDs and a/para-datives ranges from 2;01 to 2;11, in the former, and at 2;11, in the latter, as exclusively observed in Simon's and Leo’s data.

Although the girls and the boys in the two language groups (i.e. L1 Spanish and 2L1 Spanish) tend to produce DCLDs earlier than a/para-datives, individual variation is

\footnotetext{
${ }^{20}$ Juan 2's age of onset of a/para-datives (i.e. 4;08) brings about a large standard deviation to the overall L1 Spanish boys' mean age of onset of these structures $(S D=1.17543$, mean age $=3 ; 01, N=3)$. Given the presence of this outlier, normal data distribution is assumed by excluding Juan 2's emergence of a/paradatives from the data analyses. This results in a smaller standard deviation of the L1 Spanish boys' mean age of onset of $a$ /para-datives ( $\mathrm{SD}=0.04950$, mean age $=2 ; 04, \mathrm{~N}=2$ ).
} 
reflected in the children's production. As displayed in table 8 and as reflected in the order in which the target constructions begin to emerge, DCLDs start being produced before a/para-datives in 3 out of the 6 L1 Spanish girls' data, a concurrent onset of the two target structures is observed in 1 L1 Spanish girl's data at 2;02 and only DCLDs are produced by 2 L1 Spanish girls. In contrast to these findings, the earlier onset of DCLDs when compared to a/para-datives appears to be uniform in the 3 L1 Spanish boys' data.

Regarding the 2L1 Spanish children's data, an earlier onset of DCLDs if compared to a/para-datives is found in the production of 1 out of the 32L1 Spanish girls, the two Spanish DA structures emerge concurrently in 1 2L1 Spanish girl's data at 2;04 and the production of the two target constructions does not appear in another 2L1 Spanish girl's speech. Substantial variation is also present in the 2L1 Spanish boys' onset of DA structures: DCLDs start being produced before a/para-datives, as reflected in 2 out of the 6 2L1 Spanish boys' data, and an earlier onset of DCLDs is assumed in the 3 2L1 Spanish boys' speech given the lack of data found in the production of a/para-datives. Besides, the production of the two Spanish DA structures does not appear in 1 2L1 Spanish boy’s speech.

Considering the data analyzed above, the similar emergence of DCLDs and a/para-datives, as reflected in the L1 Spanish children's data and in the 2L1 Spanish children's data alike, suggests that these children are building a shared non-derivational underlying structure as complex predicates or as SC constructions, and differences are not seen when comparing the onset of these structures in the two biological gender groups. These findings are in line with Snyder and Stromswold's (1997) Property A of English DA structures, which means that the dependence of the two Spanish DA structures on a shared syntactic property would comply with the Complex Predicate Parameter (Snyder 2001, 1995), even though DCLDs are said to have a different status to English DOCs, as Spanish is grouped in the [-complex predicate] option of the parameter.

An alternative approach to the non-significant differences in the L1 Spanish and in the 2L1 Spanish children's ages of onset of a/para-datives and DCLDs could be attributed to the construction of two different underlying structures, as proposed by Cuervo (2003a, 2003b). Following Cuervo's proposal, Spanish DA constructions could be argued to differ in the status of the head projected, namely, a verb in a/para-datives 
and a dative clitic in DCLDs. In the case of DCLDs, the dative clitic is argued to function as the morphological spell-out of an applicative argument (in line with Pylkkänen's (2000) low applicatives) that base-generates post-verbally and subcategorizes for an IO-PP, as its specifier, and a DO-DP, as its complement. In order for the two Spanish DA structures to meet the Case Filter conditions, Cuervo (2003a, 2003b) argues that the DO-DP and the prepositional complement in a/para-datives are allocated accusative and dative Case by the verb and by the prepositions 'a/para', respectively. On the contrary, the dative clitic in DCLDs assigns inherent Case to the prepositional complement and the DO-DP undergoes movement to the specifier of a vP to receive accusative Case from ' $v$ ', since ' $v$ ' is argued to have obligatory EPP features (Marantz 1991). Then, the dative clitic merges with the verb in tense position once both constituents move to ' $\mathrm{v}$ ' via head-to-head movement.

In other words, the similar emergence of Spanish DA structures in the two target language groups speaks against the derivation of DCLDs from a/para-datives via the presence and the absence of a dative clitic, respectively, as argued by Demonte (1995, 1994), and followed by others (Bruhn de Garavito 2000; Kempchinsky 2004; among others).

Along with the syntactic relatedness, the non-significant differences in the onset of DCLDs and a/para-datives could also lend support to their semantic relationship, thus, complying with the UTAH requirements. This is seen in the shared theme and recipient theta roles of the DO and the IO when DCLDs alternate as $a$-datives, as allocated by the verb and by the preposition ' $a$ ', respectively, as well as in the shared theme and beneficiary theta roles when DCLDs alternate as para-datives, as allocated to the DO by the verb and to the IO by the prepositions ' $a$ ' in DCLDs and 'para' in paradatives. Despite the initial issues that DCLDs pose to the UTAH conditions, two arguments have been proposed for the theta role assignment of the dative clitic: (a) It could inherit the recipient or the beneficiary theta role allocated to the prepositional complement by the preposition ' $a$ ', depending on whether DCLDs alternate as $a$-datives or as para-datives, as argued in the Matching Principle (Suñer 1988); or (b) it could function as an affixal morpheme which, along with the verb, assign a theme theta role to the DO and an agent theta role to the subject via inflection (Anagnostoupoulou 2006, 2003; Beavers and Nishida 2009; Borer 1984; among others). 
In addition to the similar emergence of DCLDs and a/para-datives in each language group, analogous results appear when the 2L1 Spanish children's data are compared to those of their L1 peers. This monolingual-like behavior points to the fact that the presence of the 2L1 Spanish children's other language (i.e. English) does not seem to have influenced the acquisition of the similar syntactic and semantic relationship that characterizes the two Spanish DA structures. Furthermore, it points to the lack of a bilingual effect. The role played by English in the 2L1 Spanish children's acquisition of the properties underlying DCLDs and a/para-datives will be investigated in section 5.3.2.

Although the two Spanish DA structures show a similar onset, the L1 Spanish and the 2L1 Spanish children begin to produce a/para-datives later than DCLDs, and biological gender differences do not appear in the data. This may be related to the additional properties of the prepositions 'a/para' in mediating the process of dative Case and recipient/beneficiary theta role assignment to the DP, in line with Snyder and Stromswold's (1997) Property B of English to/for-datives. Moreover, these results are partially consistent with Torrens and Wexler's (2000) study on DCLDs. Based on the spontaneous data of an L1 Spanish child (María, the Ornat corpus, CHILDES), Torrens and Wexler (2000) report on the early emergence of DCLDs between 1;07 and 2;03, regardless of whether the dative clitic is optional (with non-pronominal prepositional complements) or required (with pronominal prepositional complements). This means that the L1 Spanish and the 2L1 Spanish children's earlier appearance of DCLDs in the present study, when compared to a/para-datives, complies with the Full Competence Hypothesis (Poeppel and Wexler 1993) in that dative clitics, as functional categories, are present in the children's grammar from early on. Nevertheless, these results contrast with the cross-sectional study conducted by Ungureanu (2017) in which 2 L1 Romanian boys (at 2;08 and at 3;01) show an earlier onset of mono-transitive structures that allow an accusative clitic to be co-indexed with a null DO-DP (i.e. the [-DOCD] option of the DOCD parameter), when compared to the onset of mono-transitive constructions that allow the accusative clitic doubling of a DO-DP (i.e. the [+DOCD] option of the DOCD parameter).

What is more, the lack of biological gender differences observed in the L1 Spanish and in the 2L1 Spanish children's acquisition of the syntactic and the semantic properties of DCLDs and a/para-datives argues against previous works on the earlier 
syntactic and lexical development in girls when compared to boys (e.g. Eriksson et al. 2012).

\subsubsection{Dative alternation through language development}

This section examines whether the incidence of Spanish DA structures through language development, as analyzed in the L1 Spanish children's data, provides further insight into the syntactic non-derivational relationship between DCLDs and a/paradatives, as discussed earlier in section 5.2.1, and whether this is also seen in the 2L1 Spanish children's data. Two language development measures are used for the data analyses, namely, age (section 5.2.2.1) and MLUw values (section 5.2.2.2).

\subsubsection{Age stages}

As illustrated in figure 13, the L1 Spanish children produce DCLDs through wider age stages if compared to a/para-datives. More specifically, the incidence of DCLDs ranges from 1;07-1;11 to 4;07-4;11 and that of a/para-datives is seen from 2;00-2;06 to 4;07-4;11.

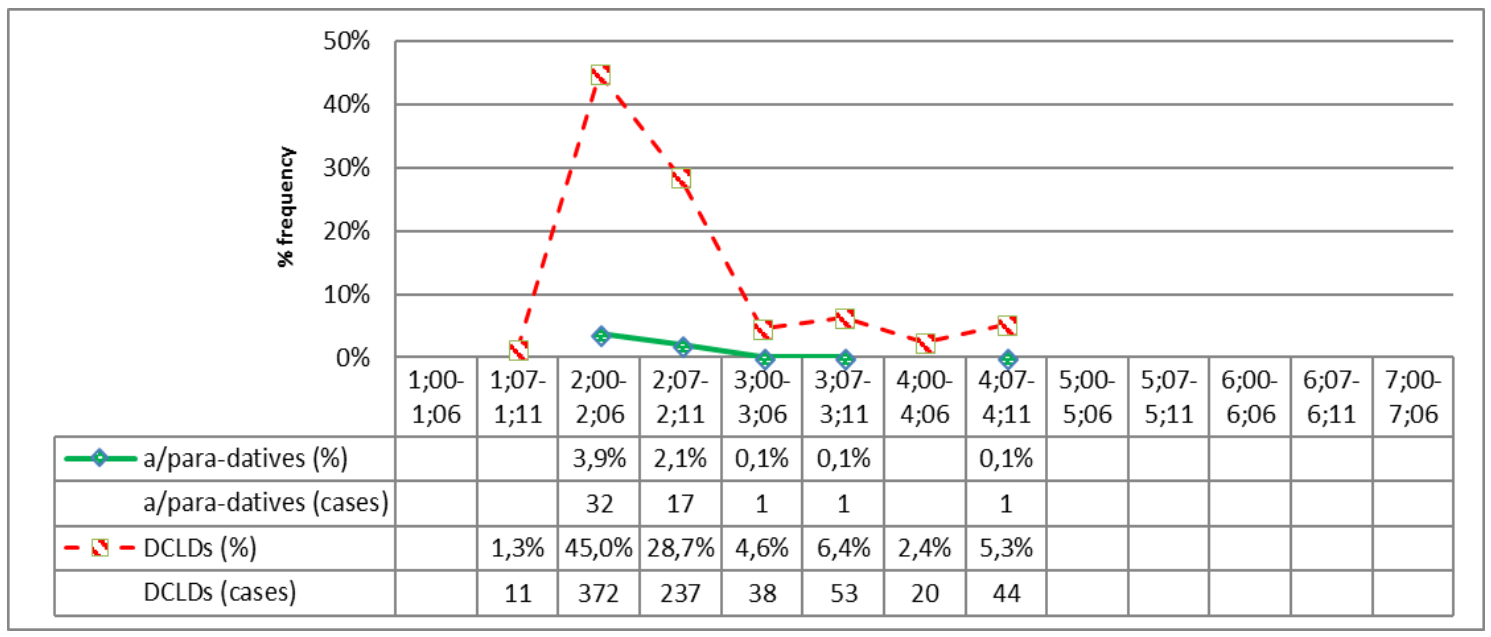

Figure 13. The monolingual Spanish children's production of dative alternation structures per age stages

[100\% = overall DA structures produced by L1 Spanish children]

In addition to the longitudinal incidence of the two Spanish DA structures, the L1 Spanish children produce DCLDs more frequently when compared to a/para-datives and this is so in each age stage $(z=-2.366, p=.018)$. A sharp rise in the use of DCLDs appears from 1;07-1;11 (11 occurrences, 1.3\%) to 2;00-2;06 (372 occurrences, 45\%), stage at which the frequency of use of DCLDs gradually decreases between 2;07-2;11 
(237 occurrences, 28.7\%) and 4;07-4;11 (44 occurrences, 5.3\%). In contrast to the incidence of DCLDs, the production of a/para-datives is low and reflects a decreasing pattern from 2;00-2;06 (32 occurrences, 3.9\%) to 4;07-4;11 (1 occurrence, 0.1\%).

As depicted in figure 14, when the L1 Spanish children's data are analyzed from a biological gender viewpoint, the girls show a wider age range in the production of DCLDs and a/para-datives (i.e. from 1;00-1;06 to 4;07-4;11), if compared to the boys' use of the target structures from 1;07-1;11 to 4;07-4;11.

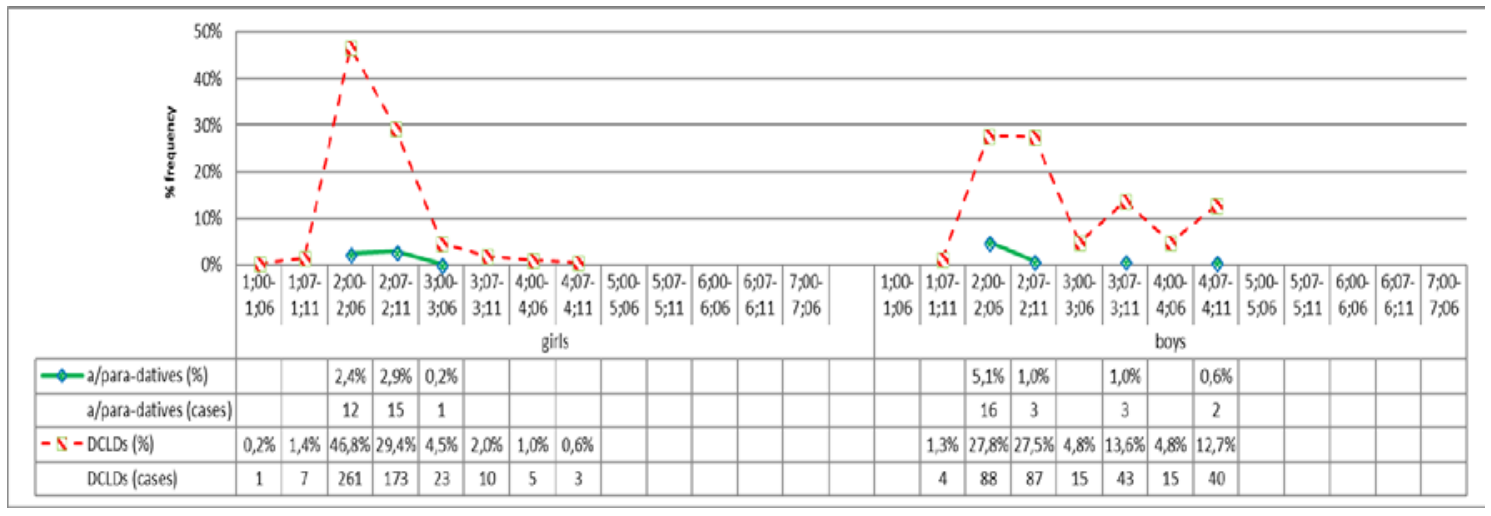

Figure 14. The production of dative alternation structures in the monolingual Spanish girls and in the monolingual Spanish boys per age stages

[100\% = overall DA structures produced by L1 Spanish girls or by L1 Spanish boys]

Regardless of the biological gender differences in the age range of production, the L1 Spanish girls $(z=-2.521, p=.012)$ do not differ from the L1 Spanish boys $(z=-2.371$, $p=.018$ ) in the incidence of DCLDs over a/para-datives through the language development. As represented in figure 14, the L1 Spanish girls show a sharp increase in the use of DCLDs from 1;00-1;06 (1 case, 0.2\%) to 2;00-2;06 (261 cases, 46.8\%), stage from which the production of these structures gradually decreases until 4;07-4;11 (3 cases, $0.6 \%)$. The low use of a/para-datives in the L1 Spanish girls' data remains stable between 2;00-2;06 (12 cases, 2.4\%) and 2;07-2;11 (15 cases, 2.4\%), and it lowers down at 3;00-3;06 (1 case, 0.2\%).

As far as the L1 Spanish boys' data are concerned, a low incidence of DCLDs is observed at the stage of onset, that is, at 1;07-1;11 (4 cases, 1.3\%). Then, the use of DCLDs increases strongly between 2;00-2;06 (88 cases, 27.8\%) and 2;07-2;11 (87 cases, $27.5 \%$ ), followed by a gradual decrease until 4;07-4;11 (40 cases, 12.7\%). In the case of a/para-datives, the L1 Spanish boys lower down the use of these structures 
progressively from 2;00-2;06 (16 cases, 5.1\%) to 2;07-2;11 (3 cases, 1\%), and the incidence remains stable at 4;07-4;11 (2 cases, 0.6\%).

Similar to the L1 Spanish children's data, the 2L1 Spanish children produce DCLDs through broader age stages when compared to a/para-datives. As illustrated in figure 15, the use of DCLDs appears between 2;00-2;06 and 6;07-6;11, and that of a/para-datives is reflected between 2;00-2;06 and 6;00-6;06.

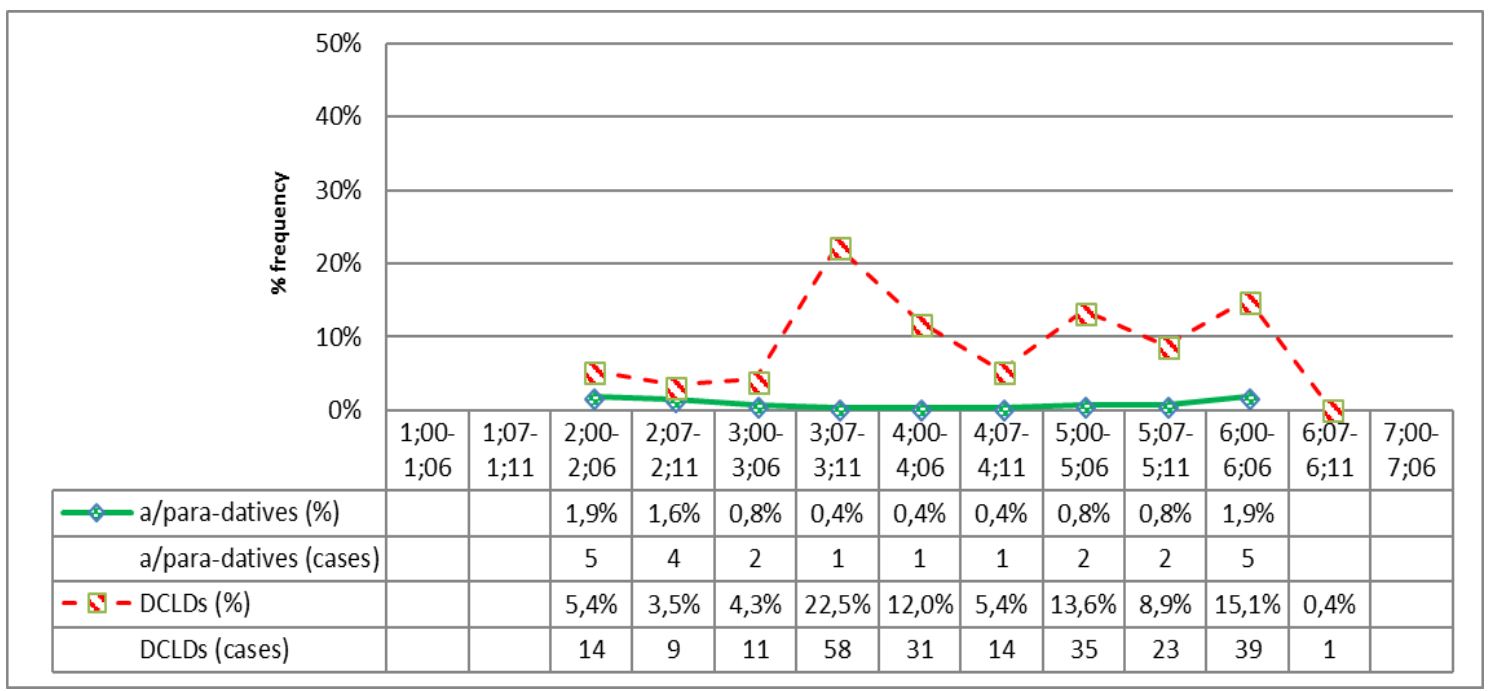

Figure 15. The bilingual Spanish children's production of dative alternation structures per age stages

[100\% = overall DA structures produced by 2L1 Spanish children $]$

Besides the contrast in the age range of production of the two Spanish DA structures, the 2L1 Spanish children reveal a higher rate in the use of DCLDs when compared to a/para-datives through the age stages $(t(8)=-3.873, p=.004)$, as also observed in their L1 peers (see figure 13). To be more precise, the 2L1 Spanish children's use of DCLDs increases progressively from 2;00-2;06 (14 occurrences, 5.4\%) to 3;07-3;11 (58 occurrences, 22.5\%), where DCLDs reach the highest stage of incidence. Although the production of DCLDs decreases slightly at 4;00-4;06 (31 occurrences, 12\%), it remains stable until 6;00-6;06 (39 occurrences, 15.1\%). At the last production stage of DCLDs (i.e. at 6;07-6;11), a sharp low incidence (1 occurrence, $0.4 \%$ ) is reflected. By contrast, the 2L1 Spanish children' use of a/para-datives remains low from 2;00-2;05 (5 occurrences, 1.9\%) to 6;00-6;05 (5 occurrences, 1.9\%).

Biological gender differences appear in the 2L1 Spanish children's data when comparing the age range of production of DCLDs and a/para-datives. As illustrated in figure 16, the 2L1 Spanish boys' use of the two Spanish DA structures is seen through 
longer age stages (i.e. from 2;00-2;06 to 6,07-6;11), when compared to the 2L1 Spanish girls' data (i.e. from 2;00-2,06 to 3;00-3,06). These findings contrast with those ones observed in their female and in their male L1 counterparts since a reversed developmental pattern is seen in the age range of production of the target constructions.

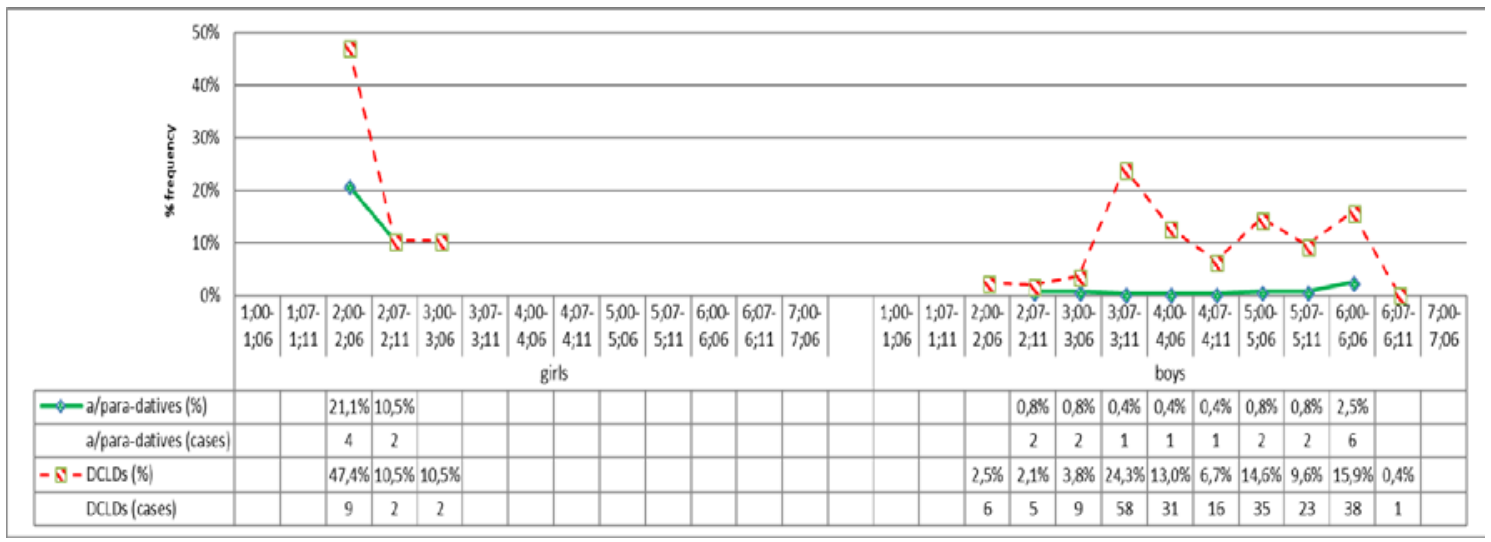

Figure 16. The production of dative alternation structures in the bilingual Spanish girls and in the bilingual Spanish boys per age stages

[100\% = overall DA structures produced by 2L1 Spanish girls or by 2L1 Spanish boys]

Despite the divergences mentioned earlier, the 2L1 Spanish girls display higher frequency rates in the use of DCLDs when compared to a/para-datives through the language development, and similar frequency rates appear in the 2L1 Spanish boys' data. Thus, the developmental production patterns of Spanish DA structures, as reflected in the data from the 2L1 Spanish girls and the 2L1 Spanish boys, are consistent with those ones observed in the production of girls and boys in their L1 peers (see figure 14).

Nevertheless, statistical differences are seen when comparing the 2L1 Spanish girls' data to the 2L1 Spanish boys' data. While the 2L1 Spanish boys' incidence of DCLDs and $a$ /para-datives through the age stages is statistically significant $(z=-2.666$, $p=.008$ ), the 2L1 Spanish girls do not show significant differences in the longitudinal use of the two Spanish DA structures $(z=-1.342, p=.180)$. We argue that, in the case of the 2L1 Spanish girls' data, the statistical results could be related to the parallel decreasing production pattern of DCLDs and a/para-datives, rather than to the clear-cut differences in their frequency of use through the age stages.

As illustrated in figure 16, the 2L1 Spanish girls' production of the two DA structures appears to be high at 2;00-2;06 (9 occurrences, $47.4 \%$ in DCLDs; 4 occurrences, $21.1 \%$ in a/para-datives), stage from which the incidence decreases until 
3;00-3;06 in DCLDs (2 occurrences, 10.5\%) and until 2;07-2;11 in a/para-datives (2 occurrences, $10.5 \%)$.

As for the 2L1 Spanish boys' data, the use of DCLDs rises from 2;00-2;06 (6 occurrences, $2.5 \%$ ) to $3 ; 07-3 ; 11$ (58 occurrences, 24.3\%). Then, a decrease in the production of these structures is seen at 4;00-4;06 (31 occurrences, 13\%), followed by a rather constant incidence until 6,00-6,06 (38 occurrences, 15.9\%). This is not seen at 6;07-6;11, where DCLDs show a strong decrease in use (1 occurrence, $0.4 \%$ ). In contrast to DCLDs, the 2L1 Spanish boys' production of a/para-datives remains low from 2;00-2;06 (2 occurrences, 0.8\%) to 6;00-6;06 (6 occurrences, 2.5\%).

When the 2L1 Spanish children's longitudinal production of Spanish DA structures is compared to that of their L1 peers, significant differences do not appear in the incidence of DCLDs $(U=83.500, p=.958)$ and $a /$ para-datives $(U=58.500, p=.157)$ through the age stages. This suggests, once more, the lack of a bilingual effect and of cross-linguistic influence.

Therefore, the lower incidence of a/para-datives when compared to DCLDs through the language development, as equally seen in the L1 Spanish children's data and in the 2L1 Spanish children's data as well as when the two language groups are compared to each other, goes hand in hand with the order in which these constructions emerge (see section 5.2.1). Besides, biological gender differences are not reflected in this respect. These data lend further support to the additional dative Case and recipient/beneficiary theta role mediated assigning properties of the prepositions 'a/para', as proposed by Snyder and Stromswold's (1997) Property B for English to/for-datives. Moreover, the frequency rates of incidence could lie in the relative frequency of exposure to the two Spanish DA constructions in the adult input, as will be looked into in section 5.2 .3 below.

\subsubsection{MLUw stages}

As illustrated in figure 17, the L1 Spanish children reflect a significantly higher incidence of DCLDs when compared to a/para-datives through the MLUw stages $(t(4)=-3.715, p=.014)$. 


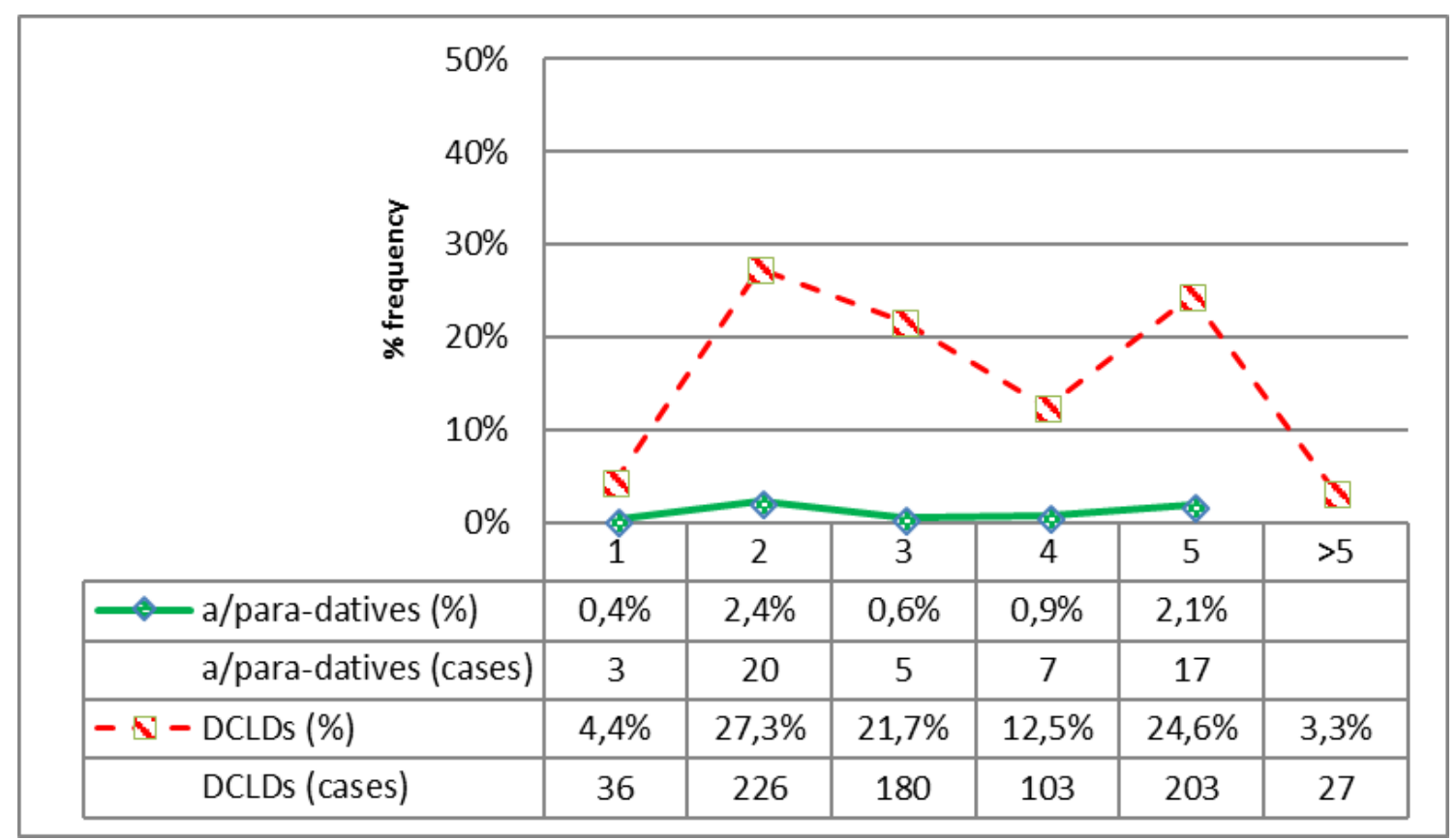

Figure 17. The monolingual Spanish children's production of dative alternation structures per MLUw stages

$[100 \%$ = overall DA structures produced by L1 Spanish children $]$

More specifically, the L1 Spanish children increase the use of the two Spanish DA structures sharply from the MLU of 1 word (36 occurrences, 4.3\%, in DCLDs; 3 occurrences, $0.4 \%$, in a/para-datives) to the MLU of 2 words (226 occurrences, 27.3\%, in DCLDs; 20 occurrences, 2.4\%, in a/para-datives). Then, a symmetric gradual decrease is observed until the L1 Spanish children reach an MLUw >5 in the production of DCLDs (27 occurrences, 3.3\%) and an MLUw 5 in the production of a/para-datives (17 occurrences, $2.1 \%)$.

In addition to the analyses of the L1 Spanish children's data collapsed, the L1 Spanish girls do not differ from the L1 Spanish boys regarding the use of DCLDs over a/para-datives through the language development, as shown in figure 18. However, statistical divergences are seen in the data: While the L1 Spanish girls' incidence of DCLDs is significantly higher in each MLUw stage when compared to a/para-datives $(t(4)=-3.047, p=.038)$, this is not reflected in the L1 Spanish boys' data $(z=-1.826$, $p=.068)$. We argue that the non-significant differences in the latter are not related to the frequency of use of DCLDs and a/para-datives; rather, they could be in line with the decreasing production pattern that the two structures present from MLUw 2 to MLUw 4. 


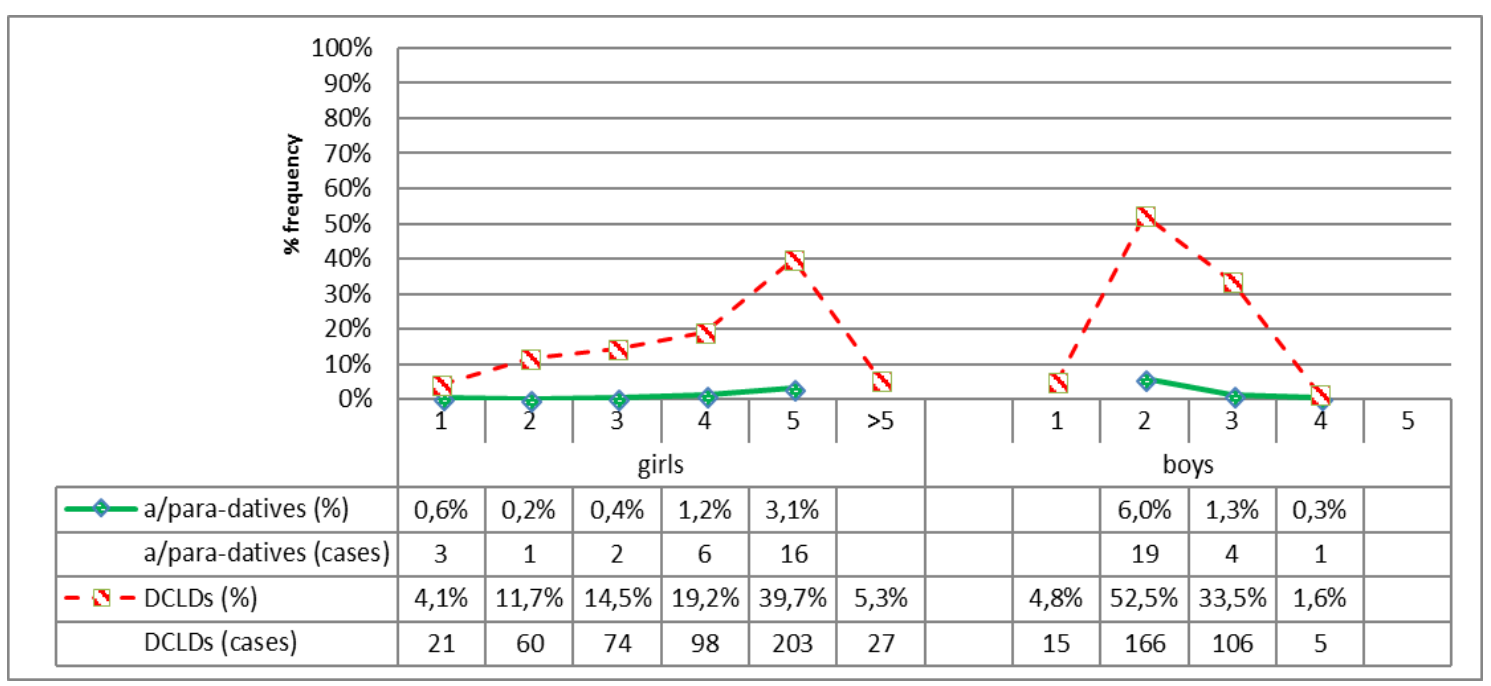

Figure 18. The production of dative alternation structures in the monolingual Spanish girls and in the monolingual Spanish boys per MLUw stages

[100\% = overall DA structures produced by L1 Spanish girls or by L1 Spanish boys]

As depicted in figure 18, the L1 Spanish girls' incidence of the two Spanish DA structures shows a gradual increase from MLUw 1 (21 DCLDs, 4.1\%; 3 a/para-datives, 0.6\%) to MLUw 5 (203 DCLDs, 39.7\%; 16 a/para-datives, 3.1\%). Then, while the use of DCLDs decreases strongly at MLUw >5 (27 occurrences, 5.3\%), a/para-datives are not produced at that stage.

The L1 Spanish boys show a low incidence of DCLDs at MLUw 1 (15 occurrences, $4.8 \%$ ), stage at which a/para-datives are not produced. It is not until the L1 Spanish boys reach MLUw 2 when Spanish DA structures are highly used (166 DCLDs, 52.5\%; 19 a/para-datives, 6\%). This stage is followed by a gradual decrease of DCLDs (5 occurrences, 1.6\%) and a/para-datives (1 occurrence, 0.3\%) at MLUw 4.

In the case of the 2L1 Spanish children's data, DCLDs also reveal higher frequency rates at each developmental stage when compared to a/para-datives $(t(4)=-$ 4.276, $p=.013$ ), as depicted in figure 19. Thus, the relative frequency rates observed in the 2L1 Spanish children's production of the two Spanish DA structures through the MLUw stages are consistent with the data from their L1 peers (see figure 17). 


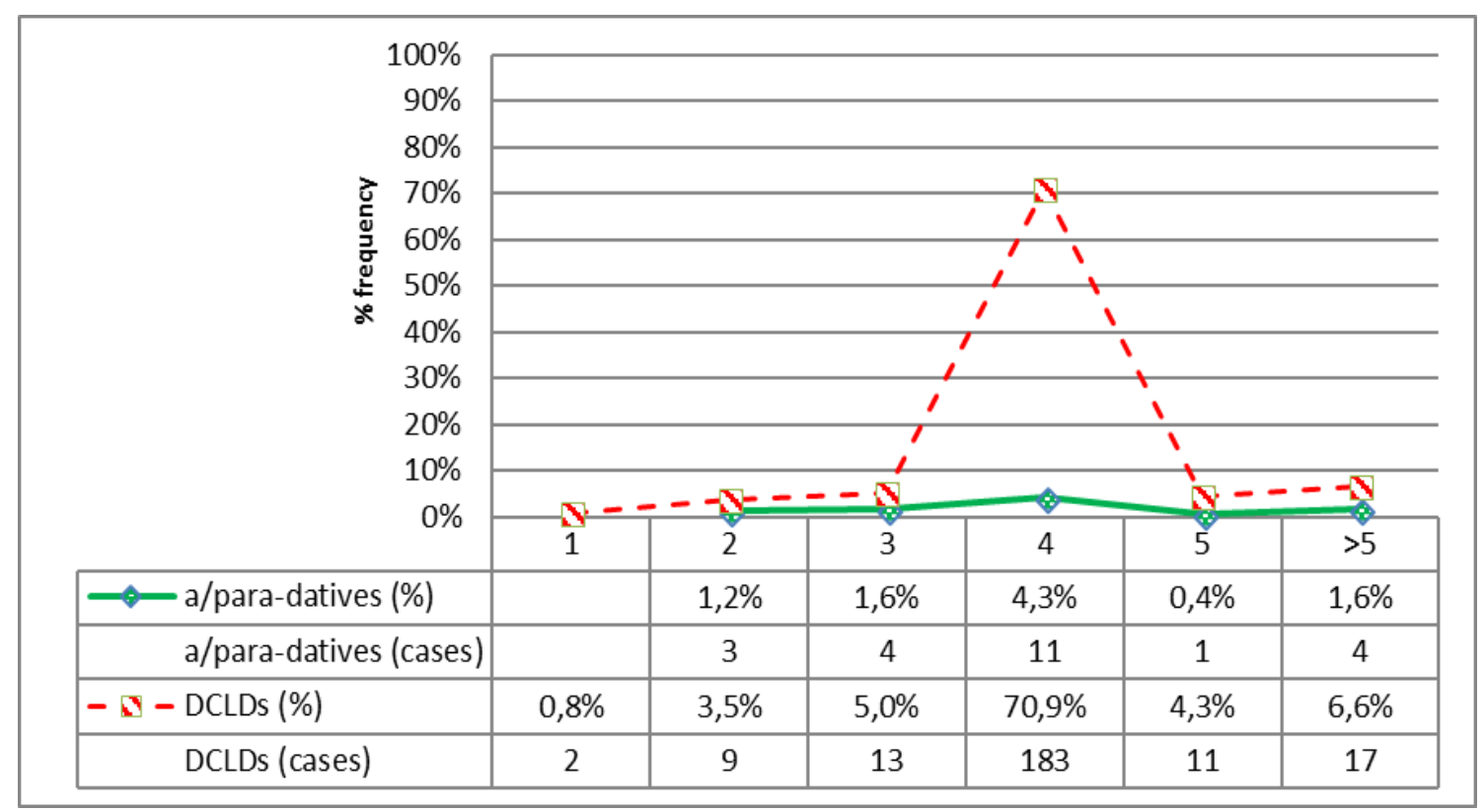

Figure 19. The bilingual Spanish children's production of dative alternation structures per MLUw stages

[100\% = overall DA structures produced by 2L1 Spanish children $]$

The 2L1 Spanish children increase the use of the two Spanish DA structures from MLUw 1 in DCLDs (2 occurrences, 0.8\%) and from MLUw 2 in a/para-datives (3 occurrences, 1.2\%) to MLUw 4 (183 DCLDs and 11 a/para-datives, 70.9\% and 4.3\%), stage at which the two constructions reach the highest stage of incidence. Then, the 2L1 Spanish children strongly decrease the production of DCLDs and a/para-datives at the last two MLUw stages, that is, at MLUw 5 (11 DCLDs and 1 a/para-dative, $4.3 \%$ and $0.4 \%$ ) and at MLUw >5 (17 DCLDs and 4 a/para-datives, 6.6\% and 1.6\%).

Similar findings to the ones reported earlier in the 2L1 Spanish children's data collapsed appear when comparing the 2L1 Spanish girls' data $(t(4)=-3.500, p=.025$ in girls) to the 2L1 Spanish boys' data $(t(4)=-3.207, p=.033)$. Therefore, the longitudinal production patterns of DCLDs and a/para-datives through the MLUw stages, as reflected in the 2L1 Spanish children's two biological gender groups, go hand in hand with the girls’ and with the boys’ data in their L1 Spanish peers (see figure 18). 


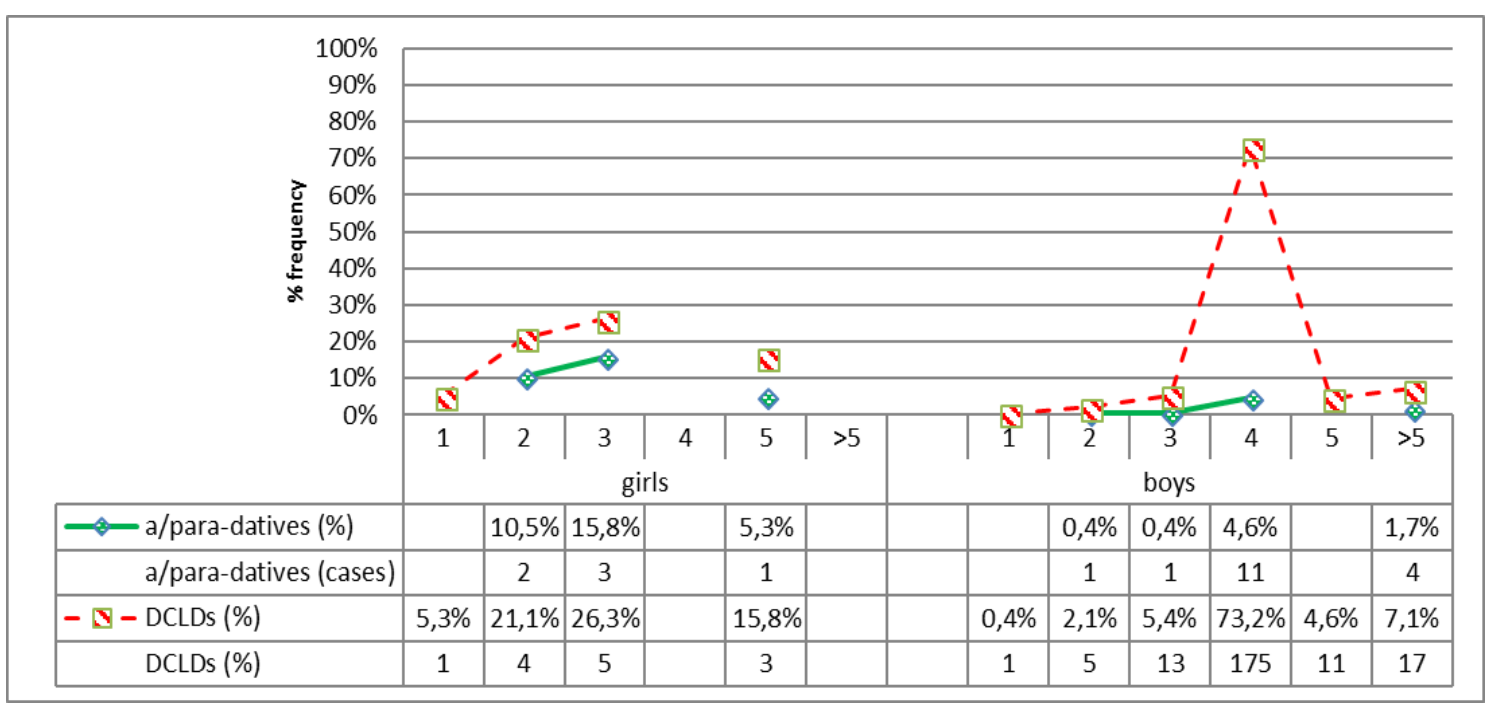

Figure 20. The production of dative alternation structures in the bilingual Spanish girls and in the bilingual Spanish boys per MLUw stages

[100\% = overall DA structures produced by 2L1 Spanish girls or by 2L1 Spanish boys]

As for the 2L1 Spanish girls' data, a low incidence of DCLDs appears at MLUw 1 (1 occurrence, 5.3\%), stage at which a/para-datives are not produced. Then, the two Spanish DA structures show a slightly increasing incidence from MLUw 2 (4 DCLDs, 21.1\%; 2 a/para-datives, 10.5\%) to MLUw 3 (5 DCLDs, 26.3\%; 3 a/para-datives, 15.8\%). It is not until the 2L1 Spanish girls reach an MLU of 5 words when the use of both DA structures decreases (3 DCLDs, 15.8\%; 1 a/para-dative, 5.3\%).

In the case of the 2L1 Spanish boys' data, the incidence of DCLDs and a/paradatives rises gradually from MLUw 1 (1 occurrence in both structures, 0.4\%) to MLUw 4 where DCLDs (175 occurrences, 73.2\%) and a/para-datives (11 occurrences, 4.6\%) reflect the highest stage of production. The two constructions decrease in use sharply from MLUw 4 to MLUw >5 (17 DCLDs, 73.2\%; 4 a/para-datives, 1.7\%).

In addition to the data analyzed in each language group, the incidence of DCLDs $(t(10)=1.977, p=.076)$ and a/para-datives $(t(10)=1.330, p=.213)$ does not show significant differences when comparing the 2L1 Spanish children to their L1 peers in their use of these structures through the different MLUw stages.

All in all, the lower rate in the use of a/para-datives through the MLUw stages, when compared to DCLDs, as seen in the data from each target language group (both in girls and boys) and when the L1 Spanish children's data are compared to the 2L1 Spanish children's data, may be attributed to the additional properties of the 
prepositions 'a/para' (Snyder and Stromswold 1997) or to the amount of exposure to these structures in the adult input, as will be examined in the following section.

Although similar results are observed when the incidence of Spanish DA structures is analyzed through the MLUw stages and through the age stages (see section 5.2.2.1), the production of DCLDs and a/para-datives appears to be more homogeneous when distributed in terms of MLUw values. As also discussed earlier for the English data (see section 5.1.2.2), this means that a more linear distribution is reflected when the production of DCLDs and a/para-datives is analyzed in terms of MLUw, if compared to the fluctuations observed in the production of these constructions in terms of age.

\subsubsection{The influence of adult input in children's output}

As displayed in figure 21, the relative frequency rates with which Spanish DA structures are used in the L1 Spanish children's adult input (4,279 DCLDs > 352 a/para-datives out of 4,631 DA structures, $92.4 \%>7.6 \%, 100 \%$ ) are also found in their output (775 DCLDs > 52 a/para-datives out of 827 DA structures, 93.7\% > 6.3\%, 100\%). Similar patterns appear in the 2L1 Spanish children's adult input (2,716 DCLDs $>251$ a/para-datives out of 2,967 DA structures, 91.5\% > 8.5\%, 100\%) and output (235 DCLDs > 23 a/para-datives out of 258 DA structures, 91.1\% > 8.9\%, 100\%), as illustrated in figure 22.

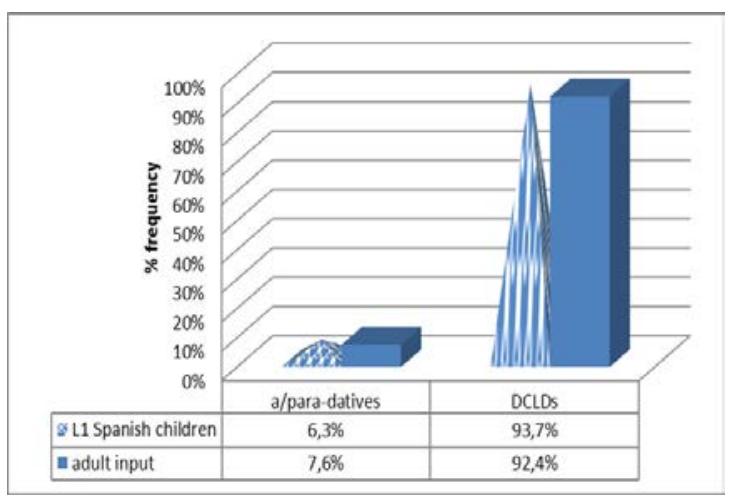

Figure 21. The production of Spanish dative alternation structures in the adult input and in the monolingual children's output

$[100 \%=$ overall DA structures produced by adults or by L1 Spanish children]

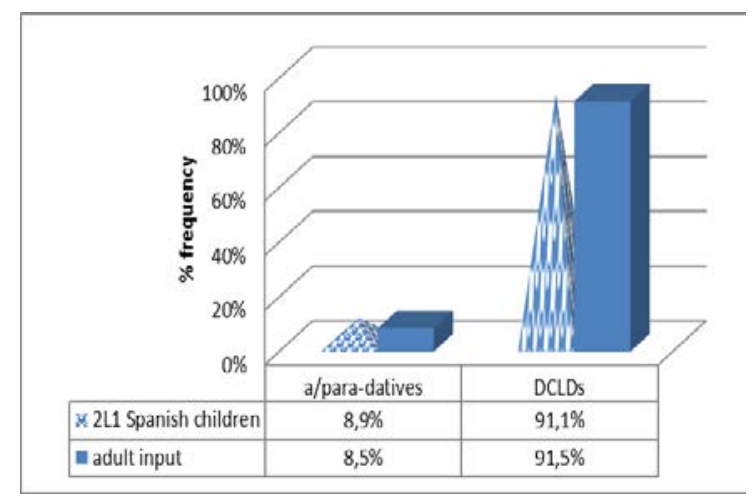

Figure 22. The production of Spanish dative alternation structures in the adult input and in the bilingual children's output

$[100 \%$ = overall DA structures produced by adults or by $2 \mathrm{~L} 1$ Spanish children]

The adult input that the L1 Spanish girls receive in the production of the two Spanish DA structures does not differ from the one that the L1 Spanish boys receive, as 
shown in figure 23. What is more, the adults' use of these constructions mirrors the L1 Spanish girls' output and the L1 Spanish boys' output alike. That is, DCLDs are more frequently produced when compared to a/para-datives, and this is seen in the L1 Spanish girls' adult input (2,670 DCLDs > 217 a/para-datives out of 2,887 DA structures, 92.5\% > 7.5\%, 100\%) and output (483 DCLDs > 28 a/para-datives out of 511 DA structures, $94.5 \%>5.5 \%, 100 \%$ ) as well as in the L1 Spanish boys' adult input (1,609 DCLDs > 135 a/para-datives out of 1,744 DA structures, 92.3\% > 7.7\%, 100\%) and output (292 DCLDs > 24 a/para-datives out of 316 DA structures, 92.4\% > 7.6\%, $100 \%)$.

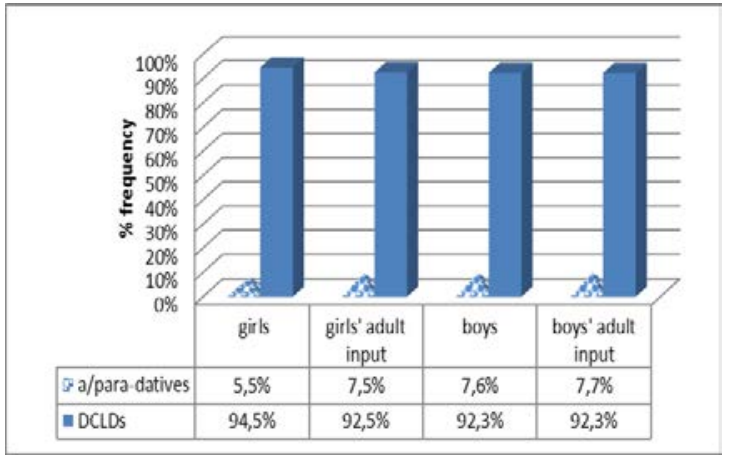

Figure 23. The production of Spanish dative alternation structures in the adult input, the monolingual girls' output and the monolingual boys' output

$[100 \%$ = overall DA structures produced by adults, by L1 Spanish girls or by L1 Spanish boys]

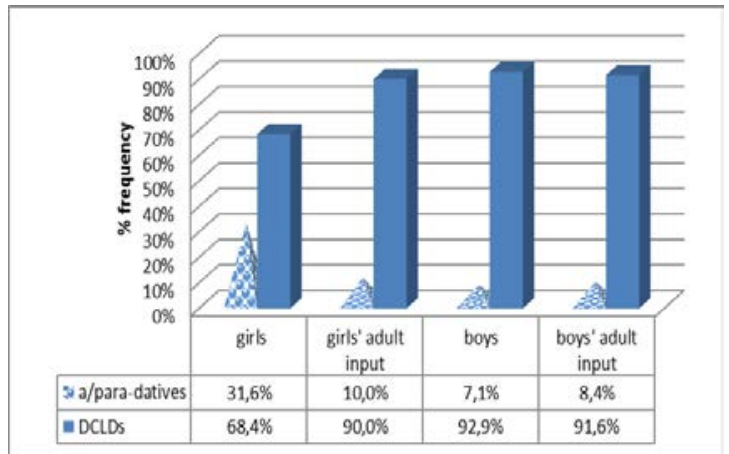

Figure 24. The production of Spanish dative alternation structures in the adult input, the bilingual girls' output and the bilingual boys' output

$[100 \%$ = overall DA structures produced by adults, by $2 \mathrm{~L} 1$ Spanish girls or by 2L1 Spanish boys]

In the case of the 2L1 Spanish children's data, the relative frequency rates with which DCLDs and a/para-datives are used by adults reflects a similar pattern in the adult input that both the 2L1 Spanish girls and the 2L1 Spanish boys are exposed to. What is more, the frequency rates of exposure to these constructions do not reflect biological gender differences in the 2L1 Spanish children's output, as also seen in the girls' and in the boys' data in their L1 peers. As illustrated in figure 24, the use of DCLDs over a/para-datives in the 2L1 Spanish girls' adult input (54 DCLDs > 6 a/para-datives out of $60 \mathrm{DA}$ structures, $90 \%>10 \%, 100 \%)$ goes hand in hand with that in their output (13 DCLDs > 6 a/para-datives out of 19 DA structures, $68.4 \%>31.6 \%$, 100\%). Analogous results are seen in the 2L1 Spanish boys' adult input (2,662 DCLDs $>245$ a/para-datives out of 2,907 DA structures, 91.6\% > 8.4\%, 100\%) and output (222 DCLDs $>17$ a/para-datives out of 239 DA structures, 92.9\% > 7.1\%, 100\%). 
The use of Spanish DA structures in the data from each child and from the adults they interact with is provided in table 8 for the two target language groups (i.e. L1 Spanish and 2L1 Spanish).

\begin{tabular}{|c|c|c|c|c|c|}
\hline $\begin{array}{l}\text { Language } \\
\text { group }\end{array}$ & Children & $\begin{array}{c}\text { Children's output } \\
\text { of DCLDs }\end{array}$ & $\begin{array}{c}\text { Adult input } \\
\text { of DCLDs }\end{array}$ & $\begin{array}{l}\text { Children's output } \\
\text { of } a \text { /para-datives }\end{array}$ & $\begin{array}{c}\text { Adult input } \\
\text { of } a \text { /para-datives }\end{array}$ \\
\hline \multirow{11}{*}{ L1 Spanish } & Idaira & $27(100)$ & $86(92.5)$ & - & $7(7.5)$ \\
\hline & Irene & $297(93.1)$ & $1,164(91.9)$ & $22(6.9)$ & $103(8.1)$ \\
\hline & Lucía & $38(90.5)$ & $86(92.5)$ & $4(9.5)$ & $7(7.5)$ \\
\hline & María & $45(97.8)$ & $589(94.1)$ & $1(2.8)$ & 37 (5.9) \\
\hline & Mendía & $6(100)$ & $621(92.1)$ & - & $53(7.9)$ \\
\hline & Koki & $70(98.6)$ & $124(92.5)$ & $1(1.4)$ & $10(7.5)$ \\
\hline & Total (girls) & 483 (94.5) & $2,670(92.5)$ & 28 (5.5) & 217 (7.5) \\
\hline & Emilio & 138 (97.9) & $566(91.6)$ & $3(2.1)$ & $52(8.4)$ \\
\hline & Juan 1 & $106(84.1)$ & 795 (91.7) & $20(15.9)$ & $72(8.3)$ \\
\hline & Juan 2 & 48 (97.9) & $248(97.3)$ & $1(2.1)$ & $11(4.2)$ \\
\hline & Total (boys) & $292(92.4)$ & $1,609(92.3)$ & $24(7.6)$ & $135(7.7)$ \\
\hline \multicolumn{2}{|c|}{ Total (overall) } & 775 (93.7) & $4,279(92.4)$ & $52(6.3)$ & $352(7.6)$ \\
\hline \multirow{11}{*}{$\begin{array}{c}\text { 2L1 } \\
\text { Spanish }\end{array}$} & Carla & $6(67.0)$ & $32(96.7)$ & $4(33.0)$ & $1(3.0)$ \\
\hline & Manuela & $5(71.4)$ & $6(71.4)$ & $2(28.6)$ & $2(28.6)$ \\
\hline & Sheila & - & $16(84.2)$ & - & $3(15.8)$ \\
\hline & Total (girls) & $13(68.4)$ & $54(90.0)$ & 6 (31.6) & $6(10.0)$ \\
\hline & Alberto & $2(100)$ & $41(87.2)$ & - & $6(12.8)$ \\
\hline & Antonio & $2(100)$ & $28(96.5)$ & - & $1(3.5)$ \\
\hline & Diego & - & $152(98.7)$ & - & $2(1.3)$ \\
\hline & John & $2(100)$ & $25(92.6)$ & - & $2(7.4)$ \\
\hline & Leo & 117 (92.9) & $1,208(91.2)$ & $9(7.1)$ & $117(8.8)$ \\
\hline & Simon & $99(92.5)$ & $1,208(91.2)$ & $8(7.5)$ & $117(8.8)$ \\
\hline & Total (boys) & 222 (92.9) & 2,662 (91.6) & $17(7.1)$ & $245(8.4)$ \\
\hline \multicolumn{2}{|c|}{ Total (overall) } & 235 (91.1) & $2,716(91.5)$ & $23(8.9)$ & $251(8.5)$ \\
\hline
\end{tabular}

Table 8. The production of Spanish dative alternation structures per monolingual and per bilingual child output and adult input (\# of cases (\%)) ${ }^{21}$

Therefore, the preference in the use of DCLDs over a/para-datives, as seen in the L1 Spanish and in the 2L1 Spanish children's data alike, seems to be in line with the relative frequency rate with which these structures are used in the adult input. Differences are not observed when comparing the adult input that the girls and the boys receive to their respective outputs in the two target language groups. These findings are consistent with Hoff et al. (2014) who demonstrate that the 2L1 English/Spanish children's amount of exposure to Spanish is a predictor of earlier vocabulary growth.

${ }^{21}$ In table 8, the participants of each target language group have been organized in terms of biological gender (first girls and then boys). 


\subsubsection{Main findings}

Section 5.2 has offered a detailed analysis of Spanish DA structures as reflected in the production of L1 Spanish and 2L1 Spanish children, including girls' and boys’ data. These findings help provide an answer to RQ 3 and RQ 4, as formulated in chapter 3.

The first issue we examine in RQ 3 is the syntactic (non-)derivational relationship that underlies and connects DCLDs and a/para-datives, as seen in the L1 Spanish children's ages of onset and incidence through language development, and whether this is so in the 2L1 Spanish children's data.

- RQ 3. Is there a syntactic derivational relationship (or lack thereof) between the two types of Spanish DA structures, namely, DCLDs and a/para-datives in the production of L1 and 2L1 children? YES, THERE IS A LACK OF DERIVATIONAL RELATIONSHIP BETWEEN DCLDs AND A/PARADATIVES

Our data analyses have shown that the two Spanish DA structures begin to be produced at approximately the same age, as equally seen in the L1 Spanish and in the 2L1 Spanish children's data, and significant differences are not seen when the onset of DCLDs and a/para-datives is compared across the two language groups. These findings could shed light on the syntactic non-derivational relationship and the similar semantics between the two Spanish DA structures. Despite the similar emergence, a/para-datives start being produced later and show a lower rate of use through language development when compared to DCLDs, as reflected in the production of the L1 Spanish children and the 2L1 Spanish children alike. This could be associated with the additional Case and theta role assigning properties of the prepositions ' $a$ /para' and/or the role played by the adult input in the children's output.

As for RQ 4, we aim at shedding light on whether the frequency with which DCLDs and a/para-datives are used by adults goes hand in hand with the L1 Spanish children's output, and whether similar patterns are seen when analyzing the adult input the 2L1 Spanish children are exposed to and their output.

- RQ 4. Does adult input play a role in L1 and in 2L1 children's production of DCLDs and a/para-datives? YES 
Our findings have revealed that adults prefer the use of DCLDs over a/paradatives and this rate of use goes hand in hand both with the L1 Spanish children's output and with the 2L1 Spanish children's output. Therefore, these results infer that the amount of exposure to the two Spanish DA structures could have played a role in the production of the two language groups.

Therefore, these data provide evidence that the 2L1 Spanish children behave as their L1 Spanish peers. This is reflected in the acquisition of the syntactic and the semantic properties that underlie the two Spanish DA structures, as analyzed in the emergence and in the use through the language development, and in the role played by adult input in child output.

\subsection{Dative alternation across English and Spanish}

This section offers a comparative analysis of English and Spanish DA structures, as seen in the production of L1 children (inter-group comparison, section 5.3.1) and 2L1 children (intra-group comparison, section 5.3.2). We adopt a different approach to the one presented in section 5.1 (English DA structures) and in section 5.2 (Spanish DA structures). In this section, the analysis is done across languages whereby prepositional and double object constructions are compared, on the one hand, in the production of L1 English and L1 Spanish children and, on the other hand, in the production of 2L1 English/Spanish children.

Considering the age of onset and the incidence of the two DA constructions through language development, as distributed in age and MLUw stages, we seek to answer whether the syntactic relationship between prepositional and double object constructions in English (i.e. DOCs and to/for-datives) is analogous to or differs from that in Spanish (i.e. DCLDs and a/para-datives).

The role that adult input plays in child output is also examined. We aim at shedding light on whether the frequency of exposure to English and Spanish DA structures in the adult input influences the L1 children's output, and whether similar findings appear in the 2L1 English/Spanish children's data.

\subsubsection{Inter-group comparison: English and Spanish dative alternation in the production of monolingual children}

Double object and prepositional DA structures emerge at approximately the same age, as reflected in the L1 English children's data $(t(11)=-2.079, p=.067)$ and in the L1 
Spanish children's data $(t(7)=.171, p=.869)$. When comparing the onset of each construction between the two language groups, significant differences do not appear in the emergence of double object constructions $(U=38.500, p=.269)$ and in that of prepositional DA structures $(U=36.000, p=.506)$.

These findings suggest that the two DA constructions are not syntactically derived from one another and, thus, a parallel underlying relation between prepositional and double object structures could be argued for across English and Spanish. As per the formal accounts discussed in chapter 1 (section 1.3), two explanations could be given. The syntactic non-derivational relationship of English DA structures could be said to differ from that of Spanish DA structures given that, following the Complex Predicate Parameter (Snyder 2001, 1995), while the availability of DA structures, in general, and that of double object constructions, in particular, is allowed in [+complex predicate] languages (i.e. English), English like-DOCs are argued to be unavailable in [-complex predicate] languages (i.e. Spanish). This means that, although a parallel structure may be argued for the two English and Spanish DA constructions, English DOCs and Spanish DCLDs would differ in their syntactic properties when alternating as prepositional DA structures. This could be so because, in English DOCs, the prepositions 'to/for' are overtly realized when alternating as to/for-datives, in contrast to Spanish DCLDs, where the dative clitic 'le(s)' is not overt when alternating as a/paradatives (Kayne 1975; Larson 2014, 1990, 1988; Snyder 2001, 1995). That is, while in English it is the production-omission of the preposition that triggers the different syntactic analyses of the two DA constructions, in Spanish it is the production-omission of the dative clitic.

Given the two alternative approaches that have accounted for the syntactic nonderivational relationship between the two English and Spanish DA structures, we leave this study open for more formal works to further shed light on this issue. Although our existing data point to the lack of syntactic derivation between prepositional and double object constructions in the two languages, we still need to have a clearer idea as to whether such a relation suggests that the two DA constructions share a parallel underlying structure across English and Spanish or, rather, they are built under two opposing underived representations.

Alternatively, as seen in the L1 children's data and when the two language groups are compared, the similar emergence of English and Spanish DA structures could also 
lend support to the formation of two different underived representations. In the case of English, DA structures are argued to be projected by a verb that subcategorizes for an SC headed, in turn, by an empty causative verb (i.e. $\varnothing_{\mathrm{HAVE}}$ ) in DOCs or by an empty verb (i.e. Ø) in to/for-datives (Mulder 1992). Other studies propose that DOCs and to/for-datives base-generate in a Chomskian-Larsonian VP-shell domain or in a single VP domain, respectively (Marantz 1993). In Spanish, two opposing underlying structures are argued in the DA formation (Cuervo 2003a, 2003b): While DCLDs are headed by a dative clitic, a/para-datives are projected by a verb.

In other words, these findings speak against earlier formal accounts on the syntactic derivational relationship of (a) English DA structures, as argued in terms of a transformational rule based on a scale of prominence (Oehrle 1976), a lexical rule (Czepluch 1982) or a passive-like movement (Haspelmath 2006; Larson 2014, 1990, 1988; Perlmutter 1980); and (b) Spanish DA structures via the presence or the absence of a dative clitic (Bruhn de Garavito 2000; Demonte 1995, 1994; Kempchinsky 2004).

Furthermore, the non-significant differences in the ages of onset of the two English and Spanish DA structures may also shed light on the analogous thematic relations between prepositional and double object constructions across these languages, conforming to the UTAH requirements.

Even if not statistically significant, a similar order of emergence appears in English and in Spanish DA structures, namely, double object constructions begin to be produced earlier if compared to prepositional DA structures. This is reflected both in the L1 English children's data (i.e. DOCs (mean age: 2;02) > to/for-datives (mean age: 2;06)) and in the L1 Spanish children's data (i.e. DCLDs (mean age: 2;00) > a/paradatives (mean age: 2;04)). And it goes in line with what has been argued in previous L1 English works (Campbell and Tomasello 2001; Gu 2010; Snyder and Stromswold 1997) and L1 Spanish studies on the emergence of DCLDs (Torrens and Wexler 2000).

In view of the later emergence of English and Spanish prepositional DA structures, when compared to double object constructions, we could infer that this could be caused by the additional dative Case and recipient/beneficiary theta role mediated assigning properties of the prepositions (Larson 1990, 1988; Marantz 1984; Pesetsky 1985; Snyder and Stromswold 1997).

Developmentally, double object constructions reveal a higher incidence if compared to prepositional DA structures in English and in Spanish alike. This is seen in 
the L1 English children's data when analyzed through the age stages $(t(11)=-4.453$, $p=.001)$ and through the MLUw stages $(t(4)=-2.743, p=.041)$. Similar findings are seen in the L1 Spanish children's data through the age stages $(z=-2.366, p=.018)$ as well as through the MLUw stages $(t(4)=-3.715, p=.014)$. Nevertheless, when the L1 English children's data are compared to the L1 Spanish children's data, statistical differences appear between the two language development measures. While the L1 English children's use of DA structures shows higher rates through the age stages if compared to the L1 Spanish children's production, both in double objects ( $U=41.000, p=.043)$ and in prepositional DA structures $(U=22.000, p=.002)$, this is not so through the MLUw stages where significant differences are not seen in the incidence of the two English and Spanish DA constructions ( $U=19.500, p=.122$ in double objects; $U=29.000, p=.511$ in prepositional DA structures). These divergences suggest that the homogeneity in the data distribution of English and Spanish DA structures per MLUw stages is a better predictor of the results obtained when compared to the production patterns per age stages. Therefore, based on the use of DA constructions in terms of MLUw values, English does not seem to differ from Spanish in the production of prepositional and double object constructions through language development, as seen in the L1 children's data.

Thus, the L1 children's lower rate in the use of English and Spanish prepositional DA structures through language development, when compared to double object constructions, seems to go hand in hand with the order of emergence of these constructions. This points to the fact that these data could also provide further evidence on the additional properties of the prepositions 'to/for' in English to/for-datives and 'a/para' in Spanish a/para-datives (Larson 1990, 1988; Marantz 1984; Pesetsky 1985; Snyder and Stromswold 1997).

As for the role played by adult input in child output, a preference in the use of double object constructions over prepositional DA structures is equally observed in both the adult input that the L1 English and the L1 Spanish children receive as well as in their output. Therefore, these findings are consistent with what has been reported in previous empirical studies on the role played by adult input in the children's output (e.g. Campbell and Tomasello 2001; De Marneffe et al. 2012; Legate and Yang 2002; Lust 2006; Pullum and Scholz 2002; Sampson 2002; Yang 2016, 2011, 2002) since the 
similar relative frequency rates with which the two English and Spanish DA structures are used by adults are also seen in the child output.

\subsubsection{Intra-group comparison: English and Spanish dative alternation in the production of bilingual children}

The 2L1 English/Spanish children begin to produce prepositional and double object constructions at a similar age in each of their two languages $(t(4)=-1.858, p=.160$ in English; $t(5)=-2.029, p=.135$ in Spanish). Furthermore, significant differences do not appear when the 2L1 English/Spanish children's emergence of double objects ( $z=-$ $1.414, p=.157)$ and that of prepositional constructions $(z=-1.342, p=.180)$ is compared across English and Spanish. This infers that the 2L1 English/Spanish children have acquired the parallel underlying non-derivational structure and the similar thematic relationship between prepositional and double object constructions across the two languages.

Even though the onset of the two English and Spanish DA structures does not show significant differences, the 2L1 English/Spanish children start producing prepositional DA structures later than double object constructions and this is so in English (i.e. DOCs (mean age: 2;04) > to/for-datives (mean age: 2;08)) and in Spanish (i.e. DCLDs (mean age: 2;04) > a/para-datives (mean age: 2;07)). These data could be related to the additional properties of the prepositions 'to/for' in English to/for-datives and 'a/para' in Spanish a/para-datives (Larson 1990, 1988; Marantz 1984; Pesetsky 1985; Snyder and Stromswold 1997).

As for the use of DA structures through language development, the 2L1 English/Spanish children show a higher incidence of double object constructions when compared to prepositional DA structures in English and in Spanish alike. This is so regardless of whether the production is distributed in terms of age stages $(t(8)=-4.335$, $p=.002$ in English; $t(8)=-3.873, p=.004$ in Spanish) or MLUw stages $(t(4)=-4.276$, $p=.013$ in Spanish). Recall that the non-significant differences in the 2L1 English/Spanish children's use of English DA structures through the MLUw stages ( $z=-$ 1.625, $p=.104$ ) could be explained by the linear decreasing production patterns of DOCs and to/for-datives (see section 5.1.2.2).

When the 2L1 English/Spanish children's incidence of double object constructions through language development is analyzed across the two languages, there are no significant differences between the production of English DOCs and Spanish DCLDs, 
as reflected per age stages $(t(12)=-2.043, p=.064)$ and per MLUw stages $(z=-.938$, $p=.348$ ). These findings are also observed when the production of English prepositional DA structures is compared to that of Spanish prepositional DA structures, regardless of the language development measure $(z=-.315, p=.752$ in age stages; $t(5)=.605, p=.571$ in MLUw stages).

All these data reveal that the 2L1 English/Spanish children's lower production of prepositional DA structures through language development in the two languages, when compared to double object constructions, appears to be consistent with the order of emergence of these constructions. This suggests that the incidence patterns of English to/for-datives and Spanish a/para-datives might be caused by the additional Case and theta role assigning properties of the prepositions (Larson 1990, 1988; Marantz 1984; Pesetsky 1985; Snyder and Stromswold 1997).

With regards to the role that adult input plays in child output, adults show a similar use of the two DA structures across English and Spanish. In particular, double object constructions (i.e. English DOCs and Spanish DCLDs) are preferred over prepositional DA structures (i.e. English to/for-datives and Spanish a/para-datives) and these patterns are consistent with the 2L1 English/Spanish children's production of these structures. This indicates that the analogous use of the two English and Spanish DA constructions in the adult input has played a role in the 2L1 English/Spanish children's dual output (e.g. Campbell and Tomasello 2001; De Marneffe et al. 2012; Legate and Yang 2002; Lust 2006; Pullum and Scholz 2002; Sampson 2002; Yang 2016, 2011, 2002).

Taking all the results discussed above into consideration, the 2L1 English/Spanish children show comparable patterns to their L1 peers (see section 5.3.1). These are reflected in the acquisition of (a) the similar underlying non-derivational structure of the two DA structures across languages; (b) the resembling additional syntactic properties between the prepositional DA constructions in the two languages; and (c) the parallel semantic relationship of the two DA structures across English and Spanish. Therefore, these data lend support to the ADH (Álvarez de la Fuente 2007; Clark 2009; Genesee et al. 1995; Mishina-Mori 2005; Paradis 2001; Paradis and Genesee 1996; Yip and Matthews 2007; among others) given that cross-linguistic influence of the syntactic and the semantic properties of prepositional and double object constructions does not seem to have occurred from English into Spanish or from Spanish into English. These 
findings argue against Gu's (2010) work which reports that, although 2L1 English/Cantonese children begin to produce DOCs (mean age: 2;00) earlier than to/fordatives (mean age: 2;09), akin to their L1 English peers (i.e. DOCs (mean age: 2;02) > to/for-datives (mean age: 2;04)), and similar to the results observed in the present study, to/for-datives appear later than in L1 English children's data, as reflected in the average temporal gap in the onset of the two structures. Gu (2010) concludes that this delay is caused by the influence from prepositional DA structures in their other L1 (i.e. Cantonese) since a disambiguation is required for the shared recipient and beneficiary theta role assigner 'bei2' in Cantonese, in contrast to the differentiated theta role markers 'to' and 'for' in English. Such a delay is not seen in the present study when comparing the 2L1 English children to their corresponding L1 peers in terms of the emergence of DOCs and to/for-datives. Nevertheless, we should take the parallelism regarding the later onset of English prepositional DA structures with caution since the two language pairs (English-Cantonese in Gu's (2010) study and English-Spanish in the present study) differ in the properties that characterize the two DA constructions.

Likewise, monolingual-like patterns are observed in the role played by the adult input in the 2L1 English/Spanish children's production of DA structures in the two languages. This means that home input conditions and, in particular, the balanced dual language exposure to English and Spanish DA structures via the one-parent onelanguage strategy (Deuchar and Quay 2000; Meisel 2004; Ronjat 1913; Takeuchi 2006; among others) could have had an effect on the 2L1 English/Spanish children's higher rates in the use of double object constructions when compared to prepositional DA structures in the two languages, as also reflected in their corresponding L1 counterparts.

\subsubsection{Main findings}

Section 5.3 has examined the syntactic derivational relationship (or lack thereof) between prepositional and double object constructions across English and Spanish by comparing the L1 English children's data to the L1 Spanish children's data (section 5.3.1) and the 2L1 English/Spanish children's two languages (section 5.3.2). These data will shed light on RQ 5 for L1 children and on RQ 7 for 2L1 children, as proposed in chapter 3. The role that adult input plays in child use of English and Spanish DA structures has been analyzed in L1 and in 2L1 children's data, and so, these findings will answer RQ 6 and RQ 8, respectively. 
As for the inter-group comparison (i.e. L1 English and L1 Spanish), RQ 5 seeks to provide further insight into the syntactic (non-)derivational relationship that characterizes the two DA structures across English and Spanish, as reflected in the L1 children’s emergence and incidence through language development.

- RQ 5. Is there an analogous syntactic derivational relationship (or lack thereof) between the two DA structures across English and Spanish in the two L1 children's groups? YES, THERE IS A LACK OF DERIVATIONAL RELATIONSHIP BETWEEN PREPOSITIONAL AND DOUBLE OBJECT CONSTRUCTIONS ACROSS THE TWO LANGUAGES

According to our results, the similar emergence of the two English and Spanish DA structures, when the L1 English children's data are compared to the L1 Spanish children's data, suggests a parallel syntactic non-derivational relationship and a thematic analogy across the two languages. Nevertheless, despite the non-significant differences in their emergence, the later onset and the lower incidence of prepositional DA structures when compared to double object constructions could be related to the additional syntactic and semantic properties of the prepositions.

Regarding RQ 6, the frequency with which English and Spanish DA structures are used by adults is examined as to whether analogous patterns are reflected when the L1 English children's output is compared to the L1 Spanish children's output.

- RQ 6. Does adult input play an analogous role in L1 children's production of English DA structures and Spanish DA structures? YES

In view of the results observed in the present study, the amount of exposure to English and Spanish DA structures in the adult input could have played a similar role in the production of the two L1 children's groups. This is seen in the higher production of double objects when compared to prepositional DA constructions across English and Spanish, as reflected in both the adults' and in the children's data.

Another issue that the present study seeks to answer is, as formulated in RQ 7, whether prepositional and double object structures share an analogous syntactic derivational or non-derivational relationship in English and in Spanish, as analyzed in the 2L1 English/Spanish children's onset and incidence through language development. 
- RQ 7. Is there an analogous syntactic derivational relationship (or lack thereof) between the two DA structures in the 2L1 English/Spanish children's two languages? YES, THERE IS A LACK OF DERIVATIONAL RELATIONSHIP BETWEEN PREPOSITIONAL AND DOUBLE OBJECT CONSTRUCTIONS ACROSS THE TWO LANGUAGES

Considering our data analyses, the similar onset of prepositional and double object constructions in the 2L1 English/Spanish children's two languages infers that these children have acquired the syntactic non-derivational relationship and the semantic similarity of DA structures across English and Spanish. Furthermore, and given the later emergence and the lower incidence of English to/for-datives and Spanish a/paradatives, the 2L1 English/Spanish children seem to have acquired the additional properties that characterize the corresponding prepositional structures in the two languages.

Finally, RQ 8 investigates whether adult input goes hand in hand with 2L1 English/Spanish children's use of DA structures in the two languages.

- RQ 8. Does adult input play an analogous role in 2L1 English/Spanish children's dual output in the production of English and Spanish DA structures? YES

The frequency with which adults have used the two English and Spanish DA structures might have played a similar role in the 2L1 English/Spanish children's dual output. This is reflected in the similar use of double object constructions over prepositional DA structures across English and Spanish in the two groups (i.e. adults and children).

All in all, the 2L1 English/Spanish children seem to have proceeded like their respective L1 peers in the acquisition of the parallel syntactic and semantic properties that underlie and connect the two DA structures across the two languages as well as in the role played by the dual adult input in the 2L1 English/Spanish children's dual output. 


\section{CONCLUSIONS}

In this study, we have examined the syntactic derivational relationship (or lack thereof) between the two DA structures, namely, prepositional and double object constructions in English (i.e. to/for-datives and DOCs) and in Spanish (i.e. a/paradatives and DCLDs), as reflected in the production of L1 and 2L1 children, both in girls and in boys. The syntactic status of the two DA structures is also compared across the languages under investigation, as seen in L1 children's data (i.e. inter-group comparison) and in 2L1 children's data (i.e. intra-group comparison). In the case of the intra-group comparison, we have provided empirical evidence that contributes to shed light on whether the syntactic (non-)derivational relationship between prepositional and double object constructions is acquired autonomously in the 2L1 English/Spanish children's two languages, thus, following analogous developmental patterns to their corresponding L1 peers, as per the ADH (Paradis 2001; Paradis and Genesee 1996; Yip and Matthews 2007; among many others), or interdependently, and so, the properties of the DA structures in one language influence those ones in the other language. This would make bilinguals differ from monolinguals with regards to maturational schedules, as per the IDH (Meisel 2004, 2001, 1989; Paradis and Genesee 1996; among others). Moreover, issues such as the role that adult input plays in L1 and in 2L1 children's use of English and Spanish DA constructions has also been addressed.

Although the phenomenon of DA is present in English (Den Dikken 1991; Larson 2014, 1990, 1988; Snyder 2001; Snyder and Stromswold 1997; among others) and in Spanish (Anagnostopoulou 2003; Aranovich 2012, 2011; Cuervo 2007, 2003a, 2003b; Demonte 1995, 1994; among others), the DA exhibits different properties across the two languages, as captured by the Complex Predicate Parameter (Snyder 2001, 1995). Furthermore, while, in English, the prepositions 'to' and 'for' in to/for-datives are removed when alternating as DOCs, English-like DOCs are unavailable in Spanish DCLDs when alternating as a/para-datives. Instead, while Spanish a/para-datives involve no clitic, in Spanish DCLDs, a pre-verbal dative clitic 'le(s)' forms a coindexed chain with a DP (headed by the preposition ' $a$ ') with the same shared features (i.e. gender, number, person, Case and theta role), complying with the Matching Hypothesis (Suñer 1988). 
There is a lack of consensus in the literature with respect to the derivation (or lack thereof) of the two English and Spanish DA structures. In English, the formal debate has focused on (a) whether DOCs are derived from to/for-datives by means of a transformational rule based on a prominence scale of grammatical relations (Oehrle 1976) or a passive-like movement via an advancement rule under RG (Hale and Keyser 2002; Haspelmath 2006) or via a DP-movement under GB theory (Larson 2014, 1990, 1988; Perlmutter 1980, among others); (b) whether to/for-datives are derived from DOCs under the so-called 'lexical-covert category PP' rule (Czepluch 1982) or in terms of a passive-like movement based on either an advancement rule that contrasts the one proposed by RG (Dryer 1986) or a DP-movement that differs from the one argued by Larson and follows Kayne’s (1984) SC analysis (Aoun and Li 1989; Koizumi 1994); or (c) whether the two English DA structures are not syntactically derived from one another, and so, three possible arguments have been resorted to. One of them argues for the projection of two different underlying structures under a Chomskian-Larsonian VPshell structure in the formation of DOCs and under one VP domain in the formation of to/for-datives (Marantz 1993). A second approach proposes a contrast in the verbal features of the SC that projects the internal argument structure of the two DA structures, namely, an empty causative verb with possessive meaning in DOCs and an empty verb in to/for-datives (Mulder 1992). The third approach focuses on a shared underlying complex predicate or SC structure in the formation of both DOCs and to/for-datives (Snyder and Stromswold 1997), as captured by the Complex Predicate Parameter (Snyder 2001, 1995).

In Spanish, there is also a dichotomy in the literature with regards to the syntactic (non-)derivational relationship between the two DA constructions. On the one hand, DCLDs are argued to derive from a/para-datives via the presence of a dative clitic that heads a DClP at a higher domain of a Chomskian-Larsonian VP-shell structure, upon which a/para-datives base-generate (Bruhn de Garavito 2000; Demonte 1995, 1994; Kempchinsky 2004). On the other hand, the two Spanish DA constructions are said to stem from two underived structures that differ in the head that each structure projects (i.e. a verb in a/para-datives and a dative clitic in DCLDs) as well as in the theta role allocated to the IO (i.e. a goal in a/para-datives and a beneficiary in DCLDs) (Cuervo 2003a, 2003b). 
Semantically, similar thematic relationships are preserved when prepositional DA structures alternate as double object constructions in English and in Spanish alike, conforming to the UTAH requirements. In prepositional DA structures (i.e. English to/for-datives and Spanish a/para-datives), the DO-DP and the prepositional complement are allocated a theme and a recipient/beneficiary theta role by the verb and by the prepositions 'to/for' in English and 'a/para' in Spanish, respectively. Yet, given that English and Spanish double object constructions differ in the superficial structure, a symmetry is not observed in the theta role assignment of their internal arguments or their adjuncts. In English DOCs that alternate as to/for-datives, the IO/A-DP and the DO-DP are allocated a recipient/beneficiary and a theme theta role by the verb and by the reanalysis of the verb and the IO/A-DP as a complex transitive verb, respectively (Larson 2014, 1990, 1988). In Spanish DCLDs that alternate as a/para-datives, the prepositional complement is assigned a recipient/beneficiary theta role by the preposition ' $a$ ' depending on whether DCLDs alternate as $a$-datives or as para-datives (note that when the prepositional complement in DCLDs that alternate as para-datives are headed by the preposition 'para' render the constructions ungrammatical) and the DO-DP receives a theme theta role from the verb. Furthermore, in order for the preverbal dative clitic in Spanish DCLDs to satisfy the Theta Criterion, two approaches have been proposed: (a) Under the co-indexation approach, the dative clitic inherits the recipient or the beneficiary theta role assigned to the prepositional complement by the preposition ' $a$ ', complying with the Matching Principle (Suñer 1988); or (b) under the affixal morpheme approach (Anagnostopoulou 2006, 2003; Beavers and Nishida 2009; Borer 1984; among others), the dative clitic and the verb perform as one single theme theta role assigner to the DO-DP. The subject receives an agent theta role from the verb in English and in Spanish, regardless of the type of DA structure. In contrast to the Theta Criterion, other works suggest a semantic difference for the two DA constructions both in English (Beck and Johnson 2004; Colleman 2010; Colleman and De Clerk 2011; Goldberg 1995, 1992; among others) and in Spanish (Demonte 1994; Romero Morales 2008; among others). In particular, while prepositional constructions are argued to denote caused motion (cause-to-GO), double object structures are said to encode transfer of possession (cause-to-HAVE).

Previous works have reported different findings in relation to child acquisition of English and Spanish DA structures. In relation to the formal debate, acquisition works 
could help shed some light. What could be suggested is that a later emergence, and possibly a lower rate of use through language development, could be triggered by an increase in grammatical complexity, such as that of a derived construction. That is, a later emergence of double object or prepositional constructions could infer that one of the two DA constructions is derived from its DA counterpart or that it is more grammatically complex. This would entail that the grammatical requirements to produce one of the two DA constructions hinge on the children's language maturation, thus, causing a delay in the production of that particular DA structure.

In the case of English monolingual acquisition, some studies have observed a similar onset of the two English DA structures given their shared underlying structure as complex predicates or as SC constructions (Snyder and Stromswold 1997), as per the Complex Predicate Parameter (Snyder 2001, 1995). Other empirical works have found that to/for-datives emerge later than DOCs (Bowerman 1990; Campbell and Tomasello 2001; Gropen et al. 1989), as explained by the special Case and theta role status of the prepositions 'to/for' that mediate the process of dative Case and goal/beneficiary theta role assignment to the DP by the verb (Snyder and Stromswold 1997). Within the context of bilingual acquisition, Gu (2010) has reported that to/for-datives start being produced later than DOCs, as seen in 2L1 English/Cantonese children's data; however, the emergence of to/for-datives is delayed if compared to their corresponding L1 peers since (a) language dominance has played a role, and so, the English-dominant child's knowledge of English DA structures, in general, and that of to/for-datives, in particular, has facilitated the onset of these constructions when compared to the Cantonesedominant children; and (b) input ambiguity factors, namely, the presence of one single recipient and beneficiary theta role marker 'bei2' in Cantonese (i.e. their other L1) has caused 2L1 English/Cantonese children to delay the disambiguation process of the two distinct recipient and beneficiary theta role markers in English, that is, 'to' and 'for', respectively.

To the best of our knowledge, earlier L1 and 2L1 acquisition works have not accounted for the relation between DCLDs and a/para-datives. However, Torrens and Wexler (2000) have reported the early onset of DCLDs in the production of an L1 Spanish child, regardless of whether the dative clitic is optional with non-pronominal prepositional complements or required with pronominal prepositional complements. Other similar L1 acquisition studies on the clitic doubling of mono-transitive 
constructions in Romanian, a [+DOCD] language, have found the earlier emergence of simple clitic mono-transitive constructions in which an accusative clitic is co-indexed with a null DO-DP, if compared to clitic doubling structures in which an accusative clitic shares similar features of Case, gender, number and person to those of an overt DO-DP (Ungureanu 2017). Thus, both Torrens and Wexler’s (2000) and Ungureanu's (2017) works show that L1 Spanish and L1 Romanian children use the dative clitic from early on, as put forward by the Full Competence Hypothesis (Poeppel and Wexler 1993).

From a biological gender approach, L1 and 2L1 acquisition studies have observed a better performance in girls than in boys concerning newborns' motor movements such as imitative gestures and index finger extensions (Nagy et al. 2007), lexical production (Berglund et al. 2005; Eriksson et al. 2012; Galsworthy et al. 2000; Halpern 2000; among others) and syntactic development (Cornett 2014; Dini 2011; Koenigsknecht 1974; Lovas 2011; Tse et al. 2002; among others). Neurological factors have been argued to be responsible for girls' advantage over boys in early language development. This is reflected in girls' bilateral and in boys' unilateral brain organization in 2 and in 1 hemisphere(s), respectively (Burman et al. 2008; Hyde and Linn 1988; Shakouri et al. 2016), as well as in parent-child interaction, that is, the higher language exposure when parents engage in conversations with girls if compared to boys (Cherry and Lewis 1975; Gleason 1990; Lovas 2011).

Moreover, previous studies have shown that the relative frequency rate with which DOCs and to/for-datives are used in the adult input has played a crucial role in the L1 English children's output (Campbell and Tomasello 2001; De Marneffe et al. 2012; Legate and Yang 2002; Lust 2006; Pullum and Scholz 2002; Sampson 2002; Yang 2016, 2011, 2002). However, different findings have been reported by earlier works with regards to the role that adult input frequency plays in the emergence of English DA structures. More specifically, while Campbell and Tomasello (2001) observe that the adult input frequency L1 English children receive has an effect on the earlier emergence of DOCs if compared to to/for-datives (Campbell and Tomasello 2001), Snyder and Stromswold (1997) do not find a correlation between the parents' higher rates in the use of DOCs when compared to to-datives and the L1 English children's earlier emergence of DOCs when compared to to-datives. The opposing views observed in Snyder and Stromswold’s (1997) and in Campbell and Tomasello’s 
(2001) studies could be influenced by the type of structures they analyze, that is to say, Snyder and Stromswold (1997) conduct an analysis on the production of DOCs and todatives with the verb 'give' and Campbell and Tomasello (2001) also include fordatives with a wider array of verbs. To the extent of our knowledge, similar works have not been conducted on Spanish DA constructions.

Taking previous formal and acquisition works on DA as a point of departure, the present dissertation has been focused on the emergence and the use of these structures through the English and Spanish monolingual and bilingual language acquisition process. In order to do so, $8 \mathrm{RQs}$ have been formulated to guide the analysis of the different issues under consideration. The first 4 RQs deal with the analysis of DA in each of the two languages. They aim at shedding light on the (non-)derivational relationship between the two DA structures (RQ 1 for English and RQ 3 for Spanish), as seen in the L1 and in the 2L1 children's ages of onset and incidence through language development, and on the role played by the adult input in the children's output (RQ 2 for English and RQ4 for Spanish). The other 4 RQs establish a comparative analysis of DA across English and Spanish. On the one hand, they investigate the syntactic derivational relationship (or lack thereof) between prepositional and double object constructions across the two languages, as reflected in both the L1 children's data (RQ 5) and in the 2L1 children's data (RQ 7). On the other hand, they examine the role that the frequency of exposure to English and Spanish DA constructions plays in both the L1 children's output (RQ 6) and the 2L1 children's output (RQ 8).

In order to address the issues formulated in the initial RQs, the spontaneous longitudinal data of 31 children have been selected, as available in CHILDES. These children have been divided into 3 language groups and include 13 L1 English children (age range: 0;06-8;00; 8 girls and 5 boys), 9 L1 Spanish children (age range: 0;11-4;08; 6 girls and 3 boys), and 9 2L1 English/Spanish children (age range: 1;01-6;11; 3 girls and 6 boys). We have also taken into consideration the speech from the adults that the children interact with (mainly parents, as well as other caregivers and researchers).

The search for English and Spanish DA structures in the children's output and in the adult input has been carried out by combining (a) the use of one of the CLAN programs available in CHILDES, KWAL, where automatic searches for the contexts in which the keyword ' $\mathrm{v}^{*}$ ' (i.e. verb) is used have been implemented in those selected corpora that display a $+\mathrm{t} \%$ mor in their transcripts; and (b) manual extraction in those 
selected corpora that do not include the $+\mathrm{t} \%$ mor tier in their transcript data. Moreover, another CLAN program, MLU, has been used to compute the children's MLUw with the aim of analyzing the incidence of English and Spanish DA structures through language development during the period under study.

English and Spanish DA constructions in their declarative and in their imperative form have been codified in terms of prepositional constructions (i.e. to/for-datives in English; a/para-datives in Spanish) and double object constructions (i.e. DOCs in English; DCLDs in Spanish). Interrogative DA utterances have been excluded from the data analysis since wh-movement poses an issue to the syntactic mechanism of DA under analysis here. We have also discarded (a) idiomatic DA constructions since they do not show a productive use of the language; (b) fronted DO-DPs in declarative DA structures given their discourse emphatic purposes; (c) null verbs, null internal arguments/adjuncts; (d) locative mono-transitive constructions with an A-PP headed by the preposition 'to' in English or ' $a$ ' in Spanish; (e) English for-datives and Spanish para-datives with a semantic approach of exchange, reason or time, which contrasts with the target DA structures where the prepositions 'for/para' are beneficiary theta role assigners; and (f) non-dativizable constructions where prepositional and double object constructions do not undergo DA.

Developmentally, the production of English and Spanish DA structures in the L1 and in the 2L1 children's data has been organized into 13 age stages (i.e. from 1;00-1;06 to 7;00-7;06) and into 6 MLUw stages (i.e. from MLUw 1 to MLUw >5). In the case of the latter, the stages have been established in terms of the first time the child has reached each of the 6 MLUw values.

In order to provide an answer to the initial RQs formulated in the present study, the following analyses have been conducted: (a) The production of English DA structures in L1 and in 2L1 children; (b) the production of Spanish DA structures in L1 and in 2L1 children; and (c) a comparative analysis of English and Spanish DA structures in the production of L1 children (i.e. inter-group comparison), on the one hand, and in the production of 2L1 children (i.e. intra-group comparison), on the other hand. Four variables have been considered for analysis, namely, age of onset, incidence through language development, biological gender and the role played by adult input in child output. 
Regarding English DA structures, significant differences have not been found in the L1 English children's emergence of DOCs and to/for-datives, and similar findings appear in the 2L1 English children's data. The L1 English girls, the L1 English boys and the 2L1 English boys reveal similar patterns of emergence (recall that only 1 to/fordative is found in the production of 1 2L1 English girl and, thus, comparative analyses cannot be established). Furthermore, the onset of the two English DA structures does not significantly differ when comparing the two language groups. These results lend support to the syntactic non-derivational relationship between DOCs and to/for-datives, and so, these structures could be argued to be construed under (a) a shared parametric property as complex predicates (Larson 2014, 1990, 1988; Marantz 1993; among others) or as SC constructions (Aoun and Li 1989; Kayne 1984; among others), as per the Complex Predicate Parameter (Snyder 2001, 1995); or under (b) two different underived underlying structures (Marantz 1993; Mulder 1992).

Even though the two English DA structures emerge at a similar age, the L1 English children start producing to/for-datives later than DOCs, and so do the 2L1 English children, as also reported in previous L1 English studies (Campbell and Tomasello 2001; Gu 2010) and 2L1 English works (Gu 2010). Differences are not seen in the data when comparing girls and boys. Thus, these findings could be associated with the additional dative Case and recipient/beneficiary theta role mediated assigning properties of the prepositions 'to/for' to the DP by means of the verb (Larson 1990, 1988; Marantz 1984; Pesetsky 1985; Snyder and Stromswold 1997). Alternatively, the similar emergence of DOCs and to/for-datives may also suggest a semantic relationship. This is seen in the analogous theme and recipient or beneficiary theta roles, depending on whether DOCs alternate as to-datives or as for-datives, respectively, conforming to the UTAH conditions.

Although the L1 English children show a higher incidence of the two English DA constructions when compared to the 2L1 English children's data, both language groups reflect analogous longitudinal patterns regarding the lower rate in the use of to/fordatives if compared to DOCs, as analyzed through the age stages and through the MLUw stages. Indeed, divergences are not seen in the data from the L1 English children's two biological gender groups and in the 2L1 English boys' data. What is more, the relative frequency rates in the use of DOCs and to/for-datives are also reflected in the adult input, which patterns closer to the L1 English and the 2L1 English 
children's overall output. Thus, the lower incidence of to/for-datives, as reflected through the two language developmental measures and in the overall use of these structures, could also be related to the Case and the theta role properties of the prepositions 'to/for' and/or to the role played by the adult input in the children's output, in line with earlier L1 English works (e.g. Campbell and Tomasello 2001; De Marneffe et al. 2012).

As far as Spanish DA structures are concerned, the L1 Spanish children show a similar emergence of DCLDs and a/para-datives, and analogous production patterns appear in the 2L1 Spanish children. Along these lines, biological gender differences are not shown in the data from the two language groups. In turn, there are no significant differences when the L1 Spanish children's onset of these constructions is compared to the 2L1 Spanish children's data. These findings suggest that DCLDs and a/para-datives do not derive from one another, and so, a shared underlying structure, as has been argued for English DA structures (Snyder and Stromswold 1997), or two opposing representations could underlie each structure (Cuervo 2003a, 2003b).

What is more, the fact that the L1 Spanish and the 2L1 Spanish children begin to produce DCLDs and a/para-datives at a similar age infers that, following the UTAH conditions, the two structures are semantically related. This means that while DCLDs that alternate as $a$-datives display analogous theme and recipient theta roles in their internal structure, DCLDs that undergo alternation as para-datives share a similar theme and beneficiary thematic relationship. The dative clitic in DCLDs could inherit the recipient or the beneficiary theta role properties allocated to the DP by the preposition ' $a$ ', as per the Matching Principle (Suñer 1988), or function as an affixal morpheme which, along with the verb, assign a theme theta role to the DO-DP (Anagnostoupoulou 2006, 2003; Beavers and Nishida 2009; Borer 1984; among others).

Despite the similar emergence of the two Spanish DA structures, a/para-datives start being produced later than DCLDs, as equally reflected in the L1 Spanish and in the 2L1 Spanish children's data. Biological gender differences are not seen in either of the two language groups. Thus, the later emergence of $a /$ para-datives could be related to the dative Case and the recipient/beneficiary theta role mediated assigning properties of the prepositions 'a/para', as proposed for English to/for-datives (Snyder and Stromswold 1997). Furthermore, the earlier emergence of DCLDs is in line with previous L1 Spanish works (Torrens and Wexler 1987), which indicates that dative 
clitics are available in the L1 Spanish and in the 2L1 Spanish children's grammar from early on, as put forward by the Full Competence Hypothesis (Poeppel and Wexler 1993).

A/para-datives show a lower incidence, when compared to DCLDs, both in the L1 Spanish children's data and in the 2L1 Spanish children's data, and this is seen when the use of these structures is analyzed through the age stages and through the MLUw stages. Girls do not differ from boys in the production patterns through language development. In addition, significant differences do not appear in the incidence of the two Spanish DA structures per age stage or per MLUw stage when the 2L1 Spanish children's data are compared to their L1 peers. The frequency rates in the use of DCLDs and a/para-datives are also seen when the relative frequency of exposure to these structures in the adult input are compared to the L1 Spanish and to the 2L1 Spanish children's overall output. Therefore, the developmental and the overall lower rate in the use of a/para-datives may be explained by two possible arguments: (a) The Case and the theta role assigning properties of the prepositions 'a/para' (Snyder and Stromswold 1997), as also seen in their order of emergence; and/or (b) the influence of the adult input in the children's output (e.g. Legate and Yang 2002; Lust 2006; Pullum and Scholz 2002; Sampson 2002; Yang 2016, 2011, 2002).

When the L1 English children are compared to the L1 Spanish children in the production of DA structures, our findings have provided supportive evidence for the parallel syntactic non-derivational relationship between prepositional and double object constructions across the two languages. This is evidenced by the statistically nonsignificant differences in their emergence, both in each language group and between language groups. Therefore, the two English and Spanish DA structures could be argued to share an underlying structure, despite their different status in English (i.e. a [+complex predicate] language) and in Spanish (i.e. a [-complex predicate] language), as captured in the Complex Predicate Parameter (Snyder 2001, 1995). This is so given the unavailability of English-like DOCs in the latter (Kayne 1975; Larson 2014, 1990, 1988; Snyder 2001, 1995). Alternatively, the parallel syntactic non-derivational pattern of DA structures in English and in Spanish could lie in the formation of two different underived representations (Marantz 1993; Mulder 1992 in English; Cuervo 2003a, 2003b in Spanish). 
Furthermore, the similar emergence of English and Spanish DA structures, as seen in the L1 children's data, could suggest analogous thematic roles when comparing prepositional and double object constructions across the two languages.

Although English and Spanish DA structures emerge at a similar age, the L1 English and the L1 Spanish children begin to produce prepositional DA structures later and show a lower incidence through language development, if compared to double object constructions. While similar frequency rates of use are shown in each language group, the L1 English children reflect a higher incidence of the two DA structures per age stage when compared to the L1 Spanish children's data, but significant differences do not appear between the language groups when the production of these constructions is distributed per MLUw stage. The order of emergence and incidence of English and Spanish DA structures shows similar results when the adults' production of these structures is compared to the L1 children's overall output. This points to the parallel additional grammatical properties of the prepositions 'to/for' in English and 'a/para' in Spanish (Snyder and Stromswold 1997) and/or to the frequency with which these structures are used in the adult input, as also reported in previous L1 English acquisition works (e.g. Campbell and Tomasello 2001; De Marneffe et al. 2012). Recall that the role played by adult input in the L1 Spanish children's use of DA structures has not been the focus of investigation in earlier empirical studies.

The syntactic and the semantic properties that characterize DA structures across English and Spanish, as reflected in the L1 children's data, show similar patterns in the 2L1 English/Spanish children's two languages. This suggests that the acquisition of the comparable syntactic non-derivational relationship and semantic analogy of the two English and Spanish DA structures develop autonomously in each of the 2L1 English/Spanish children's two languages. Hence, cross-linguistic influence does not seem to have occurred from English into Spanish or from Spanish into English, as per the ADH (Álvarez de la Fuente 2007; Clark 2009; Genesee et al. 1995; Gleitman and Newport 1995; Meisel 2001, 1989; Mishina-Mori 2005; Paradis 2001; Paradis and Genesee 1996; Yip and Matthews 2007; among many others). Furthermore, home input conditions via the one-parent one-language strategy (Deuchar and Quay 2000; Meisel 2004; Ronjat 1913; Takeuchi 2006; among others) seem to have played a crucial role in the 2L1 English/Spanish children's similar use of double object constructions over 
prepositional DA structures across English and Spanish, akin to their corresponding L1 peers.

Nevertheless, we should take these findings with caution, since the concurrence of two facts does not necessarily imply they are related. That is, we have argued that the similar age of onset of the two English and Spanish DA structures suggests that prepositional and double object constructions are syntactically and semantically related, but it could also be the case that other factors are playing a role in their similar emergence.

Several issues have been unaccounted for in the present study. Further investigation would be required to confirm that prepositional and double object constructions do not derive from one another via a passive-like mechanism, contra previous formal accounts in English DA structures (Dryer 1986; Hale and Keyser 2002; Haspelmath 2006; Larson 2014, 1990, 1988; Perlmutter 1980) and in Spanish DA structures (Bruhn de Garavito 2000; Demonte 1995, 1994; Kempchinsky 2004). In order to carry out these analyses, the emergence and the incidence of English and Spanish DA structures in both the L1 and in the 2L1 children's data would be compared to those of structures that depend on DP-movement and that, therefore, are subject to maturational schedules (Chomsky 1957; De Cos Ruiz 1999; Gómez Araquistain 1990; Kirby 2010; Marín Arrese 1993; Weiner and Labov1983; Snyder and Stromswold 1997; among others). This is the case of periphrastic passive constructions in English, as in (1), as well as periphrastic and reflexive passive structures in Spanish, as in (2).

(1) $\mathrm{He}_{\mathrm{i}}$ was killed $t_{\mathrm{i}}$ by the enemy

[Marín Arrese 1993: 10]

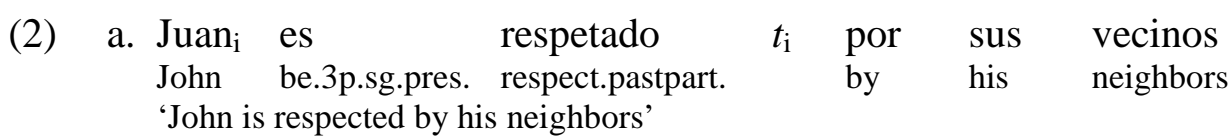
b. El piso pe $_{\mathrm{i}}$ sendió $t_{\mathrm{i}}$ the apartment refl. sell.pastpart. 'The apartment was sold'


The acquisition of other related complex predicate constructions in English and in Spanish (i.e. resultatives, causatives, perceptual report and locatives) is also a pending issue to examine whether these structures, along with prepositional and double object constructions, are all acquired as a group of complex predicate constructions that depend on a common parametric property, as captured by the Complex Predicate Parameter (Snyder 2001, 1995). Furthermore, prepositional and double object constructions that do not undergo DA (also known as non-dativizables) are especially relevant for a future analysis in English (e.g. Mazurkewich and White 1984; Oehrle 1976), as in (3a), and in Spanish (e.g. Torrens and Wexler 2000), as in (4a). Such an analysis could investigate whether L1 and 2L1 children acquire these structures substantially earlier than more complex predicate structures, as it is the case of DA constructions.

(3) a. John reported the accident to the police

b. *John reported the police the accident

[Mazurkewhich and White 1984: 262]

(4)

$$
\begin{aligned}
& \text { a. Marta te lo dijo a ti } \\
& \text { Marta you.dat. it.acc. say.3p.sg.past to you } \\
& \text { 'Marta told you it' }
\end{aligned}
$$

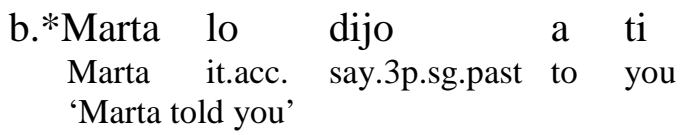

[Torrens and Wexler 2000: 279]

Finally, the analysis on English and Spanish DA could also be extended to L2 English and on L2 Spanish acquisition so that we could examine whether the exposure to the L2 shapes the participants' performance in learning the syntactic and the semantic properties of prepositional and double object constructions. In the spirit of earlier L2 Spanish works (Bruhn de Garavito 2000; Cuervo 2007; Perpiñán and Montrul 2006; among others), experimental research methods such as AJTs may provide further insight into this analysis as well.

All in all, this dissertation has contributed to provide further insight into the formal debate on English and Spanish DA. More specifically, the similar emergence of prepositional and double object constructions in the two languages points to the syntactic non-derivational relationship and to the semantic similarity between the two 
DA constructions. Although the syntactic and the semantic properties that characterize the two English and Spanish DA structures mature at around the same age, additional Case and theta role properties are required in the production of prepositional constructions (i.e. English to/for-datives and Spanish a/para-datives), as observed in their later onset and in their lower incidence when compared to double object constructions (i.e. English DOCs and Spanish DCLDs). However, the amount of exposure to these structures in the adult input could also have been influenced the children's output. All these production patterns discussed earlier are reflected when comparing across child groups (i.e. L1 and 2L1), across participants (i.e. children and adults) and across languages (i.e. English and Spanish). 


\section{BIBLIOGRAPHY}

Adger, D. (2003). Core Syntax: A Minimalist Approach. Oxford: Oxford University Press.

Aguado, G. (1988). 'Appraisal of the Morpho-Syntactic Competence in a 2.5-MonthOld Child’. Infancia y Aprendizaje 43: 73-95.

Aguado Orea, J. (2004). The Acquisition of Morpho-Syntax in Spanish: Implications for Current Theories of Development. PhD Dissertation, University of Nottingham.

Aguado Orea, J. and Pine, J. M. (2015). 'Comparing Different Models of the Development of Verb Inflection in Early Child Spanish’. PLOS ONE 10 (3): e0119613. https://doi.org/10.1371/journal.pone.0119613.

Albrecht, E. (2006). <<I Can Speak German-Und Deutsch>>: The Development and Use of Code-Switching among Simultaneous and Successive English-German Bilingual Children. PhD Dissertation, Albert-Ludwigs-Universität.

Alonso Cortés, N. (1939). El Pronombre $<<s e>>$ y la Voz Pasiva Castellana. Valladolid: Artes Gráficas Afrodisio Aguado.

Álvarez de la Fuente, E. (2007). Análisis Lingüístico de la Traducción Natural: Datos de Producción de Dos Niños Gemelos Bilingües Inglés/Español. $\mathrm{PhD}$ Dissertation, University of Valladolid.

Álvarez de la Fuente, E.; Fernández Fuertes, R. and Arratia García, O. (under review). 'Bilingual Children as Mediators in Everyday Life: How Natural Interpreting Reinforces Minority Languages’. Research on Language and Social Interaction. London: Routledge.

Anagnostopoulou, E. (2006). 'Clitic Doubling'. In The Blackwell Companion to Syntax. M. Everaert and H. van Riemsdijk (eds.). Malden: Blackwell, 519-581.

Anagnostopoulou, E. (2005). 'Cross-linguistic and Cross-categorial Variation of Datives'. In Recent Advances in Greek Generative Grammar: Festshrift for Dimitra Theophanopoulou-Kontou. In M. Stavrou and A. Terzi (eds.). Amsterdam and Philadelphia: John Benjamins, 61-126.

Anagnostopoulou, E. (2003). The Syntax of Ditransitives: Evidence from Clitics. Berlin and Boston: Mouton de Gruyter.

Anderssen, M.; Rodina, Y.; Mykhaylyk, R. and Fikkert, P. (2015). 'The Acquisition of the Dative Alternation in Norwegian’. Language Acquisition 21: 72-102.

Andersson, B. E. (1989). 'Effects of Public Day Care: A Longitudinal Study'. Child Development 60: 857-866.

Aoun, J. and Li, Y. (1989). 'Scope and Constituency'. Linguistic Inquiry 20 (2): 141172. 
Aparici, M.; Serrat, E.; Capdevilla, M. and Serra, M. (2001). 'Acquisition of Complex Sentences in Spanish and Catalan Speaking Children'. In Children's Language 11. K. Nelson, A. Aksu-Koç and C. Johnson (eds.). Hillsdale: Lawrence Erlbaum, 1-26.

Aranovich, R. (2012). 'A Lexical-Functional Account of Spanish Dative Usage'. In Case, Word Order and Prominence. P. de Swart and M. Lamers (eds.). Dordrecht: Springer Verlag, 17-42.

Aranovich, R. (2011). Optional Agreement and Grammatical Functions: A Corpus Study of Dative Clitic Doubling in Spanish. PhD Dissertation, University of Pittsburgh.

Argyri, E. and Sorace, A. (2007). 'Cross-linguistic Influence and Language Dominance in Bilingual Children’. Bilingualism: Language and Cognition 10 (1): 79-99.

Baker, M. C. (1988). Incorporation: A Theory of Grammatical Function Changing. Chicago: University of Chicago Press.

Baker, Ch. L. (1979). 'Syntactic Theory and the Projection Problem’. Linguistic Inquiry 10 (4): 533-581.

Baker, M. (1982). 'Objects, Themes, and Lexical Rules in Italian'. In Papers in LexicalFunctional Grammar. L. Levin, M. Rappaport and A. Zaenen (eds.). Indiana: Indiana University Linguistics Club, 1-45.

Baker, C. and PrysJones, S. (1998). Encyclopedia of Bilingualism and Bilingual Education. Artamon, Clevedon, Johannesburg, Philadelphia and Toronto: Multilingual Matters.

Barss, A. and Howard, L. (1986). 'A Note on Anaphora and Double Object'. Linguistic Inquiry 17: 347-354.

Bates, E.; Bretherton, I. and Snyder L. (1988). From First Words to Grammar: Individual Differences and Dissociable Mechanisms. Cambridge: Cambridge University Press.

Beavers, J. (2003). 'More Head and Less Categories: A New Look at Noun Phrase Structure'. In Proceedings of the 10th Head-Driven Phrase Structure Grammar Conference. S. Müller (ed.). Stanford: CSLI Publications, 47-67.

Beavers, J. and Nishida, Ch. (2009). 'The Spanish Dative Alternation Revisited'. In Romance Linguistics: Selected Papers from the $39^{\text {th }}$ Linguistic Symposium on Romance Languages (LSRL). S. Colina, A. Olarrea and A. M. Carvalho (eds.). Tucson: John Benjamins, 217-230.

Beck, S. and Johnson, K. (2004). ‘Double Objects Again’. Linguistic Inquiry 35 (1): 97123.

Bedore, L. M.; Peña, E. D.; Summers, C. L.; Boerger, K. M. and Resendiz, M. D. (2012). 'The Measure Matters: Language Dominance Profiles across Measures in Spanish-English Bilingual Children’. Bilingualism 15 (3): 616-629. 
Bel, A. and Rosado, E. (2009). 'Person and Number Asymmetries in Child Catalan and Spanish'. In Hispanic Child Languages. J. Grinstead (ed.). Amsterdam and Philadelphia: John Benjamins, 195-214.

Bellugi, U. (1971). 'Simplification in Children's Language'. In Language Acquisition: Models and Methods. R. Huxley and E. Ingram (eds.). London: Academic Press, 95-119.

Bellugi, U. (1965). 'The Development of Interrogative Structures in Children's Speech'. In The Language Development of Language Functions. K. Reigel (ed.). Ann Arbor: Language Development Project, 103-137.

Berglund, E.; Eriksson, M. and Westerlund, M. (2005). 'Communicative Skills in relation to Gender, Birth Order, Childcare and Socioeconomic Status in 18Month-Old Children'. Scandinavian Journal of Psychology 46: 485-491.

Bergman, C. (1976). 'Interference vs. Independent Development in Infant Bilingualism'. In Bilingualism in the Bicentennial and Beyond. G. D. Keller, R. V. Taeschner and S. Viera. (eds.). New York: Bilingual Press, 86-95.

Bernstein, N. (1982). Accoustic Study of Mothers' Speech to Language-Learning Children: An Analysis of Vowel Articulatory Characteristics. PhD Dissertation, Boston University.

Bleam, T. (2003). 'Properties of the Double Object Construction in Spanish'. In A Romance Perspective on Language Knowledge and Use. R. Nuñez Cedeño, L. López and R. Cameron (eds.). Amsterdam and Philadelphia: John Benjamins, 233-252.

Bleam, T. (2001). '(Non-)Parallels between Double Object Constructions and IO Clitic Doubling’. Linguistic Symposium on Romance Languages XXXI.

Bleam, T. (2000). Leísta Spanish and the Syntax of Clitic Doubling. PhD Dissertation, University of Pennsylvania.

Bley-Vroman, R. (1997). 'Features and Patterns of Foreign Language Learning'. Studies in Second Language Acquisition 24: 209-213.

Bley-Vroman, R. (1996). 'Conservative Pattern Accumulation in Foreign Language'. EUROSLA 6, Nijmegen.

Bliss, L. (1988). 'The Development of Modals'. The Journal of Applied Developmental Psychology 9: 253-261.

Bloom, P. (1990). 'Subjectless Sentences in Child Language’. Linguistic Inquiry 21 (4): 491-504.

Bloom, L. (1973). One Word at a Time: The Use of Single-Word Utterances before Syntax. The Hague: Mouton.

Bloom, L. (1970). Language Development: Form and Function in Emerging Grammars. Cambridge and London: MIT Press. 
Bloom, L.; Hood L. and Lightbown P. (1974). 'Imitation in Language Development: If, When and Why'. Cognitive Psychology 6: 380-420.

Bohannon, J. N. and Marquis, A. L. (1977). 'Children’s Control of Adult Speech'. Child Development 48: 1002-1008.

Borer, H. (1984). Parametric Syntax: Case Studies in Semitic and Romance Languages. Berlin and Boston: De Gruyter Mouton.

Borer, H. and Wexler, K. (1987). 'The Maturation of Syntax'. In Parameter Setting. T. Roeper and K. Wexler (eds.). Dordrecht: Reidel, 123-172.

Bosch, L. and Sebastián-Gallés, N. (1997). 'Native Language Recognition Abilities in Four-Month-Old Infants from Monolingual and Bilingual Environment'. Cognition 65: 33-69.

Bowerman, M. (1990). 'Mapping Thematic Roles onto Syntactic Functions: Are Children Helped by Innate Linking Rules?’ Linguistics 28: 1253-1289.

Braunwald, S. R. (1976). 'Mother-Child Communication: The Function of Maternal Language Input'. Word 27: 28-50.

Brown, R. (1973). A First Language: The Early Stages. Cambridge: Harvard University Press.

Brown, R. and Fraser, C. (1963). 'The Acquisition of Syntax'. In Verbal Behavior and Learning: Problems and Processes. C. N. Cofer and B. S. Musgrave (eds.). Cambridge: McGraw-Hill Book Company, 158-209.

Brownell, R. (2001). Expressive One-Word Picture Vocabulary Test. Spanish Bilingual Edition. Novato, Cambridge: Academic Therapy Publications.

Bruening, B. (2010). 'Double Object Constructions Disguised as Prepositional Datives'. Linguistic Inquiry 41 (2): 287-305.

Bruhn de Garavito, J. L. S. (2000). The syntax of Spanish Multifunctional Clitics and Near-Native Competence. PhD Dissertation, McWill University.

Bubenik, V. (1978). 'The Acquisition of Czech in the English Environment'. In Aspects of Bilingualism. M. Paradis (ed.). Columbia: Hornbeam Press, 3-12.

Burman, D. D.; Bitan, T. and Booth, J. R. (2008). 'Sex Differences in Neural Processing of Language among Children’. Neuropsuchologia 46 (5): 1349-1362.

Bybee, J. L. and Hopper, P. J. (2001). Frequency and Emergence of Linguistic Structure. Amsterdam and Philadelphia: John Benjamins.

Campbell, A. L. and Tomasello, M. (2001). 'The Acquisition of English Dative Constructions'. Applied Psycholinguistics 22 (2): 253-267.

Campos, H. (1999). 'Transitividad e Intransitividad'. In Gramática Descriptiva de la Lengua Española 2. I. Bosque and V. Demonte (coord.). Madrid: Espasa, 15201574. 
Carrier-Duncan, J. (1985). 'Linking of Thematic Roles in Derivational Word Formation’. Linguistic Inquiry 16: 1-34.

Carterette, E. C. and Jones, M. H. (1974). Informal Speech: Alphabetic and Phonemic Texts with Statistical Analysis and Tables. Berkeley, Los Angeles and London: University of California.

Catherine, G. (1979). 'An Approach to the Study of Children's Role Play'. The Quaterly News-Letter of the Laboratory of Comparative Human Cognition 1: 69-73.

Cherry, L. J. and Lewis, M. (1975). 'Mother-Child Dyad: Sex Differences in Conversational Interaction'. Ms.

Chomsky, N. (2004). 'Knowledge of Language as a Focus of Inquiry'. In First Language Acquisition. B. C. Lust and C. Foyle (eds.). Oxford: Blackwell, 15-24.

Chomsky, N. (1998). Minimalist Inquiries: The Framework. Cambridge: MIT Press.

Chomsky, N. (1996). Language and Problems of Knowledge: The Managua Lectures. Cambridge and London: MIT Press.

Chomsky, N. (1986). 'Barriers'. Linguistic Inquiry Monograph Thirteen. Cambridge and London: MIT Press.

Chomsky, N. (1981). 'On the Representation of Form and Function'. The Linguistic Review 1: 3-40.

Chomsky, N. (1972). Studies on Semantics in Generative Grammar. The Hague: Mouton.

Chomsky, Noam (1965). Aspects of the Theory of Syntax. Cambridge and London: MIT Press.

Chomsky, N. (1957). Syntactic Structures. The Hague: Mouton.

Clancy, P. (1985). 'The Acquisition of Japanese'. In The Cross-linguistic Study of Language Acquisition 1. D. Slobin (ed.). Hillsdale: Erlbaum, 373-524.

Clark, E. (2009). First Language Acquisition. Cambridge: Cambridge University Press.

Clark, E. V. (1978). 'Awareness of Language: Some Evidence from What Children Say and Do'. In The Child's Conception of Language. A. Sinclair, R. J. Jarvella and W. J. M. Levelt (eds.). Germain: Springer Verlag, 17-43.

Clearfield, M. W. and Nelson N. M. (2006). 'Sex Differences in Mothers' Speech and Play Behavior with 6-, 9- and 14-Month-Old Infants’. Sex Roles 54 (1-2): 127137.

Coates, J. (1993). Women, Men and Language. London: Longman.

Colleman, T. (2010). 'The Benefactive Semantic Potential of 'Caused Reception' Constructions: A Case Study of English, German, French, and Dutch'. In Benefactives and Malefactives: Typological Perspectives and Case Studies. F. 
Zúñiga and S. Kittilä (eds.). Amsterdam and Philadelphia: John Benjamins, 219244.

Colleman, T. and de Clerk, B. (2011). 'Constructional Semantic Specialization in the English Double Object Construction’. Cognitive Linguistics 22 (1): 183-209.

Colleman, T. and De Clerk, B. (2009). 'Caused Motion?' The Semantics of the English to-dative and the Dutch aan-dative'. Cognitive Linguistics 20: 5-42.

Colleman, T. and De Clerk, B. (2008). 'Constructional Semantics on the Move: On Semantic Specialization in the English Double Object Construction'. Cognitive Linguistics 22 (1): 183-209.

Cornett, H. E. (2014). 'Gender Differences in Syntactic Development among English Speaking Adolescents'. Inquiries Journal/Students Pulse [online] 6 (3). Available at: http://www.inquiriesjournal.com/a?id=875.

Crain, S. and Lillo-Martín, D. (1999). An Introduction to Linguistic Theory and Language Acquisition. Oxford: Blackwell.

Creissels, D. (2010). 'Benefactive Applicative Periphrases: A Typological Approach'. In Benefactives and Malefactives: Typological Perspectives and Case Studies. F. Zúñiga and S. Kittilä (eds.). Amsterdam and Philadelphia: John Benjamins, 2969.

Croft W.; Barddal, J.; Hollmann, W.; Nielsen, K.; Sotirova, V. and Taoka, Ch. (2001). 'Discriminating Verb Meanings: The Case of Transfer Verbs'. Handout, LAGB Autumn Meeting, Reading.

Cruttenden, A. (1978). 'Assimilation in Child Language and Elsewhere'. Journal of Child Language 5: 373-378.

Cuervo, C. (2007). 'Double Objects in Spanish as a Second Language: Acquisition of Morpho-syntax and Semantics'. Studies in Second Language Acquisition 29 (4): 583-615.

Cuervo, C. (2003a). Datives at Large. PhD Dissertation, MIT.

Cuervo, C. (2003b). 'Structural Asymmetries but Same Word Order: The Dative Alternation in Spanish'. In Asymmetry in Grammar. Volume I: Syntax and Semantics. A. M. Di Sciullo (ed.). Amsterdam and Philadelphia: John Benjamins, 117-144.

Crystal, D. (2004). The Language Revolution. Cambridge: Polity Press.

Czepluch, H. (1982). 'Case Theory and the Dative Construction'. The Linguistic Review 2 (1): $1-38$.

Davis, B. L.; MacNeilage, P. F. and Matyear, Ch. L. (2002). 'Acquisition of Serial Complexity in Speech Production: A Comparison of Phonetic and Phonological Approaches to First Word Productions'. Phonetica 59: 75-107. 
De Bot, K.; Lowie, W. and Verspoor, M. (2007). 'A Dynamic Systems Theory Approach to Second Language Acquisition'. Bilingualism: Language and Cognition 10 (1): 7-21.

De Bot, K. (2004). 'The Multilingual Lexicon: Modeling Selection and Control'. International Journal of Multilingualism 1: 17-32.

De Cos Ruiz, F. J. (1999). 'El Tratamiento de la Pasiva Refleja en los Manuales de Español como Lengua Extranjera'. Asociación para la Enseñanza de la Lengua Extranjera (ASELE), Proceedings $X$, 203-226.

De Groot, A. M. B. (2011). Language and Cognition in Bilinguals and Multilinguals. Abingdon, Oxford: Psychology Press.

De Houwer, A. (2009). Bilingual First Language Acquisition. Clevedon: Multilingual Matters.

De Houwer, A. (2005). 'Early Bilingual Acquisition: Focus on Morphosyntax and the Separate Development Hypothesis'. In The Handbook of Bilingualism. J. Kroll and A. De Groot (eds.). Oxford: Oxford University Press, 30-48.

De Houwer, A. and Bornstein, M. H. (2003). 'Bilingual Environments and Language Development in Belgium'. Paper presented at The XIth European Conference on Developmental Psychology. Milan, Italy.

De Houwer, A. (1990). The Acquisition of Two Languages from Birth: A Case Study. Cambridge: Cambridge University Press.

De Houwer, A. (1996). 'Bilingual Language Acquisition'. In The Handbook of Child Language. P. Fletcher and B. MacWhinney (eds.). Oxford: Blackwell, 219-250.

De Houwer, A. (1990). The Acquisition of Two Languages from Birth: A Case Study. Cambridge: Cambridge University Press.

De Houwer, A. and Bornstein, M. H. (2003). 'Balancing on the Tightrope: Language Use Patterns in Bilingual with Young Children'. Paper presented at The Fourth International Symposium on Bilingualism. Tempe, Arizona.

Delbecque, N. (1992). 'El Dativo Español: Una Tipología’. Actas XI. Centro Virtual Cervantes: $124-138$.

Demetras, M. J.-A. Working Parents Conversational Responses to their Two-Year-Old Sons. Ms. University of Arizona.

Demonte, V. (1995). 'Dative Alternation in Spanish’. Probus 7 (1):5-30.

Demonte, V. (1994). 'Datives in Spanish'. Working Papers in Linguistics 4 (1): 71-96.

De Marneffe, M.-C.; Grimm, S.; Cohen Priva, U.; Lestrade, S.; Ozbek, G.; Schnoebelen, T.; Kirby, S.; Becker, M.; Fong, V. and Bresnan, J. (2012). 'A Statistical Model of Grammatical Choices in Children's Productions of Dative Sentences'. Paper presented at The Formal Approaches to Variation in Syntax. University of York, UK. 
Den Dikken, M. (1995). 'Particles: On the Syntax of Verb-Particle, Triadic and Causative Constructions'. In Functions of Language 4 (2). E. Koktová (ed.). Amsterdam and Philadelphia: John Benjamins, 294-299.

Den Dikken, M. (1991). 'Serial Verbs, Object Sharing and the Analysis of Dative Shift'. In Linguistics in the Netherlands. F. Drijkoningen and A. M. C. van Kemenade (eds.). Amsterdam and Philadelphia: John Benjamins, 31-40.

Déprez, V. and Pierce, A. (1994). 'Cross-linguistic Evidence for Functional Projections in Early Child Grammar'. In Language Acquisition Studies in Generative Grammar. T. Hoekstra and B. Schwartz (eds.). Amsterdam and Philadelphia: John Benjamins, 57-83.

Déprez, V. and Pierce, A. (1993). 'Negation and Functional Projections in Early Grammar'. Linguistic Inquiry 24 (1): 25-67.

Deuchar, M. and Quay, S. (2000). Bilingual Acquisition: Theoretical Implications of a Case Study. Oxford: Oxford University Press.

De Villiers, J. G. and de Villiers, P. A. (1973). 'A Cross-Sectional Study of the Acquisition of Grammatical Morphemes in Child Speech'. Journal of Psycholinguistic Research 2 (3): 267-278.

Dickinson, D. K. and Tabors, P. O. (eds.) (2001). Beginning Literacy with Language: Young Children Learning at Home and School. Baltimore: Paul Brookes Publishing.

Diez-Itza, E. (1995). 'Procesos Fonológicos en la Adquisición del Español como Lengua Materna’. In Actas del XI Congreso Nacional de Lingüística Aplicada. J. M. Ruiz, P. Sheerin and E. González-Cascos (eds.). Valladolid: University of Valladolid, 225-264.

Dini, Warastuti, R. (2011). 'Gender Differences in Children Language Acquisition and Language Development’. Musawa 3 (2): 221-234.

Döpke, S. (1999). 'Cross-Linguistic Influences on the Placement of Negation and Modal Particles in Simultaneous Bilingualism’. Language Sciences 21: 143-175.

Döpke, S. (1992). One Parent One Language: An Interactional Approach. Amsterdam: John Benjamins.

Dryer, Matthew S. (1986). 'Primary Objects, Secondary Objects and Antidative'. Language 62 (4): 808-845.

Du, Lihong (2010). 'Initial Bilingual Development: One Language or Two?' Asian Social Science 6 (5): 132-139.

Durán Arboisiere, E. (2004). 'Reduplicación y Omisión de Clíticos en el Español de Tucson, Arizona'. Divergencias. Revista de Estudios Lingüísticos y Literarios 2 (2): 3-16. 
Edwards, J. (2004). 'Foundations of Bilingualism'. In The handbook of Bilingualism. T. K. Bathia and W. C. Ritchie (eds.). Oxford: Blackwell, 7-31.

Ellis, N. (2002). 'Reflections on Frequency Effects in Language Acquisition: A Response to Commentaries’. Studies in Second Language Acquisition 24: 297339.

Ellis, C. D. (1983). Spoken Cree. Revisited Edition. Edmonton: Pica Pica Press.

Eriksson, M.; Marschik, P.B.; Tulviste, T.; Almgren, M.; Pérez Pereira, M.; Wehberg, S.; Marjanovic-Umek, L.; Gayraud, F.; Kovacevic, M. and Gallego, C. (2012). 'Differences between Girls and Boys in Emerging Language Skills: Evidence from 10 Language Communities'. British Journal of Developmental Psychology 30: 326-343.

Feldman, A. and Menn, L. (2003). 'Up Close and Personal: A Case Study of the Development of Three English Fillers'. Journal of Child Language 30 (4):735768.

Fenson, L.; Marchman, V. A.; Thal, D. J.; Dale, P. S.; Reznick, J. S. and Bates, E. (2007). MacArthur Communicative Development Inventories: User's Guide and Technical Manual (2nd edition). Baltimore: Paul H. Brookes Publishing Company.

Fenson, L.; Dale, P. S.; Reznick, J. S.; Bates, E.; Thal, D. J.; Pethick, S.; Tomasello, M.; Mervis, C. B. and Stiles J. (1994). 'Variability in Early Communicative Development'. Monographs of the Society for Research in Child Development 59 (5): 1-185.

Fernández Fuertes, R. and Álvarez de la Fuente, E. (2017). 'The Acquisition of Spanish and English as Two First Languages through the Analysis of Natural Interpreting in Bilingual Children'. Revista Española de Lingüística Aplicada (RESLA) 30 (1): 142-165.

Fernández Fuertes, R. and Liceras Muñoz, J. (2018). 'Bilingualism as a First Language: Language Dominance and Cross-linguistic Influence'. Language Acquisition and Contact in the Iberian Peninsula. A. Cuza and P. Guijarro-Fuentes (eds.). Berlin: De Gruyter, 159-186.

Fernández Fuertes, R.; Liceras Muñoz, J. and Alba de la Fuente, A. (2016). 'Beyond the Subject DP versus the Subject Pronoun Divide in Agreement Switches in Spanish'. In Romance Linguistics 2013: Selected Papers from the $43^{\text {rd }}$ Linguistics Symposium on Romance Languages (LSRL). C. Tortora, M. den Dikken, I. L. Montoya and T. O’Neill (eds.). Amsterdam and Philadelphia: John Benjamins, 79-98.

Fernández Fuertes, R. and Liceras Muñoz, J. M. (2010). 'Copula Omission in the English Developing Grammar of English/Spanish Children'. International Journal of Bilingual Education and Bilingualism 26: 252-551. 
Fletcher, P. and Garman, M. (1988). 'Normal Language Development and Language Impairment: Syntax and Beyond’. Clinical Linguistics and Phonetics 2: 97-114.

Forrester, M. (2002). 'Appropriating Cultural Conceptions of Childhood: Participation in Conversation'. Childhood 9: 255-278.

Galsworthy, M. J.; Dionne, G.; Dale, P. S. and Plomin, R. (2000). 'Sex Differences in Early Verbal and Non-Verbal Cognitive Development'. Developmental Science 3 (2): 206-215.

García Maroto, R. (1985). 'Varios Aspectos de los Pronombres Clíticos en la Teoría de la Rección y el Ligamento’. VERBA 12: 107-146.

Gathercole, V. and Thomas, E. M. (2009). 'Bilingual First-Language Development: Dominant Language Takeover, Threatened Minority Language Take-Up’. Bilingualism: Language and Cognition 12 (2): 213-237.

Gathercole, S. E. (2007). 'The Concept of Working Memory'. In Cognitive Psychology of Memory 2. H. L. Roediger (ed.). Oxford: Elsevier, 33-52.

Gathercole, V. (1986). 'The Acquisition of the Present Perfect: Explaining Differences in the Speech of Scottish and American Children'. Journal of Child Language 13: $575-560$.

Gathercole, V. (1986). Birdies Like Birdseed the Bester than Buns: A Study of Relational Comparatives and their Acquisition. PhD Dissertation, University of Kansas.

Gawlitzek-Maiwald, I. and Tracy, R. (1996). 'Bilingual Bootstrapping'. Linguistics 34 (5): 901-926.

Genesee, F. (2003). 'Rethinking Bilingual Acquisition'. In Bilingualism: Challenges and Directions for Future Research. J. M. deWaele (ed.). Clevedon: Multilingual Matters, 158-152.

Genesee, F.; Nicoladis, E. and Paradis, J. (1995). 'Language Differentiation in Early Bilingual Development’. Journal of Child Language 22 (3): 611-631.

Gerlach, B. (2002). Clitics Between Syntax and the Lexicon. Amsterdam and Philadelphia: John Benjamins.

Givón, T. (1990). Syntax: A Functional Typological Introduction. Amsterdam and Philadelphia: John Benjamins.

Gleason, J. B. (1990). 'Sex Differences in Parent-Child Interaction'. In Language, Gender and Sex in Comparative Perspective. S. U. Philips, S. Steele and C. Tanz (eds.). Cambridge: Cambridge University Press, 189-199.

Gleason, J. B. (1980). 'The Acquisition of Social Speech and Politeness Formulae'. In Language: Social Psychological Perspectives. H. Giles, W. P. Robinson and P. M. Smith (eds.). Oxford: Pergamon, 21-27. 
Gleitman, L. and Newport, E. L. (1995). 'The Invention of Language by Children: Environmental and Biological Influences on the Acquisition of Language'. In Invitation to Cognitive Science. L. Gleitman and M. Liberman (eds.). Cambridge and London: MIT Press, 1-24.

Goldberg, A. E. (2006). Constructions at Work: The Nature of Generalization in Language. Oxford: Oxford Linguistics.

Goldberg, A. E. (1995). A Construction Grammar Approach to Argument Structure. Chicago: The University of Chicago Press.

Gómez Araquistain, M. (1990). Adquisición de la Pasiva en Castellano: Comprensión y Expresión de Oraciones Pasivas en el Niño. PhD Dissertation, University of Deusto.

Goodluck, H. (1991). Language Acquisition: A Linguisitc Introduction. Oxford: Blackwell.

Gropen, J.; Pinker, S.; Hollander, M.; Goldberg, R. and Wilson, R. (1989). 'The Learnability and Acquisition of the Dative Alternation in English'. Language 65: 203-257.

Grosjean, F. (2008). Studying Bilinguals. Oxford: Oxford University Press.

Grosjean, F. (2001). ‘The Bilingual’s Language Modes’. In One Mind, Two Languages: Bilingual Language Processing. J. L. Nicol (ed.). Oxford: Blackwell, 1-22.

Grosjean, F. (1982). Life with Two Languages: An Introduction to Bilingualism. Cambridge: Harvard University Press.

Grüter, T. and Paradis, J. (2014). Input and Experience in Bilingual Development. Amsterdam and Philadelphia: John Benjamins.

Grüter, T.; Hurtado, N.; Marchman, V. A. and Fernald, A. (2014). 'Language Exposure and Online Processing Efficiency in Bilingual Development: Relative versus Absolute Measures'. In Input and Experience in Bilingual Development. T. Grüter and J. Paradis (eds.). Amsterdam and Philadelphia: John Benjamins, 1536.

Grüter, T.; Rhode, H. and Schafer, A. J. (2014). 'The Role of Discourse-Level Expectations in Non-Native Speakers' Referential Choices'. In Proceedings of the $38^{\text {th }}$ Boston University Conference on Language Development. W. Orman and M. J. Valleau (eds.). Boston: Cascadilla Press, 179-191.

Gu, Ch. C. (2010). 'Cross-linguistic Influence in Two Directions: The Acquisition of Dative Constructions in Cantonese-English Bilingual Children'. International Journal of Bilingualism 17 (1): 87-103.

Guasti, M. T. (2004). Language Acquisition: The Growth of Grammar. Cambridge and London: MIT Press. 
Gutiérrez Ordoñez, S. (1999). 'Los Dativos'. In Gramática Descriptiva de la Lengua Española 2. I. Bosque and V. Demonte (coord.). Madrid: Espasa, 1807-1854.

Haegeman, L. and Guerón, J. (1999). English Grammar: A Generative Perspective. Oxford: Blackwell.

Haggerty, L. (1929). 'What a Two-and-One-Half-Year-Old Child Said in One Day'. Journal of Genetic Psychology 38: 75-100.

Hale, K. and Keyser, S. J. (2002). 'On Argument Structure and the Lexical Expression of Syntactic Relations'. In The View from Building 20; Essays in Linguistics in Honor of Sylvain Bromberger. H. Kenneth and S. J Keyser. (eds.). Cambridge, and London: MIT Press, 53-110.

Hall, W. S.; Nagy, W. E. and Linn, R. (1984). Spoken Words: Effects of Situation and Social Group on Oral Word Usage and Frequency. Hillsdale: Erlbaum.

Halpern, D. F. (2000). Sex Differences in Cognitive Abilities. Hillsdale: Erlbaum.

Harley, H. (2006). Possession and the Double Object Construction. Ms., University of Arizona.

Harley, H. (2003). 'Distributed Morphology'. In The Second Glot International State of the Article Book. L. Cheng and R. Sybesma (eds.). Berlin and Boston: Mouton de Gruyter, 463-496.

Harley, H. (2002). 'Possession and the Double Object Construction'. Yearbook of Linguistic Variation 2: 29-68.

Harris, B. (1978). 'The Difference between Natural and Professional Translation'. Canadian Modern Language Review 34: 417-427.

Haspelmath, M. (2006). 'Ditransitive Constructions in RRG and Some Other Approaches'. Paper presented at The International Conference on Role and Reference Grammar. University of Leipzig.

Haspelmath, M. (1995). 'Ditransitive Constructions'. Annual Review of Linguistics 1: 125.

Henry, A. (1995). Belfast English and Standard English: Dialect Variation and Parameter Setting. Oxford: Oxford University Press.

Hernanz, M. L. and Brucart, J. M. (1987). La Sintaxis: Principios Teóricos. La Oración Simple. Barcelona: Editorial Crítica.

Hess, Z. K. (2003). El Desarrollo Lingüístico en los Años Escolares: Análisis de Narraciones Infantiles. PhD Dissertation, El Colegio de México.

Hickey, T. (1991). 'Mean Length of Utterance and the Acquisition of Irish'. Journal of Child Language 18: 553-569.

Higginson, R. P. (1985). Fixing-Assimilation in Language Acquisition. PhD Dissertation, Washington State University. 
Hill, S.; Mayberry, M. and Baranowski, E. (2014). Bilingual Grammar of EnglishSpanish Syntax. Lanham: Rowman and Littlefield.

Hoff, E.; Welsh, S.; Place, S. and Ribot, K. M. (2014). 'Properties of Dual Language Input that Shape Bilingual Development and Properties of Environments that Shape Dual Language Input'. In Input and Experience in Bilingual Development. T. Grüter and J. Paradis (eds.). Amsterdam and Philadelphia: John Benjamins, 119-140.

Hoff, E.; Core, C.; Place, S.; Rumiche R.; Señor, M. and Parra, M. (2012). 'Dual Language Exposure and Early Bilingual Development'. In Journal of Child Language 19: 1-27.

Horgan, D. (1976). 'Sex Differences in Early Language Development'. Paper presented at The Midwestern Psychological Association. Chicago.

Howe, Ch. (1981). Acquiring Language in a Conversational Context. London: Academic Press.

Hudson, R. (1991). 'Double Objects, Grammatical Relations and Proto Roles'. UCL Working Papers in Linguistics 3: 332-368.

Hurtado, A. (1984). 'On the Properties of LF'. Cornell Working Papers in Linguistics 6: 121-150.

Harris, B. (1992). 'Natural Translation: A Reply to Hans P. Krings'. Target 4 (1): 97103.

Harris, B. (1977). 'The Importance of Natural Translation'. Working Papers in Bilingualism 12: 96-114.

Hoper, P. J. and Thompson, S. A. (1980). 'Transitivity in Grammar and Discourse'. Language 56 (4): 251-299.

Hsin, L. (2012). 'Accelerated Acquisition in Spanish-English Bilinguals: The Structural Transfer Hypothesis'. In Proceedings of the $29^{\text {th }}$ West Coast Conference on Formal Linguistics. J. Choi, A. Hogue, J. Punske, D. Tat, J. Schertz and A. Trueman (eds.). Somerville: Cascadilla Proceedings Project, 108-116.

Hulk, A. (1997). 'The Acquisition of French Object Pronouns by a Dutch/French Bilingual Child'. In Proceedings of GALA 1997. Language Acquisition: Knowledge Representation and Processing. A. Sorace, C. Heycock and R. Shilcock (eds.). Edinburgh: University of Edinburgh Press, 512-526.

Hulk, A. and Müller, N. (2000). 'Cross-linguistic Influence in Bilingual Children: Object Omission and Root Infinitives'. In Proceedings of the $24^{\text {th }}$ Annual Boston University Conference on Language Development (BUCLD). S. C. Howell, S. A. Fish and T. Keith-Lucas (eds.). Somerville: Cascadilla Press, 546-557.

Hyams, N. (2004). 'Underspecification and Modularity in Early Syntax: A Formalist Perspective on Language Acquisition'. In The Child Language Reader. K. Trott, S. Dobbinson and P. Griffiths (eds.). London: Routledge, 241-258. 
Hyams, N. (1987). 'The Theory of Parameters and Syntactic Development'. In Parameter Setting. T. Roeper and E. Williams (eds.). Dordrecht: Reidel, 1-22.

Hyams, N. H. (1986). Language Acquisition and the Theory of Parameters. Dordrecht: Reidel.

Hyde, J. S. and Linn, M. C. (1988). 'Gender Differences in Verbal Ability: A MetaAnalysis’. Psychological Bulletin 104 (1): 53-69.

Inkelas, S. and Rose, Y. (2003). 'Velar Fronting Revisited'. In Proceedings of the $27^{\text {th }}$ Annual Boston University Conference on Language Development. B. Beachley, A. Brown and F. Conlin (eds.). Somerville: Cascadilla Press, 334-345.

Kirby, S. (2010). 'Passives in First Language Acquisition: What Causes the Delay?' In Proceedings of the $33^{\text {rd }}$ Annual Pennsylvania Linguistics Colloquium. Working Papers in Linguistics 16 (1). S. Vejdemo (ed.). Pennsylvania: University of Pennsylvania, 109-117.

Koenigsknecht, R. A. and Friedman, P. (1976). 'Syntax Development in Boys and Girls’. Child Development 47 (4): 1109-1115.

Jackendoff, R. (1990). Semantic Structures. Cambridge and London: MIT Press.

Jackson-Maldonado, D.; Thal, D. J.; Marchman, V.; Fenson, L.; Newton, T. and Conboy, B. (2003). MacArthur Inventarios del Desarrollo de Habilidades Comunicativas: User's Guide and Technical Manual. Baltimore: Paul H. Brookes.

Jackson-Maldonado, D. and Thal, D. (1993). Lenguaje y Cognición en los Primeros Años de Vida. Project funded by the J. D. and C. T. Mac Arthur Foundation and CONACYT, Mexico.

Jaeggli, O. (1986). 'Three Issues in the Theory of Clitics: Case, Doubled NPs, and Extraction'. In The Syntax of Pronominal Clitics. H. Borer (ed.). London: Academic Press, 15-42.

Jaeggli, O. (1982). Topics in Romance Syntax. Dordrecht: Foris.

Jake, J. L.; Myers-Scotton, C. M. and Gross, S. (2002). 'Making a Minimalist Approach to Codeswitching Work: Adding the Matrix Language'. Bilingualism: Language and Cognition 5 (1): 69-91.

Joseph, R. (2000). 'The Evolution of Sex Differences in Language, Sexuality and Visual-Spatial Skills'. Archives of Sexual Behavior 29 (1): 35-66.

Jaeggli, O. (1982). 'Topics in Romance Syntax'. Linguisticae Investigationes 9 (1): 170-177.

Kayne, R. S. (1994). 'The Antisymmetry of Syntax'. Linguistic Inquiry Monograph 25. Cambridge and London: MIT Press.

Kayne, R. (1984). Connectedness and Binary Branching. Dordricht: Foris. 
Kayne, R. (1981). Morphological Theory. Oxford Theory. Oxford: Blackwell.

Kayne, R. (1975). French Syntax: The Transformational Cycle. Cambridge and London: MIT Press.

Kempchinsky, P. (2004). 'Romance SE as an Aspectual Element'. In Contemporary Approaches to Romance Linguistics. J. Auger, J. Clancy and B. Vance (eds.). Amsterdam and Philadelphia: John Benjamins, 239-256.

Kimura, D. (1992). 'Sex Differences in the Brain'. Scientific American 267 (3): 118125.

Kittilä, S. (2005). 'Recipient Prominence vs. Beneficiary Prominence'. Linguistic Typology 9: 269-297.

Klima, E. and Bellugi, U. (1966). 'Syntactic Regularities in the Speech of Children'. In Psycholinguistic Papers. J. Lyons and R. J. Wales (eds.). Edinburgh: Edinburgh University Press, 183-208.

Koenigsknecht, R. A. and Friedman, P. (1976). 'Syntax Development in Boys and Girls’. Child Development 47: 1109-1115.

Koenigsknecht, R. A. 'Statistical Information on Developmental Sentence Analysis'. In Developmental Sentence Analysis: A Clinical Procedure for the Assessment of Children's Syntactic Development. L. L. Lee (ed.). Evanston: Northwestern University Press, 1-48.

Koizumi, M. (1994). 'Nominative Objects: The Role of TP in Japanese'. In Formal Approaches to Japanese Linguistics 1. M. Koizumi and H. Ura (eds.). MIT Working Papers in Linguistics, 211-230.

Köpke, B.; Schmid, M. S.; Keijzer, M. and Dostert, S. (2007). Language Attrition. Theoretical Perspectives. Studies in Bilingualism. Amsterdam and Philadelphia: John Benjamins.

Köpke, B. and Schmid, M. S. (2003). 'Language Attrition. The Next Phase'. In First Language Attrition. Interdisciplinary Perspectives on Methodological Issues. M. Schmid, B. Köpke, M. Keijzer and L. Weilemar (eds.). Amsterdam: John Benjamins, 1-143.

Krifka, M. (2003). 'Semantic and Pragmatic Conditions for the Dative Alternation'. Paper presented at The Kasell International Conference on English Language and Linguistics, Hanyang University.

Kuczaj, S. (1977). 'The Acquisition of Regular and Irregular Past Tense Forms'. Journal of Verbal Learning and Verbal Behavior 16: 589-600.

Kupisch, T. (2006). The Acquisition of Determiners in Bilingual German-Italian and German-French Children. Munich: Lincom.

Kupisch, T. (2005). 'Acceleration in Bilingual First Language Acquisition'. In Languages and Linguistic Theory, Selected Papers from Going Romance 2003. 
T. Gaerts, I. Van Ginneken and H. Jacobs (eds.). Amsterdam: John Benjamins, 183-203.

Kvaal, J. T.; Shipstead-Cox, N.; Nevitt, S. G.; Hodson, B. W. and Launer, P. B. (1988). 'The Acquisition of 10 Spanish Morphemes by Spanish-Speaking Children'. Language, Speech and Hearing Services in Schools 19: 384-394.

Larson, R. K. (2014). On Shell Structure. London: Routledge.

Larson, R. K. (1990). 'Double Objects Revisited: Reply to Jackendoff'. Linguistic Inquiry 21 (4): 589-632.

Larson, R. K. (1988). 'On the Double Object Construction'. Linguistic Inquiry 19: 335391.

Lee, L. L. (1974). Development Sentence Analysis: A Grammatical Assessment Procedure for Speech and Language Clinicians. Evanston: Northwestern University Press.

Lee, L. L. and Canter, S. M. (1971). 'Developmental Sentence Scoring: A Clinical Procedure for Estimating Syntactic Development in Children's Spontaneous Speech'. Journal of Speech and Hearing Disorders 36: 315-340.

Legate, J. A. and Yang, C. (2002). 'Empirical Re-Assessment of Stimulus Poverty Arguments’. The Linguistic Review 19: 151-162.

Levin, B. and Rappaport Hovav, M. (2001). 'What Alternates in the Dative Alternation?' Ms., Colloquium Series, Department of Linguistics and Philosophy, MIT.

Liceras Muñoz, J.; Fernández Fuertes, R. and Klassen, R. (2016). 'Language Dominance and Language Nativeness: The View from English-Spanish Codeswitching'. In Spanish-English Codeswitching in the Caribbean and the US. R. E. Guzzardo Tamargo, C. M. Mazak and M. C. Parafita Couto (eds.). Amsterdam and Philadelphia: John Benjamins, 107-138.

Liceras Muñoz, J., Fernández Fuertes, R. and Alba de la Fuente, A. (2012). 'Subject and Copula Omission in the English grammar of English-Spanish bilinguals: On the Issue of Directionality of Interlinguistic Influence'. First Language 32 (1-2): 88115.

Liceras Muñoz, J. M.; Fernández Fuertes, R.; Perales, S.; Pérez-Tattam, R. and Spradlin, K. T. (2008). 'Gender and Gender Agreement in Bilingual Native and Non-Native Grammars: A view from Child and Adult Functional-Lexical Mixings'. Lingua 118: 827-851.

Lieven, E. (2010). 'Input and First Language Acquisition: Evaluating the Role of Frequency’. Lingua 120 (1): 2546-2556.

Lieven, E. (2008). 'Building Language Competence in First Language Acquisition'. European Review 16 (4): 445-456. 
Linaza, J.; Sebastián, M. E. and del Barrio, Cristina (1981). 'Lenguaje, Comunicación y Comprensión. La Adquisición del Lenguaje’. Journal for the Study of Education and Development 4 (1): 195-197.

Lindholm, K. J. and Padilla, A. (1978a). 'Language Mixing in Bilingual Children'. Journal of Child Language 5: 327-335.

Lindholm, K. J. and Padilla, A. (1978b). 'Child Bilingualism: Report on Language Mixin, Switching and Translations’. Linguistics 211: 23-44.

Loeb, D. F. and Leonard, L. B. (1991). 'Subject Case Marking and Verb Morphology in Normally Developing and Specifically Language-Impaired Children'. Journal of Speech and Hearing Research 34: 340-346.

López Ornat, S. (1994). La Adquisición de la Lengua Española. Madrid: Siglo XXI.

López Ornat, S. (1990). 'La Formación de la Oración Simple: La Omisiones de Categorías Sintácticas (S/V/O) en la Adquisición del Español’. Estudios de Psicología 41: 41-72.

Lovas, G. S. (2011). 'Gender and Patterns of Language Development in MotherToddler and Father-Toddler Dyads’. First Language 31 (1): 83-108.

Lust, B. (2006). Child Language: Acquisition and Growth. Cambridge: Cambridge University Press.

Mackey, W. F. (2000). 'The Description of Bilingualism'. Canadian Journal of Linguistics/Revue Canadienne de Linguistique 7 (2): 51-85.

MacWhinney, B. (2000). The CHILDES Project: Tools for Analyzing Talk. $3^{\text {rd }}$ Edition. Hillsdale: Erlbaum. Available at: <http://childes.talkbank.org>.

Malakoff, M. E.; Mayes, L. C.; Schottenfeld, R. and Howell, S. (1999). 'Language Production in 24-Month-Old Inner-City Children of Cocaine-and-Other-DrugUsing Mothers'. Journal of Applied Developmental Psychology 20 (1): 159-180.

Malchukov, A.; Haspelmath, M. and Comrie, B. (2007). 'Ditransitive Constructions: A Typological Overview'. In Studies in Ditransitive Constructions: A Comparative Handbook. A. Malchukov, M. Haspelmath and B. Comrie (eds.). Berlin and Boston: De Gruyter, 1-60.

Marantz, A. (1993). 'Implications of Asymmetries in Double Object Constructions'. In Theoretical Aspects of Bantu Grammar. S. A. Mchombo (ed.). Stanford: Leland Stanford Junior University Press, 113-150.

Marantz, A. (1991). 'Case and Licensing’. In Argument and Case: Explaining Burzio’s Generalization. E. J. Reuland (ed.). Amsterdam and Philadelphia: John Benjamins, 11-30.

Marantz, A. (1984). On the Nature of Grammatical Relations. Cambridge: MIT Press.

Marín Arrese, J. I. (1993). La Pasiva en Inglés: Un Estudio Funcional Tipológico. Madrid: Editorial de la Universidad Complutense de Madrid. 
Masullo, P. J. (1992). Incorporation and Case Theory in Spanish: A Cross-linguistic Perspective. PhD Dissertation, University of Washington.

Mazurkewich, I. and White, L. (1984). 'The Acquisition of the Dative Alternation: Unlearning Overgeneralizations’. Cognition 16: 261-283.

Meisel, J. M. (2004). 'The Bilingual Child'. In The handbook of Bilingualism. T. K. Bathia and W. C. Ritchie (eds.). Oxford: Blackwell, 91-113.

Meisel, J. M. (2001). 'The Simultaneous Acquisition of Two First Languages: Early Differentiation and Subsequent Development of Grammars'. In Trends in Bilingual Acquisition. J. Cenoz and F. Genesee (eds.). Amsterdam and Philadelphia: John Benjamins, 11-41.

Meisel, J. M. (1989). 'Early Differentiation of Languages in Bilingual Children'. Bilingualism across the Lifespan: Aspects of Acquisition, Maturity and Loss. Cambridge: Cambridge University Press, 13-40.

Michaelis, S. and Haspelmath, M. (2003). 'Ditransitive Constructions: Creole Languages in a Cross-Linguistic Perspective'. Creolica: 1-16.

Miller, J. F. (1981). Assessing Language Production in Children: Experimental Procedures. Baltimore: University Park Press.

Miller, J. F. and Chapman, R. S. (1981). 'The Relation between Age and Mean Length of Utterance in Morphemes'. Journal of Speech and Hearing Research 24 (2): 154-161.

Mills, D. L.; Coffey-Corina, S. A. and Neville, H. J. (1993). 'Language Acquisition and Cerebral Specialization in 20-Month-Old Infants'. Journal of Cognitive Neuroscience 5 (3): 317-334.

Mishina-Mori, S. (2005). 'Autonomous and Independent Development of Two Language Systems in Japanese/English Simultaneous Bilinguals: Evidence from Question Formation’. First Language 25 (3): 291-315.

Montes, R. (1992). Achieving Understanding: Repair Mechanism in Mother-Child Conversations. PhD Dissertation, Georgetown University.

Montrul, S. A. (2008). Incomplete Acquisition in Bilingualism: Re-examining the Age Factor. Amsterdam and Philadelphia: John Benjamins.

Montrul, S. A. (2004). 'Convergent Outcomes in Second Language Acquisition and First Language Loss'. In First Language Attrition: Interdisciplinary Perspectives on Methodological Issues. M. Schmid, B. Köpke, M. Keijzer and L. Weilemar (eds.). Amsterdam and Philadelphia: John Benjamins, 259-280.

Montrul, S. A. (2002). 'Incomplete Acquisition and Attrition of Spanish Tense/Aspect Distinctions in Adult Bilinguals’. Bilingualism: Language and Cognition 5: 3968. 
Montrul, S. A. (2000). 'Transitivity Alternations in L2 Acquisition: Toward a Modular View of Transfer'. In Studies in Second Language Acquisition 22 (2). S. Gass (ed.). Cambridge: Cambridge University Press, 229-273.

Morisset, C. H.; Barnard, K. E. and Booth, C. L. (1995). 'Toddlers' Language Development: Sex Differences within Social Risk'. Developmental Psychology 31 (5): 851-865.

Mulder, R. (1992). The Aspectual Nature of Syntactic Complementation. Holland: Holland Institute of Generative Linguistics.

Müller, N. and Cantone, K. F. (2009). 'Language Mixing in Bilingual Children: CodeSwitching?' In The Cambridge Handbook of Linguisitc Code-Switching. B. E. Bullock and A. J. Toribio (eds.). Cambridge: Cambridge University Press, 199220.

Müller, N. and Hulk, A. (2001). 'Cross-linguistic Influence in Bilingual Language Acquisition: Italian and French as Recipient Languages'. Bilingualism: Language and Cognition 4 (1): 1-21.

Nagy, E.; Kompagne, H.; Orvos, H. and Pal, A. (2007). 'Gender-Related Differences in Neonatal Imitation’. Infant and Child Development 16: 267-276.

Nelson, K. (ed.). Narratives from the Crib. Cambridge: Harvard University Press.

Nicoladis, E. (2012). 'Cross-linguistic Influence in French-English Bilingual Children’s Possessive Constructions’. Bilingualism 15 (2): 320-328.

Nieva Ramos, S. (2013). Función de la Estructura de Diálogo en la Transición de una a dos Palabras. PhD Dissertation, Complutense University of Madrid.

Ninio, A.; Snow, C. E.; Pan, B. A. and Rollins, P. R. (1994). 'Classifying Communicative Acts in Children's Interactions'. Journal of Communications Disorders 25: 157-188.

Nippold, M. A.; Mansfield T. C. and Billow J. L. (2007). 'Peer Conflict Explanations in Children, Adolescents and Adults: Examining the Development of Complex Syntax’. American Journal of Speech-Language Pathology 16: 179-188.

O’Grady, W. (1997). Syntactic Development. Chicago: The University of Chicago Press.

Oehrle, R. T. (1976). The Grammatical Status of the Dative Alternation. PhD Dissertation, MIT.

Ormazabal, J. and Romero, J. (1999). On the Syntactic Nature of the me-lui and the Person-Case Constraint. Ms. University of the Basque Country and MIT.

Padilla, A. and Liebman, E. (1975). 'Language Acquisition in the Bilingual Child'. The Bilingual Review 2: 34-55.

Paradis, J. (2001). 'Do Bilingual Two-Year-Olds Have Separate Phonological System?' The International Journal of Bilingualism 5 (1): 19-38. 
Paradis, J.; Nicoladis, E.; Crago, M. and Genesee, F. (2011). 'Bilingual Children’s Acquisition of the Past Tense: A Usage-Based Approach'. Journal of Child Language 38: 554-578.

Paradis, J.; Crago, E. and Genesee, F. (2006). 'Domain-Specific Versus DomainGeneral Theories of the Deficit in SLI: Object Pronoun Acquisition by FrenchEnglish Bilingual Children'. Language Acquisition 13 (1): 33-62.

Paradis, J. and Genesee, F. (1996). 'Syntactic Acquisition in Bilingual Children: Autonomous or Interdependent?' Studies in Second Language Acquisition 18: 125.

Paradis, J. and Navarro, S. (2003). 'Subject Realization and Cross-linguistic Interference in the Bilingual Acquisition of Spanish and English: What is the Role of the Input?' Journal of Child Language 30: 371-393.

Pater, J. (1997). 'Minimal Violation and Phonological Development'. Language Acquisition 6 (3): 201-253.

Patterson, J. L. and Pearson, B. Z. (2004). 'Bilingual Lexical Development: Influences, Contexts and Processes’. In Bilingual Language Development and Disorders in Spanish-English Speakers. B. A. Goldstein (ed.). Baltimore: Paul H. Brookes, 77-104.

Pearson, B. Z. (2012). 'Children with Two Languages'. In The Cambridge Handbook of Child Language. E. L. Bavin (ed.). Cambridge: Cambridge University Press, 379-397.

Pearson, B. Z.; Fernández, S. C. and Oller, D. K. (1993). 'Lexical Development in Bilingual Infants and Toddlers: Comparison to Monolingual Norms'. Language Learning 43: 93-120.

Pena Díaz, C. (2006). Bilingual Speech: A Case Study of a Bilingual Community. Madrid: University of Alcalá.

Pérez-Bazán, M. J. (2002). Predicting Early Bilingual Development: Towards a Probabilistic Model of Analysis. PhD Dissertation, University of Michigan.

Pérez-Leroux, A. and Dalious, J. (1998). 'The Acquisition of Spanish Interrogative Inversion.’ Hispanic Linguistics 10: 84-114.

Perlmutter, D. M. (1980). 'Relational Grammar'. In Syntax and Semantics: Current Approaches to Syntax 13. E. A. Moravcsik and J. R. Wirth (eds.). Orlando: Academic Press, 195-229.

Perpiñan, S. and Montrul, S. (2006). 'On Binding Asymmetries in Dative Alternation Constructions in L2 Spanish'. In Proceeding on the $7^{\text {th }}$ Conference on the Acquisition of Spanish and Portuguese as First and Second Languages. C. A. Klee and T. L. Face (eds.). Somerville: Cascadilla Proceedings Project, 135-148.

Pesetsky, D. (1985). ‘Morphology and Logical Form’. Linguistic Inquiry 16: 193-248. 
Peters, A. (1987). 'The Role of Imitation in the Developing Syntax of a Blind Child'. Text 7: 289-311.

Pierce, A. (1992). Language Acquisition and Syntactic Theory. Dordrecht: Kluwer.

Pineda, A. (2012). 'Double Object Constructions and Dative/Accusative Alternations in Spanish and Catalan: A Unified Account'. Borealis: An International Journal of Hispanic Linguistics 2 (1): 57-115.

Poeppel, D. and Wexler, K. (1993). 'The Full Competence Hypothesis of Clause Structure in Early German’. Language 69: 1-33.

Polka, L. and Sundara, M. (2003). 'Word Segmentation in Monolingual and Bilingual Infant Learners of English and French'. In Proceedings of the $15^{\text {th }}$ International Congress of Phonetic Sciences. M. J. Solé, D. Recasens and J. Romero (eds.). Barcelona: Universidad Autónoma de Barcelona, 1021-1024.

Post, K. (1992). The Language Learning Environment of Laterborns in a Rural Florida Community. PhD Dissertation, Harvard University.

Pullum, G. K. and Scholz, B. C. (2002). 'Empirical Assessment of Stimulus Poverty Arguments’. The Linguistic Review 19: 9-50.

Pylkkänen, L. (2002). Introducing Arguments. PhD Dissertation, MIT.

Pylkkänen, L. (2000). 'What Applicative Heads Apply to'. In Proceedings of the $24^{\text {th }}$ Annual Penn Linguistics Colloquium. M. Minnick, A. Williams and E. Kaiser (eds.). Pennsylvania: University of Pennsylvania Working Papers in Linguistics 7 (1), 191-210.

Quirk, R.; Greenbaum, S.; Leech, G. and Svartvik, J. (1985). A Comprehensive Grammar of the English Language. New York: Longman.

Radford, A. (1990). Syntactic Theory and the Acquisition of English Syntax: The Nature of Early Child Grammars of English. Oxford: Blackwell.

Rappaport Hovav, M. and Levin, B. (2001). 'An Event Structure Account of English Resultatives’. Language 77: 766-797.

Rice, M. L. and Wexler, K. (2001). Test of Early Grammatical Impairment: Examiner's Manual. San Antonio: The Psychological Corporation.

Rill, J. (2011). A Unified Analysis of 'Dative Shift' in English and the Applicative Construction in Chichewa. PhD Dissertation, University of North Carolina.

Rizzi, L. (1994). 'Early Null Subjects and Root Null Subjcts'. In Language Acquisition Studies in Generative Grammar. T. Hoekstra and B. D. Schwartz (eds.). Amsterdam and Philadelphia: John Benjamins, 151-176.

Roeper, T. and Rohrbacher, B. (1994). 'Null Subjects in Early Child English and the Theory of Economy of Projection'. Studies in Theoretical Psycholinguistics 26: 345-396. 
Rollins, P. R. (2003). 'Caregiver Contingent Comments and Subsequent Vocabulary Comprehension’. Applied Psycholinguistics 24: 221-234.

Romaine, S. (2004). 'Bilingual Language Development'. In The Child Language Reader. K. Trott, S. Dobbinson and P. Griffiths (eds.). London: Routledge, 287303.

Romaine, S. (1989). Bilingualism. Oxford: Blackwell.

Romero Morales, J. (2008). Los Dativos en Español (Cuadernos de Lengua Española). Madrid: Arco/Libros.

Romero, S.; Santos, Á. and Pellicer, D. (1992). The Construction of Communicative Competence in Mexican Spanish Speaking Children (6 Months to 7 years). Mexico City: University of the Americas.

Ronjat, J. (1913). Le Développement du Langage Observé Chez an Enfant Bilingue. Paris: Librairie Ancienne H. Champion.

Rowland, C. (2014). Understanding Child Language Acquisition. London: Routledge.

Rowland, C. F. and Fetcher, S. L. (2006). 'The Effect of Sampling on Estimates of Lexical Specificity and Error Rates’. Journal of Child Language 33: 859-977.

Sachs, J. (1983). 'Talking about the There and Them: The Emergence of Displaced Reference in Parent-Discourse'. In Children's Language 4. K. E. Nelson (ed.). Hillsdale: Erlbaum, 1-28.

Sadler, L. and Camilleri, M. (2013). 'Ditransitive Predicates and Dative Arguments in Maltese'. Lingua 134: 36-61.

Sampson, G. (2002). 'Exploring the Richness of the Stimulus'. The Linguistic Review 19: 73-104.

Sanders, N. (2000). The Double Object Construction. Ms.

Schutze, C. T. and Wexler, K. (1996). 'Subject Case Licensing and English Root Infinitives'. In Proceedings of the $20^{\text {th }}$ Annual Boston University Conference on Language Development. A. Stringfellow, D. Cahana-Amitay, E. Hughes and A. Zukowski (eds.). Boston: Cascadilla Press, 670-681.

Schwartz, B. D. and Sprouse, R. (1996). 'L2 Cognitive States and the Full Transfer/Full Access Model’. Second Language Research 12: 40-72.

Schwartz, B. D. and Sprouse, R. (1994). 'Word Order and Nominative Case in Nonnative Language Acquisition: A Longitudinal Study of (L1 Turkish) German Interlanguage'. In Language Acquisition Studies in Generative Grammar. T. Hoekstra and B. D. Schwartz (eds.). Amsterdam and Philadelphia: John Benjamins, 317-368.

Sebba, M. (2009). 'On the Notions of Congruence and Convergence in CodeSwitching'. In The Cambridge Handbook of Linguistic Code-Switching. B. E. 
Bullock and J. Almeida Toribio (eds.). Cambridge: Cambridge University Press, 40-57.

Shakouri, N.; Birjandi, P. and Maftoon, P. (2016). 'On Revisiting the Sex Differences in Language Acquisition: An Etiological Perspective’. International Journal of English Linguistics 6 (4): 87-95.

Shaywitz, B. A.; Shaywltz, S. E.; Pugh K. R.; Constable R. T.; Skudlarski, P.; Fulbright, R. K.; Bronen, R. A.; Fletcher, J. M.; Shankweiler, D. P.; Katz, L. and Gore, J. C. (1995). 'Sex Differences in the Functional Organization of the Brain for Language.' Nature 16 (373): 607-609.

Shirai, Y. and Andersen, R. (1995). 'The Acquisition of Tense/Aspect Morphology: A Prototype Account'. Language 71: 743-762.

Shiro, M. (1997). Getting the Story Across: A Discourse Analysis Approach to Evaluative Stance in Venezuelan Children's Narratives. PhD Dissertation, Harvard University.

Silva Corvalán, C. (2014). Bilingual Language Acquisition: Spanish and English in the First Years. Cambridge: Cambridge University Press.

Silva Corvalán, C. and Sánchez Walker, N. (2007). 'Subjects in Early Dual Language Development’. In Spanish in Contact: Policy, Social and Linguistic Inquiries. K. Potowski and R. Cameron (eds.). Amsterdam and Philadelphia: John Benjamins, 3-22.

Silva Corvalán, C. (1994). Language Contact and Change: Spanish in Los Angeles. Oxford: Oxford University Press.

Sikorska, M. (2009). 'Low Applicative Datives in Spanish as a Second Language: Acquisition of Semantics and Morphosyntax’. Revista Española de Lingüística Aplicada (RESLA) 22: 327: 350.

Slavkov, N. (2012). 'A Fine Balance: Shifts between Passive and Active Bilingualism'. In Proceedings of the 2012 Annual Conference of the Canadian Linguistic Association (CLA). P. Caxaj (ed.). Montreal: Université du Québec à Montréal, 1-13.

Slobin, D. I. (1985). 'Cross-linguistic Evidence for the Language-Making-Capacity’. In The Cross-linguistic Study of Language Acquisition 2. D. I. Slobin (ed.). Hillsdale: Erlbaum, 1157-1256.

Smith, N. V. (1973). The Acquisition of Phonology: A Case Study. Cambridge: Cambridge University Press.

Snyder, W. (2001). 'On the Nature of Syntactic Variation: Evidence from Complex Predicates and Complex Word-Formation'. Language 77: 324-342.

Snyder, W. and Stromswold, K. (1997). 'The Structure and Acquisition of English Dative Constructions’. Linguistic Inquiry 28 (2): 281.317. 
Snyder, W. (1995). 'A Neo-Davidsonian Approach to Resultatives, Particles, and Datives'. In Proceedings of North East Linguistic Society 25. J. Beckman (ed.). Amherst: Graduate Linguistic Student Association of the University of Massachusetts, 457-472.

Stein, G. (1979). Studies in the Function of the Passive.Tübingen: Gunter Narr Verlag.

Stowel, T. A. (1981). Origins of Phrase Structure. PhD Dissertation, MIT.

Strozer, J. R. (1976). Clitics in Spanish. PhD Dissertation, UCLA.

Suñer, M. (1988). 'The Role of Agreement in Clitic-Doubled Constructions'. Natural Language and Linguistic Theory 6: 391-434.

Suppes, P. (1974). ‘The Semantics of Children's Language'. American Psychologist 29: 103-114.

Swain, M. (1972). Bilingualism as a First Language. PhD Dissertation, University of California.

Takeuchi, M. (2006). Raising Children Bilingually Through the 'One Parent-One Language' Approach: A Case Study of Japanese Mothers in the Australian Context. Bern: Peter Lang.

Theakston, A. L.; Maslen, R.; Lieven, E. V. M. and Tomasello, M. (2012). 'The Acquisition of the Active Transitive Construction in English: A Detailed Case Study’. Cognitive Linguistics 23 (1): 91-128.

Theakston, A. L.; Lieven, E.; Pine, J. M. and Rowland, C. F. (2004). 'Semantic Generality, Input Frequency and the Acquisition of Syntax'. Journal of Child Language 31 (1): 61-99.

Theakston, A. L.; Lieven, E.; Pine, J. M. and Rowland, C. F. (2001). 'The Role of Limitations in the Acquisition of Verb-Argument Structure: An Alternative Account'. Journal of Child Language 28: 127-152.

Tomasello, M. (2008). Origins of Human Communication. Cambridge and London: MIT Press.

Tomasello, M. (2003). Constructing a Language: A Usage-Based Theory of Language Acquisition. Cambridge: Harvard University Press.

Tomasello, M. (1999). The Cultural Origins of Human Cognition. Cambridge: Harvard University Press.

Tommerdahl, J. and Kilpatrick, C. (2014). 'The Reliability of Morphological Analyses in Language Samples’. Journal of Language Testing 31 (1): 3-18.

Tomiyama, M. (2009). 'Age and Proficiency in L2 Attrition: Data from Two Siblings'. Applied Linguistics 30 (2): 253-275.

Torrens, V. and Wexler, K. (2000). 'The Acquisition of Clitic Doubling in Spanish'. In The Acquisition of Scrambling and Cliticzation. Studies in Theoretical 
Psycholinguistics 26. S. M. Powers and C. Hamann (eds.). Dordrecht: Springer, 279-297.

Tse, S. K.; Chan, C., Kwong, S. M. and Li, H. (2002). 'Sex Differences in Syntactic Development: Evidence from Cantonese-Speaking Preschoolers in Hong Kong'. International Journal of Behavioral Development 26 (6): 509-517.

Ungureanu, M. L. (2017). 'L1 Acquisition of Direct Object Clitic Doubling'. Linguistica Atlantica 36 (1): 15-29.

Uriagereka, J. (1988). On Government. PhD Dissertation, University of Connecticut.

Valian, V. (1991). 'Syntactic Subjects in the Early Speech of American and Italian Children’. Cognition 40: 21-81.

Vihman, M. (1996). Phonological Development. Cambridge: Blackwell Publishers.

Vihman, M. (1982). 'The Acquisition of Morphology by a Bilingual Child: A WholeWord Approach’. Applied Psycholinguistics 3: 141-160.

Vila, I. (1990). Adquisición y Desarrollo del Lenguaje. Barcelona: Graó.

Wei, L. (2000). 'Dimensions of Bilingualism'. In The Bilingual Reader. L. Wei (ed.). London: Routledge, 3-25.

Weiner, J. E. and Labov, W. (1983). 'Constraints on the Agentless Passive'. Journal of Linguistics, 19: 29-58.

Wells, G. (1981). Learning through Interaction: The Study of Language Development. Cambridge: Cambridge University Press.

Wexler, K. (1994). 'Optional Infinitives, Head Movement and the Economy of Derivations'. In Verb Movement. D. Lightfoot and N. Hornstein (eds.). Cambridge: Cambridge University Press, 305-350.

Yang, C. (2016). The Price of Linguistic Productivity: How Children Learn to Break the Rules of Language. Cambridge and London: MIT Press.

Yang, C. (2011). 'Computational Models of Syntactic Acquisition'. WIREs Cognitive Science. DOI: 10.1002/wcs.1154.

Yang, C. (2002). Knowledge and Learning in Natural Language. Oxford: Oxford University Press.

Yang, C. and Montrul, S. (2016). 'Learning Datives: The Tolerance Principle in Monolingual and Bilingual Acquisition'. Second Language Research 33 (1): 119-144.

Yip, V. and Matthews, S. (2007). The Bilingual Child: Early Development and Language Contact. Cambridge: Cambridge University Press.

Yip, V. and Matthews, S. (2005). 'Dual Input and Learnability: Null Objects in Cantonese-English Bilingual Children’. In Proceedings of the $4^{\text {th }}$ International 
Symposium on Bilingualism. J. Cohen, K. T. McAlister, K. Rolstad and J. MacSwan (eds.). Somerville: Cascadilla Proceedings Project: 2421-2431.

Yip, V. and Matthews, S. (2000). 'Syntactic Transfer in a Cantonese-English Bilingual Child’. Bilingualism: Language and Cognition 3 (3): 193-208.

Yuan, Q. (2016). 'An Analysis of Inter-linguistic Influence between Chinese and English in Direct Object Realization in Chinese-English Bilingual Children'. PhD Dissertation, University of Valladolid.

Yule, G. (1996). The Study of Language. Cambridge: Cambridge University Press.

Zhang, N. N. (1998). 'Argument Interpretations in the Ditransitive Construction'. Nordic Journal of Linguistics 21: 179-209. 